P P P

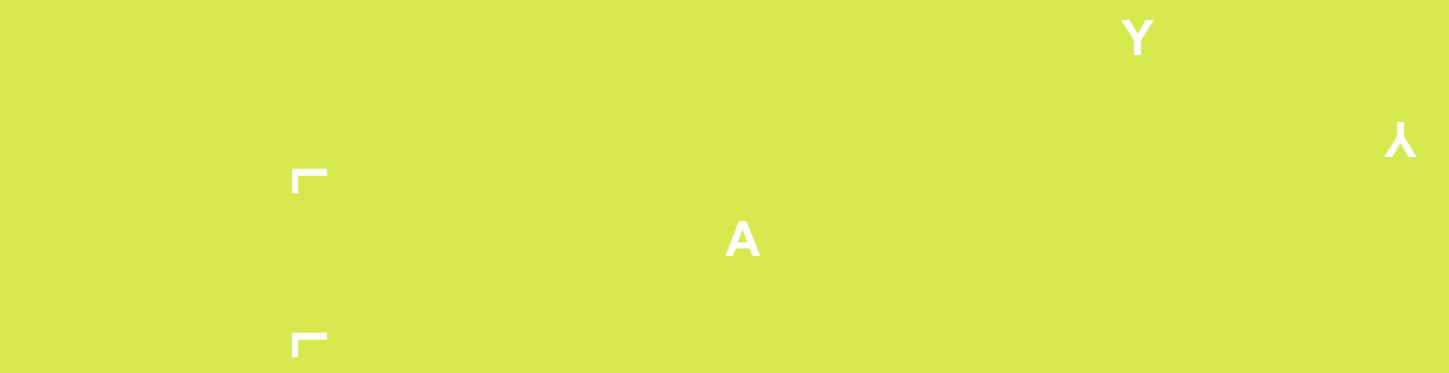

F U L

V

S

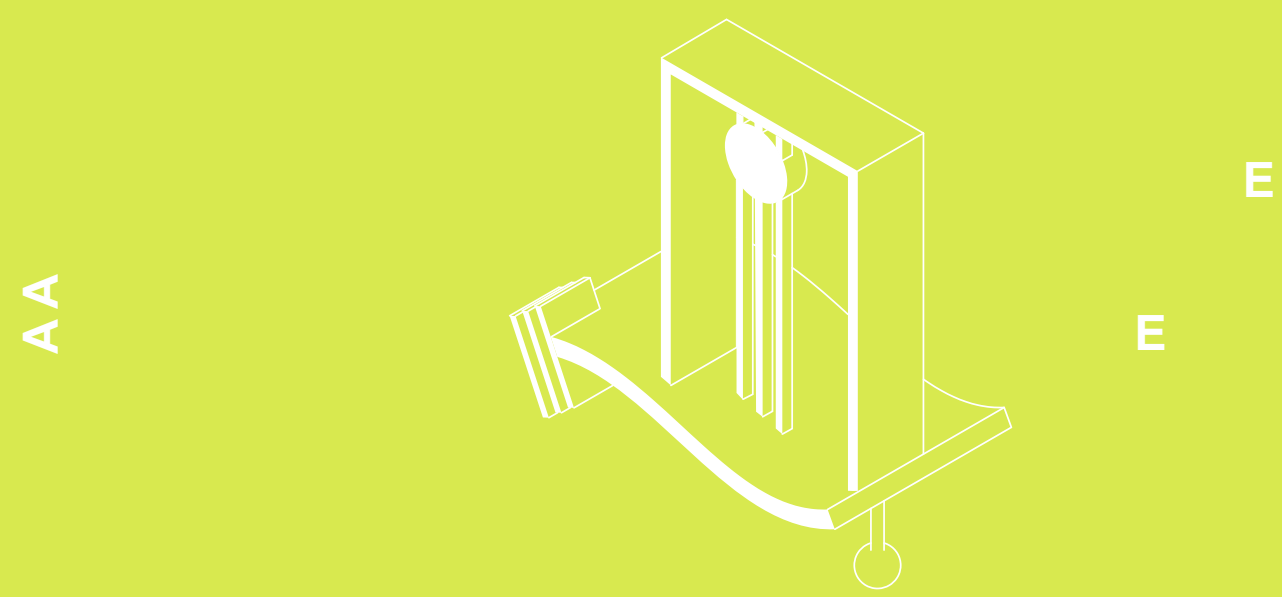

S

E

$\Gamma$

m $B$ 


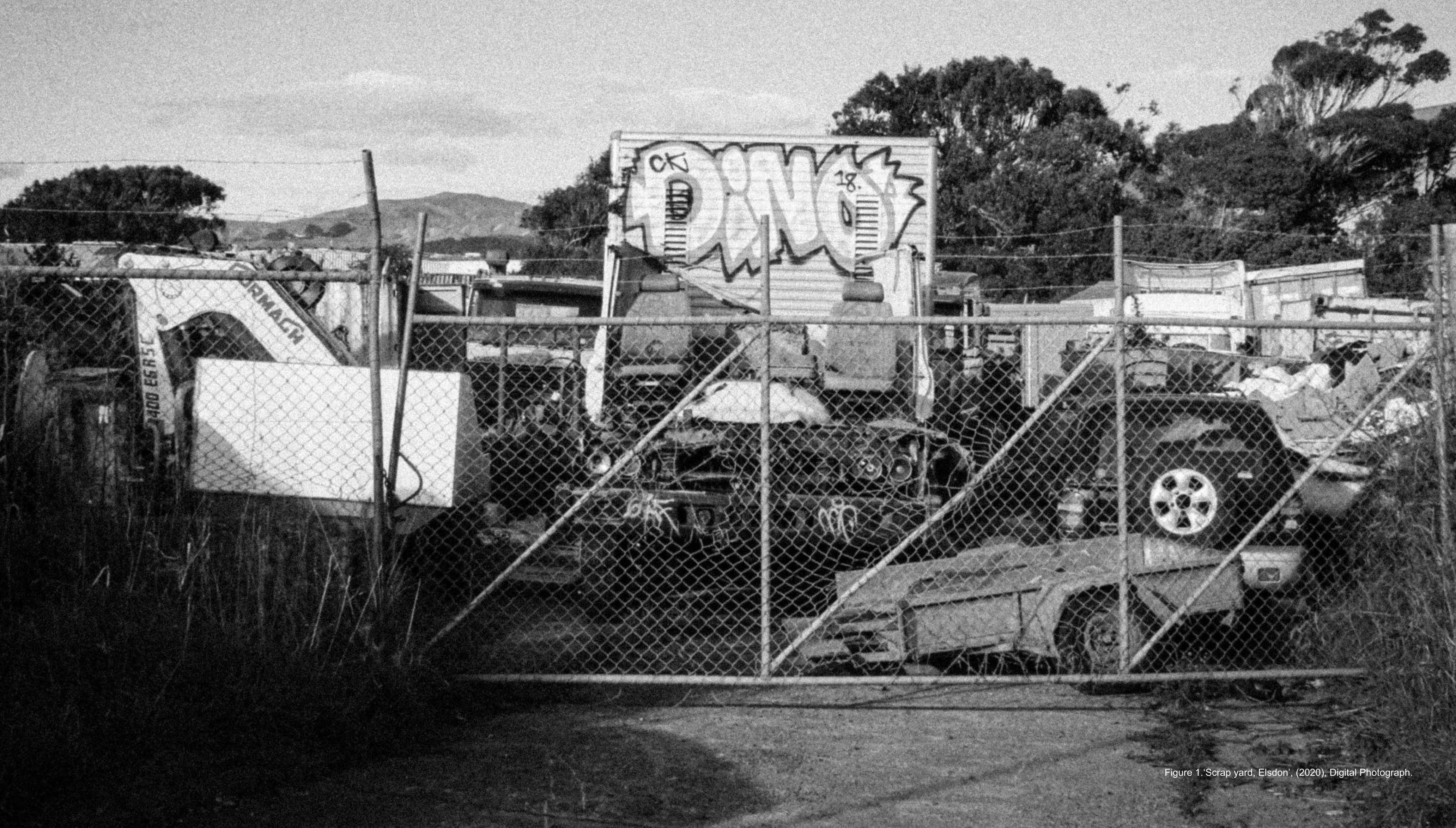


I had a travelling childhood existing in cities, countries and towns as places I called home. My 'home' in the world quickly became a network of places rather than just one. Some places are made of more pieces than others but somehow, they manage to fit together seamlessly. The world began to look like a puzzle. I was naturally drawn to the rubik's cube and later to the city; and the city is the greatest puzzle of them all.

As a child I assembled jigsaws and now I assemble architecture. Through a series of compositions this thesis plays with art, architecture and the city as it follows a playful assembly process.

I am still assembling puzzles through an elemental process, just with bigger, more sophisticated and complex toys. 


\section{acknowledgements*}

Thanks to my supervisor Sam Kebbell for encouraging me to

"have fun with it".

Thanks to my friends, especially my flatmates, for their constant support, laughter and collective sense of humour.

As always, thanks to my Mum, for everything. 


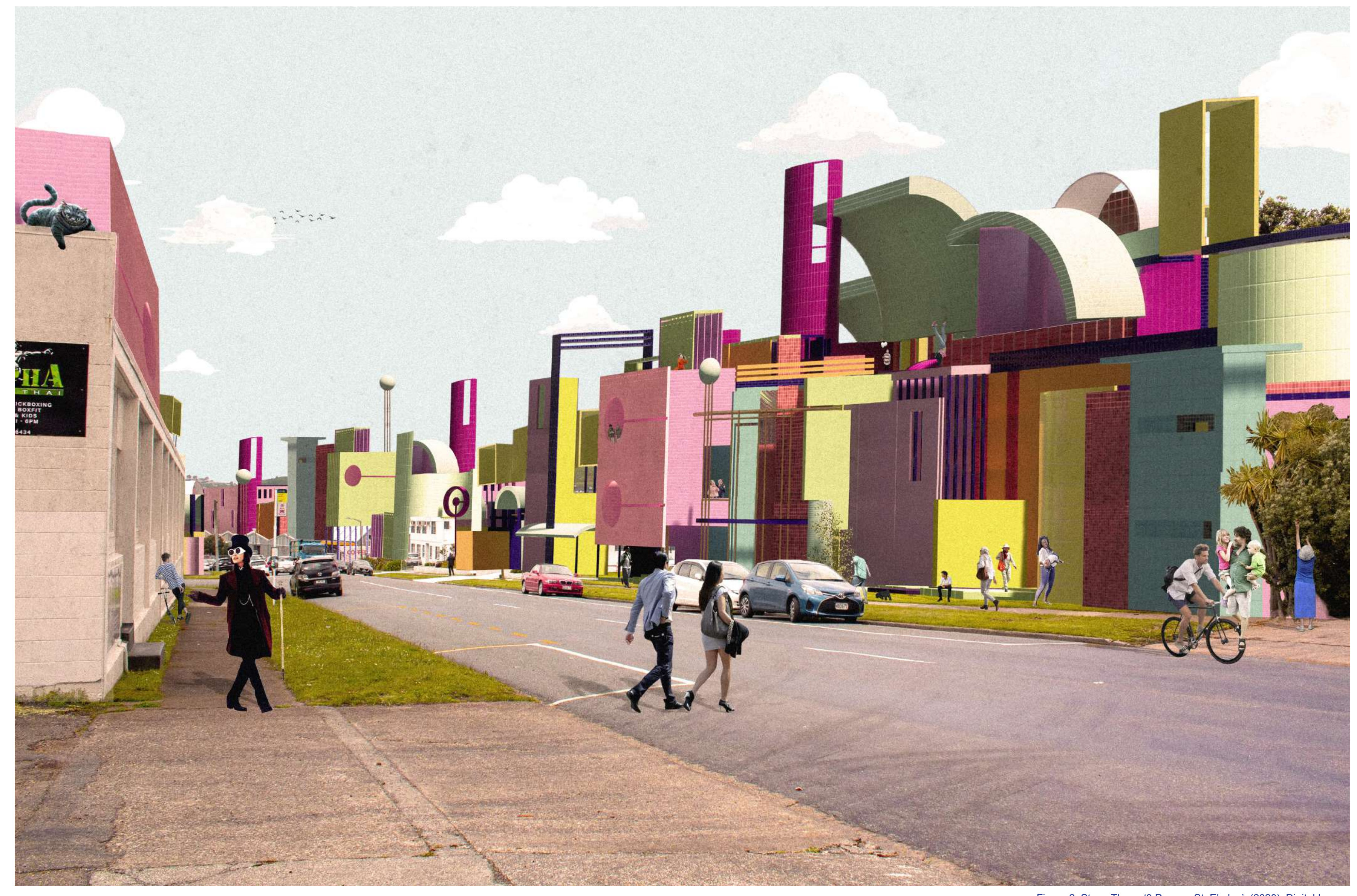


"The benign professionalism of architecture and design had, in their opinion, led to a sterilization of the world that threatened to wipe out any sense of spontaneity or playfulness."

(Sadler, 1999, p. 5) 



\section{abstract*}

Porirua is a small city I lived in from the age of ten to sixteen. It is the home to Wellington region's best indoor go-karting track and fallen victim to urban sprawl. The first of four of my homes in this area was in the newly developed Aotea block and at the time it was the first house on the street. My four year old brother would sit and watch diggers and tractors all day, and in the afternoon we climbed them. All this destruction was intensely entertaining to a child. The devastation hit when the neighbour's house got built, along with the rest of the street, in what felt like a week. Just like that, the glory days were over. We moved a couple years after this closer into the Whitby community. Aotea development was so new all it had was houses, I wouldn't even call them homes. My mum got sick of travelling to Whitby all the time for milk and so on, so we eventually moved closer to the town. I could walk or bike to and from school. It was all so close; the dairy, friends' houses, football park, playground, skatepark, everything! The glory days were back and better than ever.

This move into an established community felt more like home. The simple rituals of walking to the dairy to get milk (and a lolly bag) became something I regularly enjoyed. The accessibility of amenities gave me independence and made life easier. The 'home' broke through the boundaries of the house and into the park, the biked streets and the football pitch. If one can feel at home within a whole community then why build new houses separate from established towns? All on their lonesome, dependent on cars and with diggers for neighbours.
This thesis re-conceives Porirua as a playful assembly. With an emphasis on cultural wealth, this process establishes an architectura language promoting Porirua's development towards a creative city. Cultural wealth is a term which gives priority to the cultural layer of the city, it emphasises creation rather than consumption. Creativity sits at the heart of this layer making it a crucial element of the creative city. The wealth of culture in Porirua comes from its depth of diversity; in Maori, Pasifika and Pakeha and others coming together. While the specific cultures aren't emphasised, the importance lies within this diversity. This is one of the reasons I chose the Porirua CBD as the site for my thesis.

My playful process crosses paths with art, architecture and urban perspectives to develop a visual language emphasising creation within the city. The search for my own creative voice lends itself to the importance of self-expression within the city. Through this thesis work I wanted to encourage people to more openly produce self-expressive work. I recognise that the city already has these processes and the products and processes of my creative voice target the creation of these spaces giving them priority and emphasis in the city. This thesis aims to create a welcoming, inclusive environment for people to create. Within the urban realm an alternative view is presented holding creativity at the heart of the city rather than economy. 


\section{contents*}

introduction

20

making stuff

lockdown ${ }^{*}$

brick*

painting*

1:1 sculptural frame

visual diary ${ }^{*}$

making city

city networks*

playful assembly of the city*

archipelago

anti-zoning*

positive congestion

making stuff in the city

architecture in the city ${ }^{*}$

paper models

paper model process*

5 Heriot Drive*

2b Raiha Street ${ }^{*}$

creative production

reflection*

flash exhibition*

review realizations ${ }^{*}$

composition criteria*

form + colour compositions*

materiality*

9 Prosser St

circulation*

sectional composition*

tile reflection*

last physical model*

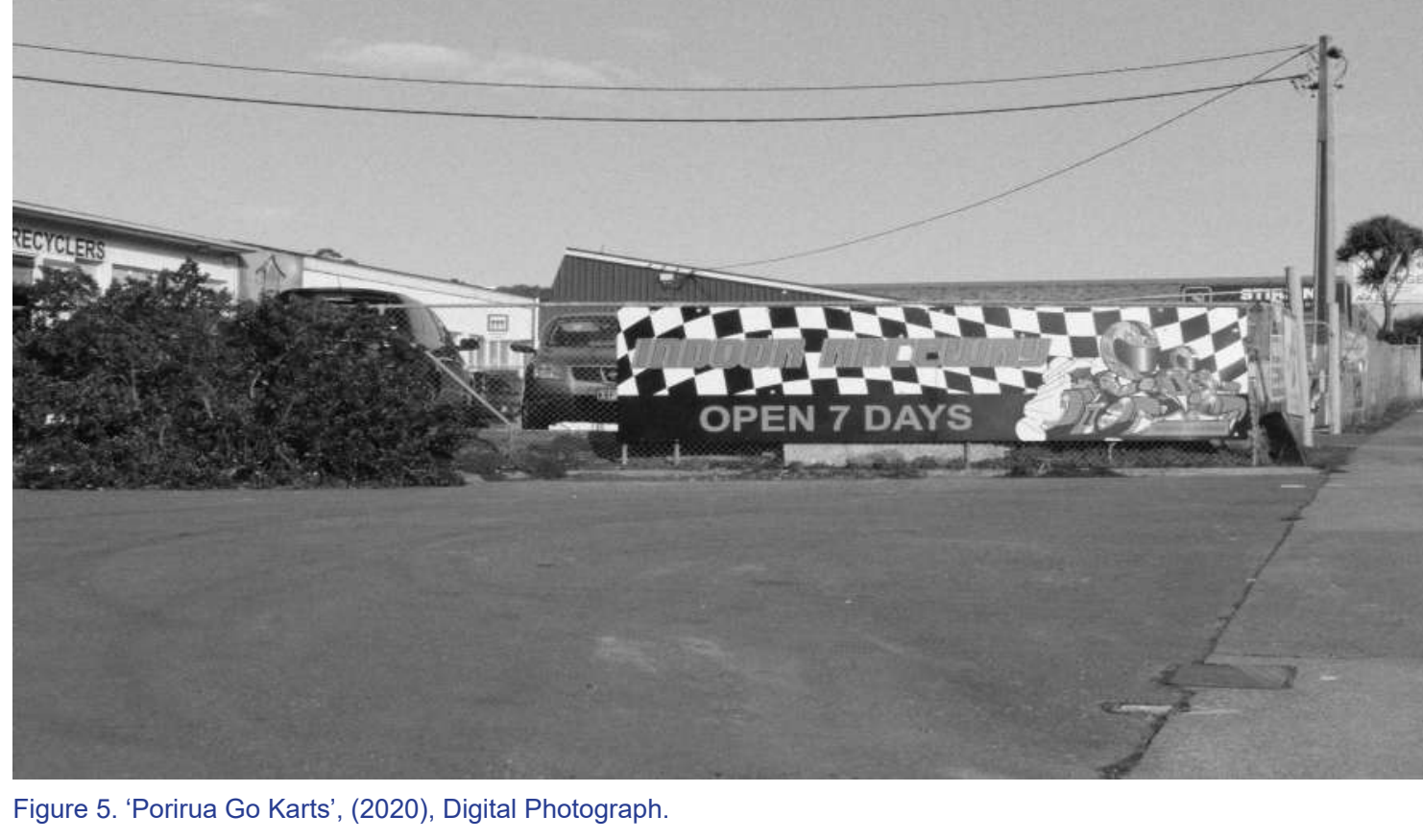

new babylon*

312

creative monumentality*

324

concluding comments

playful assembly*

everchanging architecture

archipelago porirua*

stitl city life composition*

future research*

the end

326

330
339

340

347 


\section{introduc-}

\section{tion*}

This thesis explores an architectural language rooted in playfulness and fit for a city driven by cultural wealth, not mere financial gain. This started as a search for my creative voice and which has led down explorations of the city, art and architecture.

This thesis has a somewhat unique beginning, as it began alongside the Covid-19 pandemic within the lockdowns that were implemented to keep our country safe. In this isolation I attempted to begin a thesis, discovering a natural playful approach to creation . Through painting, I developed this naturally playful process, which is analyzed and developed through the city and architectural ensembles in this thesis. This cross-disciplinary approach to the architectural discipline is pushed to blend with city planning and art composition. The search for my creative voice has surfaced the importance of individual creative voices as a purposeful expression of self which can contribute to society. The creation of an environment where locals can create, thrive and live within their city is the main aim for this thesis.

I am interested in how architecture can impact the city and grow with it. Urban research draws on topics beyond capitalism and zoning to understand how cities can develop positively. It explores the benefits of congestion and chaos and starts to re-interpret the city as a 'Playful Assembly', a sort of sophisticated playground where adults can play. Instead of promoting the city as a Monopoly it promotes it as a Lego set, with pieces built here and there. A Lego city requires the creative production of its locals to further grow the city. Locals are empowered to creatively produce rather than endlessly consume.

Instead of putting the economy at the heart of the city, this thesis prioritises creativity. Instead of giving value to money, I have developed a process which gives value to craft. Instead of applying wealth to capital, this thesis applies wealth to culture. Then we have the Creative City, full of creative factories instead of industrial factories. This polemical position is in sync with the situationist motif. It develops an architecture for all creative lifestyles, living in an archipelago framework and designed with a compositional criteria.

\section{Method}

The term 'Playful Assembly' has developed from my playful processes and constant desire to make stuff. This process has not emerged from a logical or defined plan and never follows any set routine. The process follows my intuition, inclination and natural desire to do whatever, where-ever. My creative motivation comes from the inner subconscious and is analysed through self-reflection and peer discussion. To research through design. It leaves an initial trail of mis-matched exploration of piles of all sorts which are later pieced together. It follows no preliminary rules or guidelines. It uses a cross-disciplinary mixed media approach to surface alternative perspectives and alternating topics of conversation to overcome issues and surface new ones.

It is a jump to the left, from making stuff to making cities. Making stuff is a mess everyone is trying to make sense of when really the sub- 
conscious sense is all the sense we rely on. Constant reflection, production and discussion brings an understanding of the work as a process developing ideas around positive community growth. By doing more and more design work, patterns become noticed through reflection and announced in discussions. It eventually reveals a criteria that defines my emerging process. Even though such criteria was not apparent at the time, it allows my process to be repeated and refined in doing so. Research through design. Iterations explore my creative voice surfacing my need to produce and my inspiration from the city and painting. This process lends itself to the physical. It strives when you can touch, see, and hear it. Physical models are preferred over digital models as seeing and making the model reveals design, construction, materiality, circulation and scale issues. The craft knife cuts in the nail of your thumb are worth it; just like stubbing your toe while running to the ice cream shop in January at Manly Beach.

The sharp bends and frantic change in directional nature of this exploration engages the core and has a hazard of causing headaches. There were some dead ends and distractions along the way but through reflection and discussion patterns were revealed. The common denominator was constantly creating playful assembly's out of any medium I was drawn to.

This thesis is less about the end, the big finale, and more about the adventure of getting there. It is not about the materials used but more about using lots of different materials. My creations are formed around

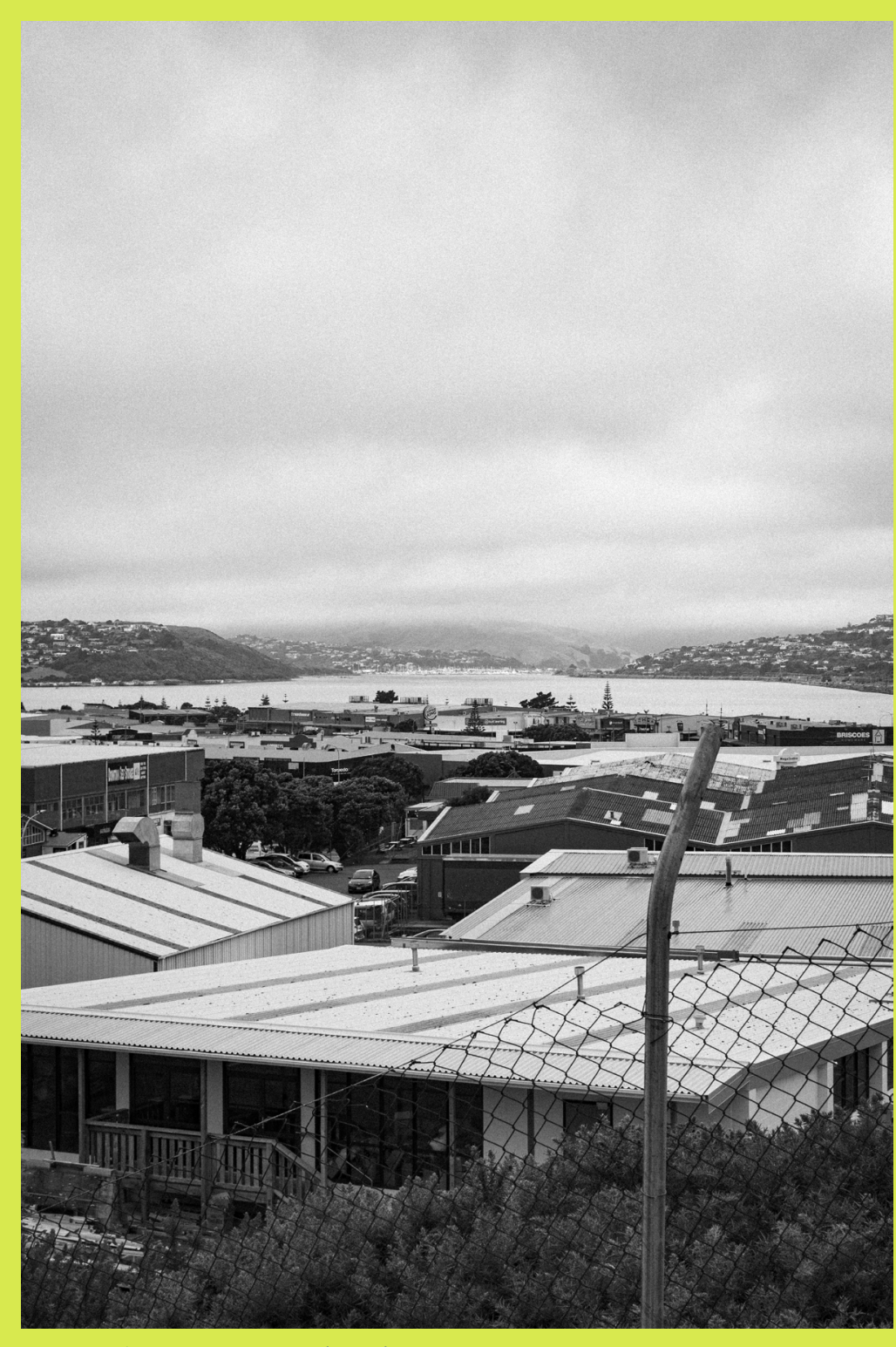

igure 6. 'Porirua Harbour', (2020), Digital Photograph. 


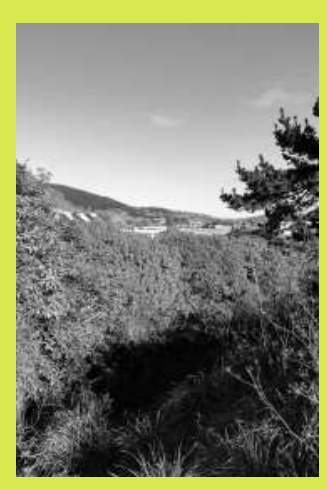

a democracy of architecture rather than a dictatorship. I have tried to give autonomy to my architecture so it develops itself. There are pauses of relief rather than 'ends'. This process can keep on going, bending, stretching and pushing boundaries of all sorts but it's March 2021.

\section{Process / what I did}

The process follows the gut through a snake-like squirm of drawings, models, readings, paintings, photography, readings, digital stuff and a window frame. It starts in lockdown with digital issues where refuge was seeked in painting and roaming around in the garage. To put it plainly, I made stuff, then I made a layer of the city, then I made the stuff in the city.

The lockdown exploration allowed me to make stuff. I then interpreted my painting as a composition of the city which led to an urban scale plan of Porirua. This follows an 'Archipelago' framework which focuses on the cultural layer of the city. Within this cultural layer architectural interventions were explored, discovering the Creative Factory. These followed the same compositional painting process but with architectural specific medians such as physical model making, architectural drawings and diagrams. This was the first step into designing and it was a door I found difficult to open. Because of this I kept it open to allow a constant back-and-forth between designs, art and urban discussions.
I found the cross-disciplinary discussions very helpful for processing thoughts and design issues. Through an alternative perspective I was able to separate myself from my work allowing a clear analysis. For instance, discussing my painting from an urban perspective revealed it as an urban plan. I also found jumping around mediums very useful throughout the whole design process. Each medium surfaces new issues while solving old ones. I found this an efficient process to develop my designs. Using a range of materials also changed the focus to different elements of the design allowing a balanced development to occur. When the design had gone through multiple mediums it resolved architectural issues and developed compositional ideas. This multi-media process was inspired by my range of exploration during lockdown. On reflection of this collection of stuff I realised that despite the desire to use a variety of materials the same ideas were being explored. This gave me confidence to continue with the multi-media approach throughout this thesis.

The work created along the way developed into an architectural language which promotes the creative city. 


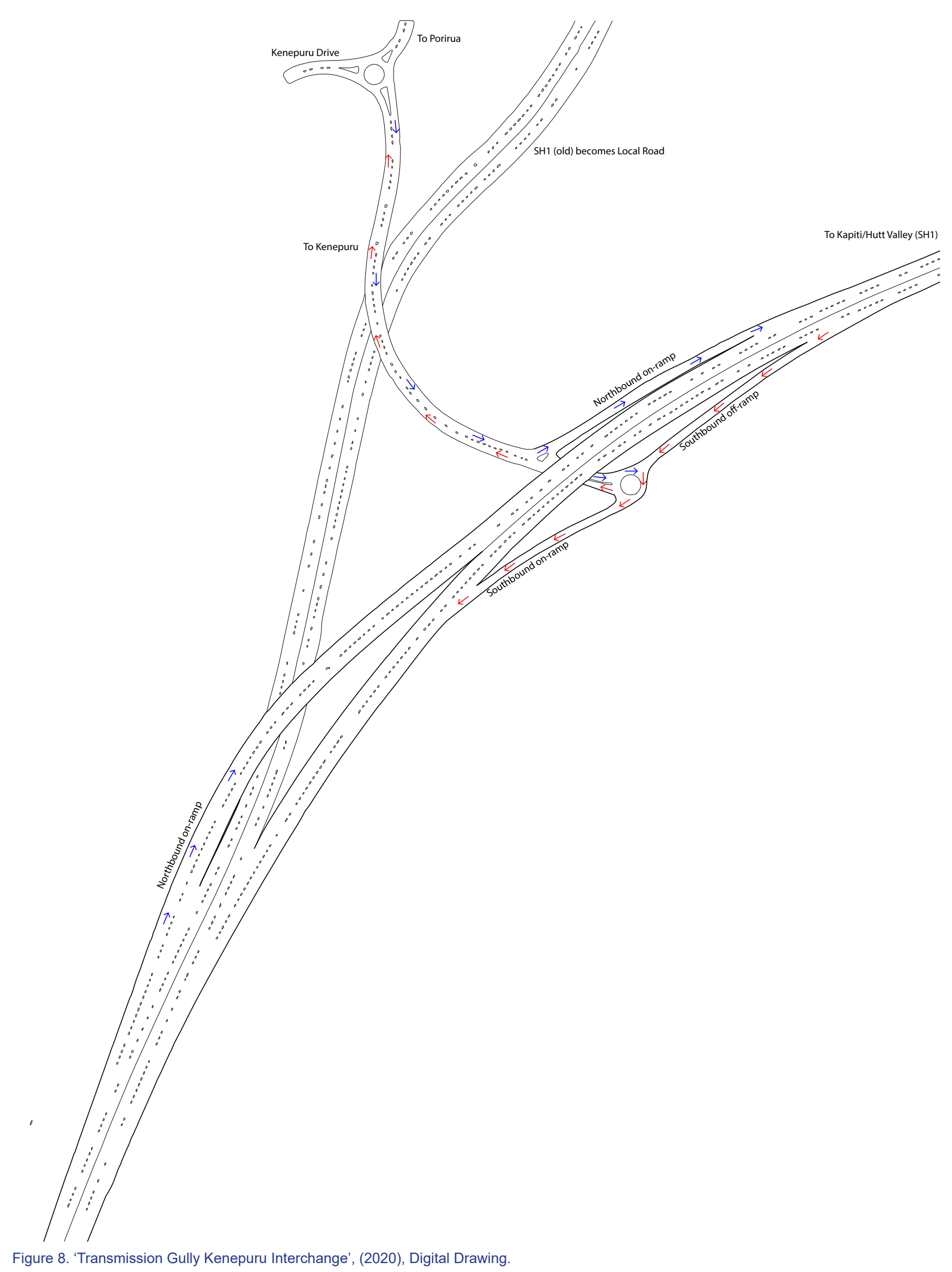

Figure 8. 'Transmission Gully Kenepuru Interchange', (2020), Digital Drawing. 


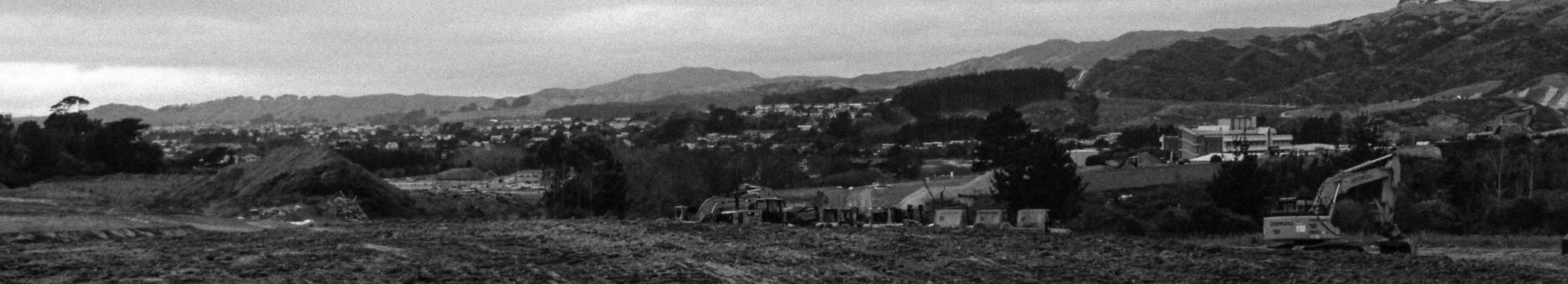
enting

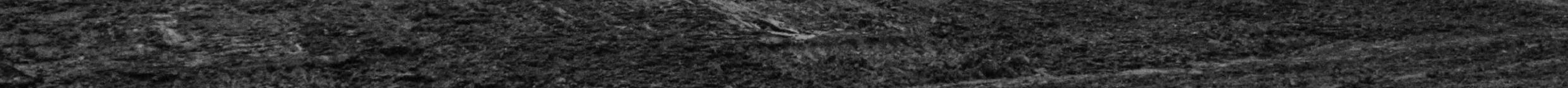

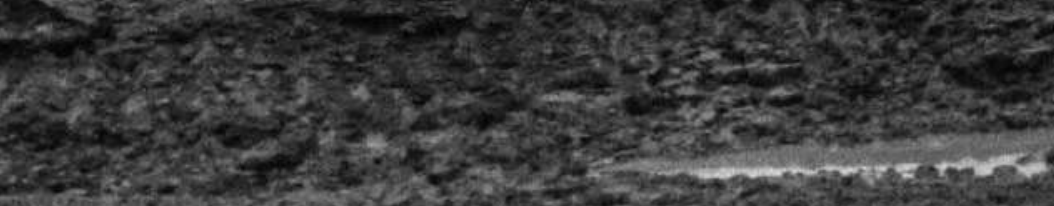
acescos

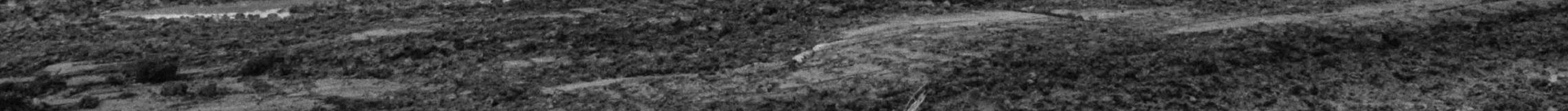
2.

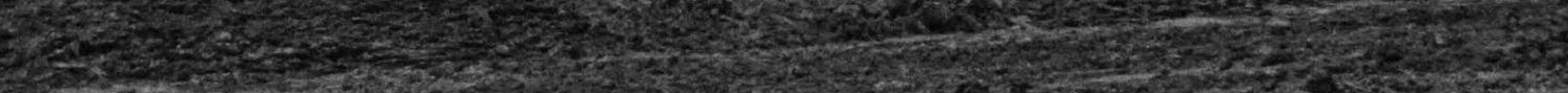

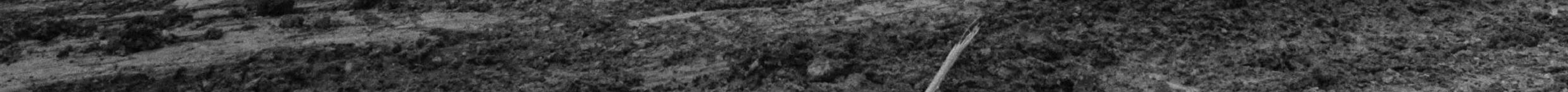

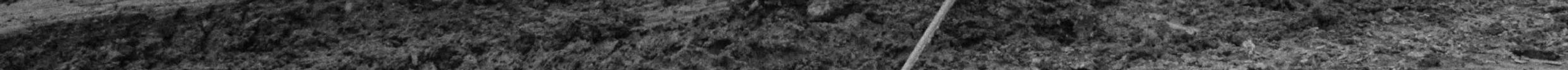

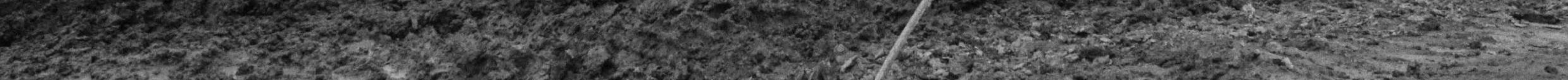

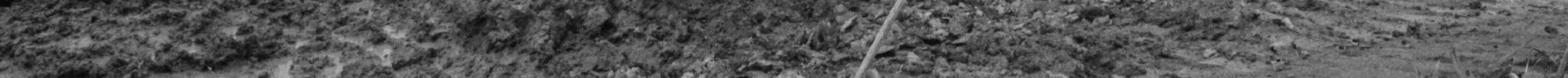
2.

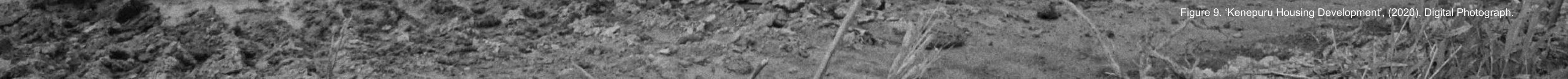




\section{making stuff}


This chapter follows the yellow brick road down my lockdown mind and the creations which occurred there. It stops for a moment of reflection at the May review and continues along a post-lockdown exploration path. The path leads to discoveries of my creative voice and will continue to develop this through an architectural language. 


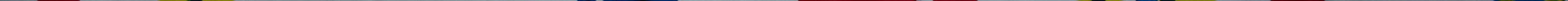




\section{lockdown*}

This thesis began in lockdown at my mum's house in Raumati Beach. With the struggles of zoom and the dying of my laptop, I seeked refuge with the beach, 3x 1000 piece puzzles, some gloopy old window sill paint, a brick, my brother's Xbox and a big canvas I got on sale two years ago. My sixteen year old cat (Bonkers) and I became inseparable, along with Delirious New York.

Being at home was a challenging setting to begin a thesis. I struggled to think architecturally, I have always kept that very separate from this home. Even Delirious New York did not help at first. It made me sad that New York is now empty, but it also made me dream, my imagination has never been so stimulated as it was in lockdown. In a way it was all I had. Dreaming of the city and what it could be, missing Wellington city and friends, while enjoying the calm coast. The garage was a great place to scavenge, there are lots of beauties down there, in amongst the years of puzzles.

es.

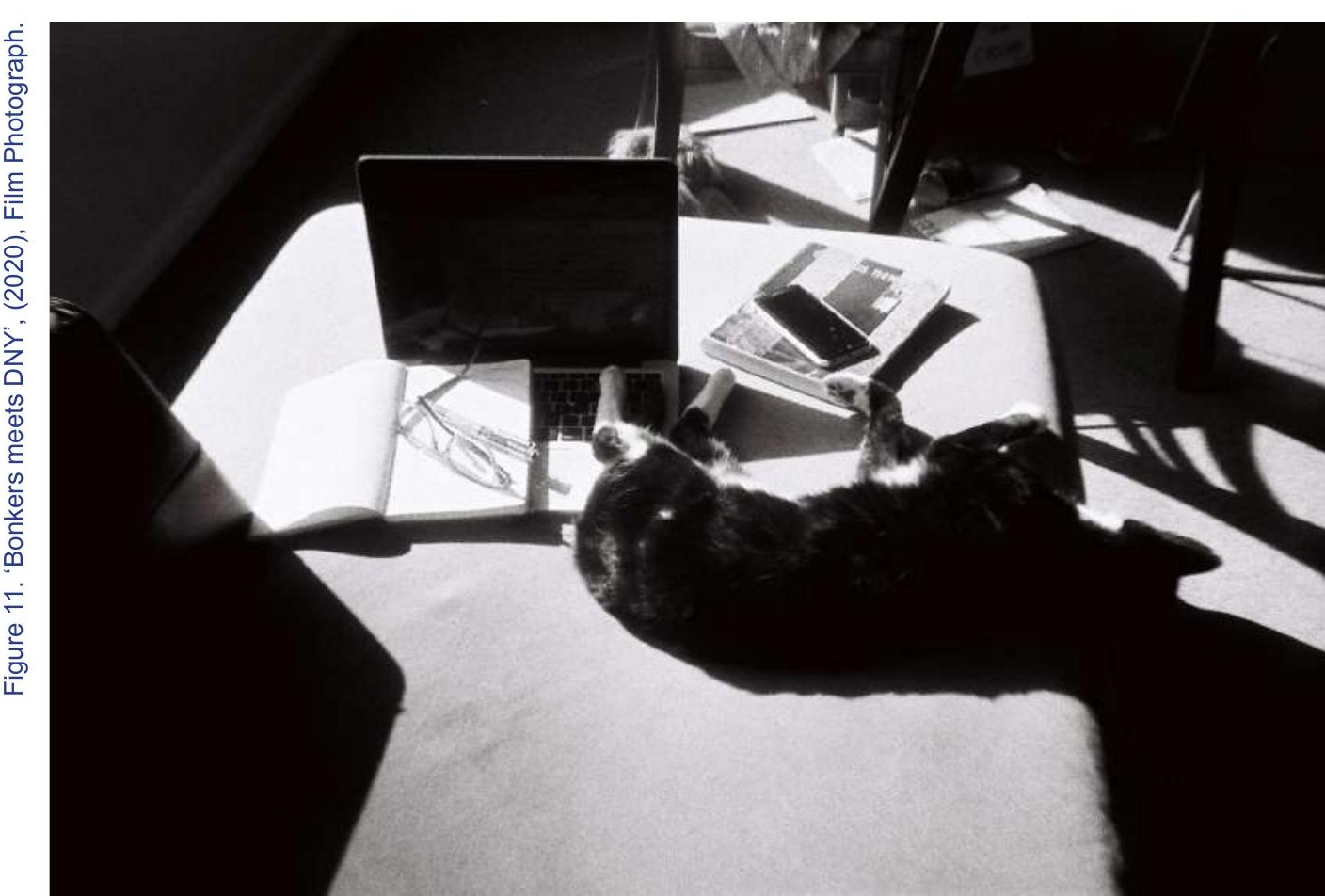




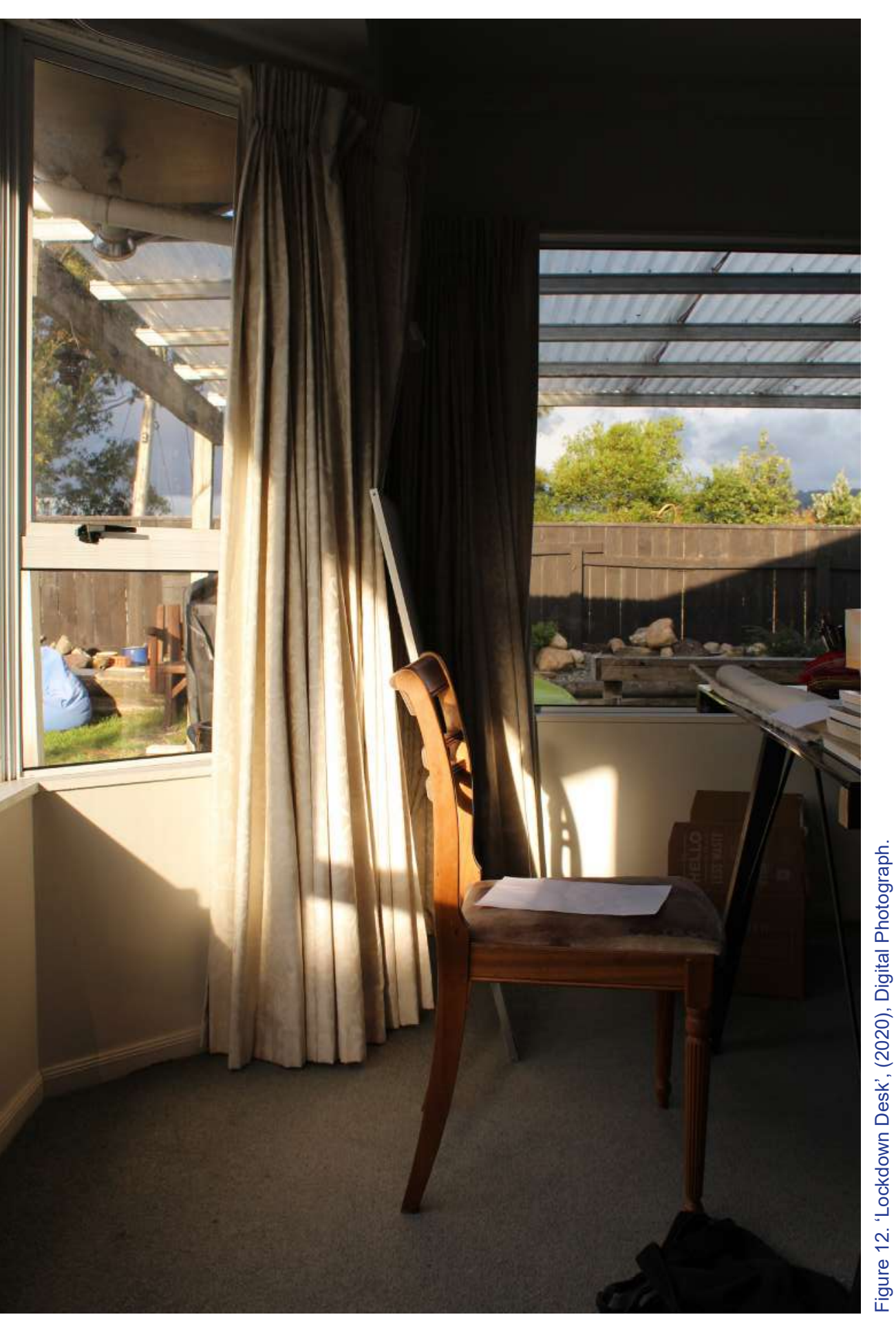




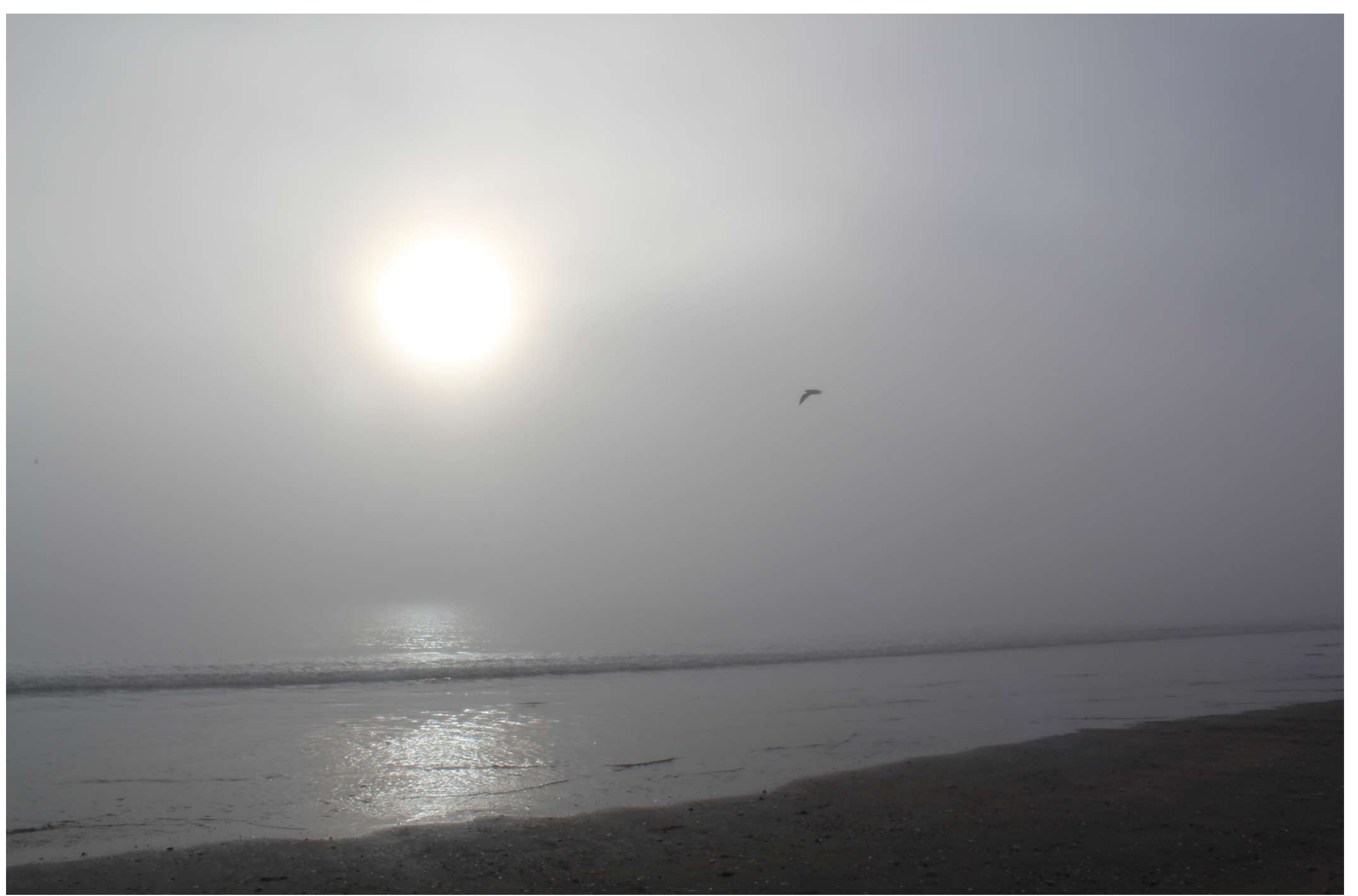




$$
1
$$




\section{brick*}

This brick and gloopy white paint was my muse for a week. I had previously found an interesting red brick in the garden and had the desire to make it seem plastic. It is so rugged and rustic it would be interesting to see the transition into a plastic glossy white object.

I had so much fun with that old window sill paint. I poured, dipped, splattered, peeled and painted all sorts of objects but the brick was most captivating. It was its symmetrical circle holes juxtaposed with the broken top and not so rectangular shape which got my attention.

Dipping it into the paint was like submerging it in Mr. Whippy ice cream and then watching it drip down the brick until it semi-dried. It does resemble a gingerbread house with icing on top, somehow the plasticity makes it look edible, desirable. I felt this experiment was an attempt to entertain myself and once I had done that it did not serve me much architectural motivation. It was fun but an experiment my more childlike half took-over. This child in me was hard to contain while at my family home.

A playful assembly of two opposing elements, rustic brick and glossy white paint. The process was playful and fun and so is the outcome. It made me realise, the more enjoyable the process, the more enjoyable the outcome (potentially edible even).

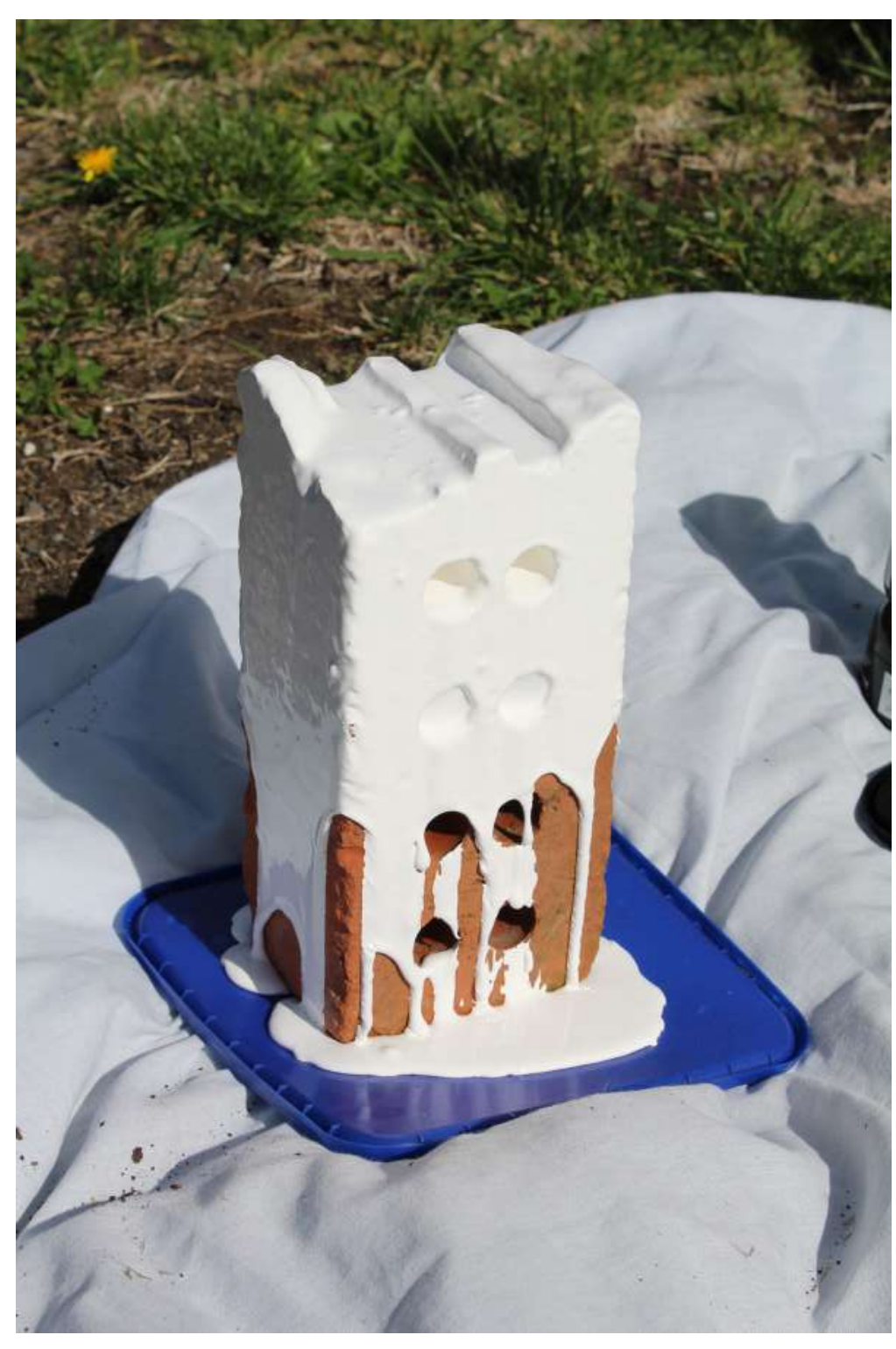

Figure 15. 'Brick meets Paint', (2020), Digital Photograph. 

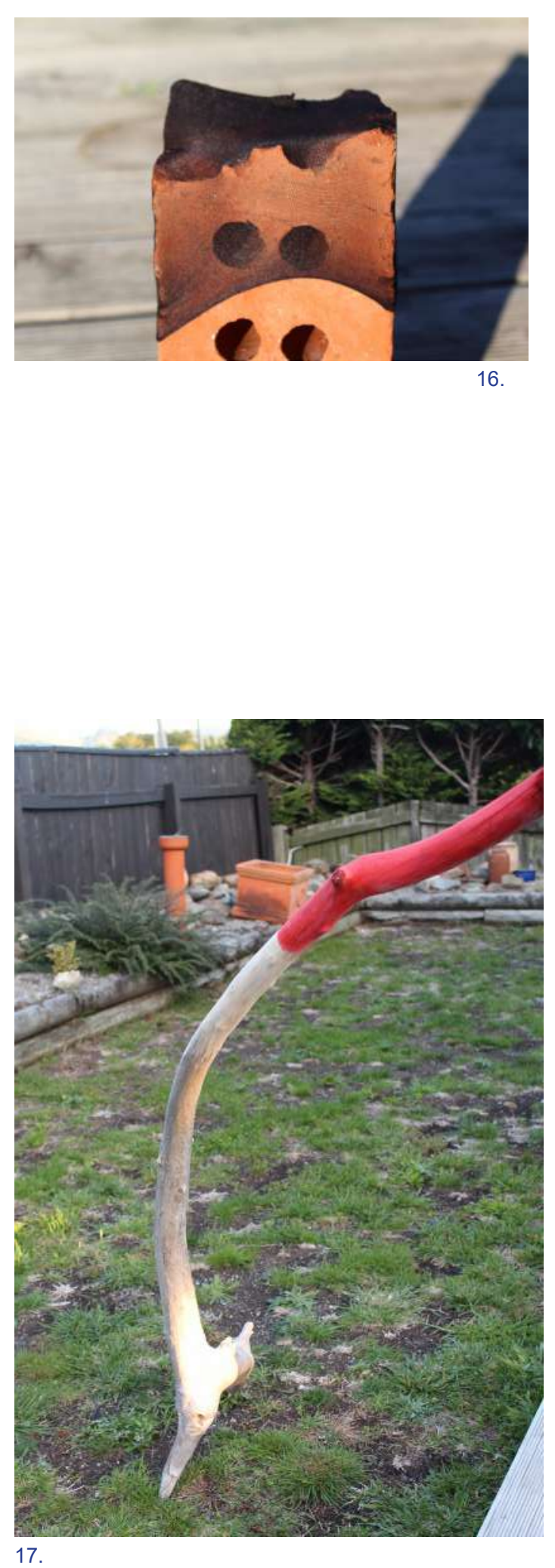
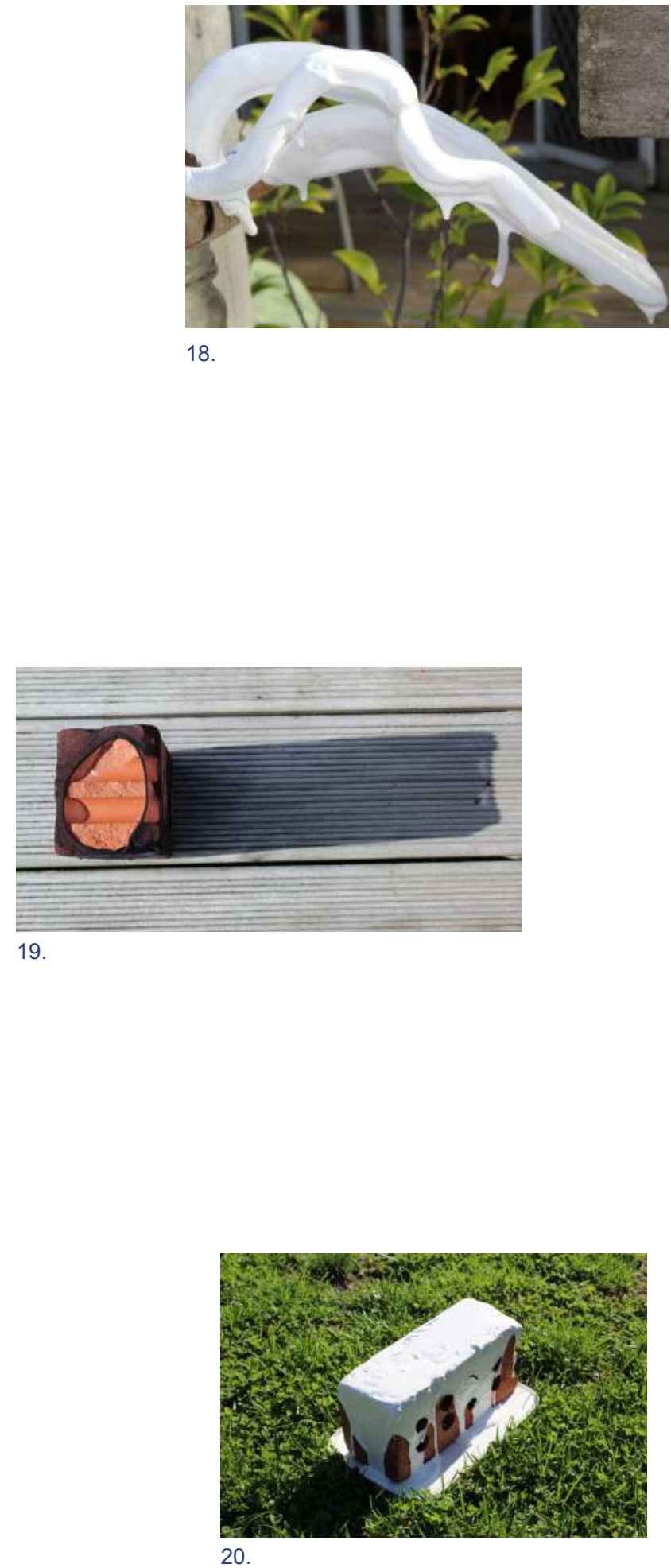
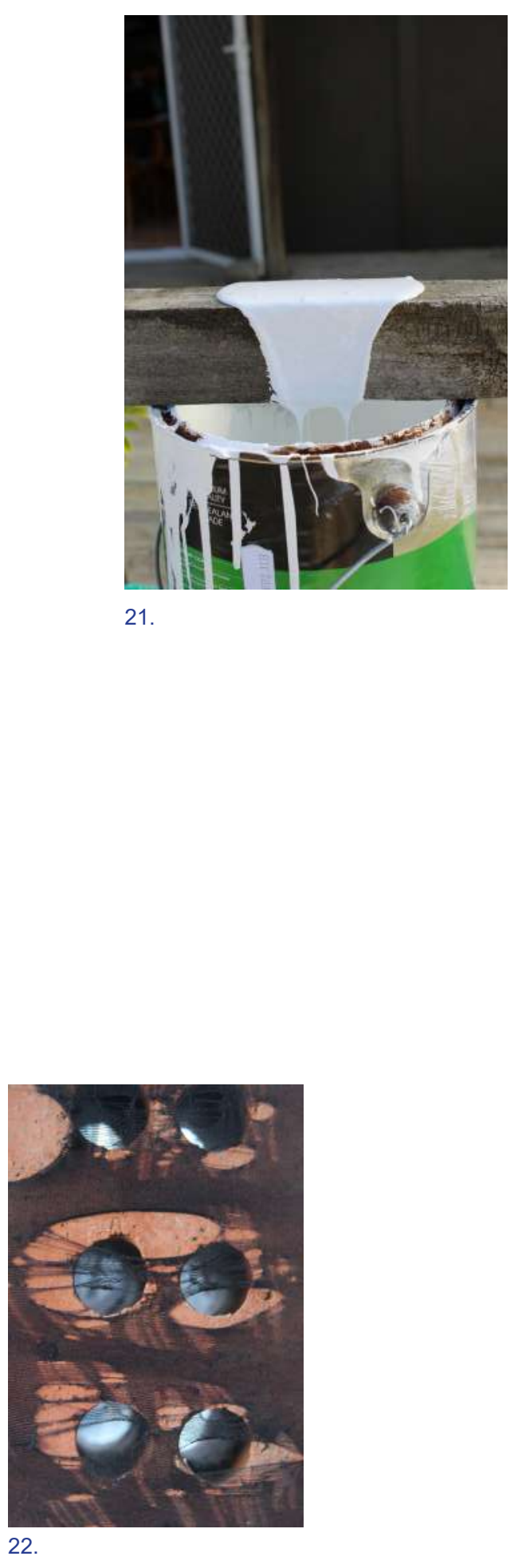
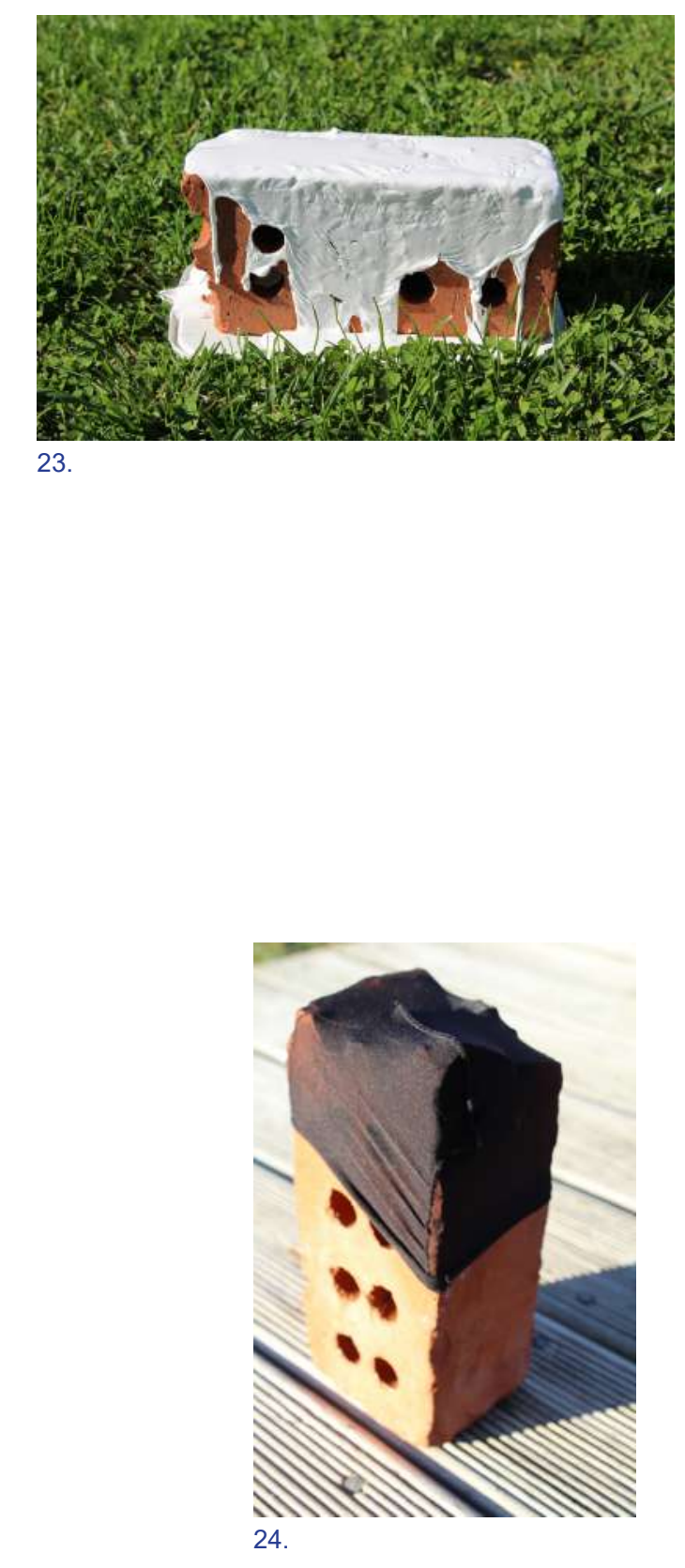

Figure 16. 'Brick Tights', (2020), Digital Photograph. Figure 17. 'Big Stick', (2020), Digital Photograph. Figure 18. Small Stick, (2020), Digital Photograph Figure 20, 'Brick Paint', (2020). Digital Photograph. Figure 21. 'Wood', (2020), Digital Photograph. Figure 22. 'Brick Tights, (2020), Digital Photograph Figure 23. 'Brick Paint,', (2020), Digital Photograph
Figure 24. 'BrickTights', (2020), Digital Photograph 


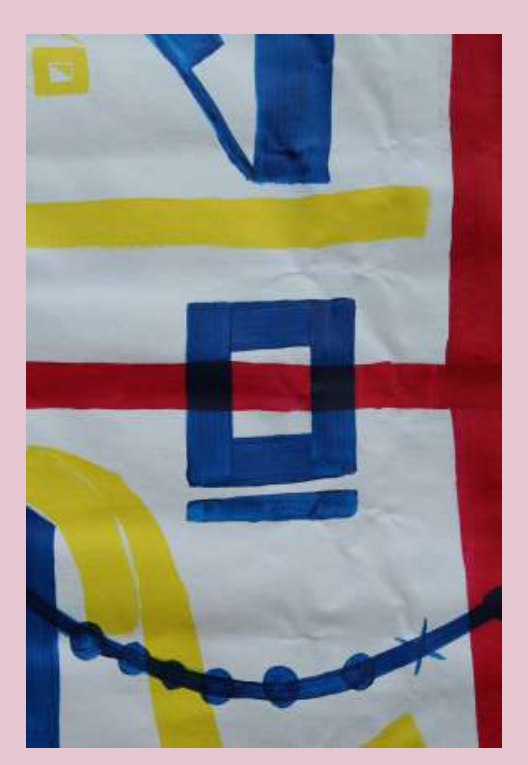





\section{painting*}

This painting developed as it went, making it a deeply satisfying process. I have mainly dabbled in watercolours on A5 paper so this was something new. Not knowing the outcome of this was exhilarating, the most fun I had in lockdown for sure. The first move was the scariest, but accompanied by an IPA, Prince and aspirations for the city's dance floor I was ready to go. I painted on the weekends to give myself something to look forward to. I had no idea if it was going to be relevant to my thesis or not, at the time it was simply for fun. I think that was one of the few perks of lockdown, most things were done simply to keep myself entertained, it took the academic pressure out of the picture allowing a more fluid personal approach to the beginning of this thesis.

Missing the bustle of flatting in Wellington, I became consumed in the congestion of Delirious New York. The city became a subconscious inspiration for the painting. This was a key moment for discovering my creative voice and its inspiration from the city. Despite perhaps the illogical process of starting with a painting as big as me, it has constantly provided me with inspiration, guidance and reassurance as this project has developed. It still remains my proudest piece of work.

As I composed this painting autonomous parts came together as a whole, a playful assembly of elements. The colours are kept pure and bold, yet harmonious and complementary in their opposites. Every element had to be attached, nothing could be floating otherwise it would be completely individual and not contribute to the collective painting.

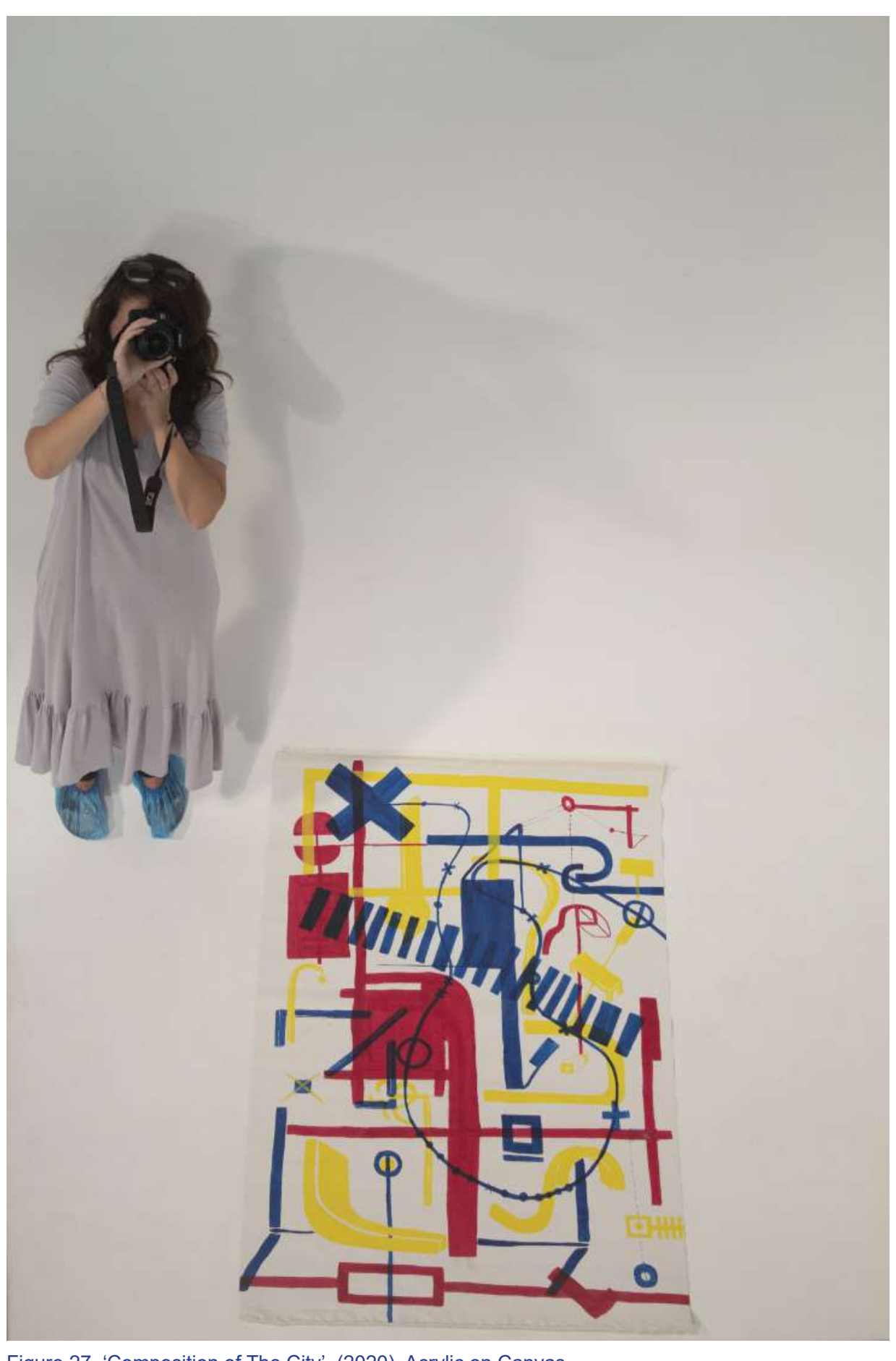

Figure 27. 'Composition of The City', (2020), Acrylic on Canvas. 

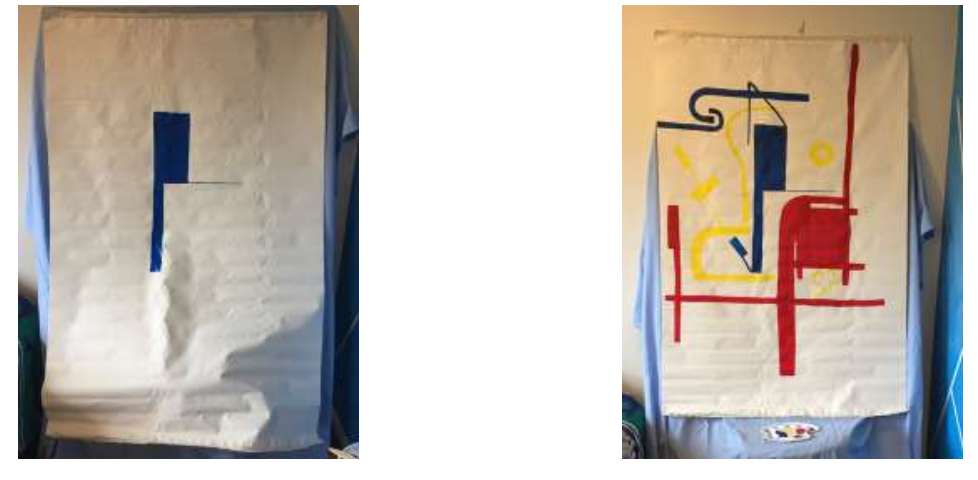

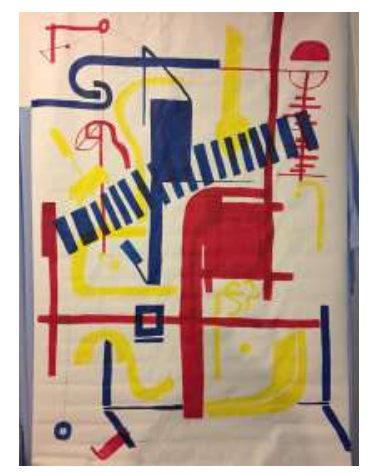

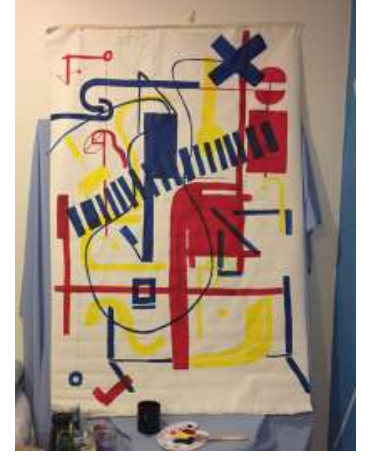

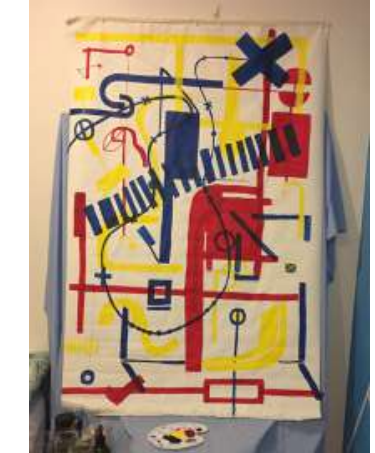

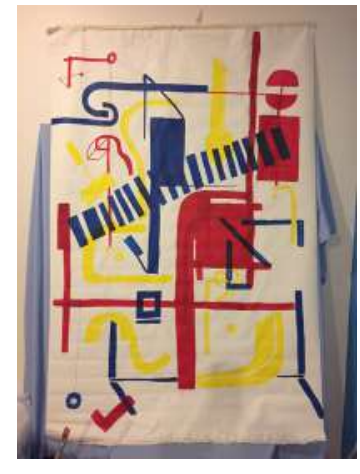

I would frequently step back and look at the painting progress from a far, it made everything clearer somehow. I started with symbol-like forms and moved towards common three-dimensional objects such as a table and lamp post. This grounded the generic symbols into reality. It gave the painting a level of simple detail while tying it together with the larger colour blocks.

I began to understand this painting as a composition of the city. The hap-hazard clash of red, blue, yellow, saw sirens from lamposts as one attempted to cross the road in a straight sophisticated line. The swig-swag motion of fun. A playful assembly of the city and a release for my imagination when my body remained static.

Excited by the act of creating and the feeling that the more I created the more I understood my creations, I continued to make stuff throughout this thesis. 


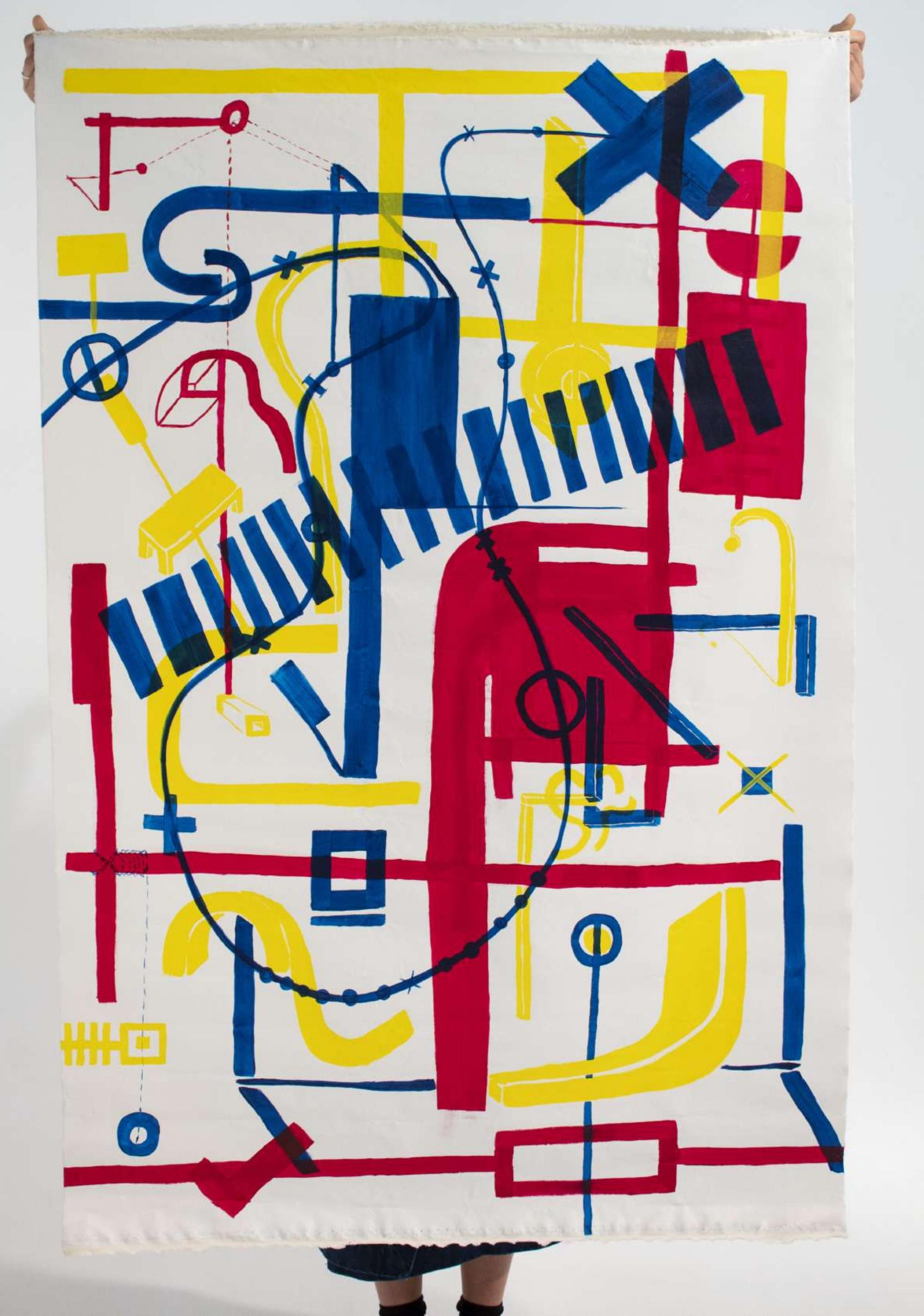



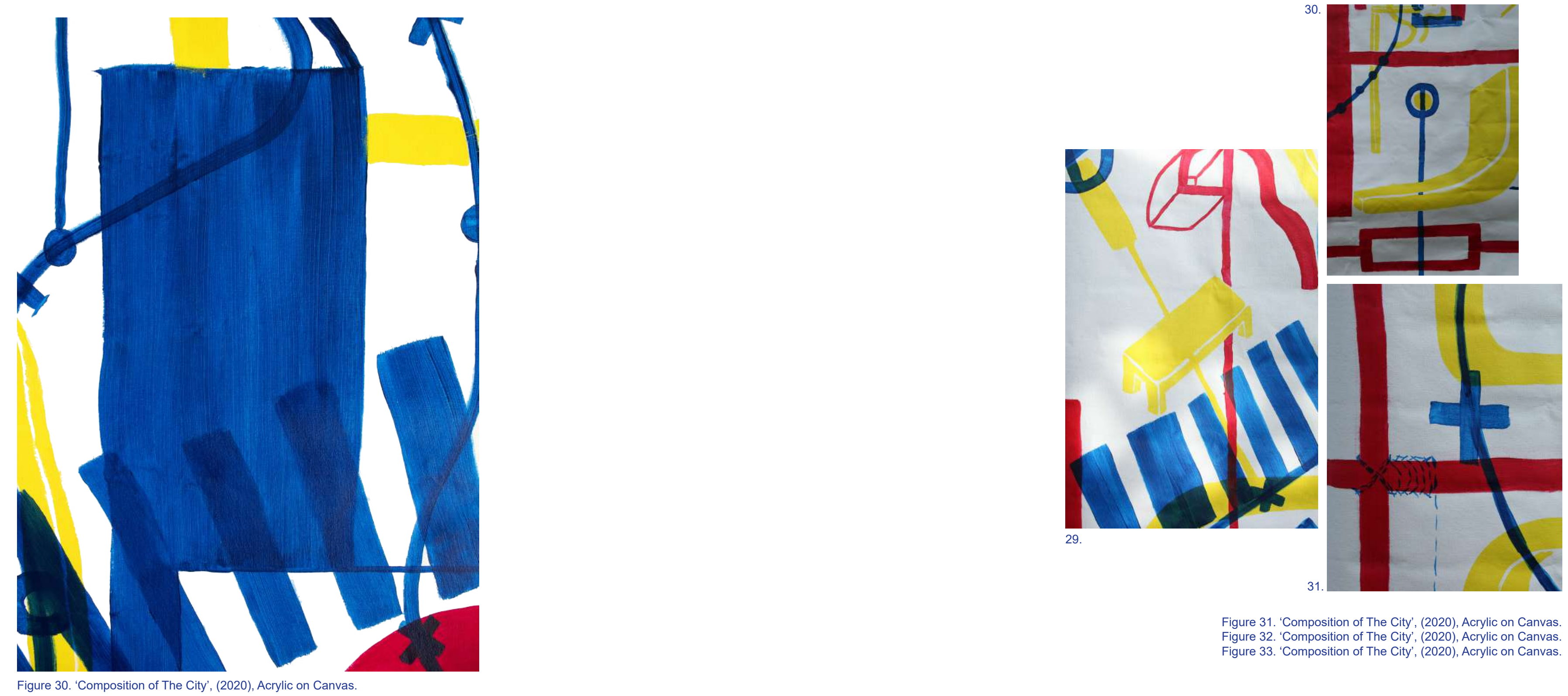

Figure 31. 'Composition of The City', (2020), Acrylic on Canvas
Figure 32. 'Composition of The City', (2020) Acrylic on Canvass Figure 33. 'Composition of The City', (2020), Acrylic on Canvas 


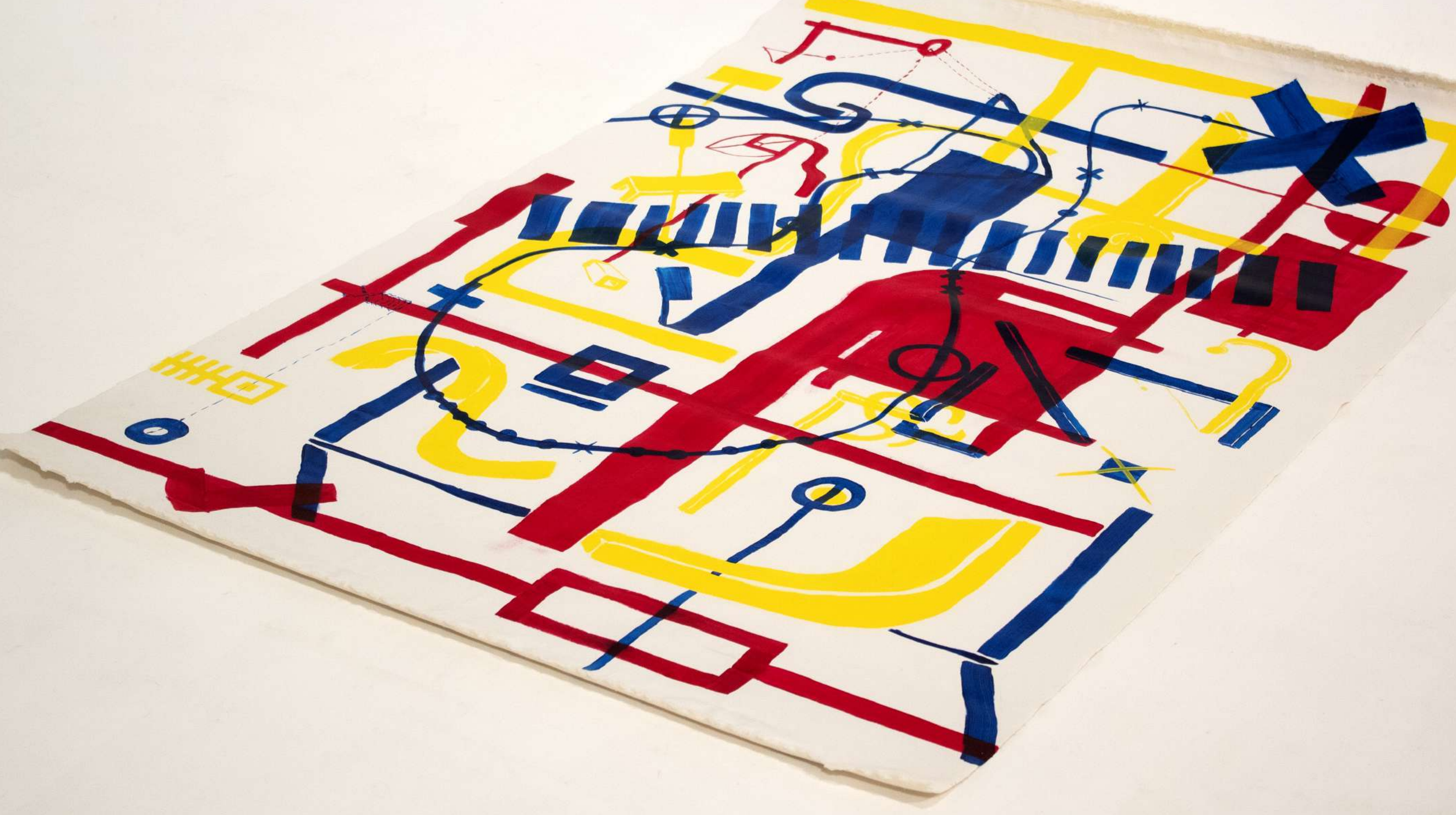



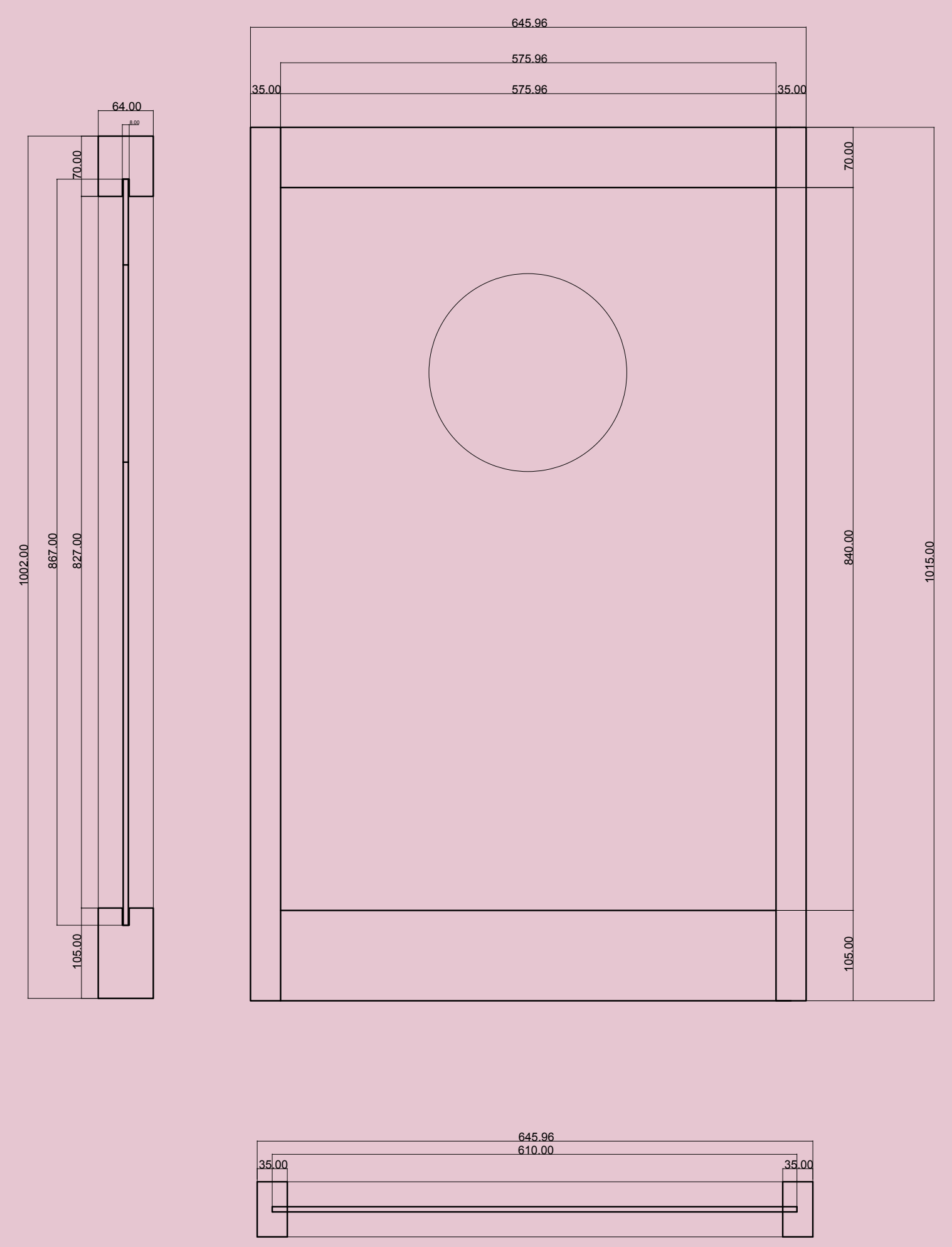

Figure 35. 'Frame Dimensions', (2020), Digital Drawing. 


\section{1:1 sculptural frame*}

This sculptural frame aims to apply the playful assembly process specifically to buildings. From a large painting to a window framing glass with a perfect circle cut out of it may seem like a big move but follows the same process. I also enjoyed the jump in scales. The plane of glass came from my friend's garage, a frequently visited place for materials.

Woodwork has never been a strong point of mine but again something I found exciting and challenging to complete. Being out of my comfort zone tended to become more frequent and more familiar as the thesis continued. I found I learnt the most this way and felt more satisfied with my results.

The frame exists both as a sculpture and an architectural model. The frame challenges the architectural discipline by implying it can be read as a sculpture and architectural model. It questions where art starts and architecture ends and pushes them to exist together, as a collective, like the complementary colours of my painting. It explores how building materials can be playfully assembled at a detailed scale. Where the painting zoomed out the frame zoomed in, allowing the development of an architectural language across a range of scales. 

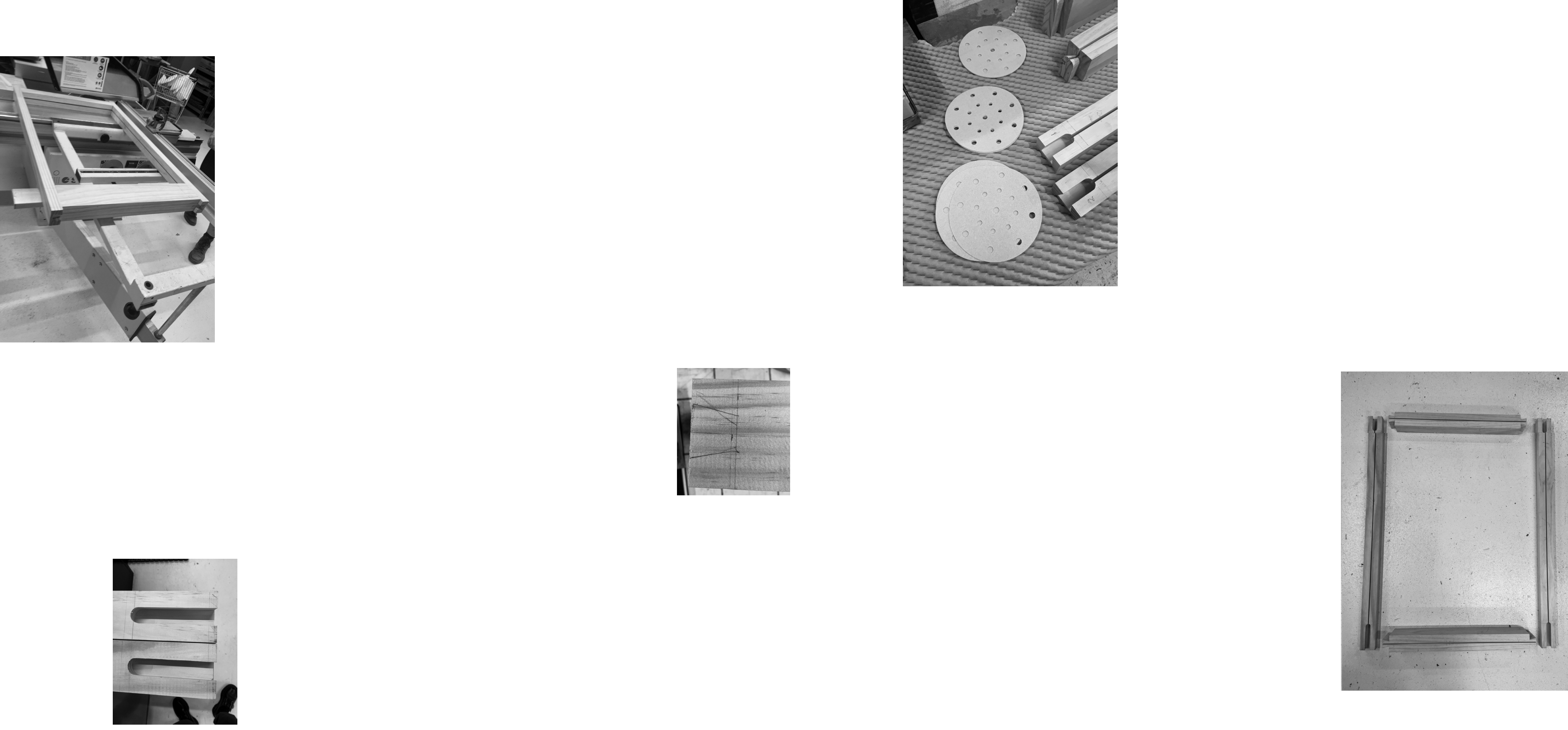

Constructed with dovetail joinery the top piece can be removed and the glass can slide out. This allows the frame to be repurposed, perhaps as a picture frame. It made no sense to use up that much material for a single purpose, so I designed it to be re-used.
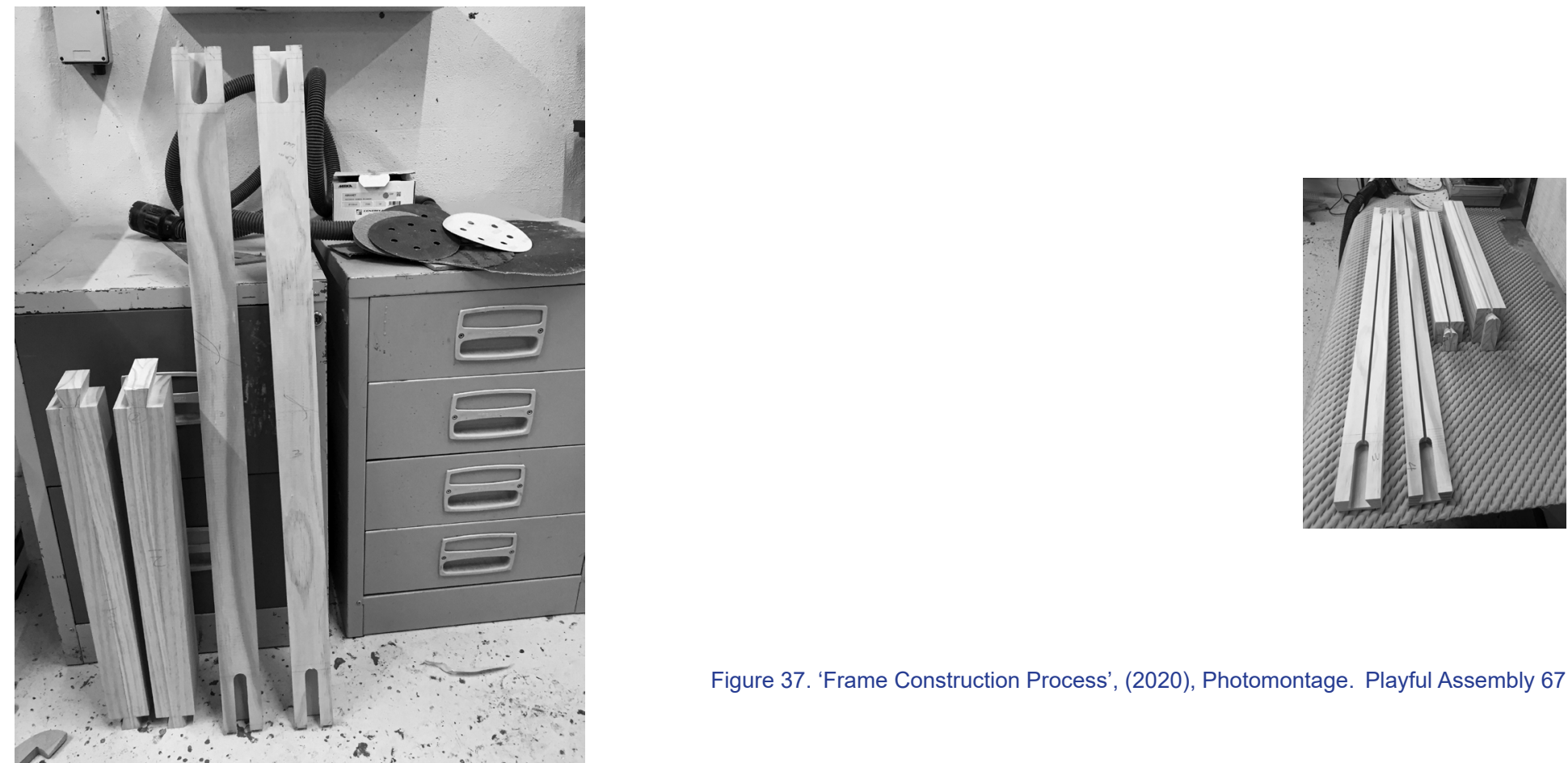
M0000 


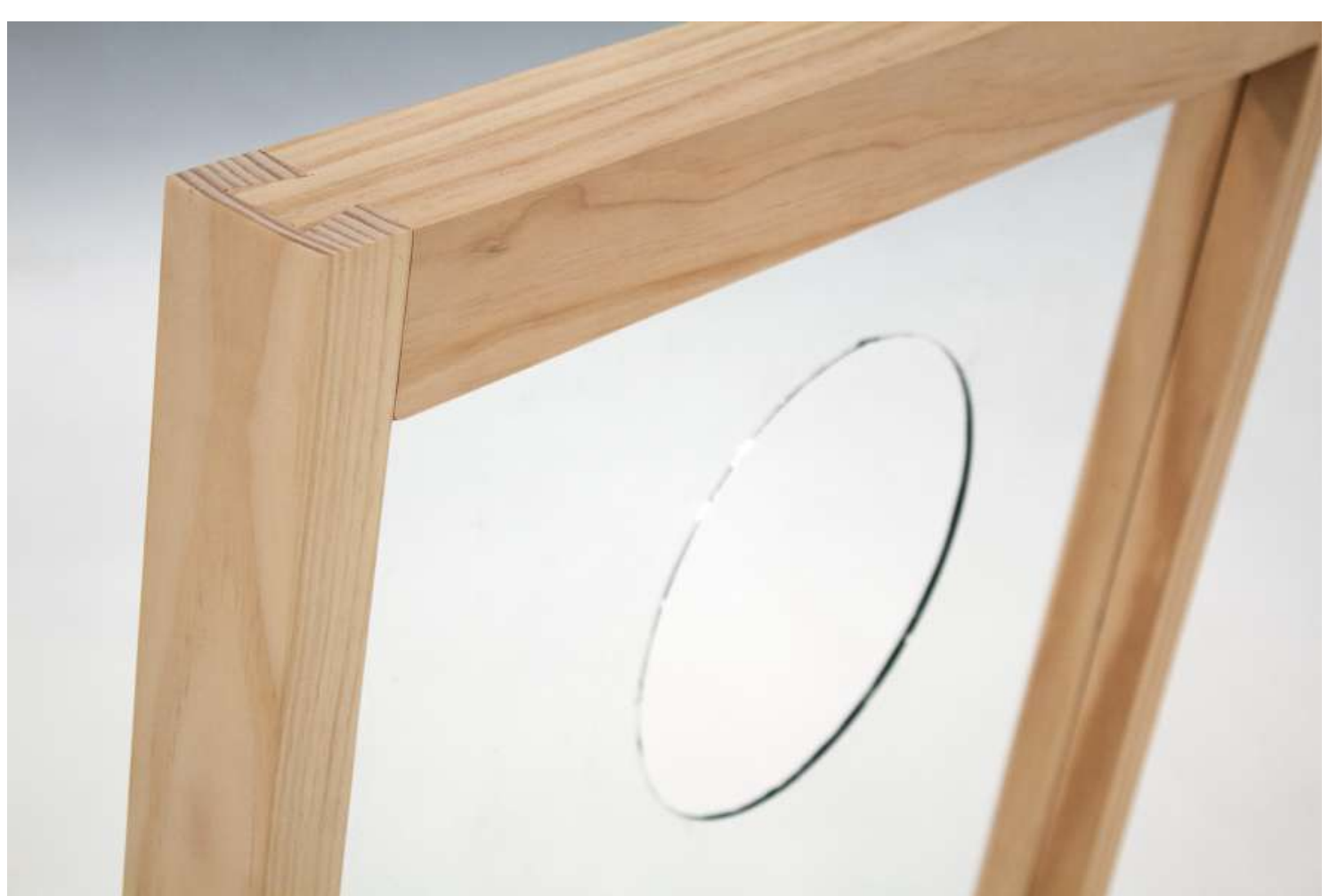

Figure 39. 'Frame Sculpture', (2020), Plywood, Glass.

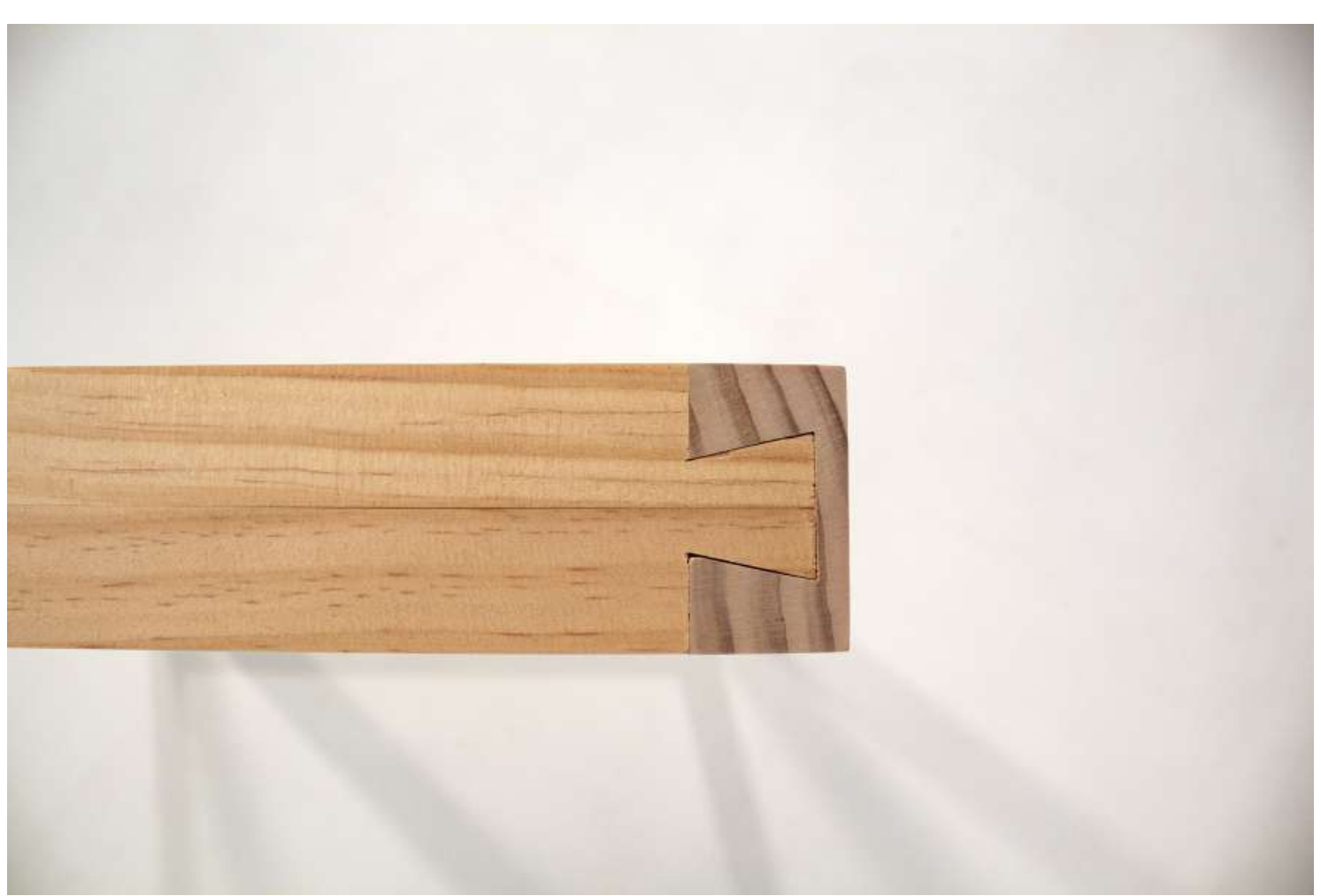

Figure 40. 'Frame Sculpture', (2020), Plywood, Glass. 


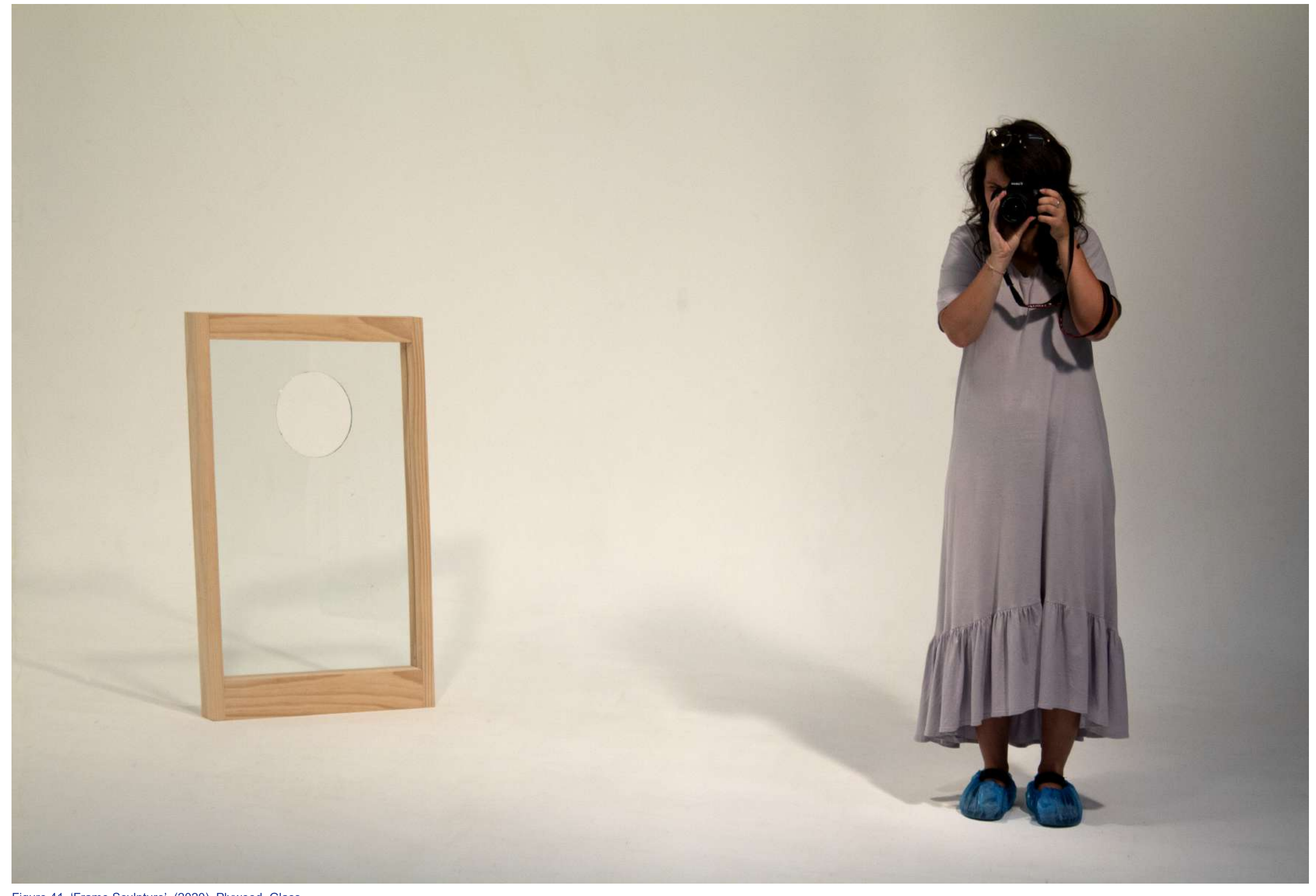

Figure 41. 'Frame Sculpture', (2020), Plywood, Glass. 


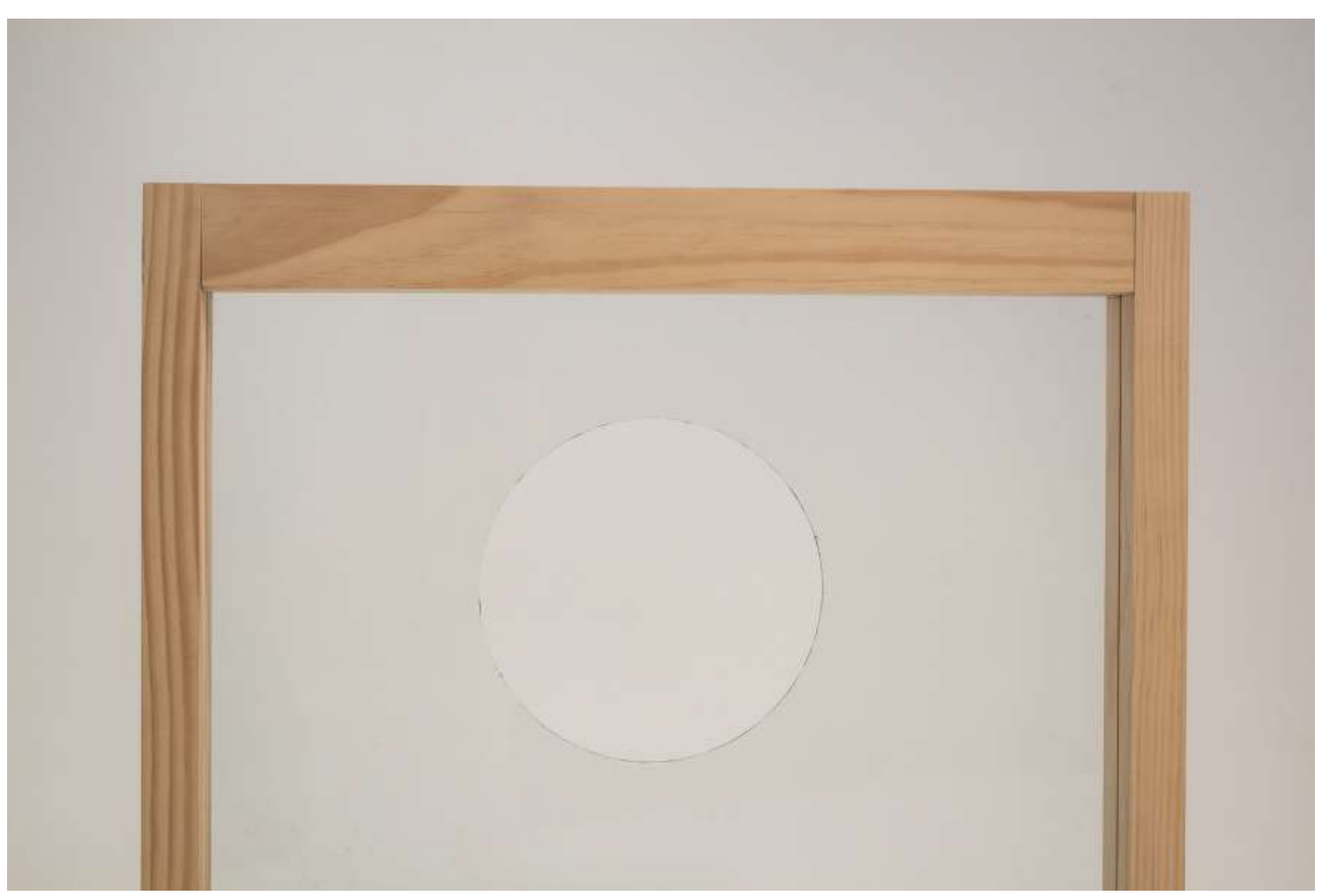

Figure 42. 'Frame Sculpture', (2020), Plywood, Glass.

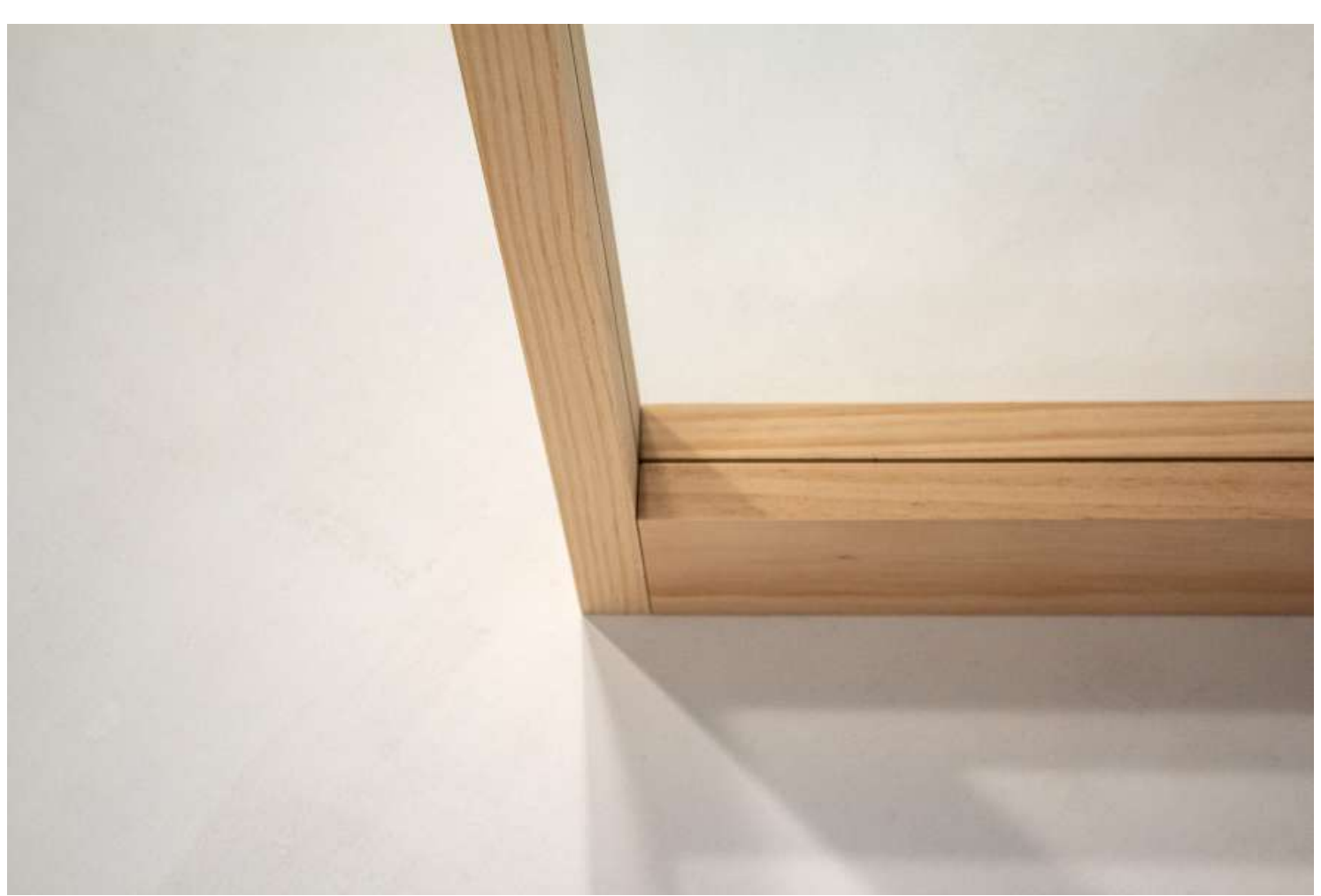

Figure 43. 'Frame Sculpture', (2020), Plywood, Glass. 


$$
\text { [] }
$$




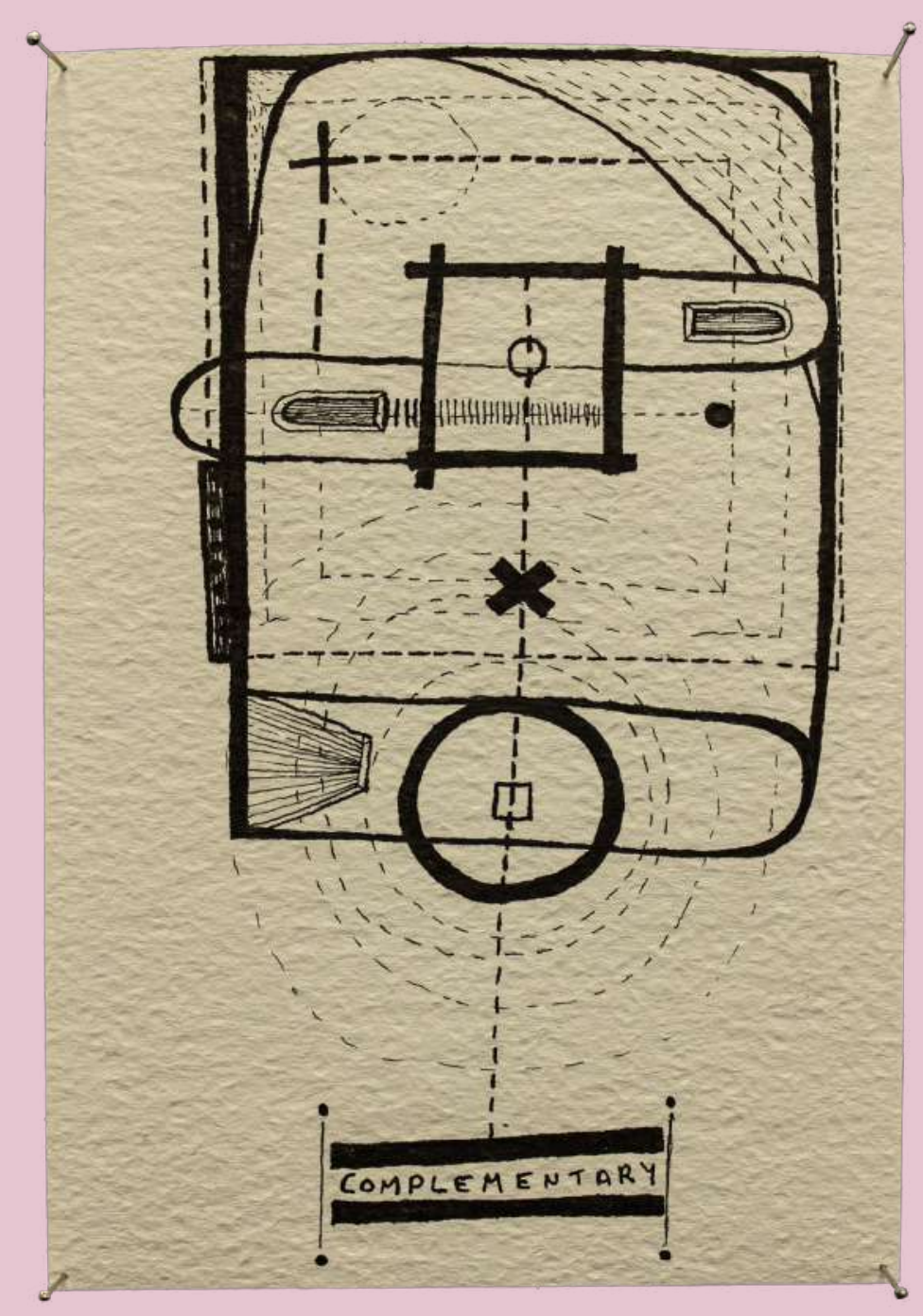




\section{visual diary*}

These were a tool for me to process thoughts and readings done at the time. Drawn on A5 rough watercolour paper with black fountain pen. The drawings very quickly got limited to $2 \mathrm{D}$ so paper sketch models were developed alongside these to develop them in 3D. At this time in the thesis I was still grappling with what this thesis is and trying to narrow down its main themes and purpose. This exploration allowed me to visually process my thoughts, discussions and understandings of topics such as, archipelago, singularity of place, forma development, urban grid and the importance of complementary elements. Quick sketches are a great way to develop an inkling of an architectural language.

These became a crucial part of the process and allowed me to develop form from art into the reality of architecture.

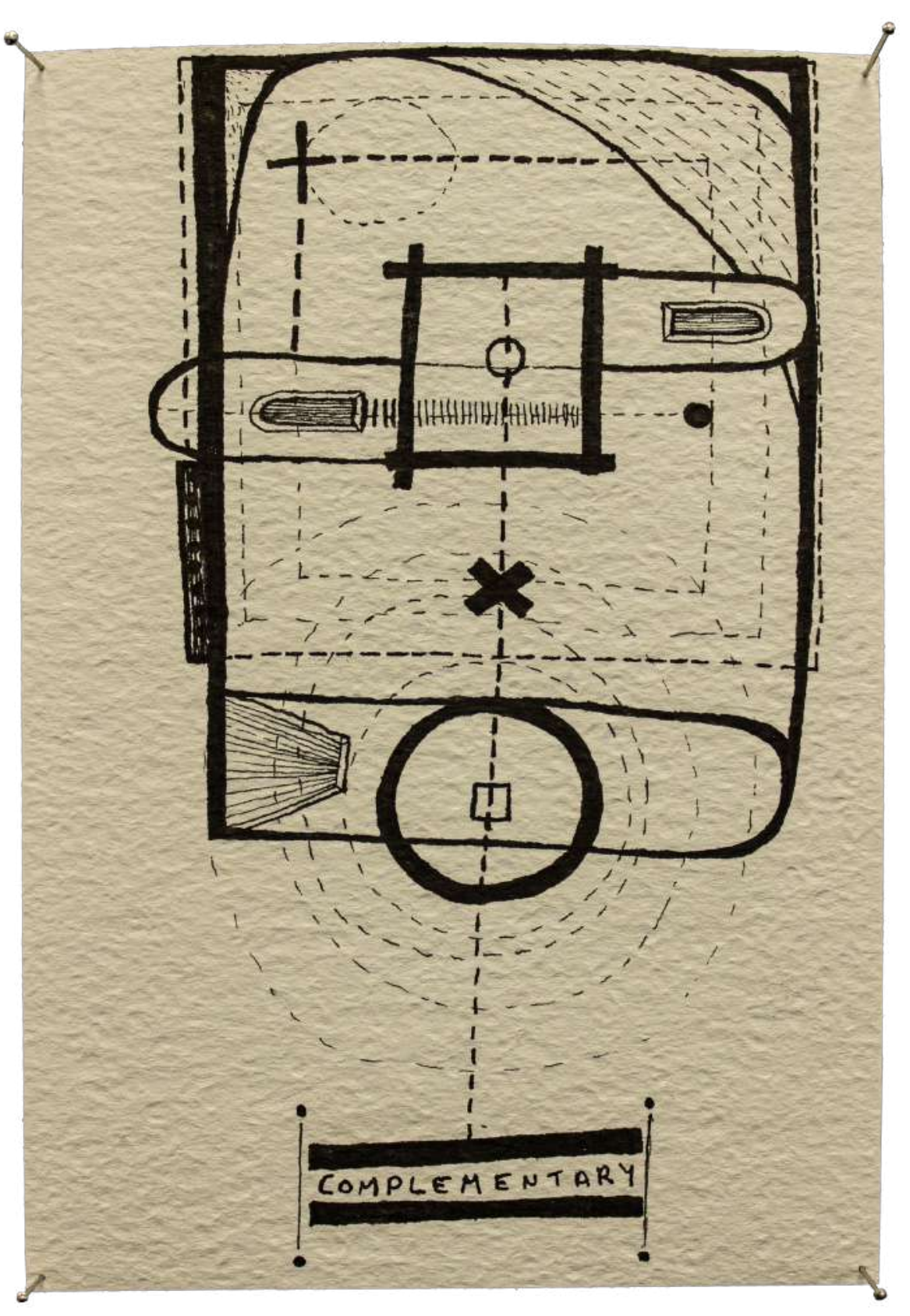

Figure 46. 'Objects to Form', (2020), Fountain Pen on Watercolour Paper.

Figure 48. 'Imperfect Urban Grid', (2020), Fountain Pen on Watercolour Paper.

Figure 49. 'Circle and Square', (2020), Fountain Pen on Watercolour Paper.

Figure 50. 'Singularity of Place', (2020), Fountain Pen on Watercolour Paper.

Figure 51. 'Ahhh-chipelago', (2020), Fountain Pen on Watercolour Paper.
Figure 52. 'Playful Assembly of Complementary Elements', (2020), Fountain Pen on Watercolour Paper 

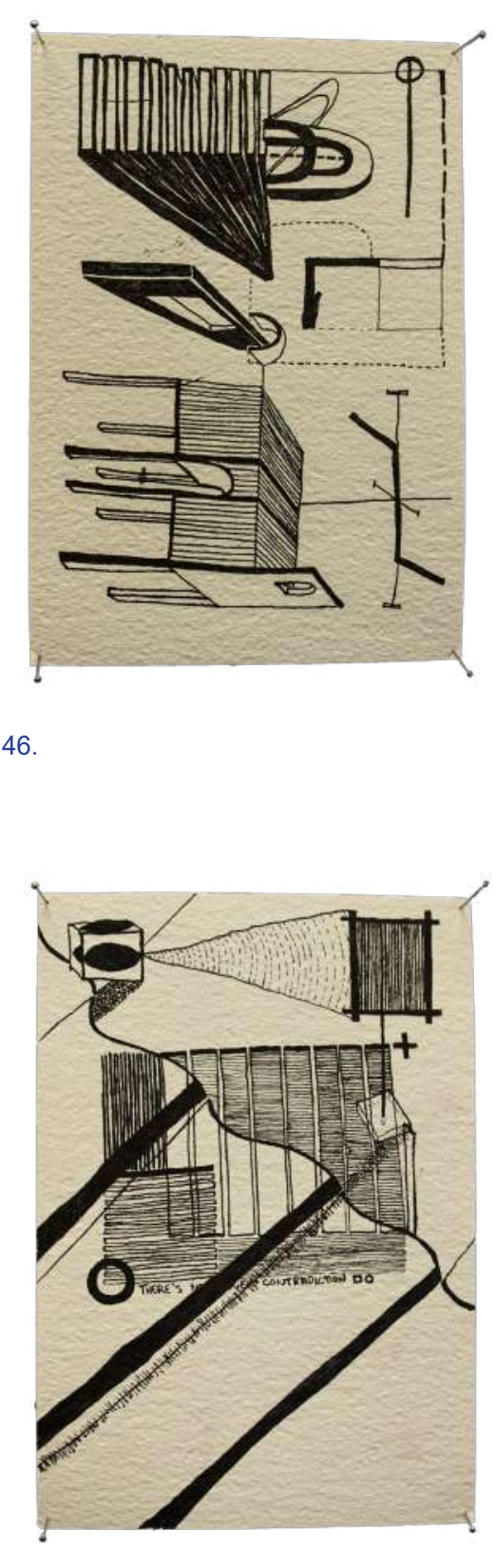

49.

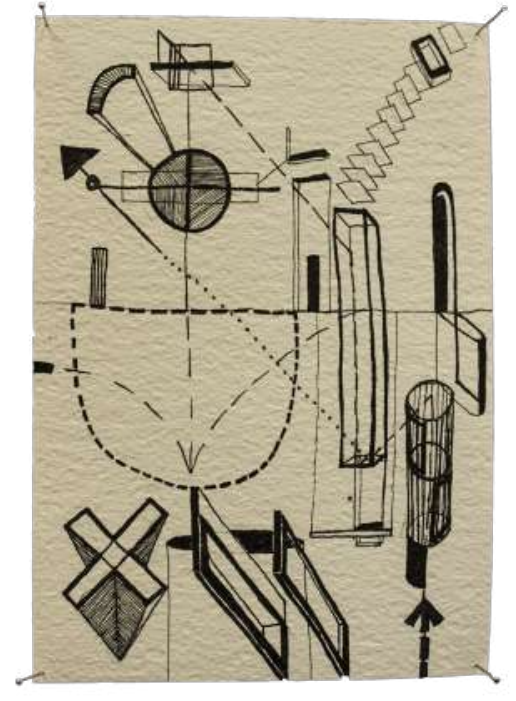

47.

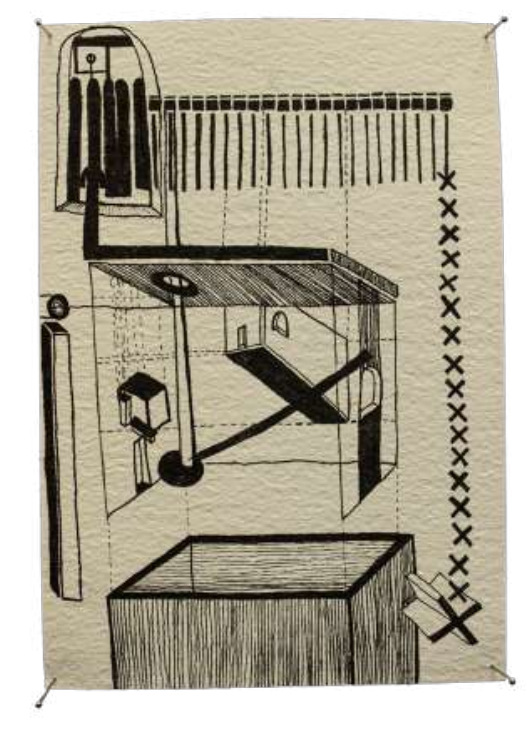

50.

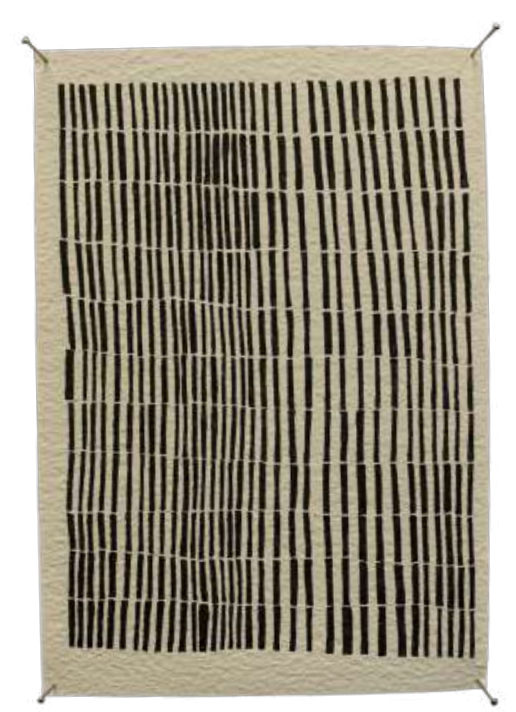

48.

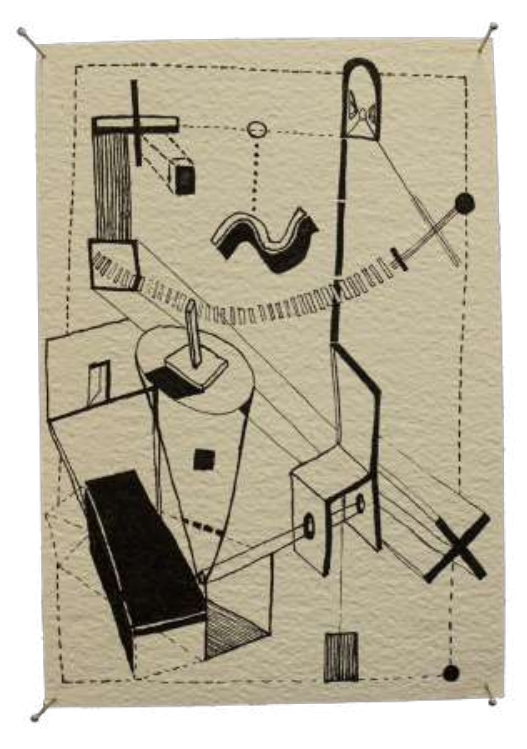

51. 

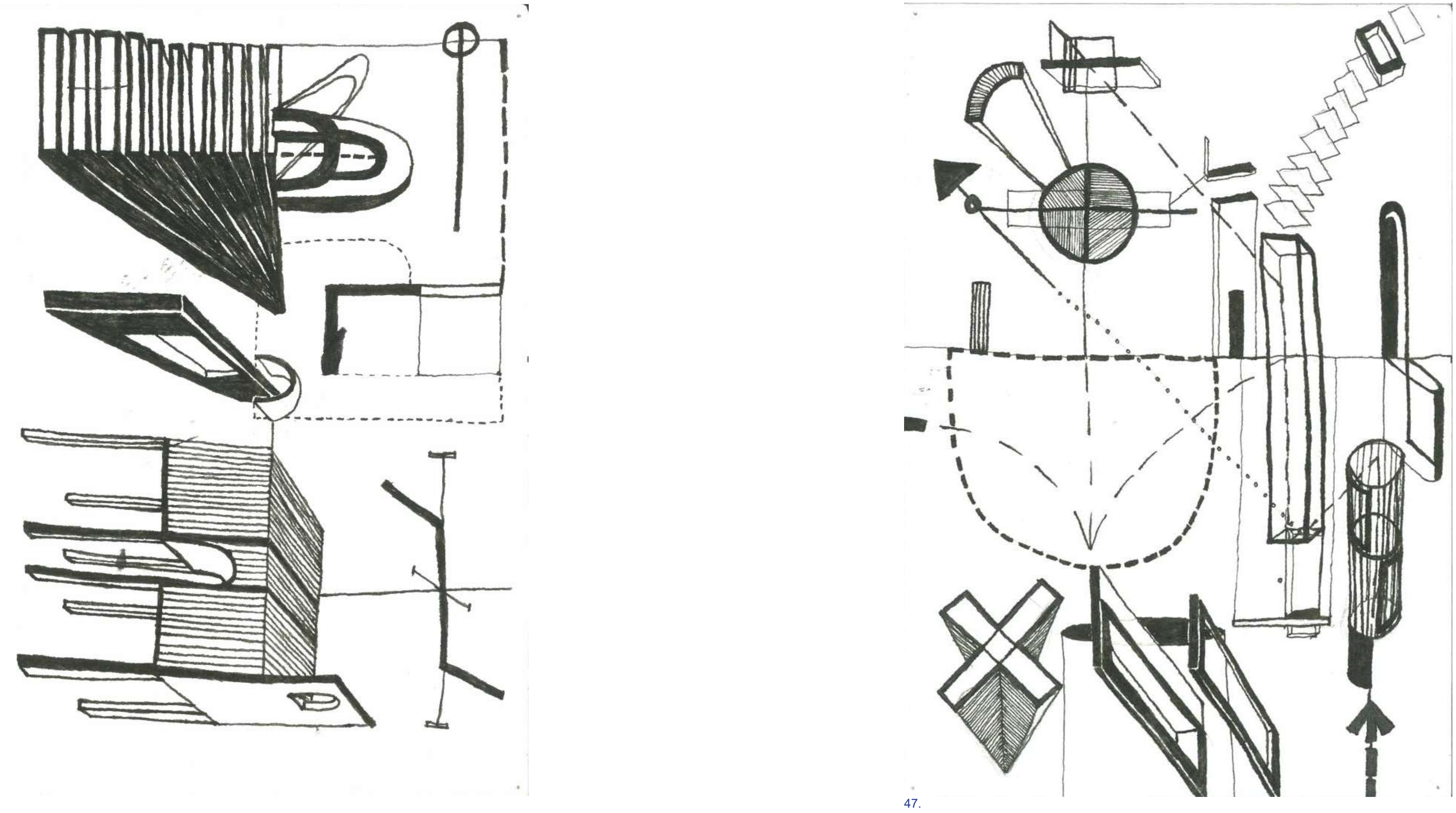


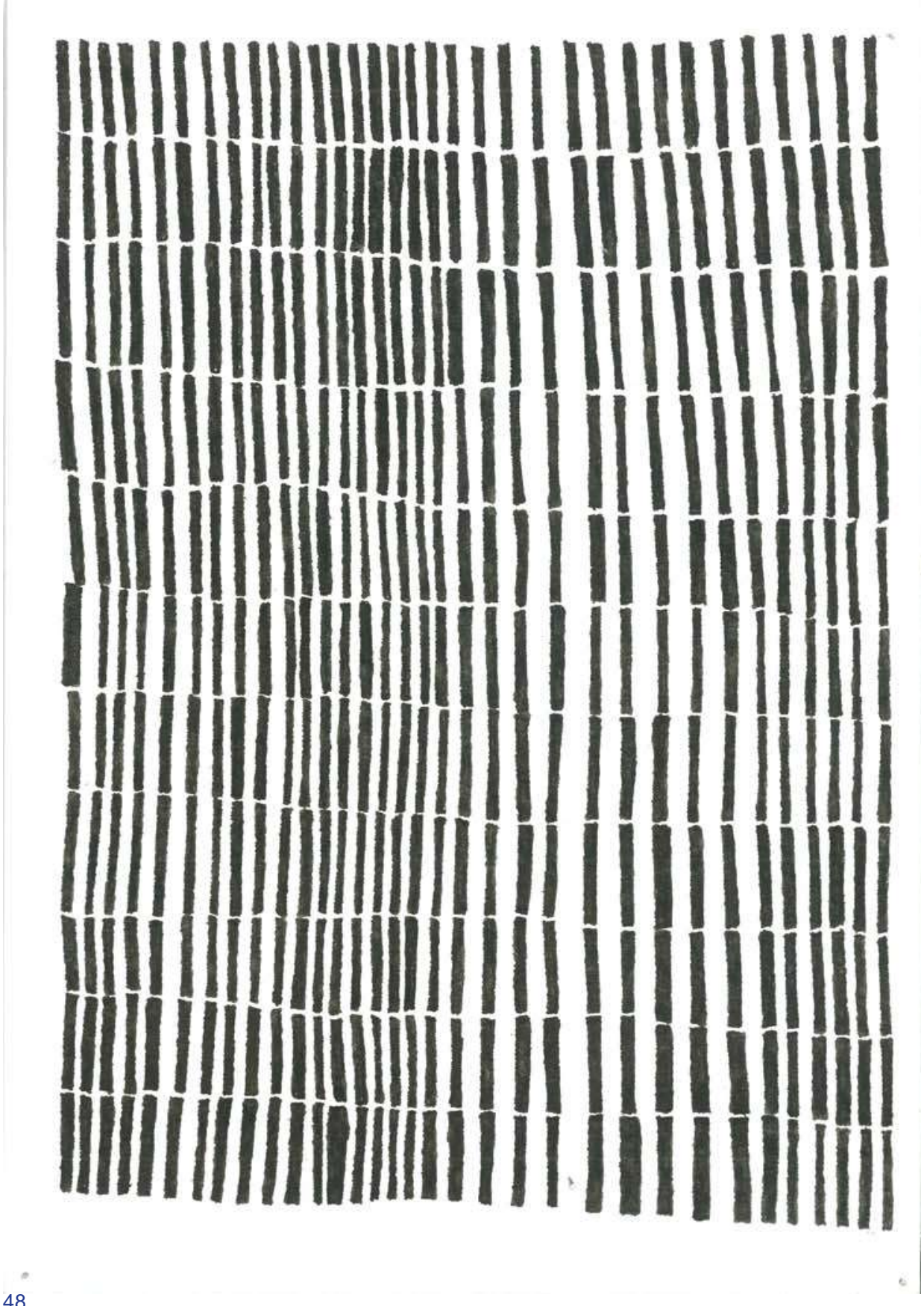

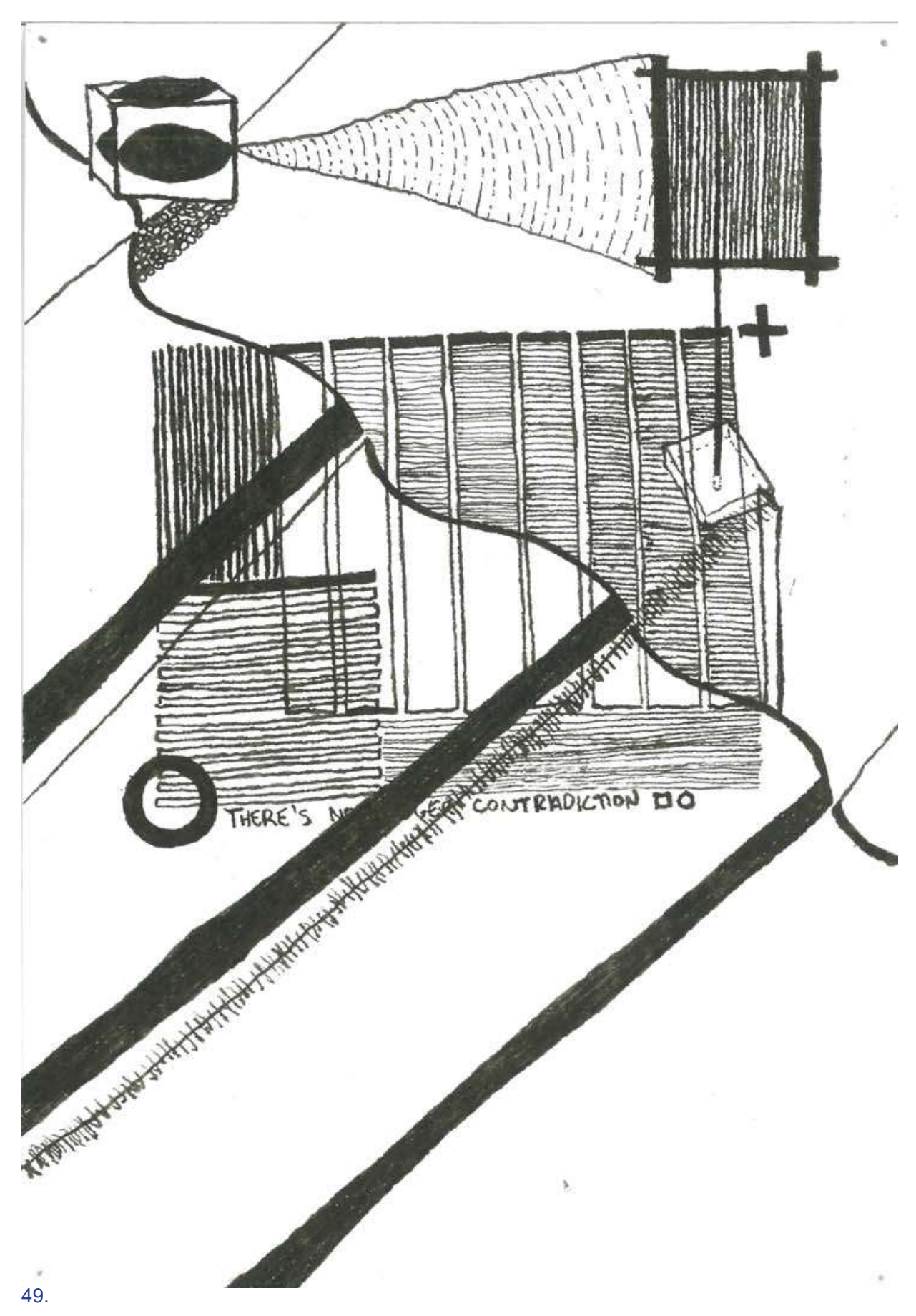



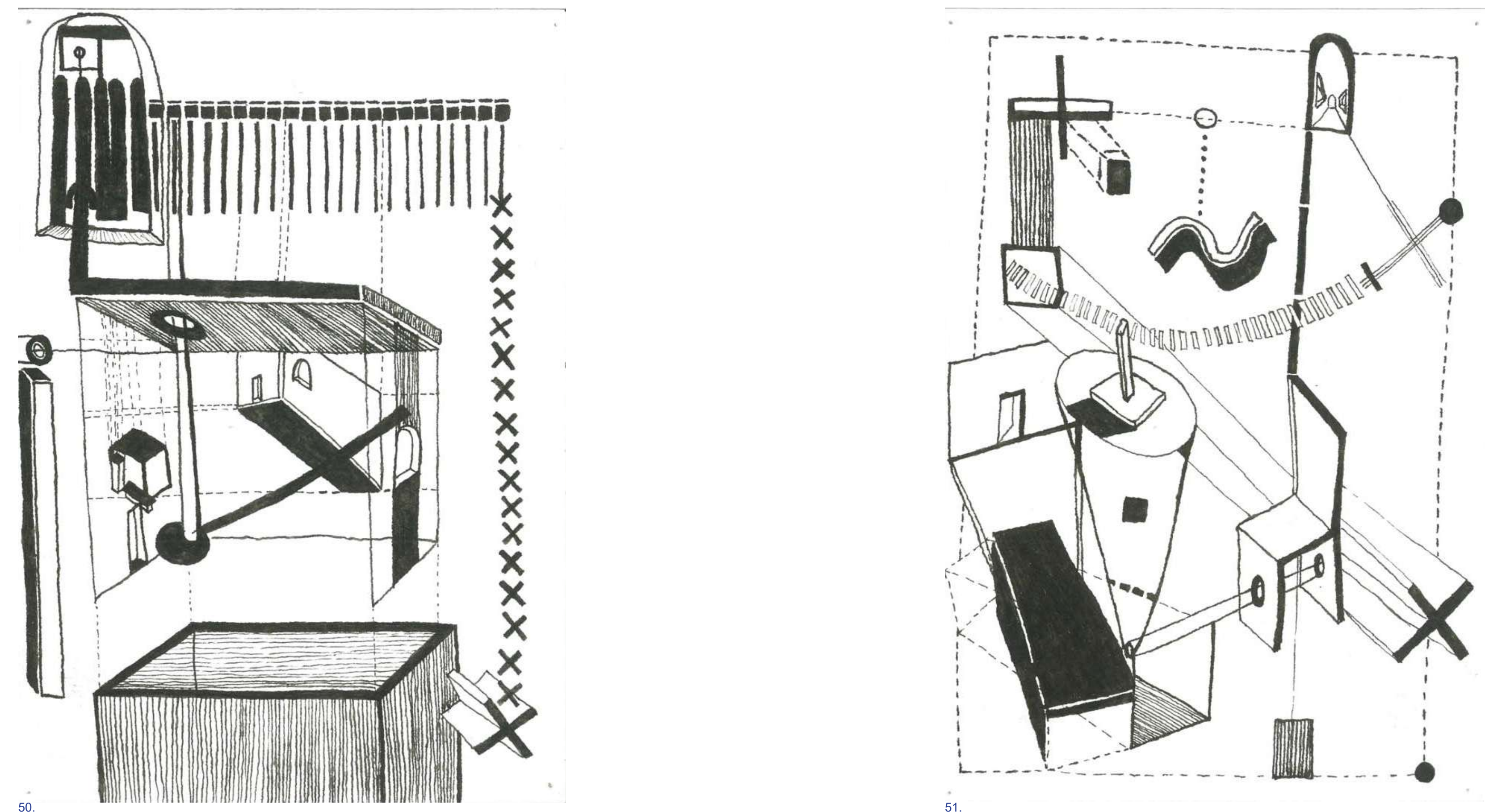
<smiles>C1=C[C@H]2C=C[C@H]1O2</smiles> 


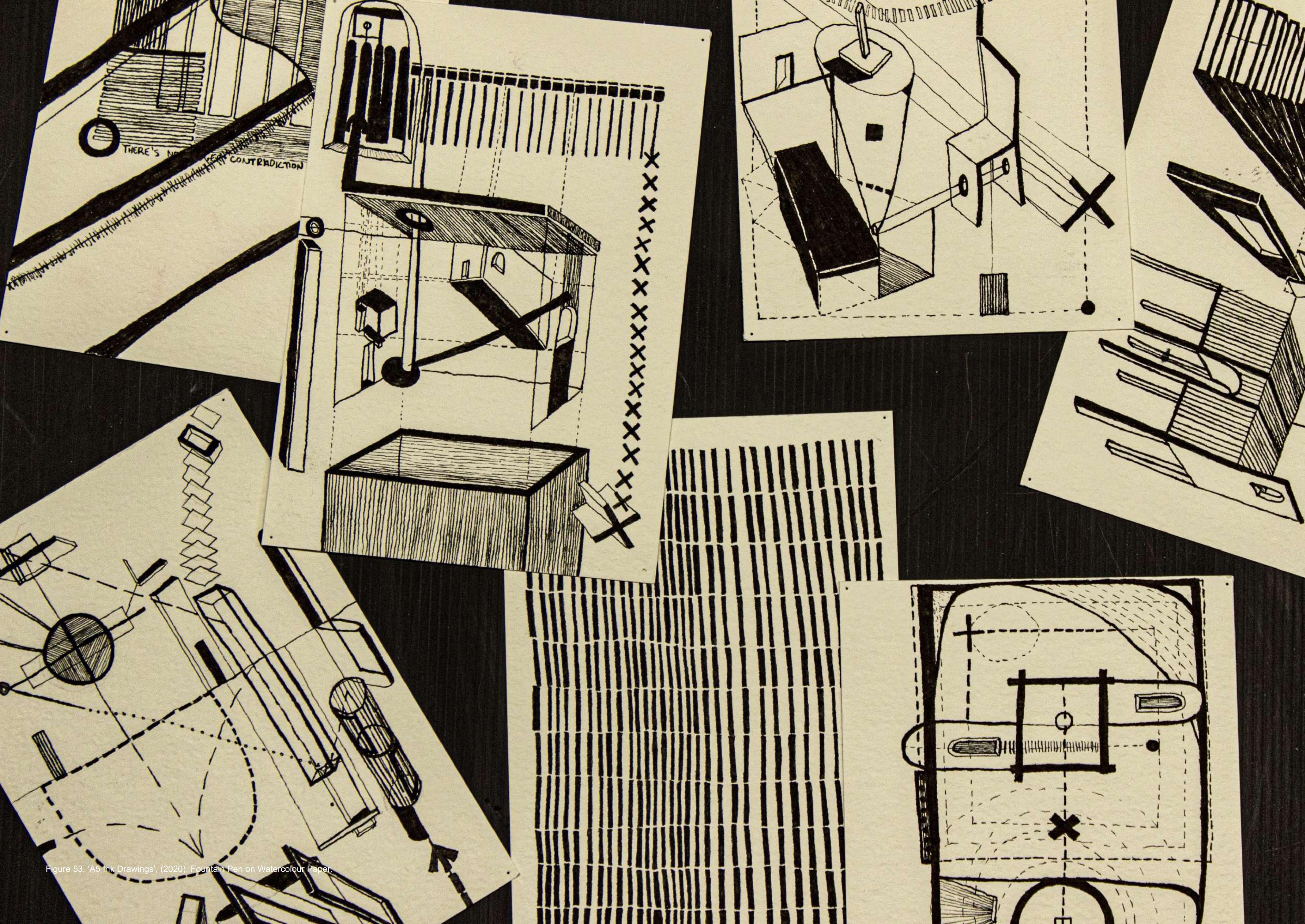



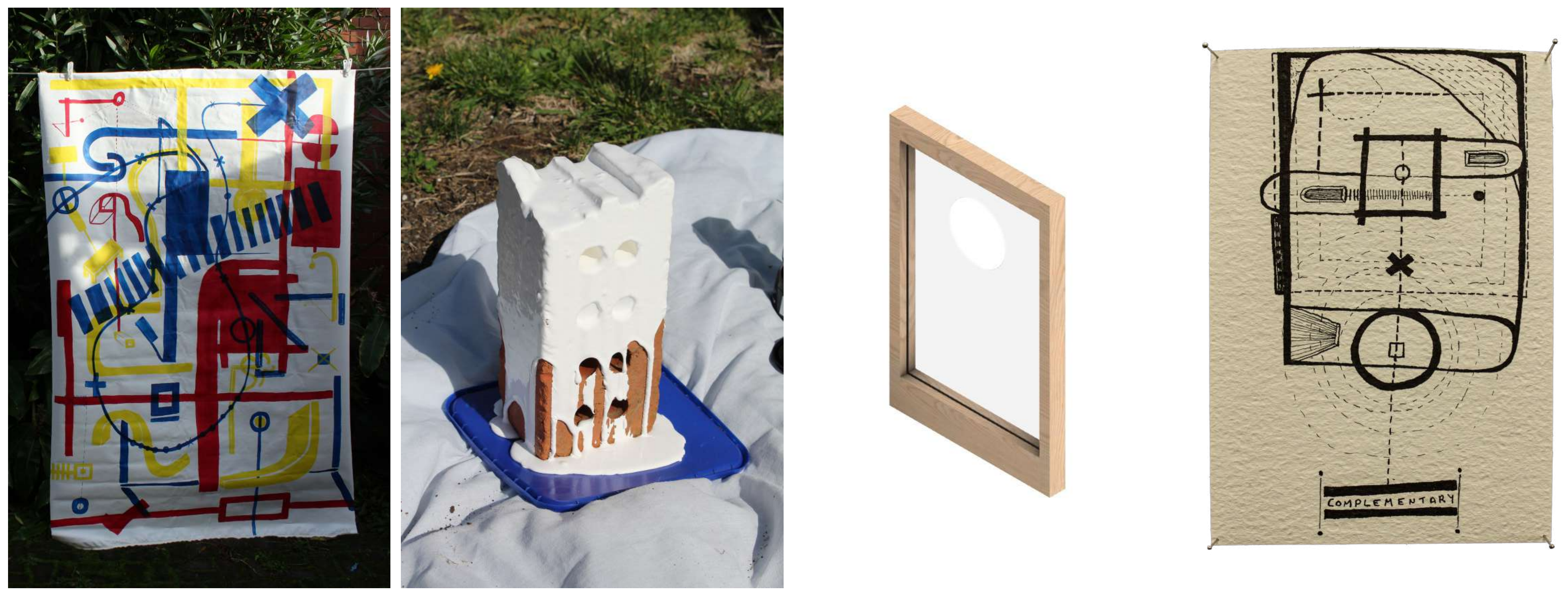

Figure 54. 'Exploration', (2020), Mixed Media. 


\section{may review*}

The May review was on zoom and I found it difficult to engage. It offered an opportunity to collate what I had completed which led to the discovery of my painting being understood as an urban plan. It pushed me to think bigger and be bolder. Excited by the idea of translating my painting into an urban scale I started with this post-review.
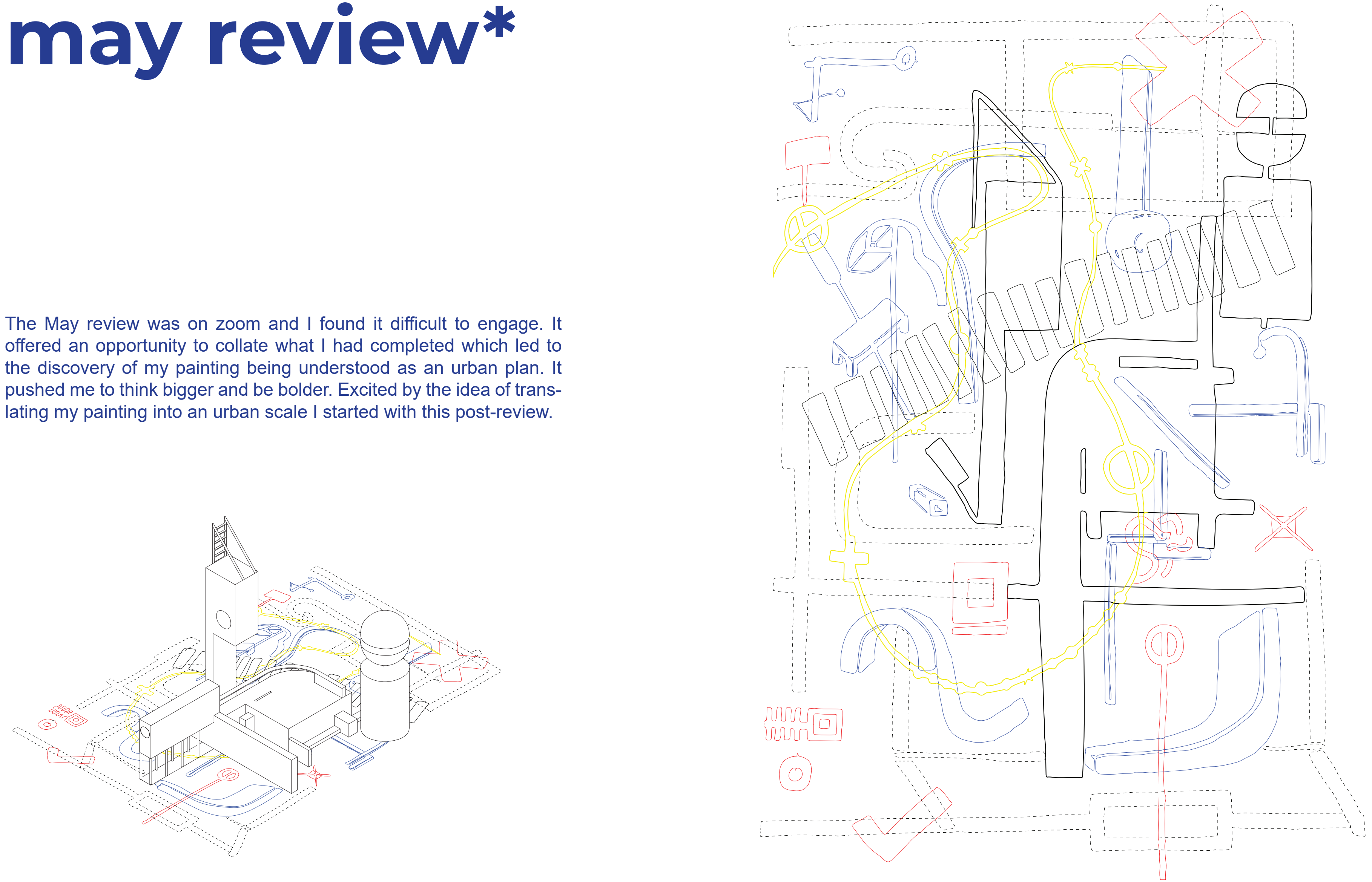

Figure 56. Plan, 'Painting to Form', (2020), Digital Drawing. 


\section{making city}

* 


\title{
city networks*
}

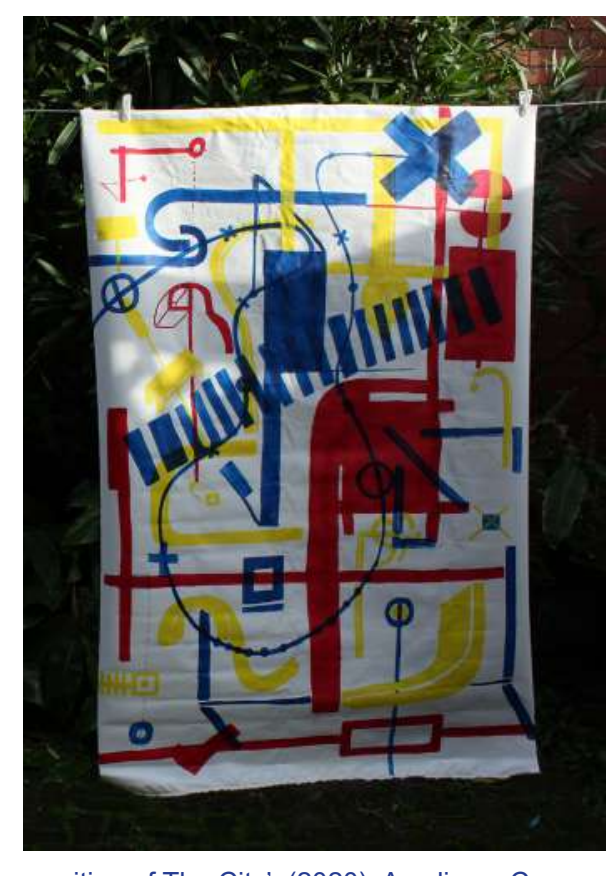

Figure 57. 'Composition of The City', (2020), Acrylic on Canvas.

\begin{abstract}
Understanding my painting as a composition of the city, led to a general urban analysis of Porirua. This chapter explores a playful assembly of the city, inspired by painting and group analysis of the layers of Porirua. Through this analysis, the cultural network's implications on Porirua city is discovered.

I grew up constantly on the move from city, town, home, school and coast. I understand places run on layers of entwined networks, especially cities. I have grown to believe the most important network of the city is one which gives the city character, makes it unique and contributes value to the larger network of the world. A city with its own self-expression. People hold character, and the more opportunity there is for individual expression, the more character is expressed in the city. The creative city is focused around culture, welcoming diversity and encouraging creative self-expression within the community. It's creativity in all its forms.
\end{abstract}




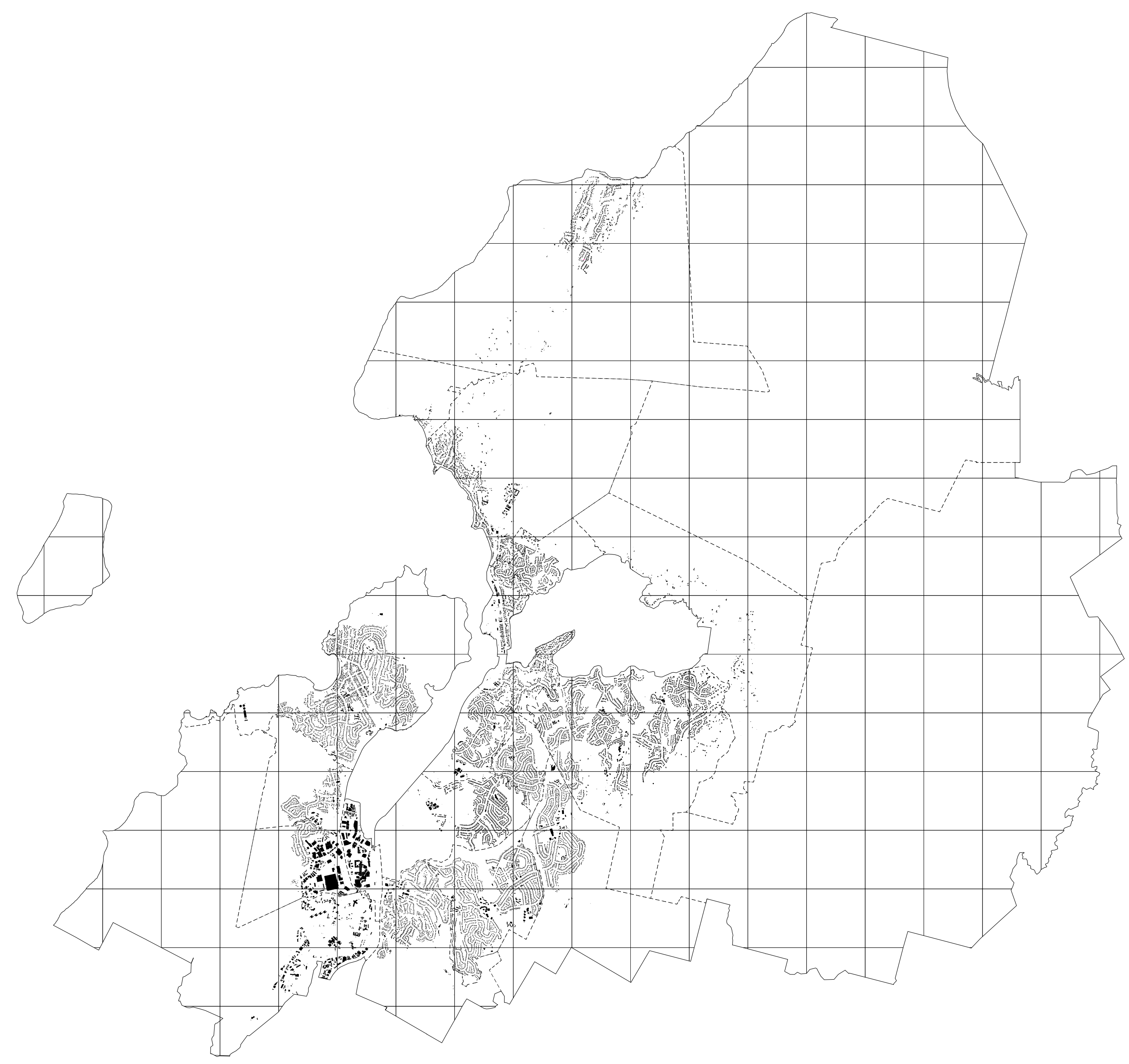




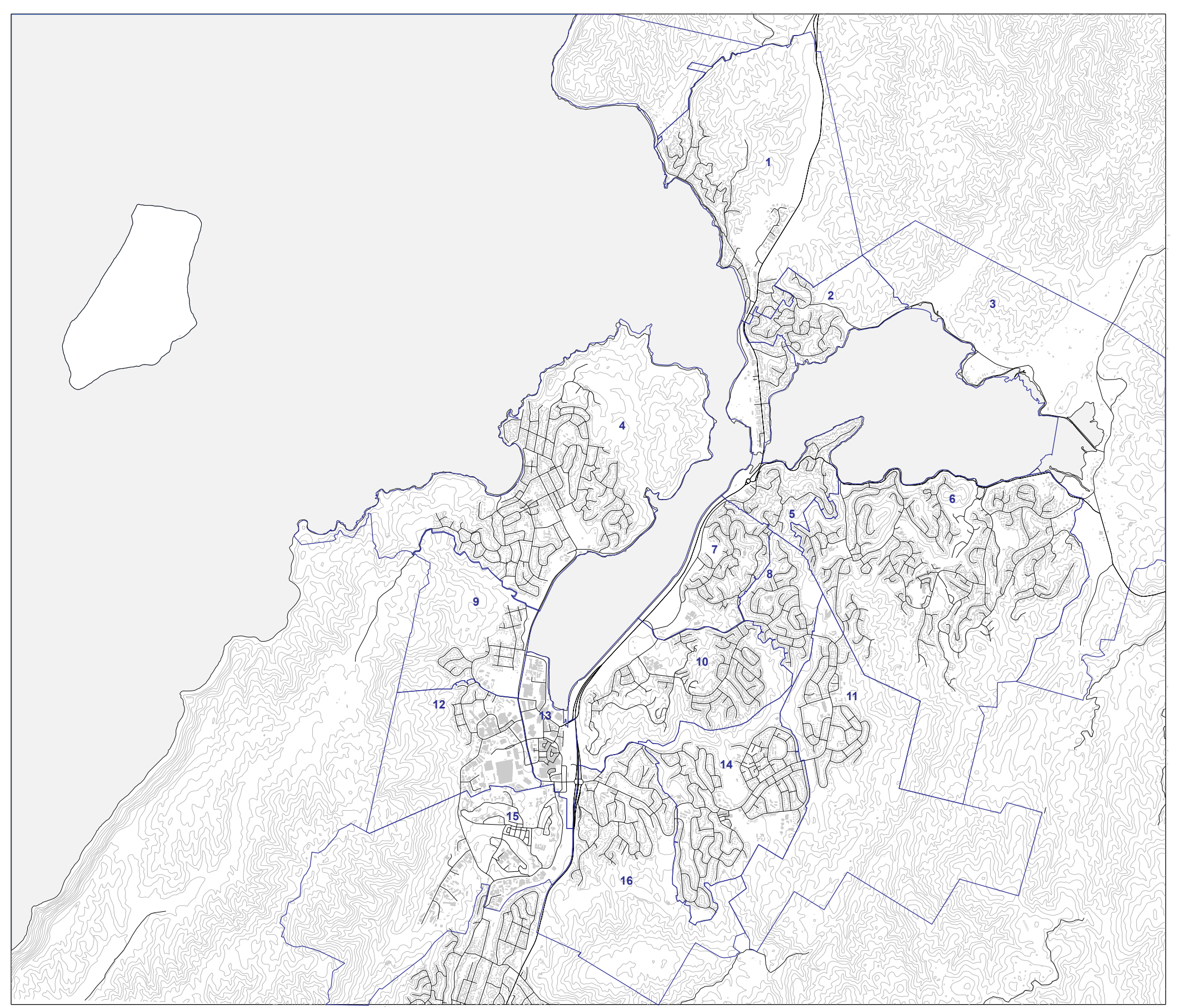

Key

Porirua City Average $3.24 \mathrm{pph}$

1. Plimmerton $3.19 \mathrm{pph}$

2. Camborne $2.78 \mathrm{pph}$

3. Pāuatahanui
Paekākäriki Hill
$0.12 \mathrm{pph}$

4. Titahi Bay $\quad 8.85 \mathrm{pph}$

5. Paremata $\quad 17.11 \mathrm{pph}$

6. Whitby $21.99 \mathrm{pph}$

7. Papakowhai $10.85 \mathrm{pph}$

8. Ascot Park $22.24 \mathrm{pph}$

9. Takapuwhaia $1.53 \mathrm{pph}$

10. Aotea $10.85 \mathrm{pph}$

11. Waitangirua $12.80 \mathrm{pph}$

12. Elsdon $1.53 \mathrm{pph}$

13. Porirua Central $1.53 \mathrm{pph}$

14. Cannons Creek $27.94 \mathrm{pph}$

15. Kenepuru $1.53 \mathrm{pph}$

16. Porirua East $18.17 \mathrm{pph}$

Figure 59. Population Density, 'Porirua Networks', (2020), Group Work, Digital Drawing. 


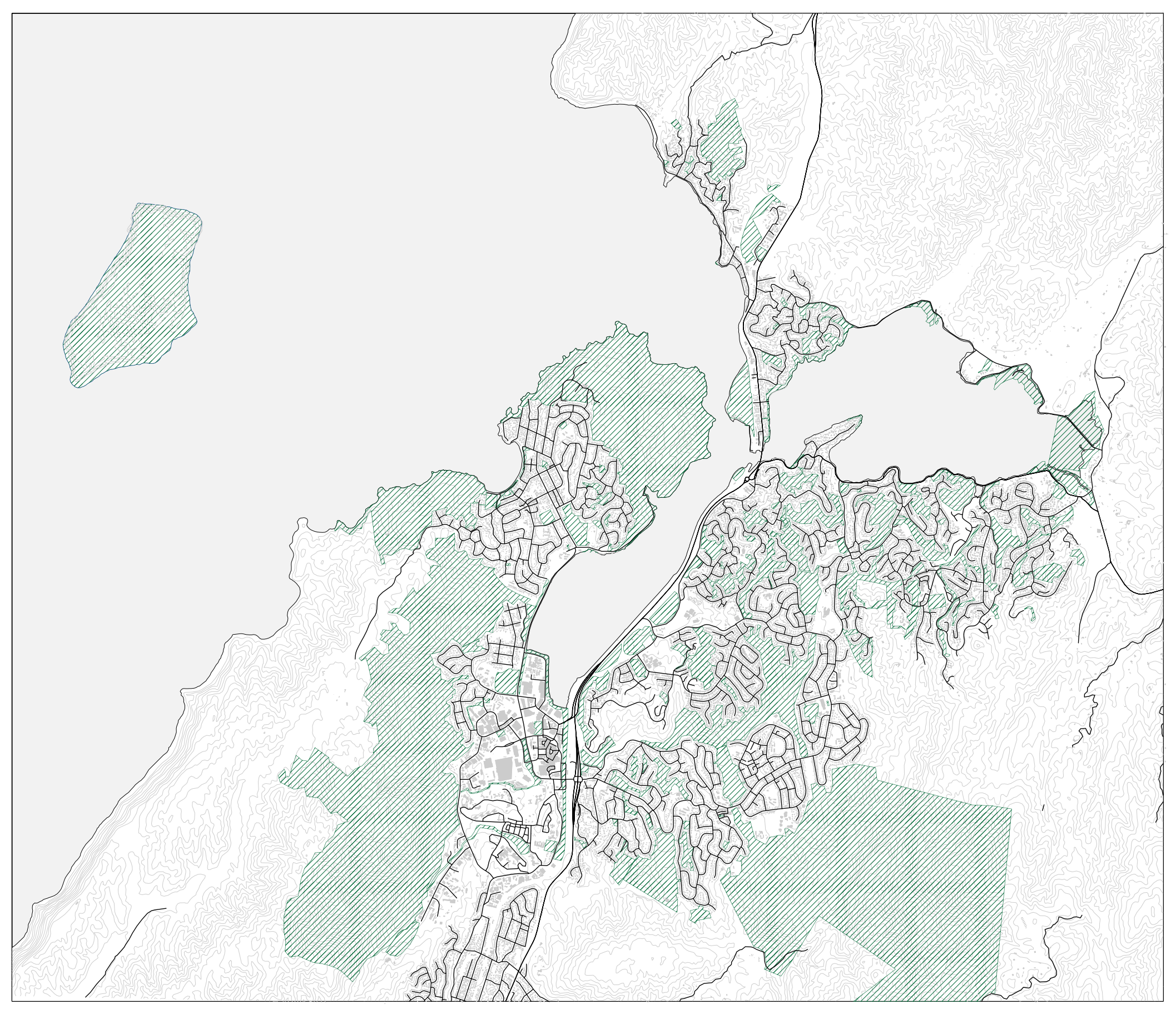

Figure 60. Parks and Reserves, 'Porirua Networks', (2020), Group Work, Digital Drawing. 


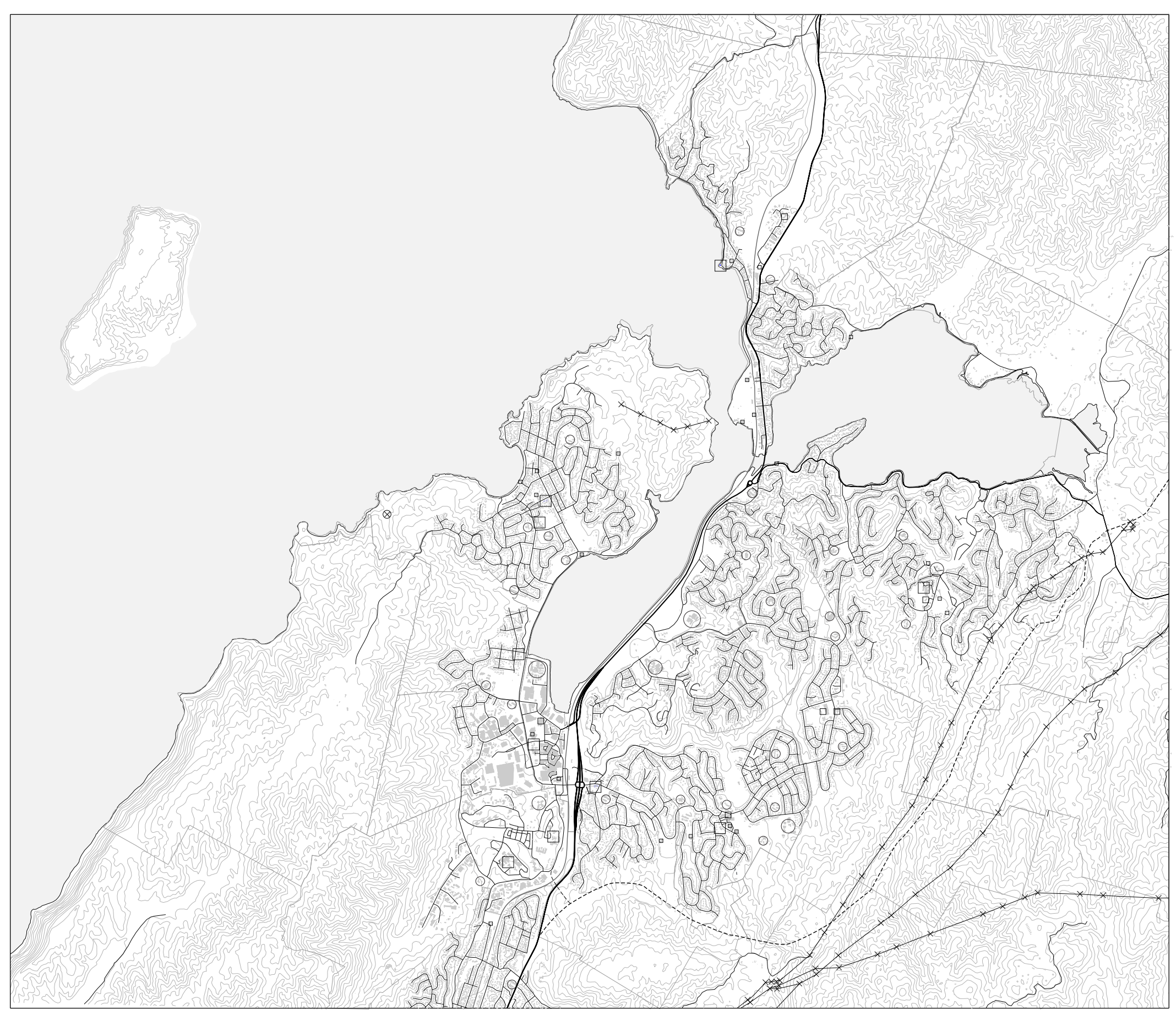

Key

- SH58

— Major Local Road

— Major Local Road

- _ - Transmission Gully

— Railway (NIMT)

P Primary School

Secoundary School

Tertiary School

口 Recreation (Pool, Sports Clubs, Gyms)

$\square$ Community (Library, Gallery, Markets)

$\square$ Emergency Services

$\times \quad$ Primary Electrical Service

$\otimes$ Waste water Plant

Figure 61. Schools and Public Services, 'Porirua Networks', (2020). Group Work, Digital Drawing 


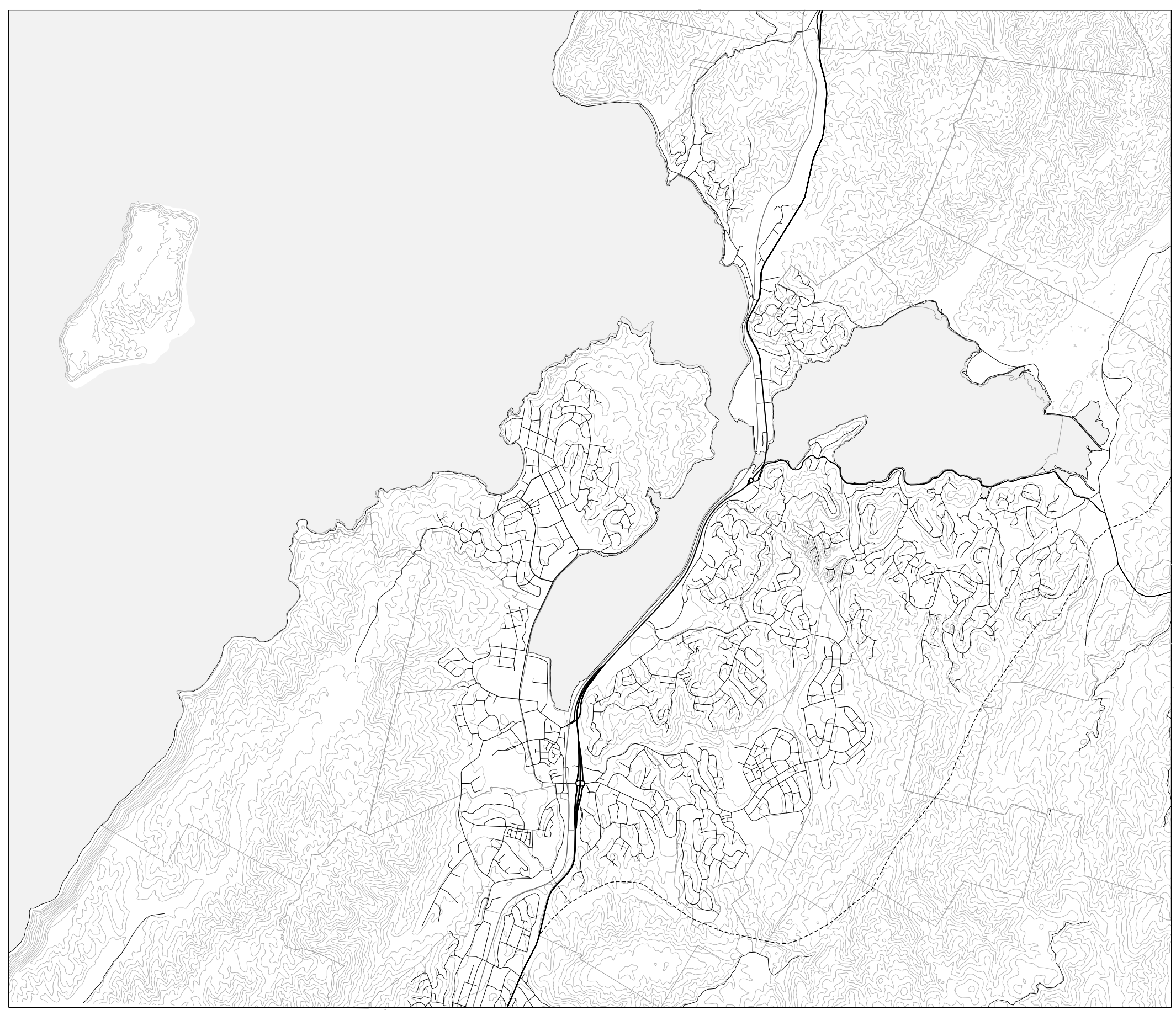




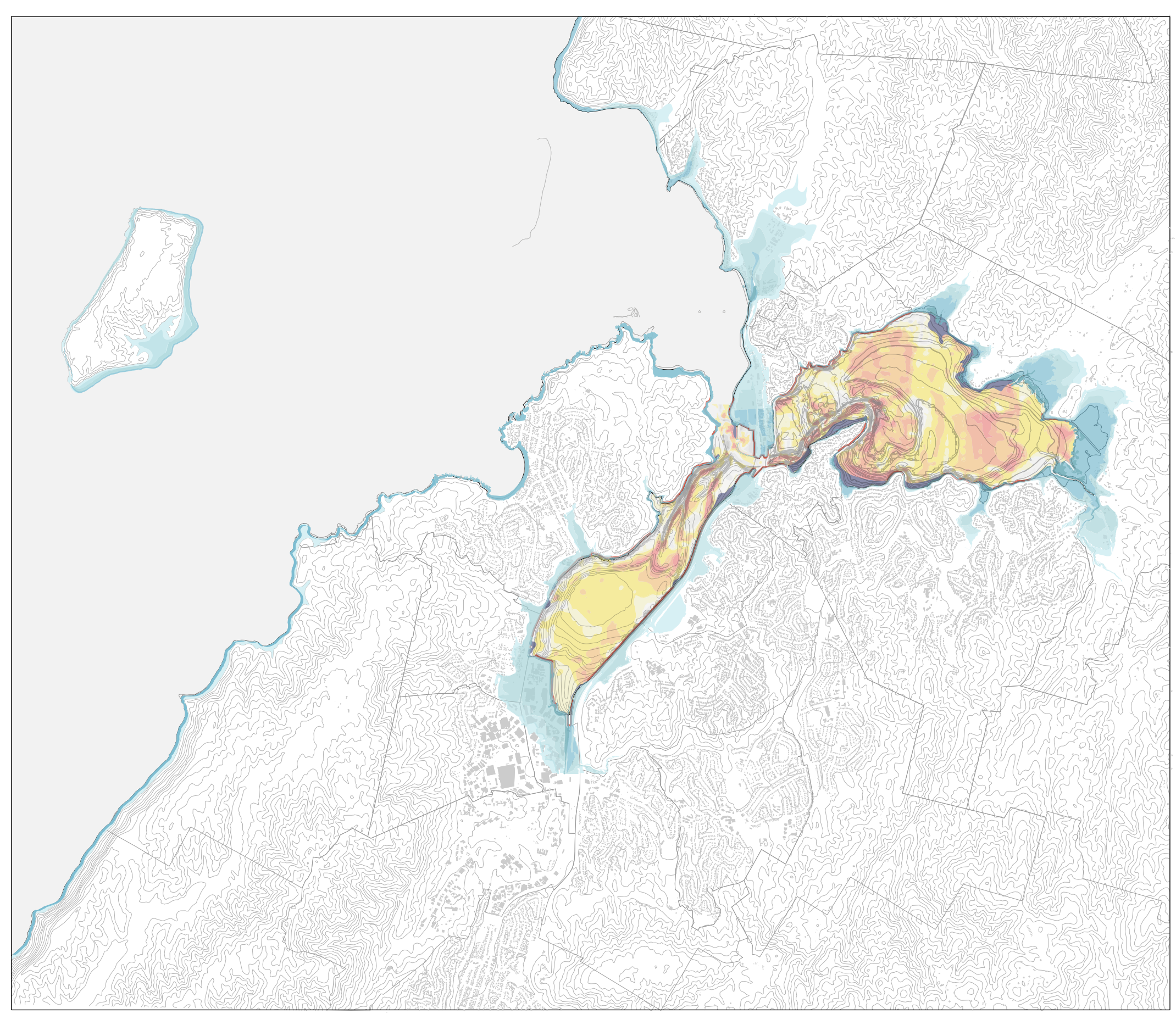

Key

을 $2 \mathrm{~m}$

$1.8 \mathrm{~m}$

$1.6 \mathrm{~m}$

$1.4 \mathrm{~m}$

$1.2 \mathrm{~m}$

$1.0 \mathrm{~m}$

$0.8 \mathrm{~m}$

$0.6 \mathrm{~m}$

$0.4 \mathrm{~m}$

$0.2 \mathrm{~m}$

0

$-0.2 \mathrm{~m}$
$-0.4 \mathrm{~m}$

$-0.6 \mathrm{~m}$

$-0.8 \mathrm{~m}$

$-1.0 \mathrm{~m}$

$-1.2 \mathrm{~m}$

$-1.4 \mathrm{~m}$

$-1.6 \mathrm{~m}$

흠 $-1.8 \mathrm{~m}$

迸 $-2.0 \mathrm{~m}$

Figure 63. Harbour Patterns, 'Porirua Networks', (2020), Group Work, Digital Drawing

Edge Erosion

Edge Deposition 
" The concept of the city as archipelago, far from being a fantasy superimposed upon reality, would actually only need to be revealed as the city's underlying reality, and pursued." (Ungers, 43)

in:

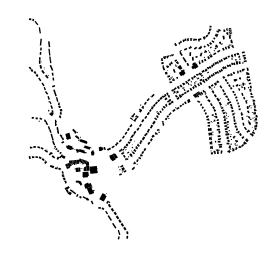




\section{playful \\ assembly of the city*}

When interpreted as a playful assembly, the city is separated into its layers. These layers and their individual elements are composed to form a creative conglomeration of city; promoting diversity, community interaction and creativity. It supports a diverse array of people congregating in the same area, crossing paths and bumping into each other. It is based around creative production rather than consumption. This city measures wealth through culture instead of economy. It requires spaces for individual expression of creativity. Therefore, emphasis goes towards the arts, the theatres, studios, galleries, workshops, etc. Because it values cultural wealth these buildings are designed to last, grow, move and mould with the city. The architecture is to be an individual expression itself, it is to have as much autonomy as the city's people. The architecture must be united by its diversity, by its self-expression,. Consequently the city can be read as a playful assembly of architecture, building programs, people, craft, entertainment, creativity and culture.

Each area/district/island is to hold as much diversity as the next to promote movement between them. The islands are a network, a system, they contribute to the collective while being autonomous.

The cultural network focussed on the existence of sites for creative production (fig. 65). I have developed an architectural language for these sites as an expression of my own creative production.

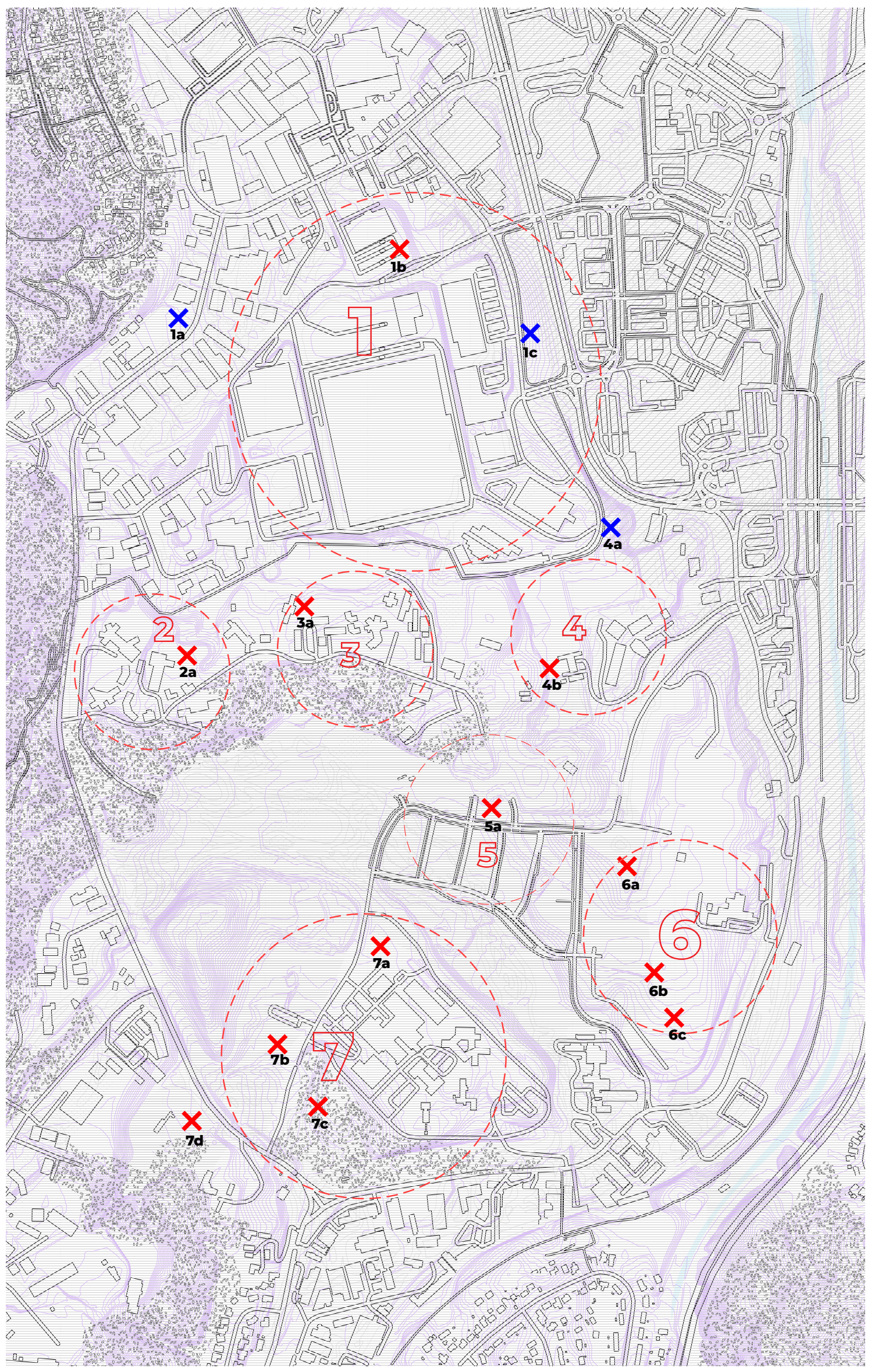





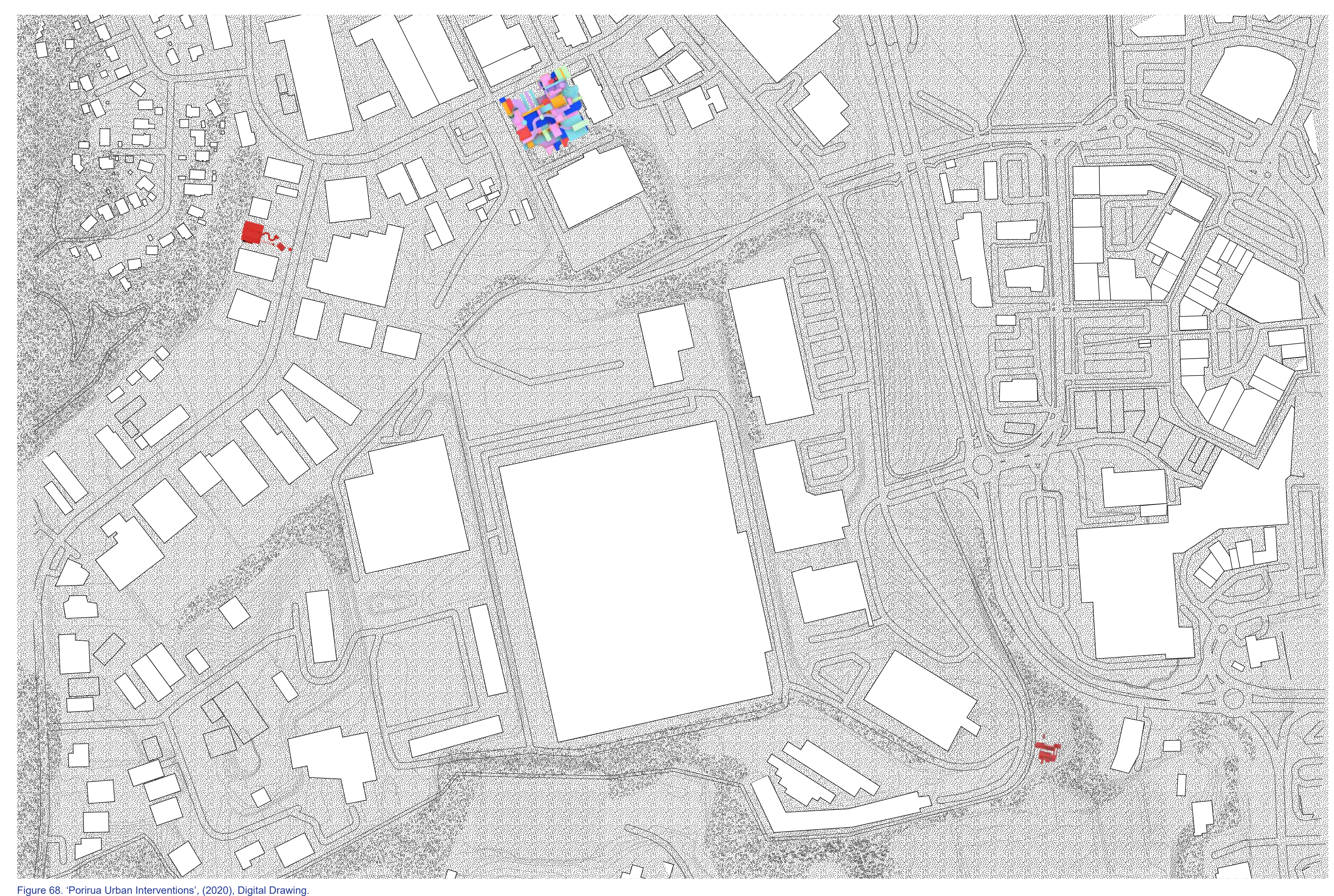




\section{archipelago*}

An example of a playful assembly city proposal is the "The City in The City, Berlin: A Green Archipelago" By Oswald Ungers and Rem Koolhaus. Green Archipelago is a response to the post-war degrading city of Berlin in 1977. It proposes the various areas in Berlin, which are reduced to their building structure devised from their distinctive postwar urban fabric. It holds the diversity and restoration of a singular place which contributes to the other places of Berlin. It aims to develop the shrinkage of cities highlighting the density of the last part of the city. The city in the city. This would see a range of unique urban islands creating a polycentric model for the city which maintains the singularity of place for each place. This creates an enriching metropolis environment catering for many walks of society.

These pockets of diversity unite as a whole, as a network of unique individualized parts. In a contemporary society an archipelago city reduces the notion of sprawl and large suburban development by creating smaller areas of a higher density. The city grows inwards rather than outwards to create congestion of the city. Porirua has the potential to be understood as an archipelago with its variety of areas battling to portray their sense of place. Yet the large suburban developments are being developed around the grey boring city. Rather than enriching the city it is taking away its green areas and moving further away from the city leaving it grey and mundane.

Archipelago provides an alternative way to compose the city. It creates rich relationships between the elements of the city. Originally proposed as an effort to keep the character and life of a degrading city alive, it is now relevant for small cities facing exponential growth. In a contemporary sense it is similar to Delirious New York's mantra "The culture of congestion is the culture of the 20th century" (Koolhaas, 1994, p. 125). The city as an archipelago in today's society is "...far from being a fantasy of superimposed upon reality, would actually only need to be revealed as the city's underlying reality, and pursued" (The City in The City: Berlin: A Green Archipelago, 2013, p. 43). It moves the city "...away from typecasting and standardization" (The City in The City: Berlin: A Green Archipelago, 2013, p. 43) by giving each place authority to contribute to the collective on their own terms. It gives autonomy to its' individual 'islands' while composing them in a united network with other 'islands', making the city a collective composition of diversity over normality. 


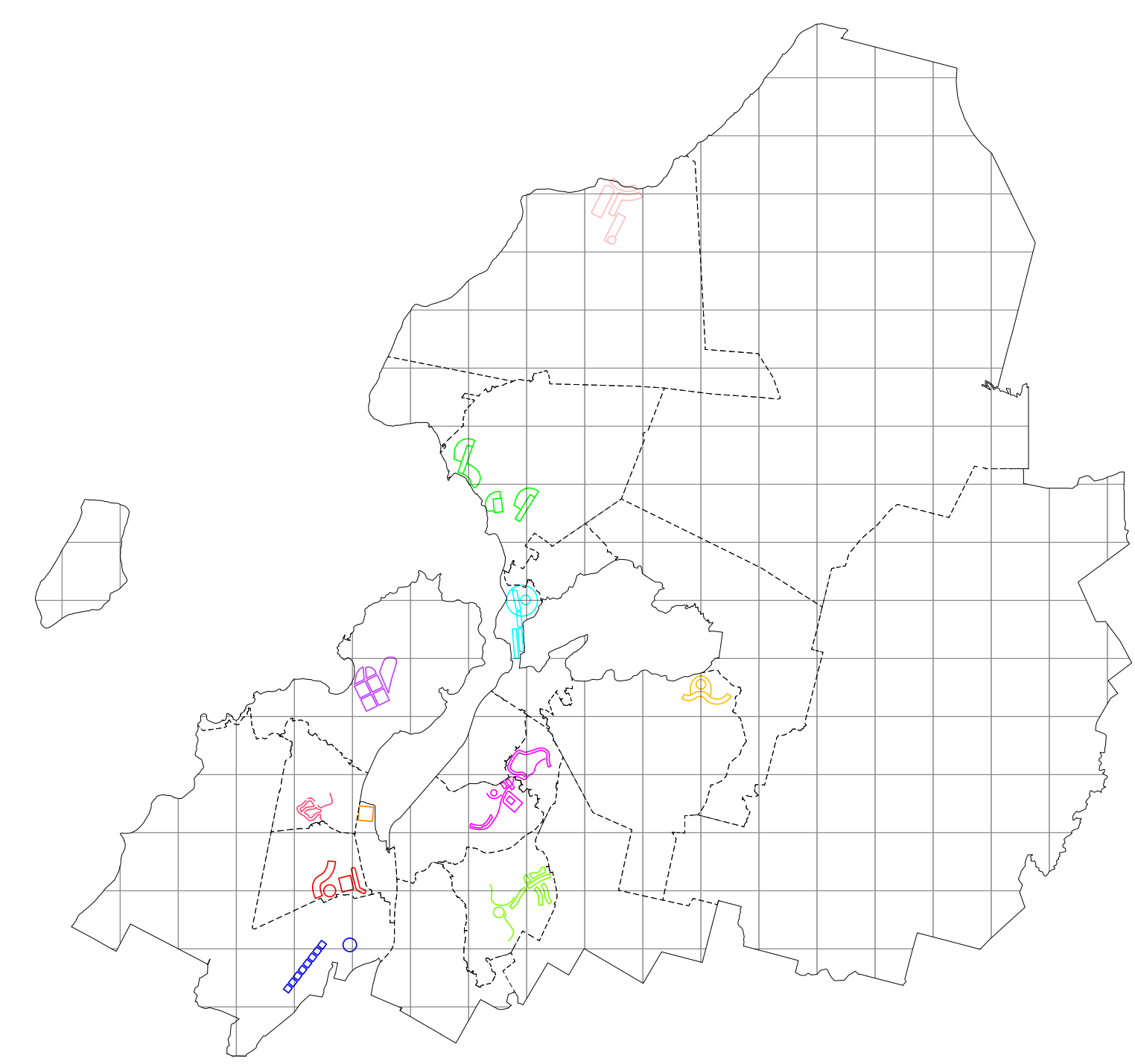

Figure 69. 'Archipelago Porirua', (2020), Digital Drawing.

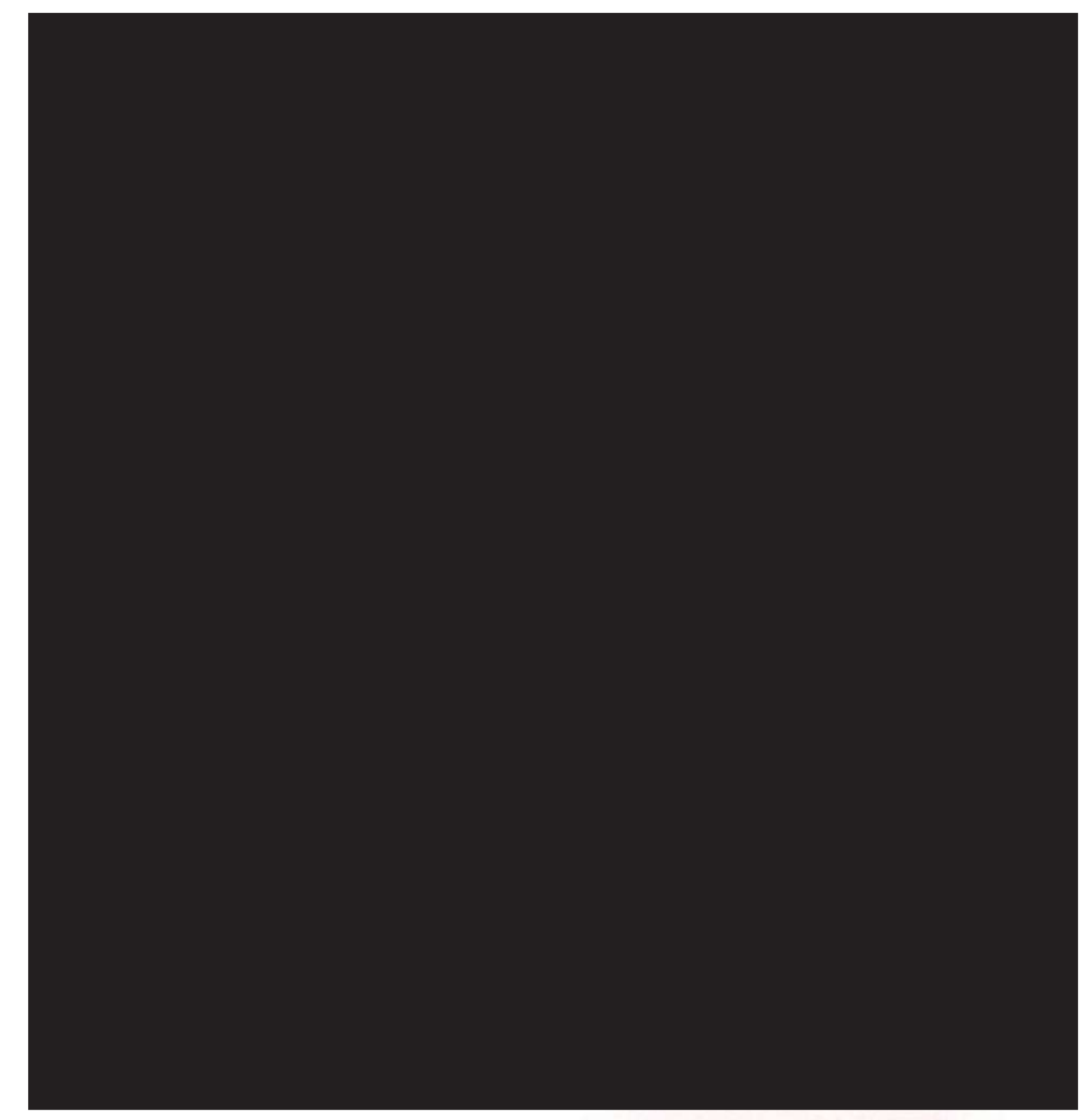

Figure 70. Oswald Ungers, 'Berlin Archipelago Proposal', (1977), Drawing. 
"With time, the city grows upon itself; it acquires a consciousness and memory. In the course of its construction, its original themes persist, but at the same time it modifies and renders these themes of its own development more specific."

(Rossi, 1982, p. 21) 


\section{anti-zoning*}

Why is the city always zoned? My perspective on the urban realm is legislation based and trying to break down the big rules. Why is there a desire to force a commercial sector, industrial area and accommodation zone? The zoning model can be seen as a model of segregation, promoting the separation and mingling of same types.

The opposite follows a diversity based model, a congested mix of types focussed on self-expression not conformity. This section is based on my understanding and memory of Porirua City's areas and does not focus on a set zoning plan, circulation or any societal order. I am less interested in urban design guidelines and more interested in the urban realm, the general urban scale of cities, and how the layers of the city have an impact on eachother.

A set of figure grounds show a dispersed model of Porirua city. This, contrasted with Porirua's original city model presents the implications of Porirua's cultural network. If this anti-zoning model is interpreted within a building design it would see a jumble of programme, mixed use (Sadler, 1999). Instead of having all offices on one floor and all studios on another, they can be jumbled and dispersed. This encourages chances of interaction with a variety of different people.

Following Aldo Rossi's three primary elements of the city; "...the urban whole tends to be divided according to three principal functions: housing, fixed activities, and circulation" (Rossi, 1982, p. 86) a series of diagrams are created. The "'Fixed activities' include stores, public and

commercial buildings, universities, hospitals and schools..." (Rossi, 1982, p.86) they have been divided into a further three sub-sections shifting focus away from circulation towards housing and fixed activities. This allows a thorough understanding of cities current ordered structure contrasted with an archipelago-esque dispersal.

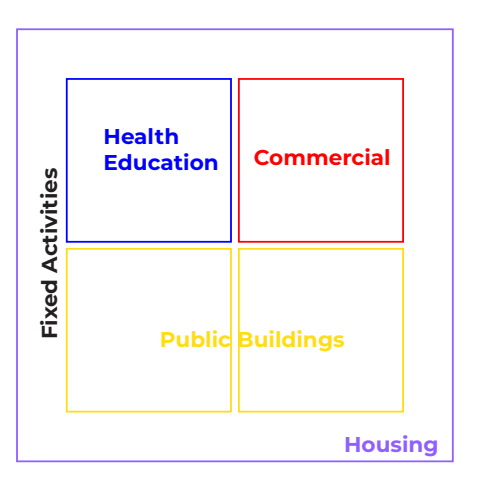

Ordered Circulation

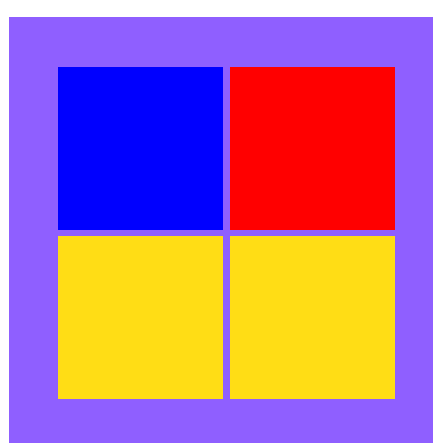

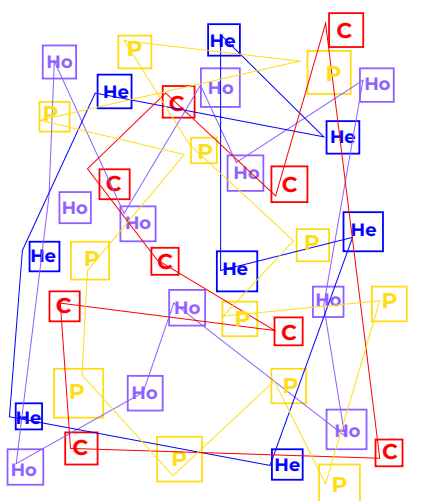

Dispersed Circulation

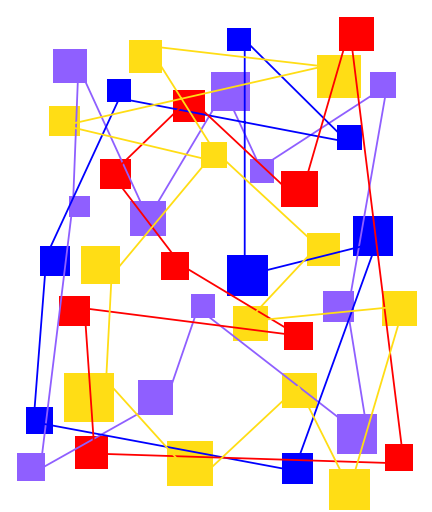




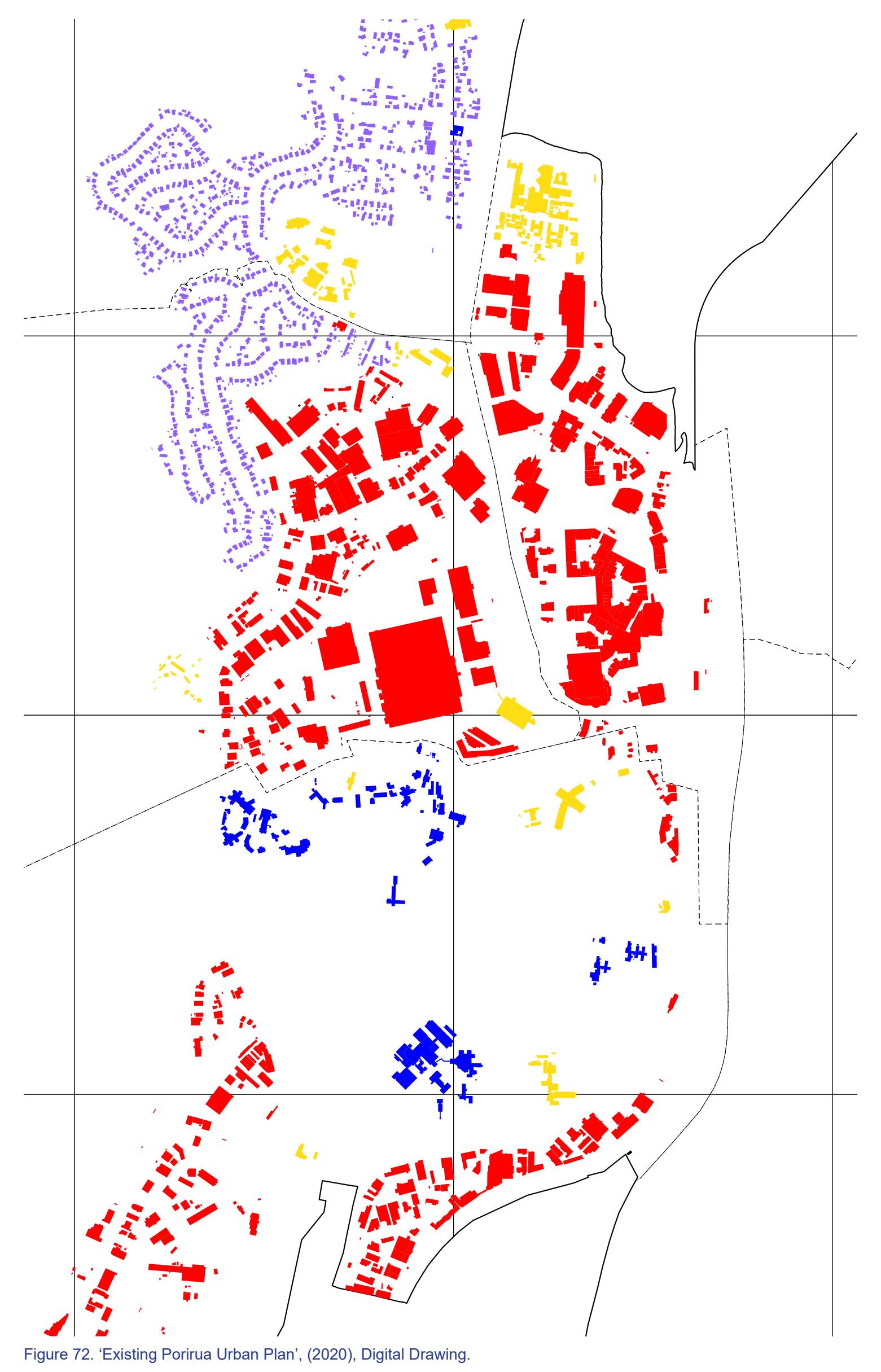

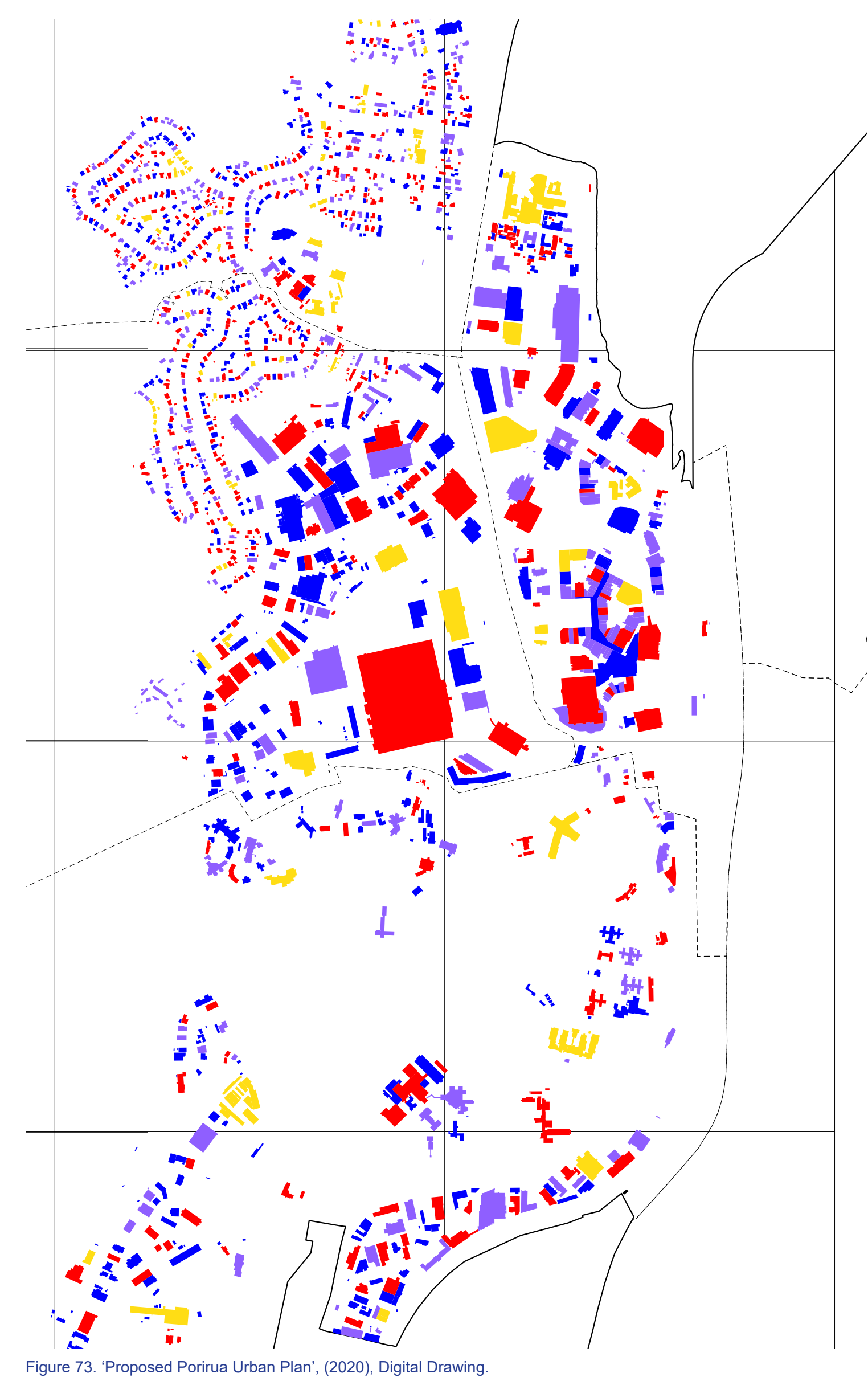




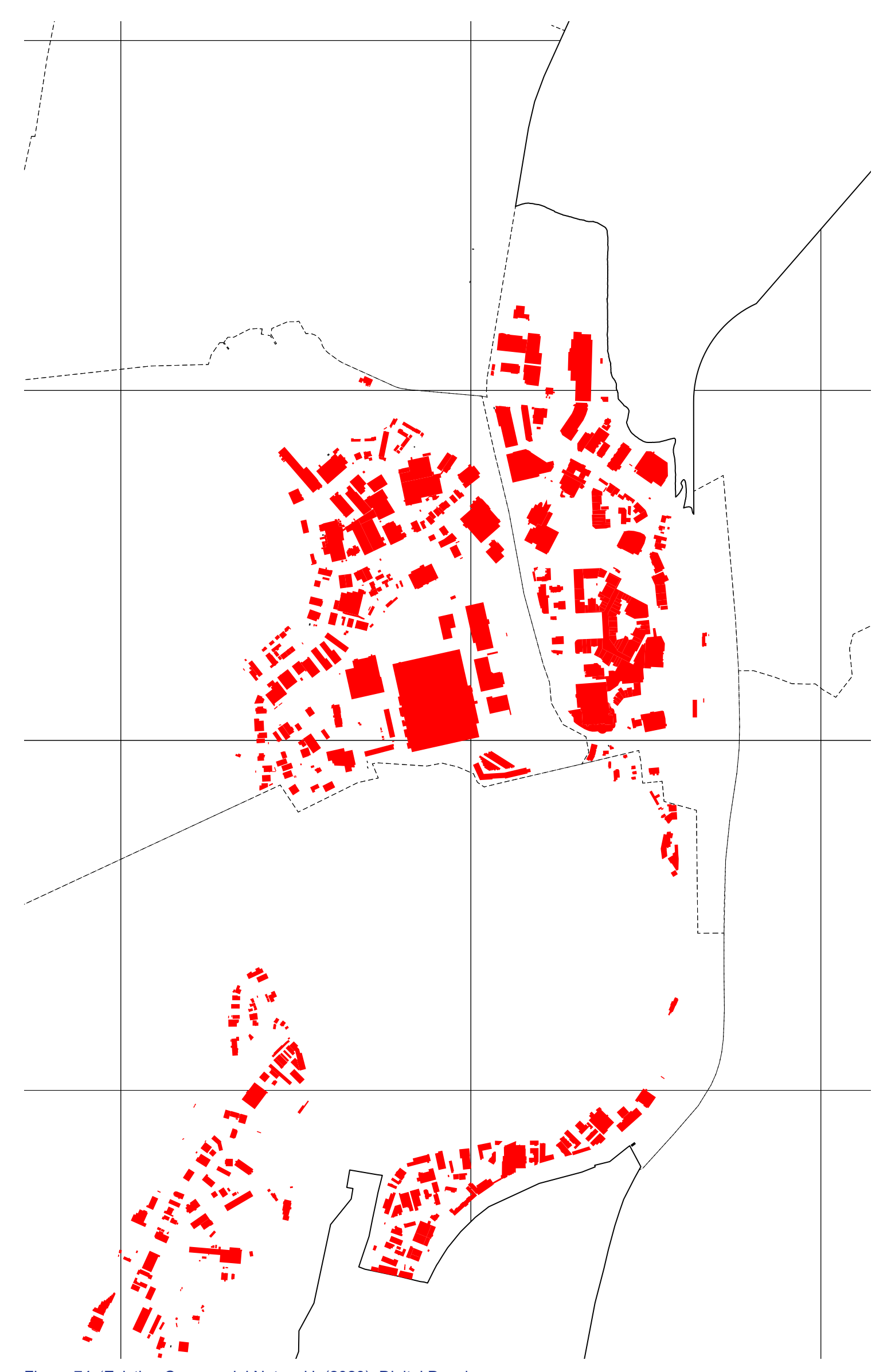

Figure 74. 'Existing Commercial Network', (2020), Digital Drawing

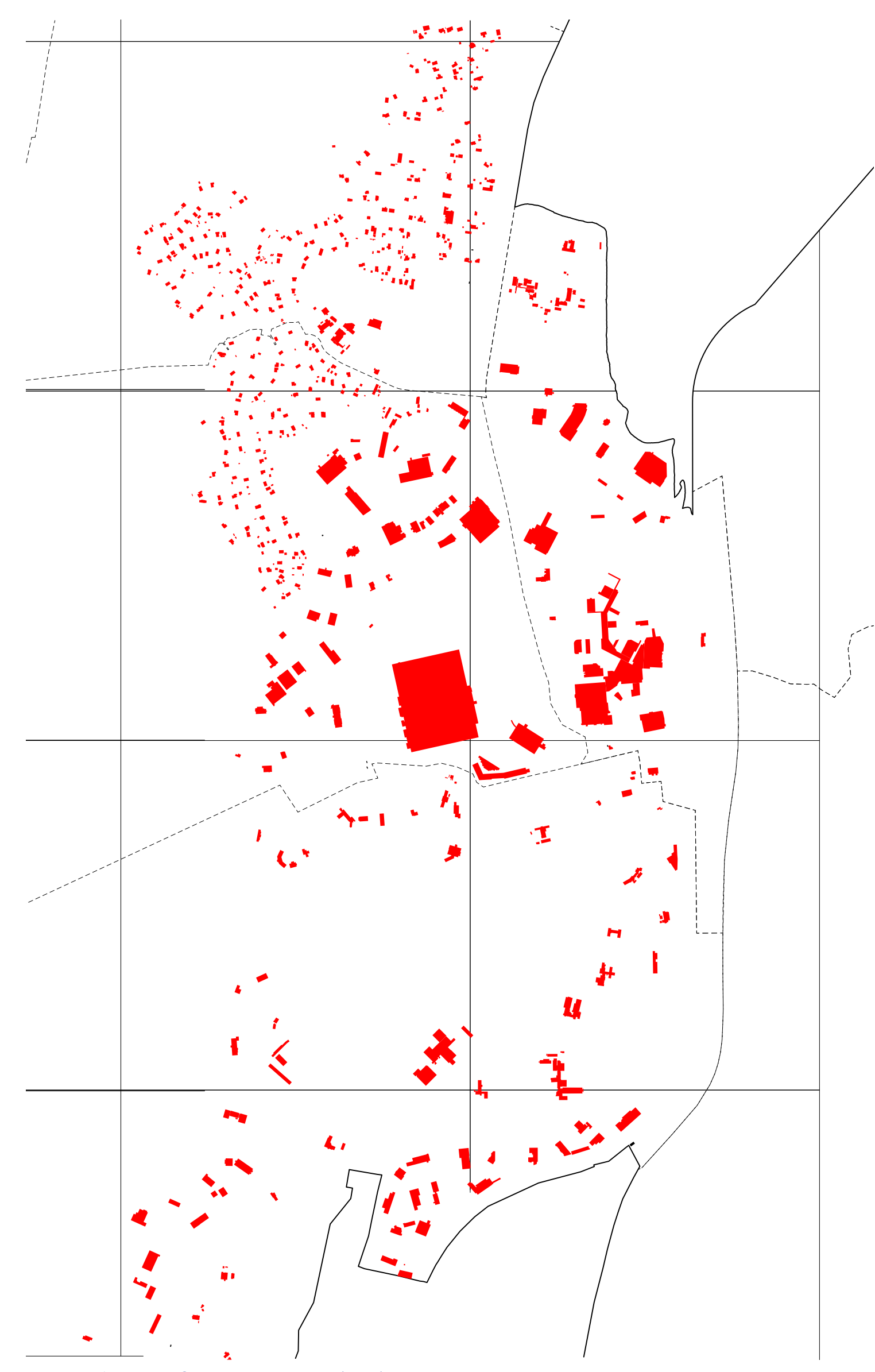

Figure 75. 'Proposed Commercial Network', (2020), Digital Drawing. 


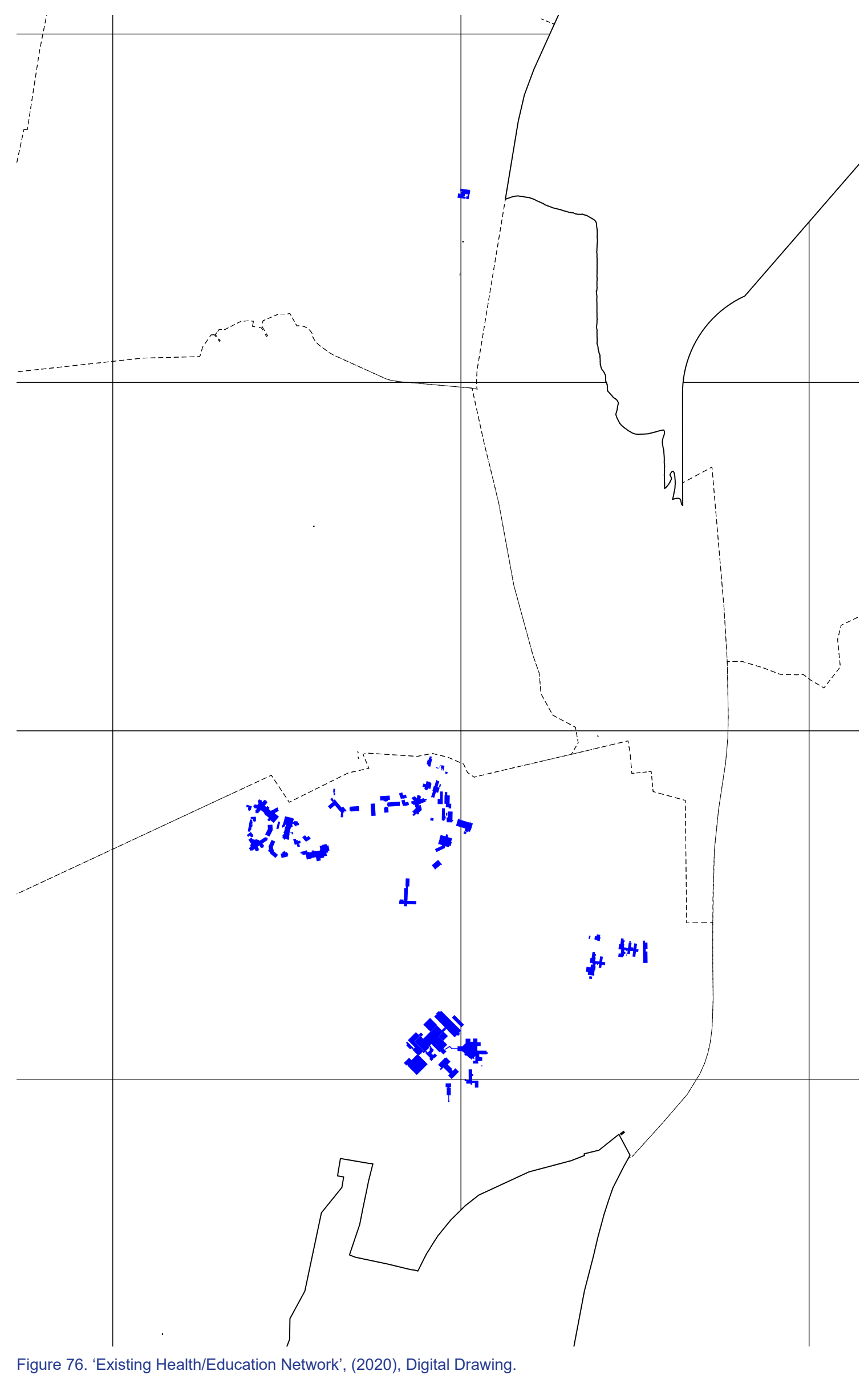

134 Playful Assembly

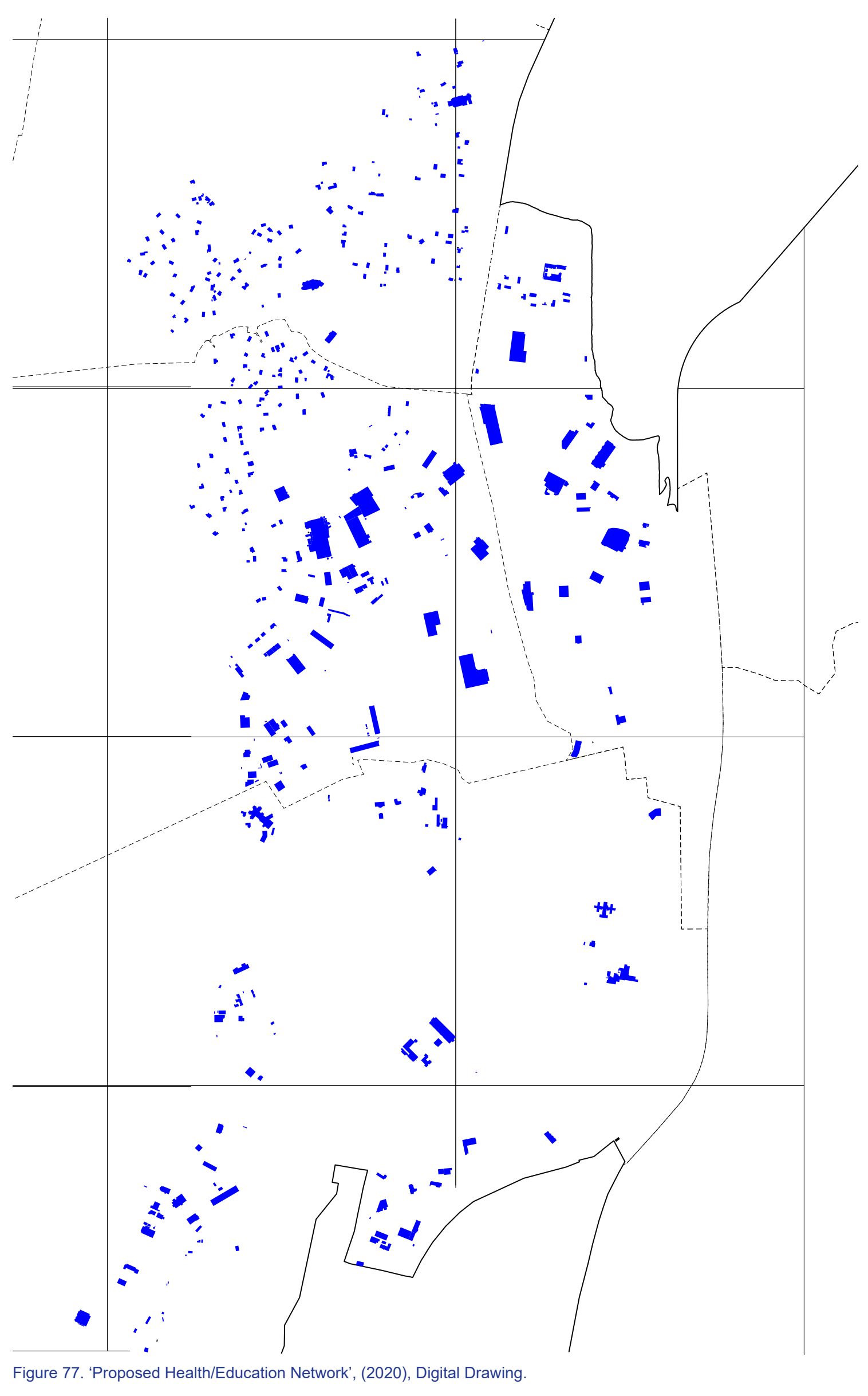

Playful Assembly 135 


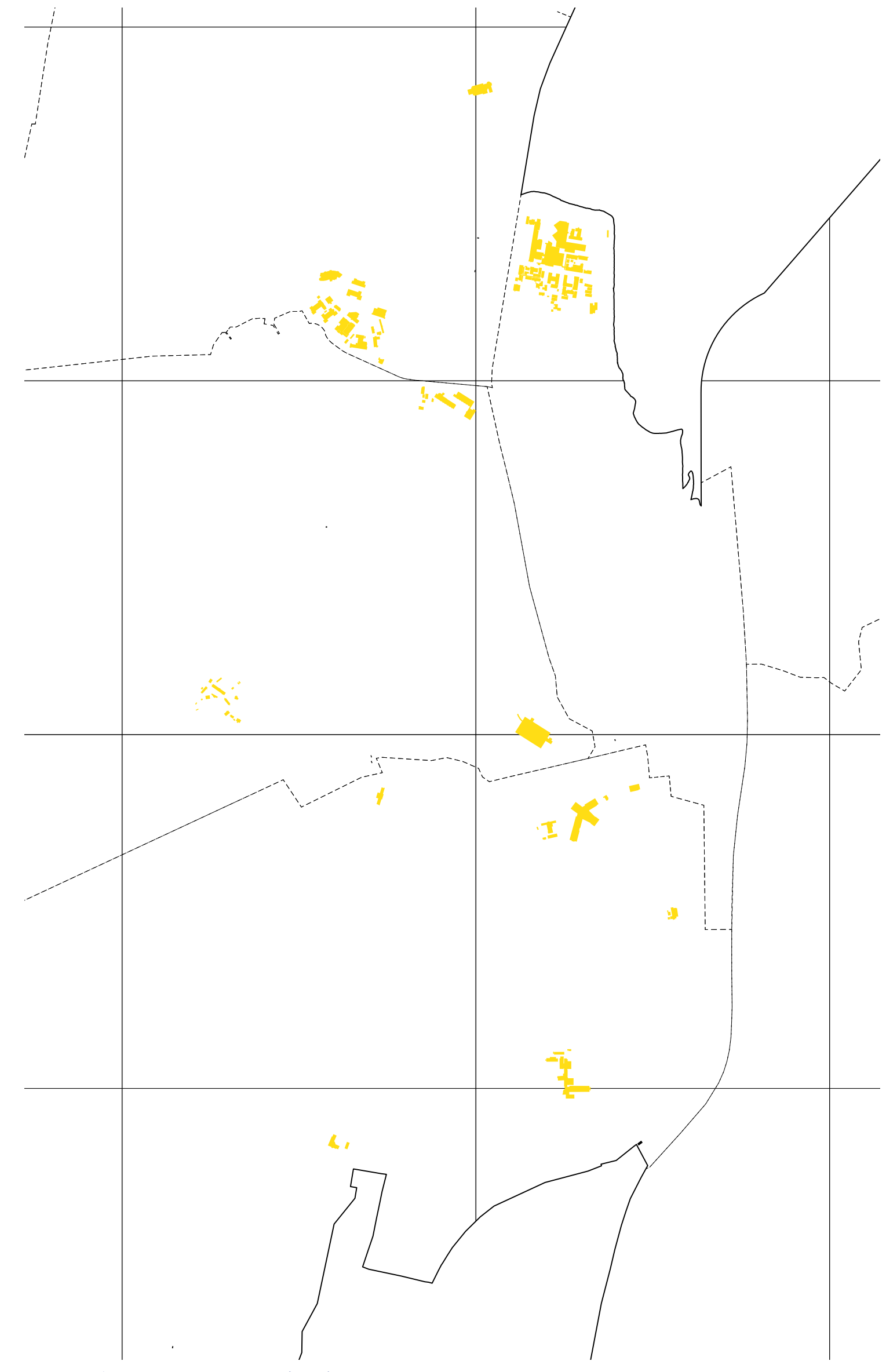

Figure 78. 'Existing Public Network', (2020), Digital Drawing.

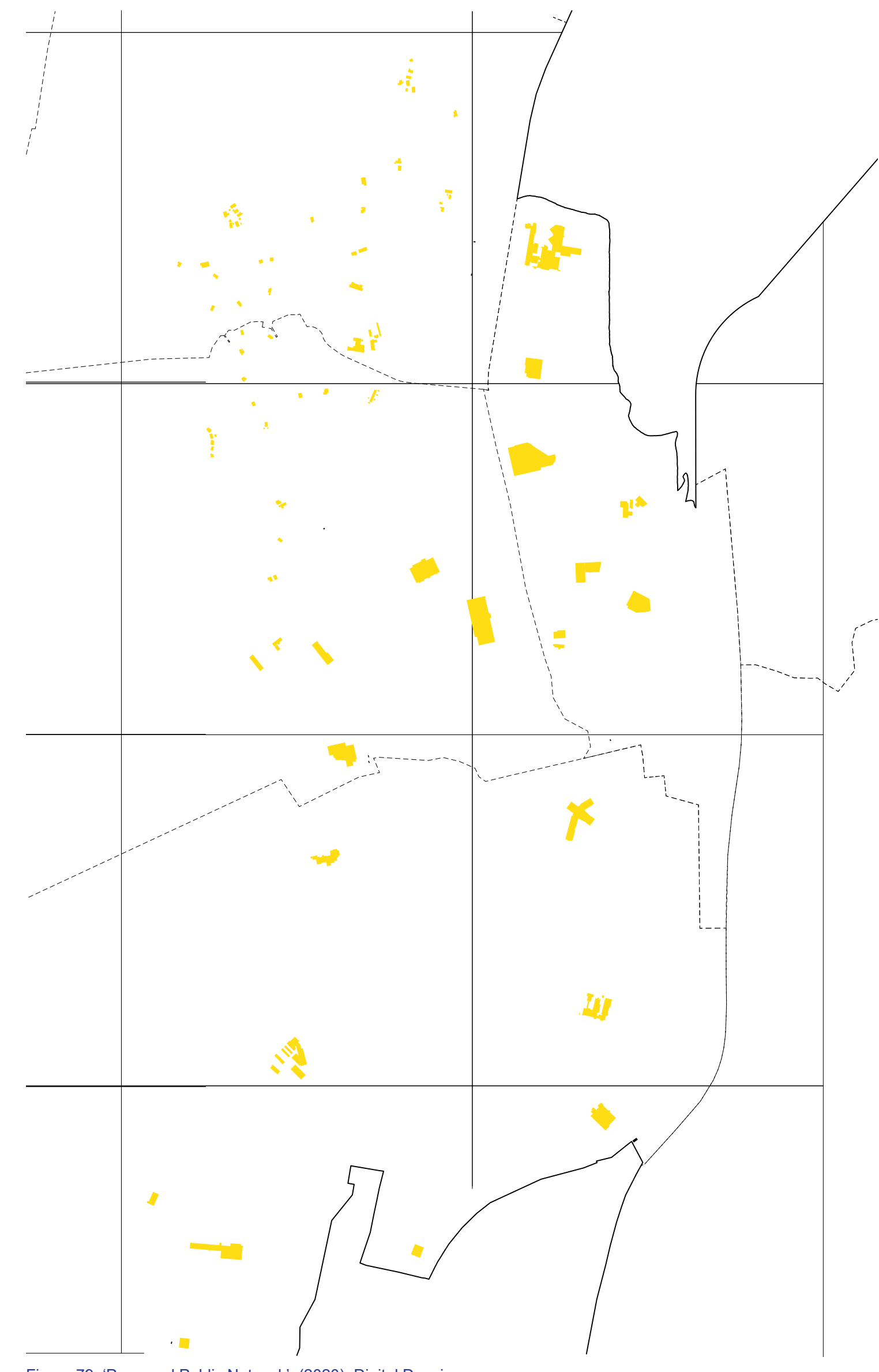

Figure 79. 'Proposed Public Network', (2020), Digital Drawing. 


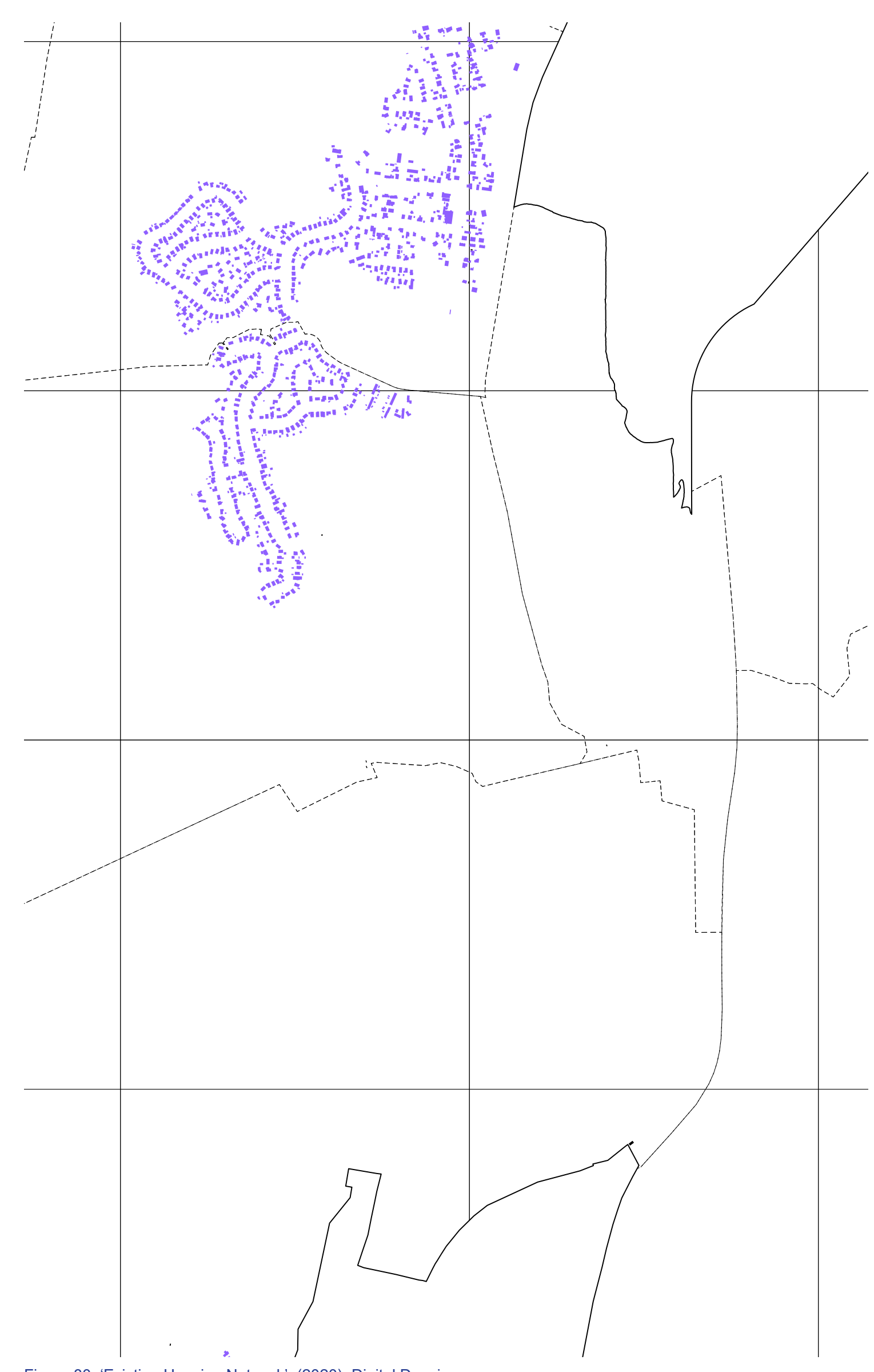

Figure 80. 'Existing Housing Network', (2020), Digital Drawing.

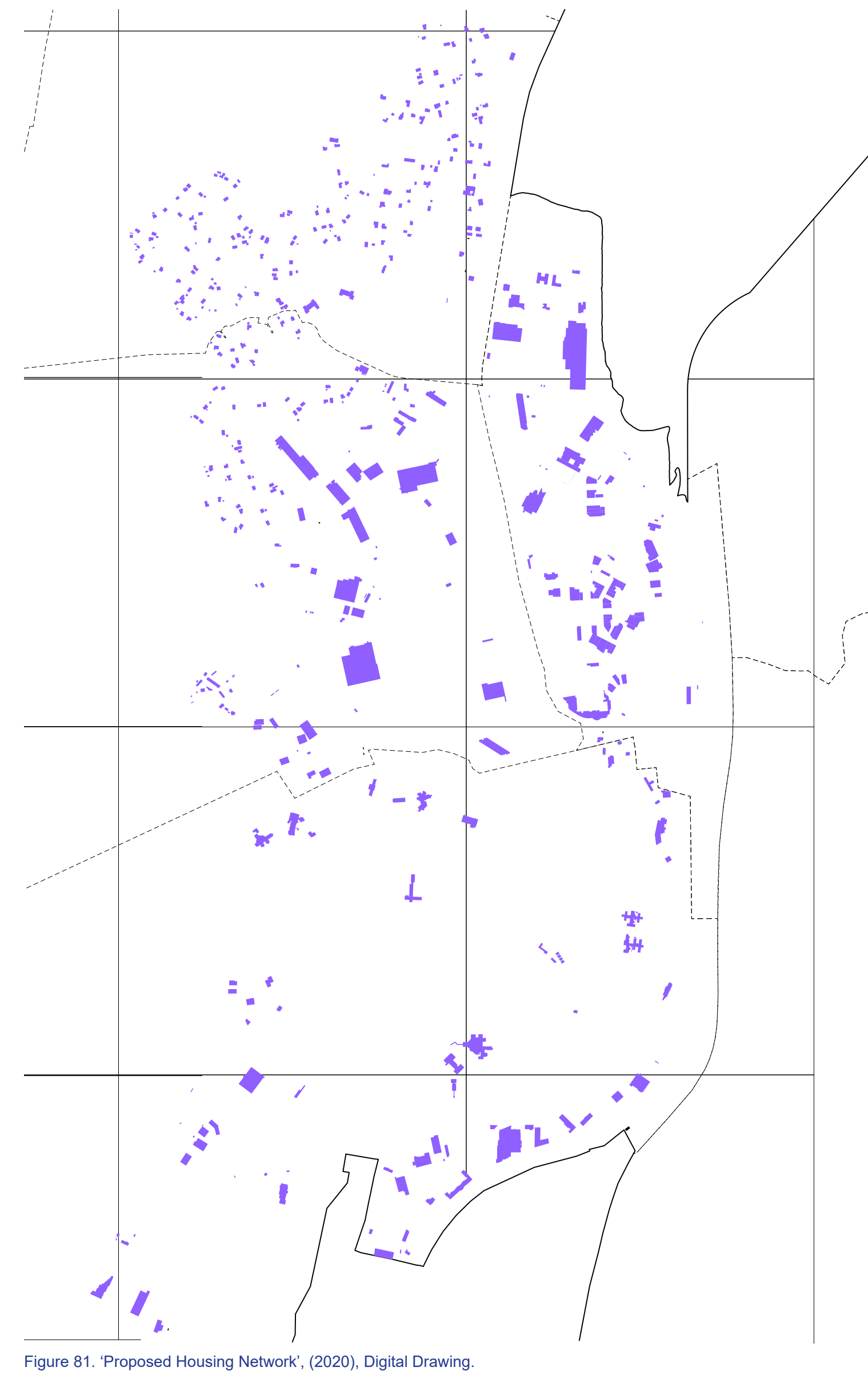

Figure 81. 'Proposed Housing Network', (2020), Digital Drawing. 


\section{positive congestion*}

Cities are developed over time and often include a hap-hazard conglomeration of countless building types, activities, transport, infrastructure, art, culture, leisure, entertainment, go karts, boxing and eating prawns (Koolhaas, 1994). This jamming together into, onto around, in out and upside down smash of elements is exhilarating. I will never forget the pure mess of Mexico City and all its people. It was magical and I thought I was going to hate it. The ridiculous hot corn on the cob lined the streets of Roma. The culture was everywhere and despite the cramped sweaty mistake of taking the metro in rush hour, the public transport was easy. The city did not stop. The public bus in Frida Kahlo's town kept moving, you learnt to run and jump.

Mexico city is the largest city I have experienced and was a pleasure to visit. The growing population in New Zealand gives me hope we will one day have cities as exciting as this. It is scary seeing so much development but I see it as an opportunity for the development of a playful assembly of current dull low-density cities. New Zealand has the opportunity to grow positive congestion when densifying its rising ci

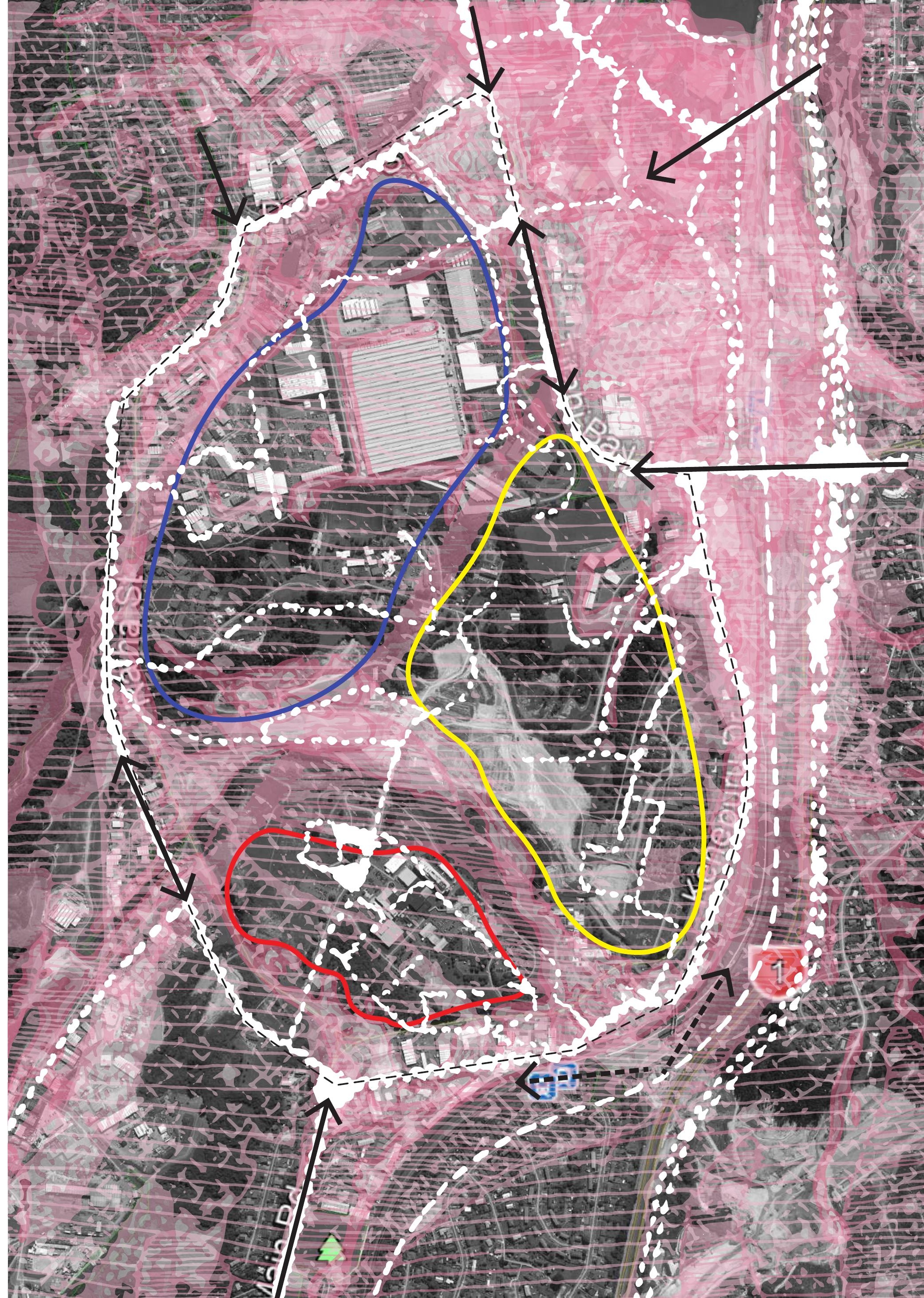


“...reality is itself pregnant with fictions that architecture, alternating between the roles of analyst and midwife, can bring into the world." (Ungers 33) 


\section{making stuff in the city}


Figure 84. Constant Nieuwenhuys, (1959), New Babylon, Mixed Media..

This chunky chapter develops an architectural language for the network of sites for creative production. It includes descriptions of physical models, their translation into buildings and an introduction to the 'Creative Factory'. It taps into developing in plan and section, and reveals the importance of using a variety of mediums. The architectural process discovers the brilliance of tiles and challenges 'static' architecture in the city. 


\section{architecture}

\section{in the city*}

City and architecture come hand-in-hand. For example, the architecture of San Francisco is much different to the architecture of Los Angeles and so are the cities. Each city should express its own unique architecture or collection of architectures.

Porirua city needs some life, it needs more than just an awesome go karting place. Its architecture is mainly industrial, concrete. Architecture as a playful assembly follows the same logic as the city, just at a smaller scale. It aims to develop an architectural language which expresses creative production. It gets inspiration from the 'stuff' previously created. With this transition architectural issues such as circulation, layout, program, structure and so on are battled with the playful assembly mind set. It assembles all aspects of the building with an elemental eye. Each element is autonomous and composed to contribute to the whole.

Physical model making allowed me to continue playfully assembling stuff while applying it directly to an architectural language. This led to many physical models, with the first translating the previous sketch drawings into 3D and then into a building. Physical models continued to be a technique I used to get unstuck and develop form. Drawings and diagramming were continued alongside the design process and were often inspiration for physical models. Modeling is an effective way to develop form, test materials and understand scale. The models could very quickly turn into buildings and vice versa making them a quick way to resolve design issues. 

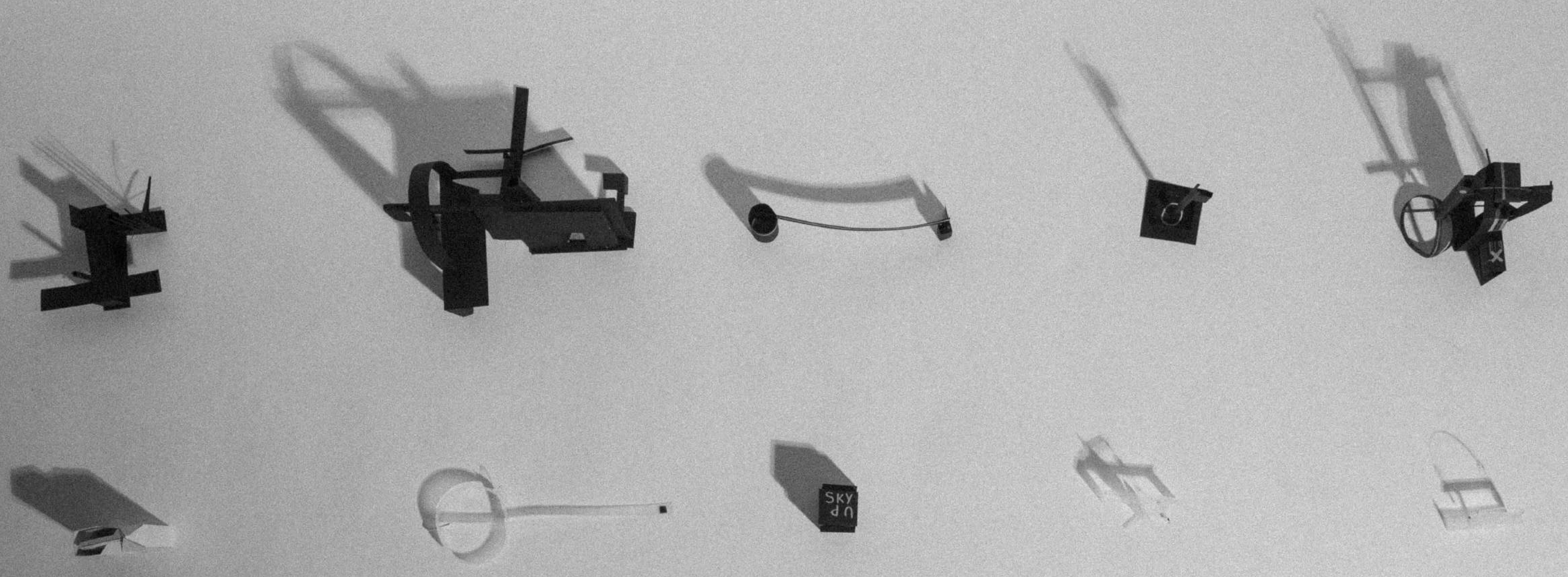

11

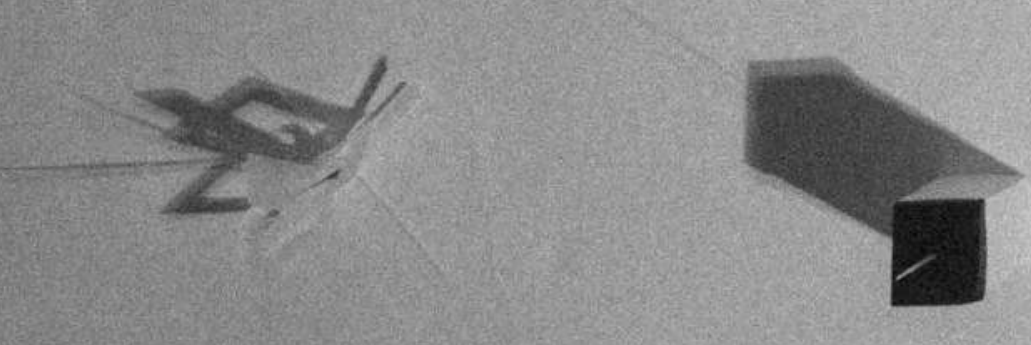

Figure 86. 1:100 Sketch Models', (2020), Digital Photograph.
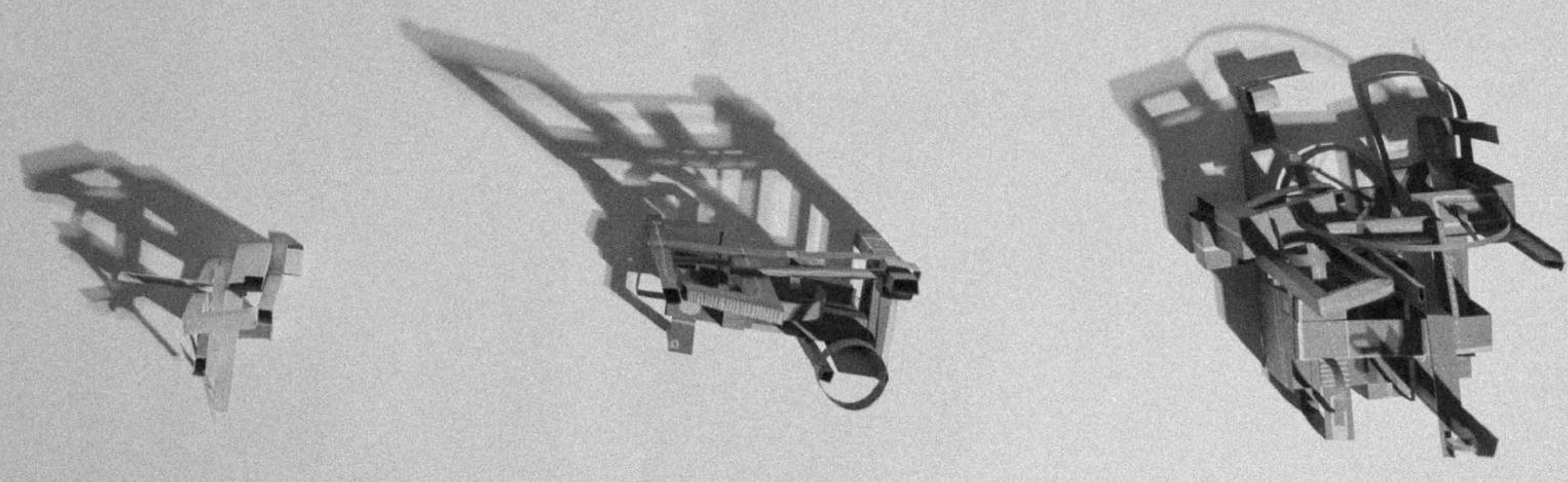


\section{paper models*}

The models deal directly with architectural elements of space, structure and circulation while tapping into the same elemental process themes discovered through drawing. This is the first step into architectural design, a move I was very hesitant to do. The outcome has clearly tied the drawings to the architectural realm which is a step I have previously struggled with. The question now is how literal these models are perceived? How much complexity can be translated and what will be sacrificed in the translation into a building.

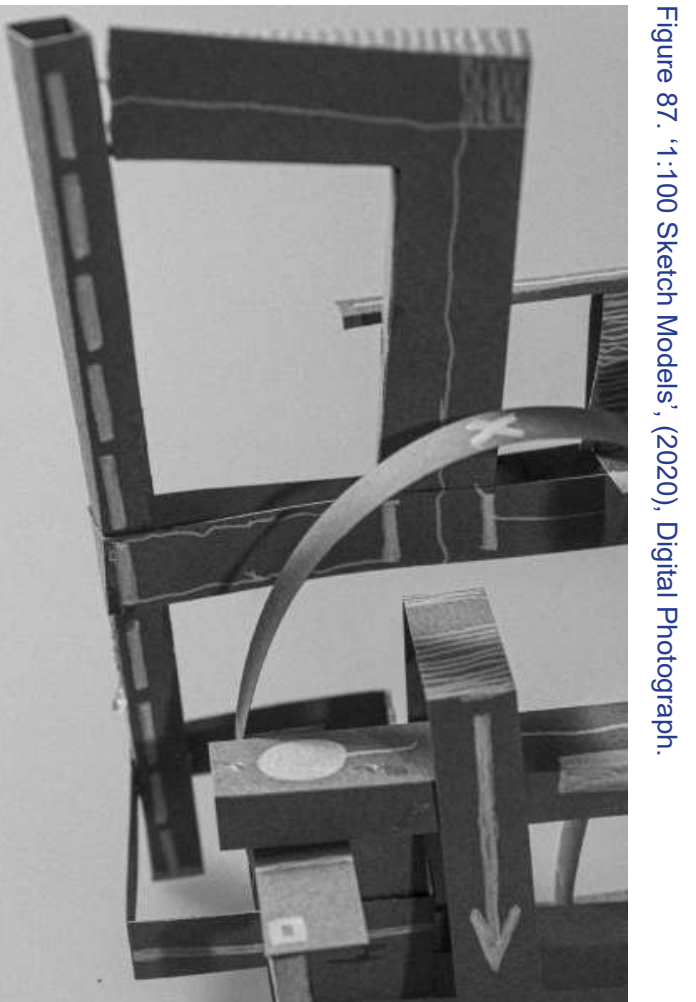

Figure 88. '1:100 Sketch Models', (2020), Digital Photograph. 


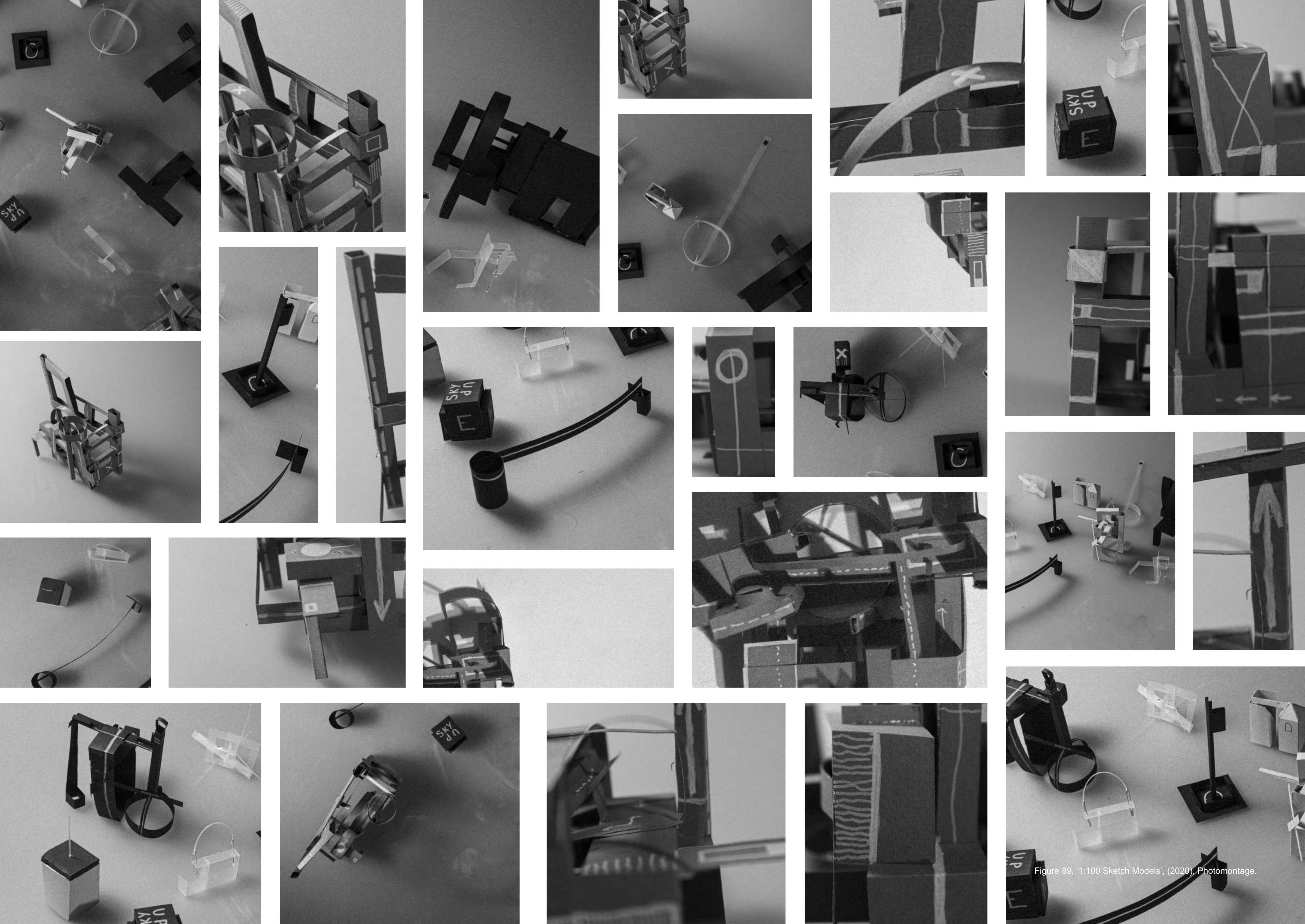




\section{paper model process*}

With the aim to translate two dimensional pen drawings into three dimensions these models faced the first architectural challenges. Paper models with white pen markings discovered the excitement and efficiency of physical modelling. The markings aim to create a three dimensional drawing giving the formal nature of the models inspiration from drawing and vice versa.

The paper modelling material has led the design to a tectonic outcome exploring structure and circulation. Working in 2D planes rather than 3D volumes, the models developed a skeletal, constructivist language. This planar system allowed for more movability as the model was constructed, allowing opportunities to play. The markings draw out opposing elements to further enrich the three dimensional composition. The models struggle when developed as volumes, leaving the more playful models developed in two-dimensional plains.

This process has given a direct translation from drawing to spatial arrangement. It surfaced the tendency to work with structure and circulation first which creates an exposed architecture. This is the biggest issue faced when developing a structure first without an envelope; for some reason I keep wanting it to rain inside.
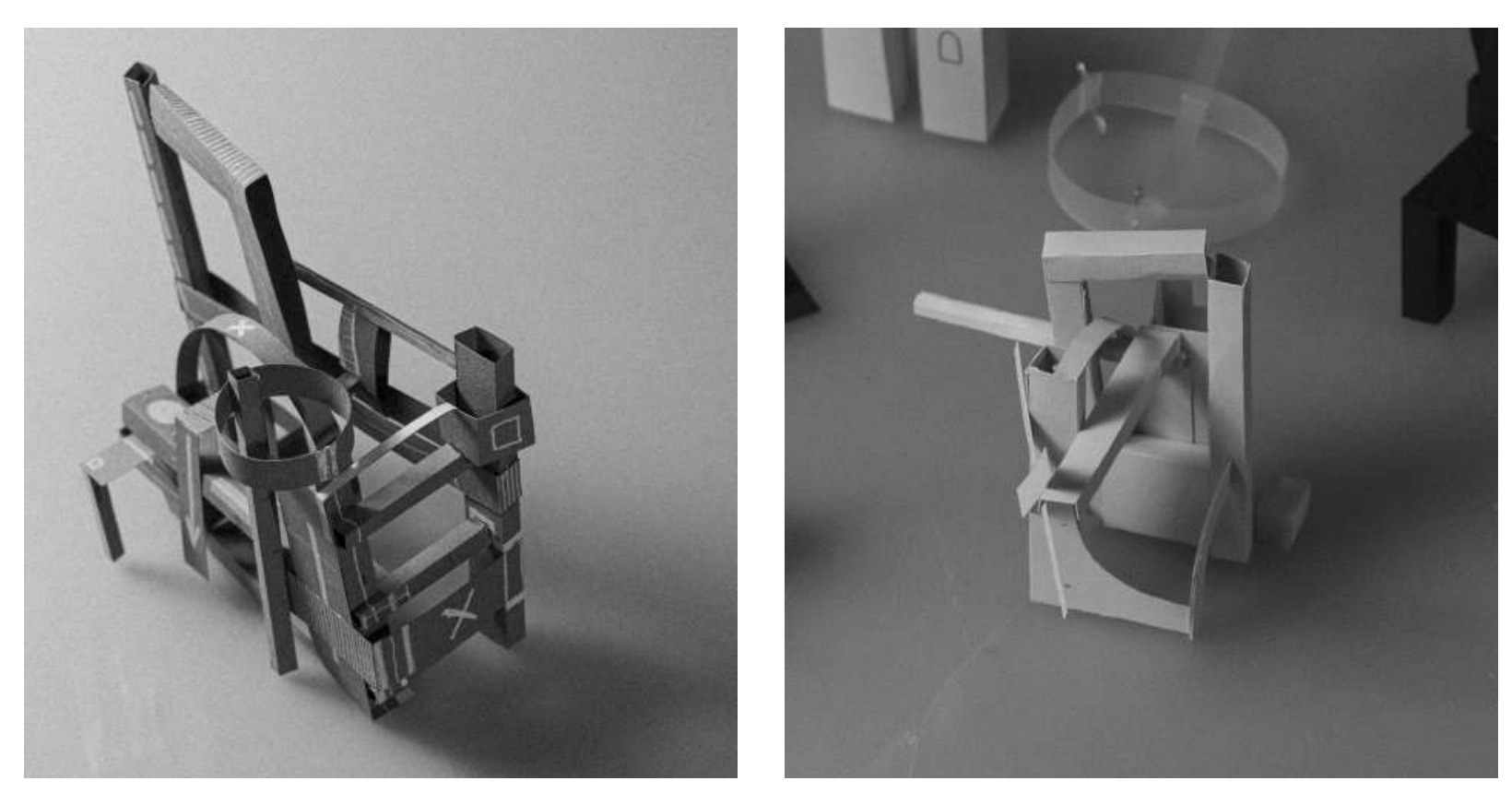

Figure 90. '1:100 Sketch Model', (2020), Digital Photograph. 


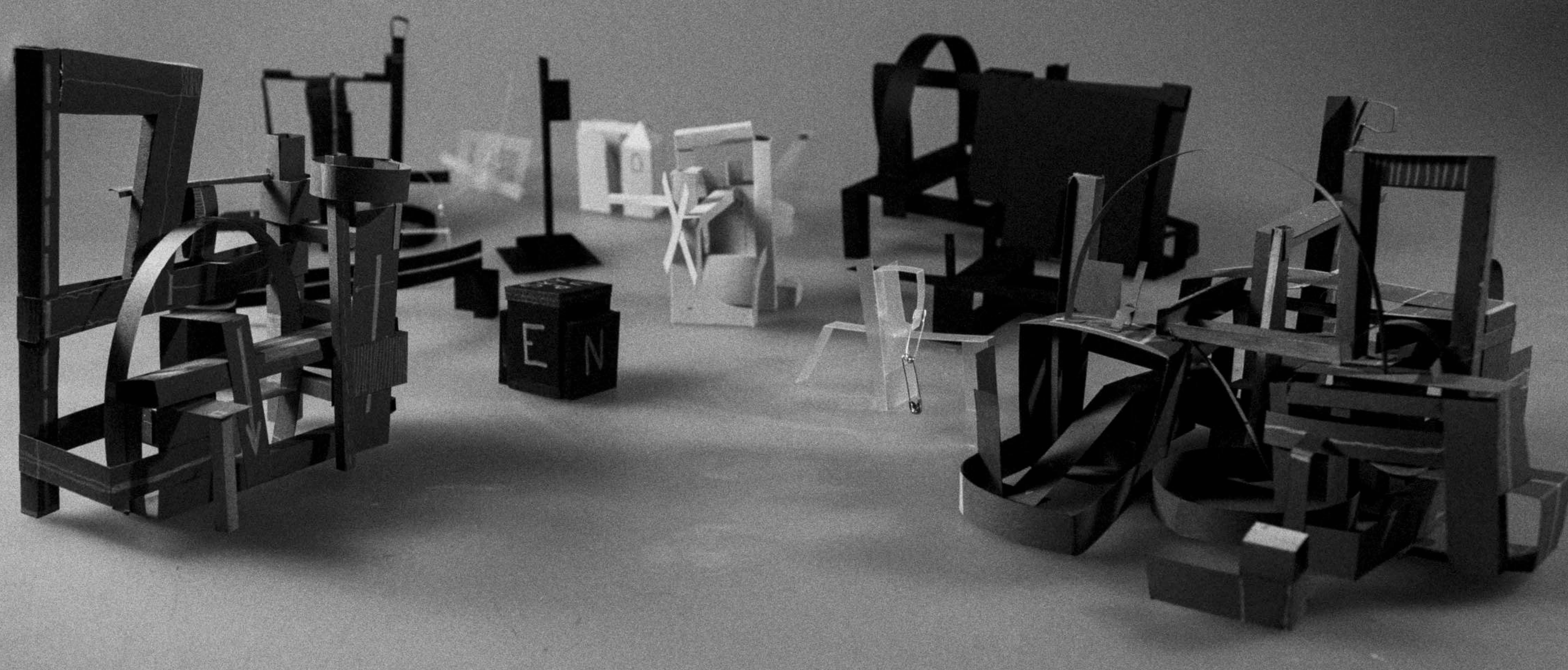




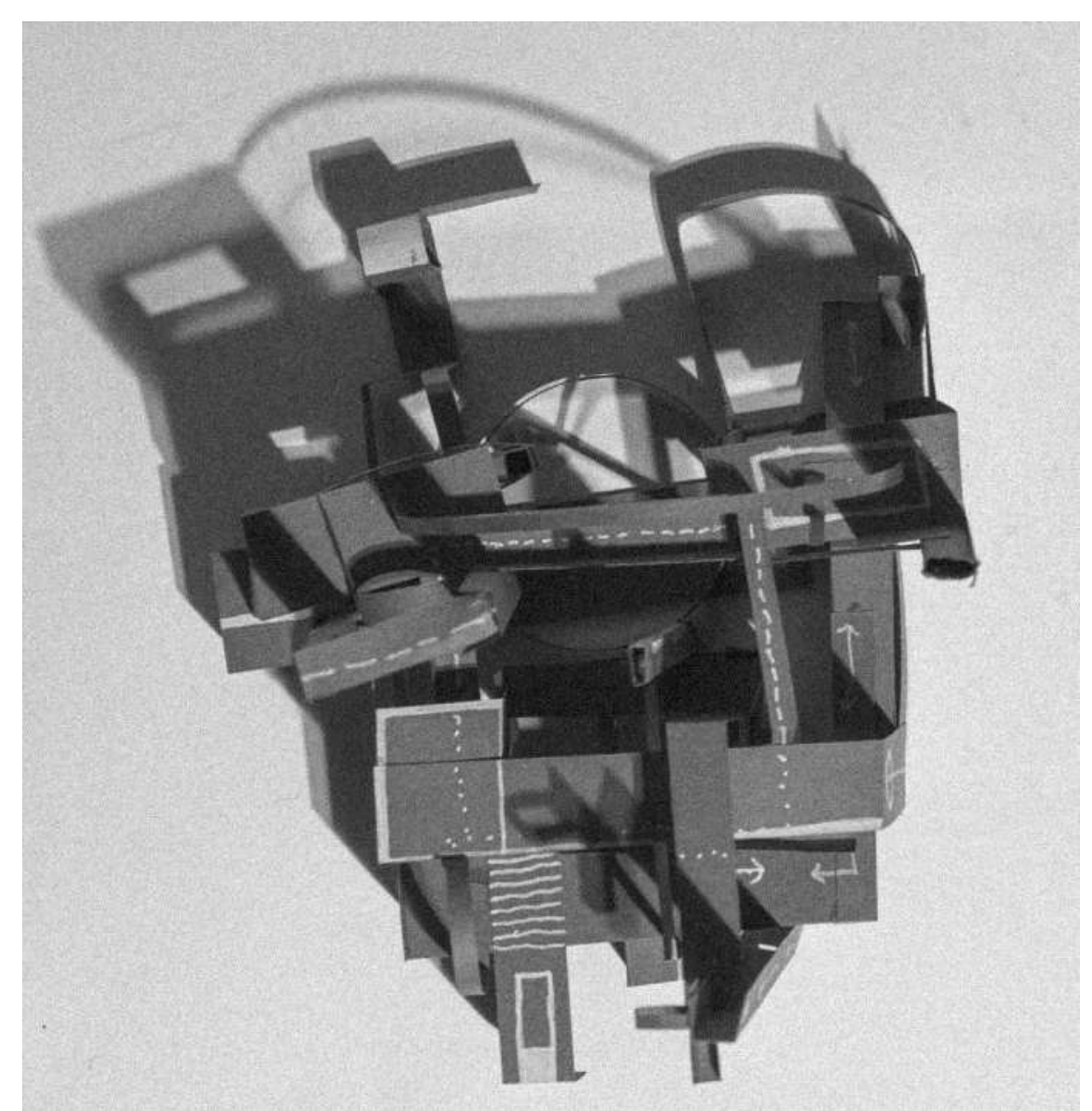

Figure 93. '1:100 Sketch Model', (2020), Digital Photograph. 
Grele SQUIRH

STEUCWRE OF GRCULATTON

CIRCWLAKON OF STRUCTURE

complex slar

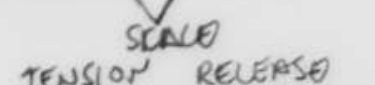

Tensior RELERESO

Verticke HORTONTLC

COURTMARD COND.

RONDOOR COURTYART

WAITING HUSTLING

MOVEMENT

MOUEMENT

SPACE

Grecrating

Thewen

LAGRES ASTA

$\checkmark$ OA SPRACES

Circulation

NAT BOTH

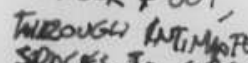

CRONTENG WTIMAK

PUQULC SPACES

ROM OEN COOSC

NARE ROOMS TO

CRAMMES COARIDPRS

cutrueg WiTH

MixES \& ANO

Bups Hed in avo

Rorst out. PEople

colloge, wiveresity,

Anruces, seenrs,

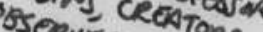


$1+i$
$8=-1$

Figure 98. Plan Sketch, '5 Heriot Drive', (2020), Drawing.

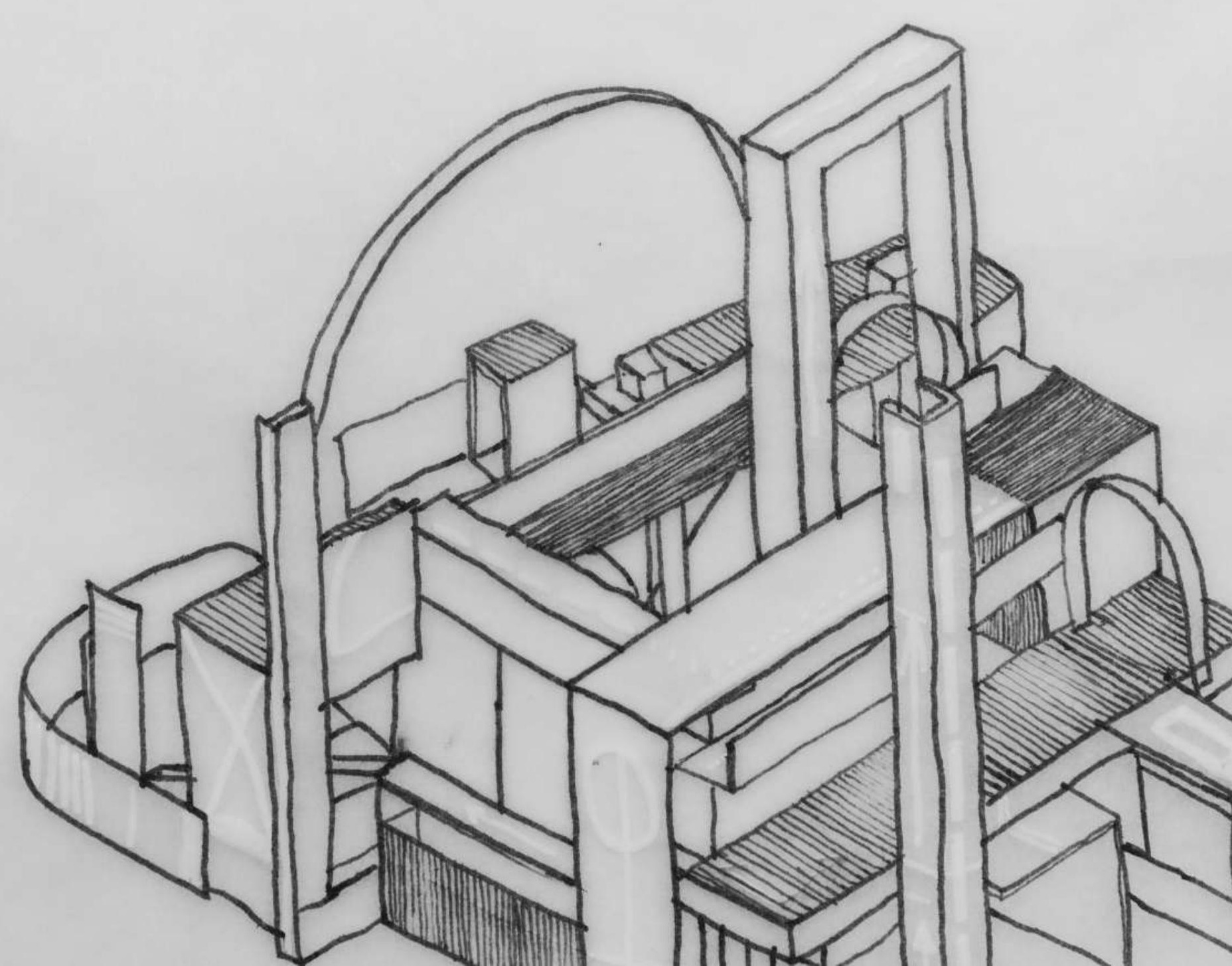




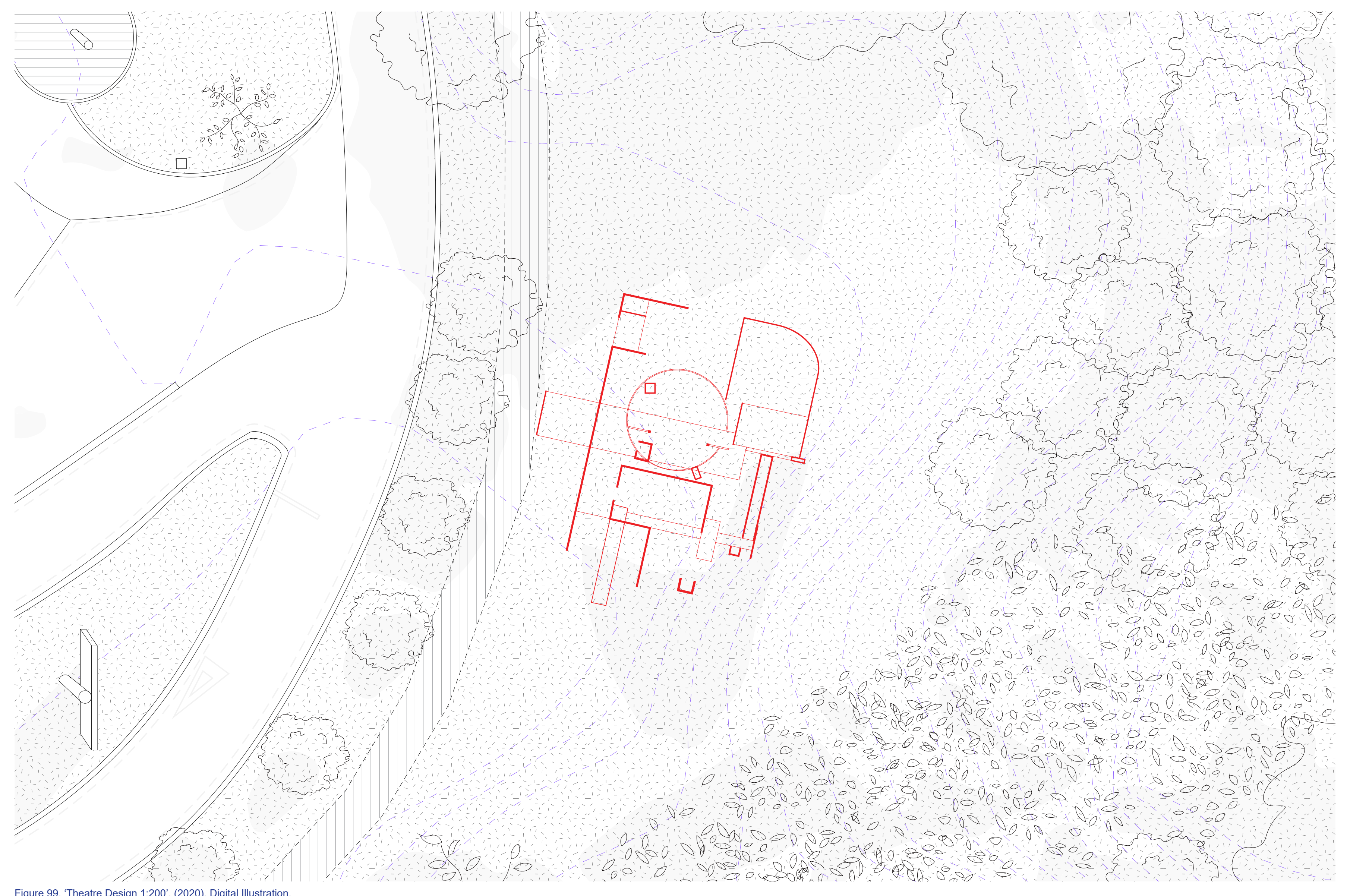

Figure 99. 'Theatre Design 1:200', (2020), Digital Illustration. 


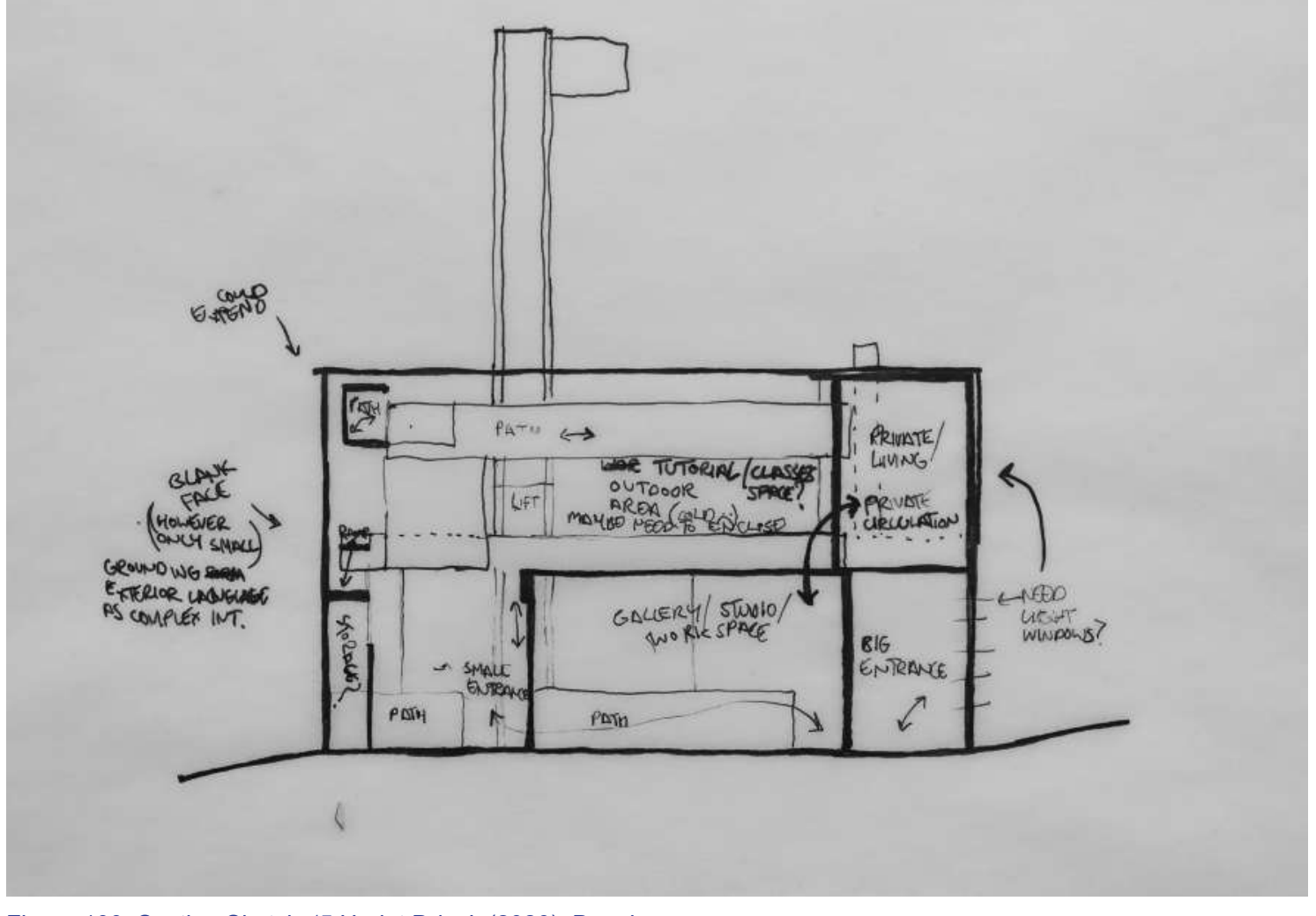

Figure 100. Section Sketch, '5 Heriot Drive', (2020), Drawing.

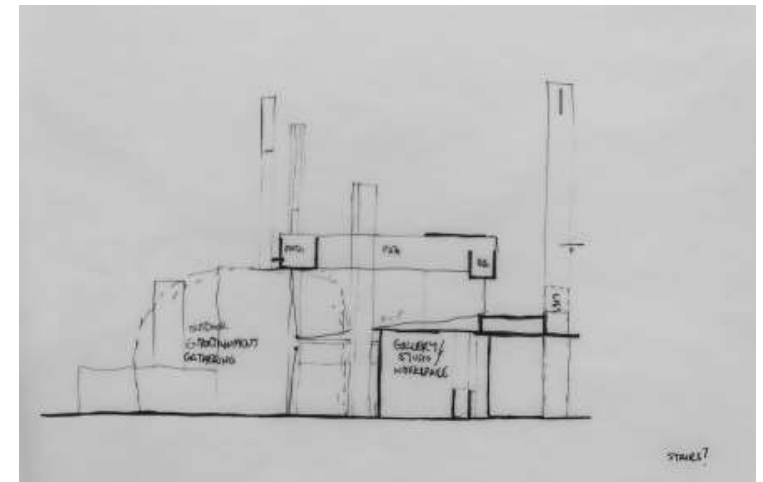




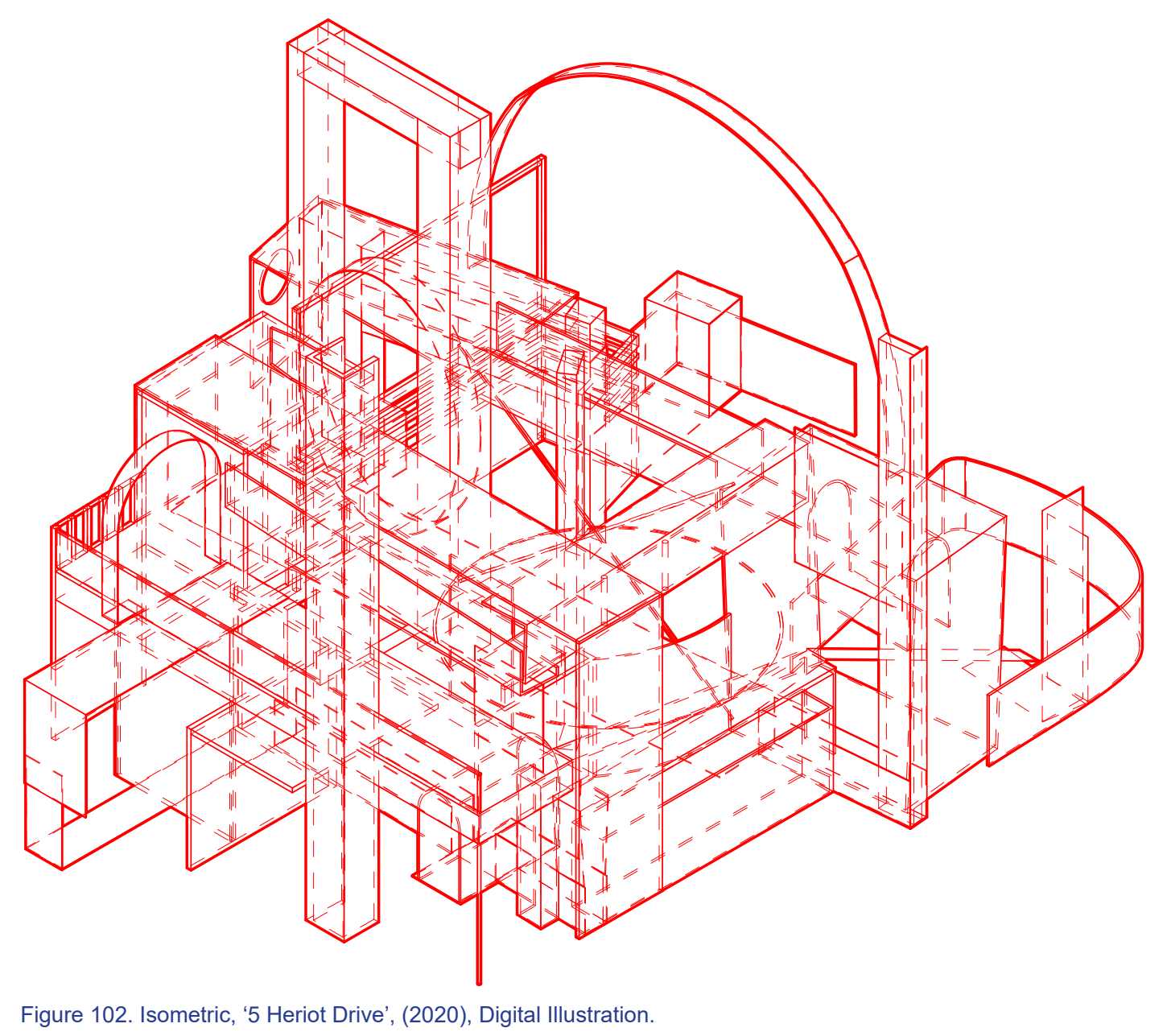




\section{2b Raiha}

\section{Street*}

This design develops the constructivism reference and purpose of the creative factory.

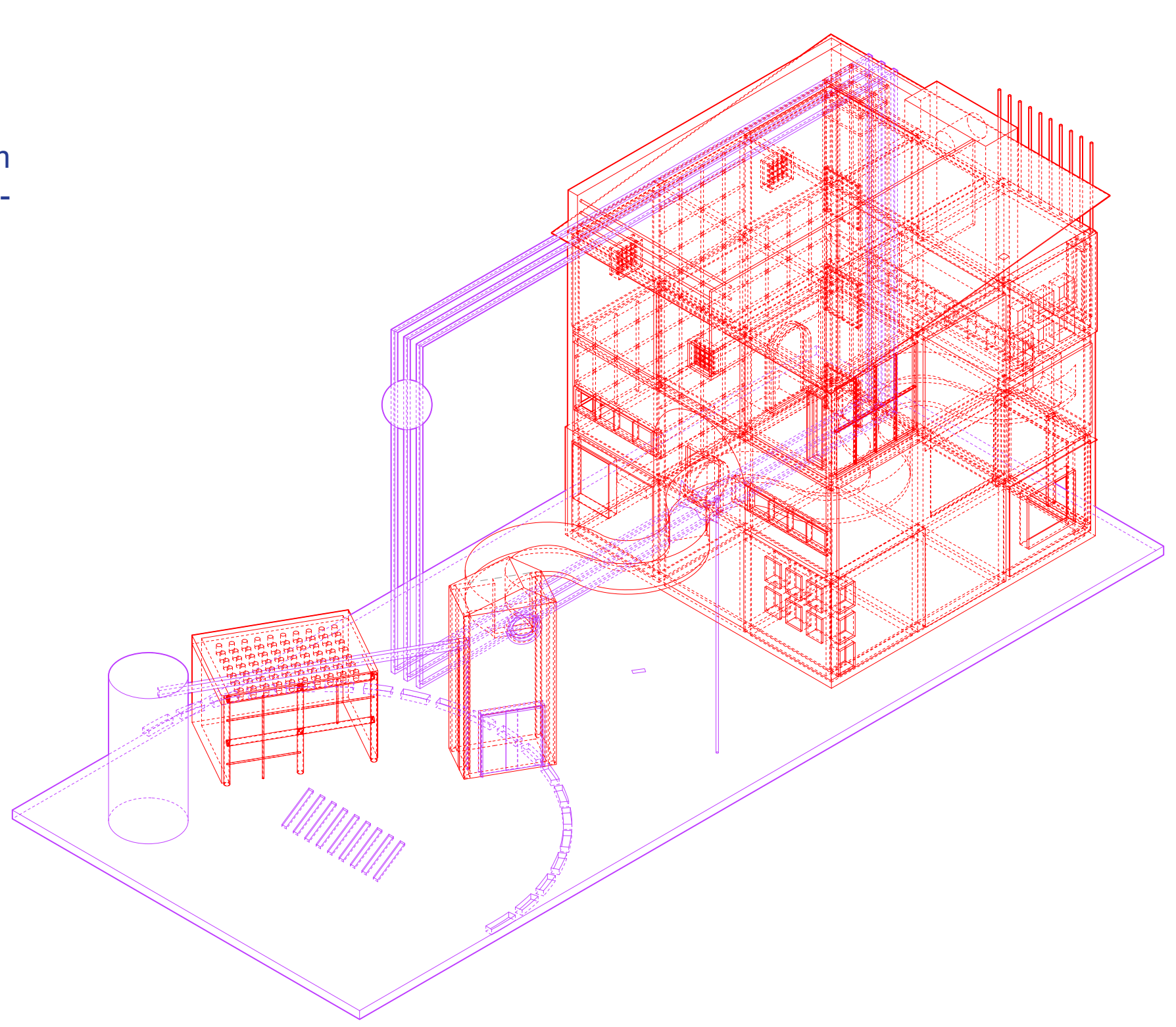

Figure 104. Isometric, '2b Raiha St', (2020), Digital Drawing. 


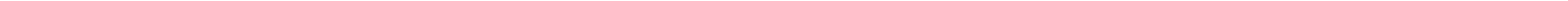




\section{creative \\ production*}

A factory for creative production instead of debt provoking consumption. The creative factory is an alternative view of the industrial factory as a building for local craft creation not mass consumption. A factory for autonomous individuals with their own area for self-expression. A space of ultimate creative freedom.

I often find inspiration in the old, the junk, the garage, the tip shop, so it is only logical to locate this factory in the industrial area of Porirua, surrounded by scrap yards of many kinds for the imagination to thrive.

This challenges the industrial to be much more than concrete by providing an alternative view of industrial production. The factory is to value more than mass production. To instead value sustainability, self-expression and creativity. A place for the community to interact, create and contribute. It will consist of studios, galleries, cafes, a variety of workshops, meeting rooms, performance spaces, installations and homes. By providing housing it can promote more use of the current grey space and brings existing local character to the architecture.

The network of creative production aims to engage the community with its city. This industrial area is currently home to more trucks than people. It has resulted in a low density area making it difficult and unusual to walk around. This part of the city gives way to mass production, turning this into creative production keeps hold of the area's factory character with an added twist of fun. Creative production strives to engage people and create welcoming areas for the community.
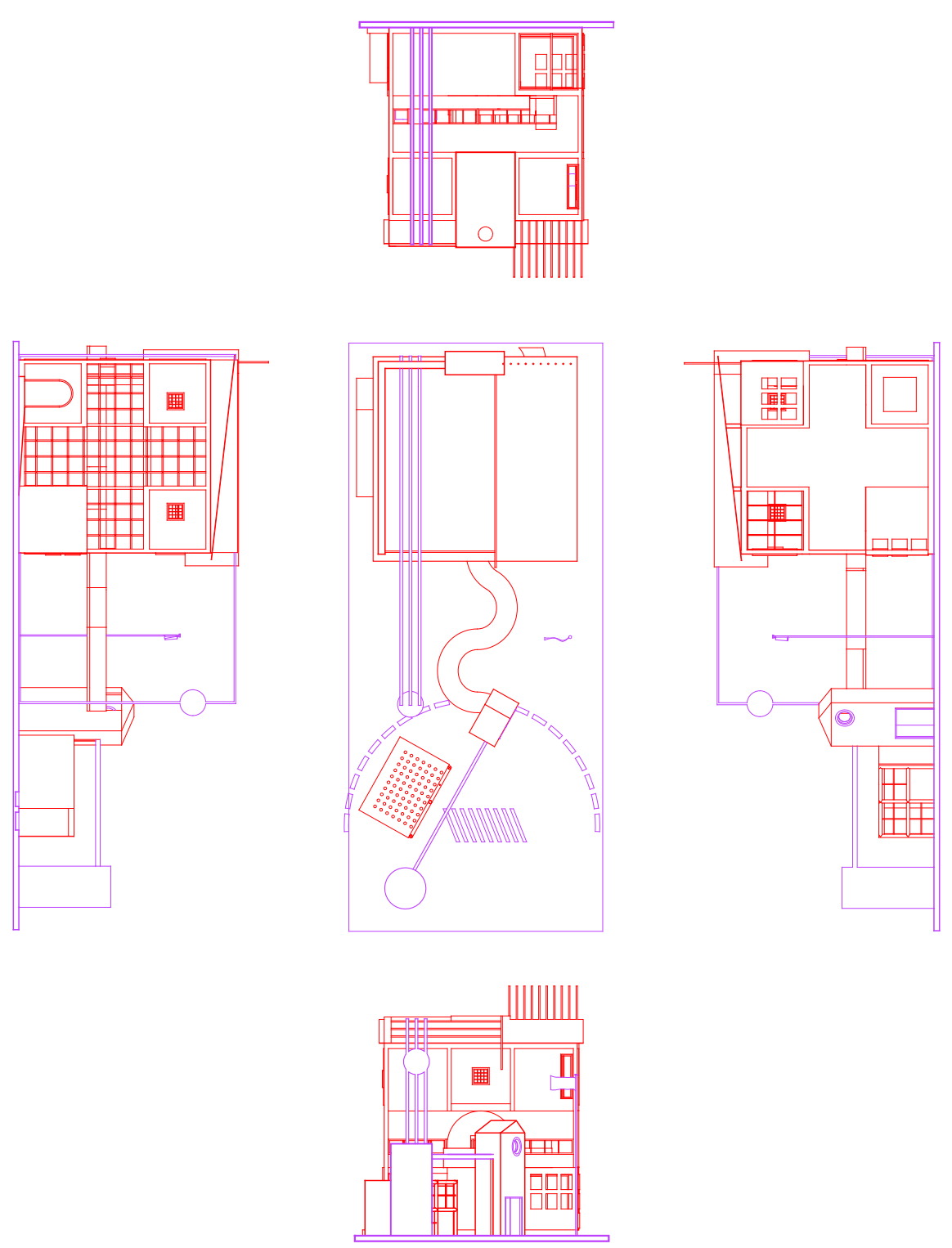

Figure 106. Unfolded Elevation, '2b Raiha St', (2020), Digital Illustration. 

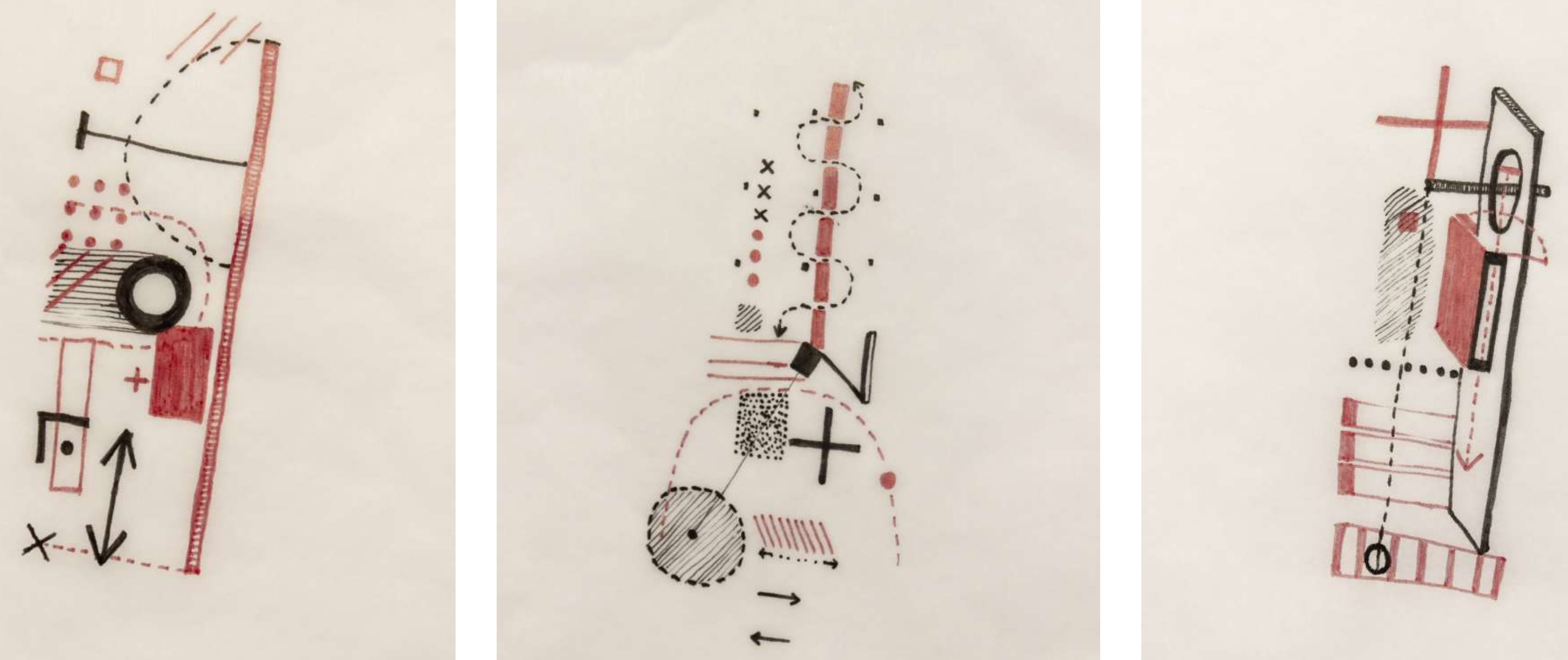


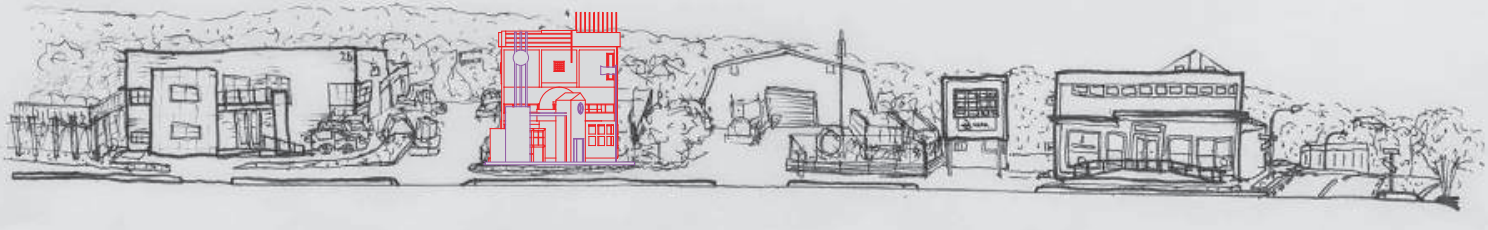

Figure 110. Street Elevation, '2b Raiha St', (2020), Mixed Media. 


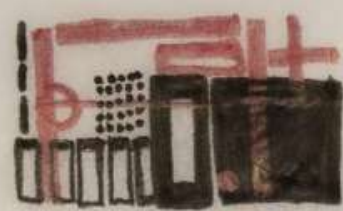
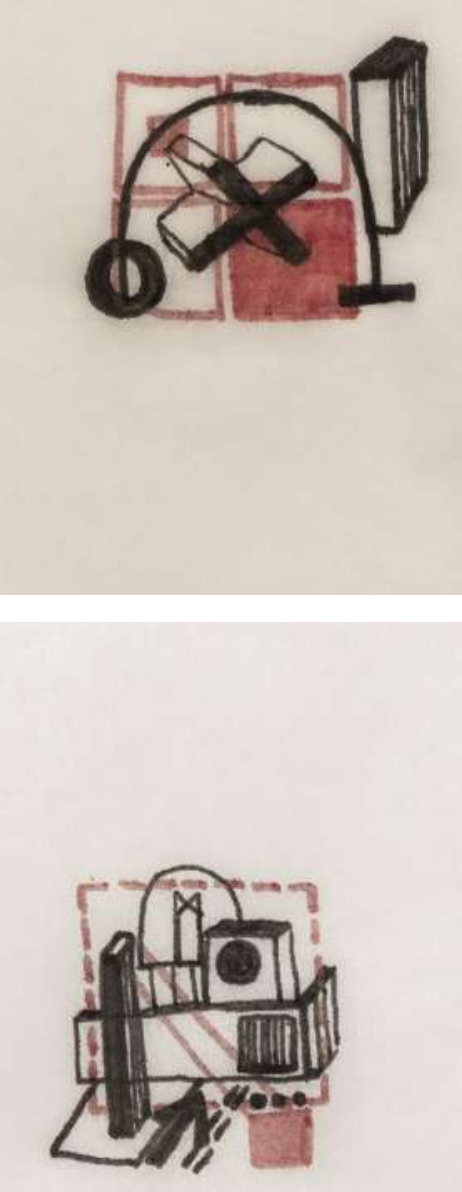

Figure 111. Elevation Diagram, '2b Raiha St', (2020), Fountain Pen and Red Pen on Butter Paper. Figure 113. Elevation Diagram, '2b Raiha St', (2020), Fountain Pen and Red Pen on Butter Paper. 

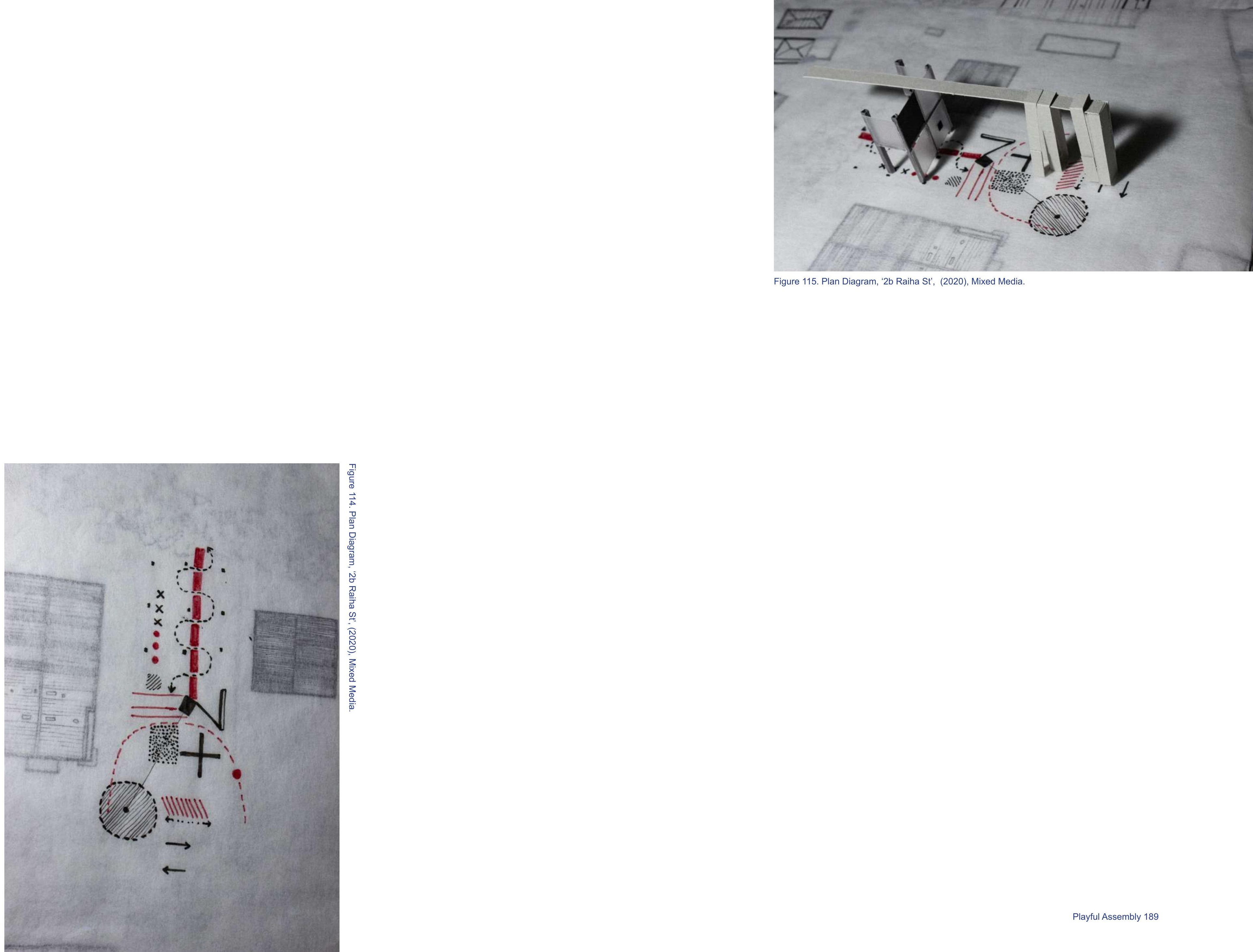
A moment of clarity was watching Tim Burton's Charlie and The Chocolate Factory in Turangi after visiting the Trout Centre. The complete entrancement of this chocolate river indulgent, oompa loompa singing factory surprisingly took me back to my thesis. I couldn't help but see it as a creative factory, a playful assembly of treats, flavor discovering and chocolate turning mechanisms all for the creative production of chocolate. It's fanatically brilliant and a huge landing moment for understanding what these creative factories could be and hold within them.

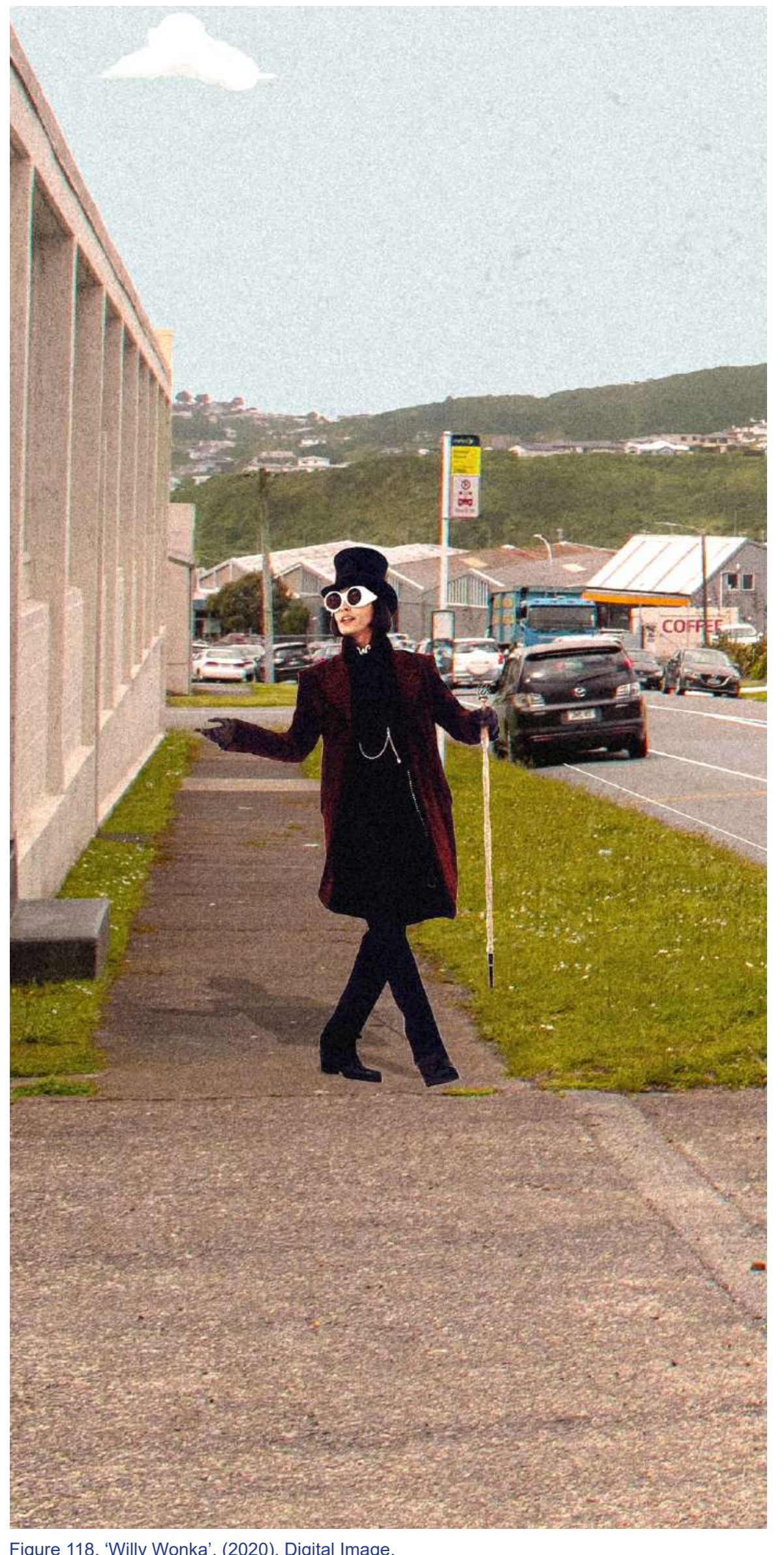

Figure 118. 'Willy Wonka', (2020), Digital Image. 


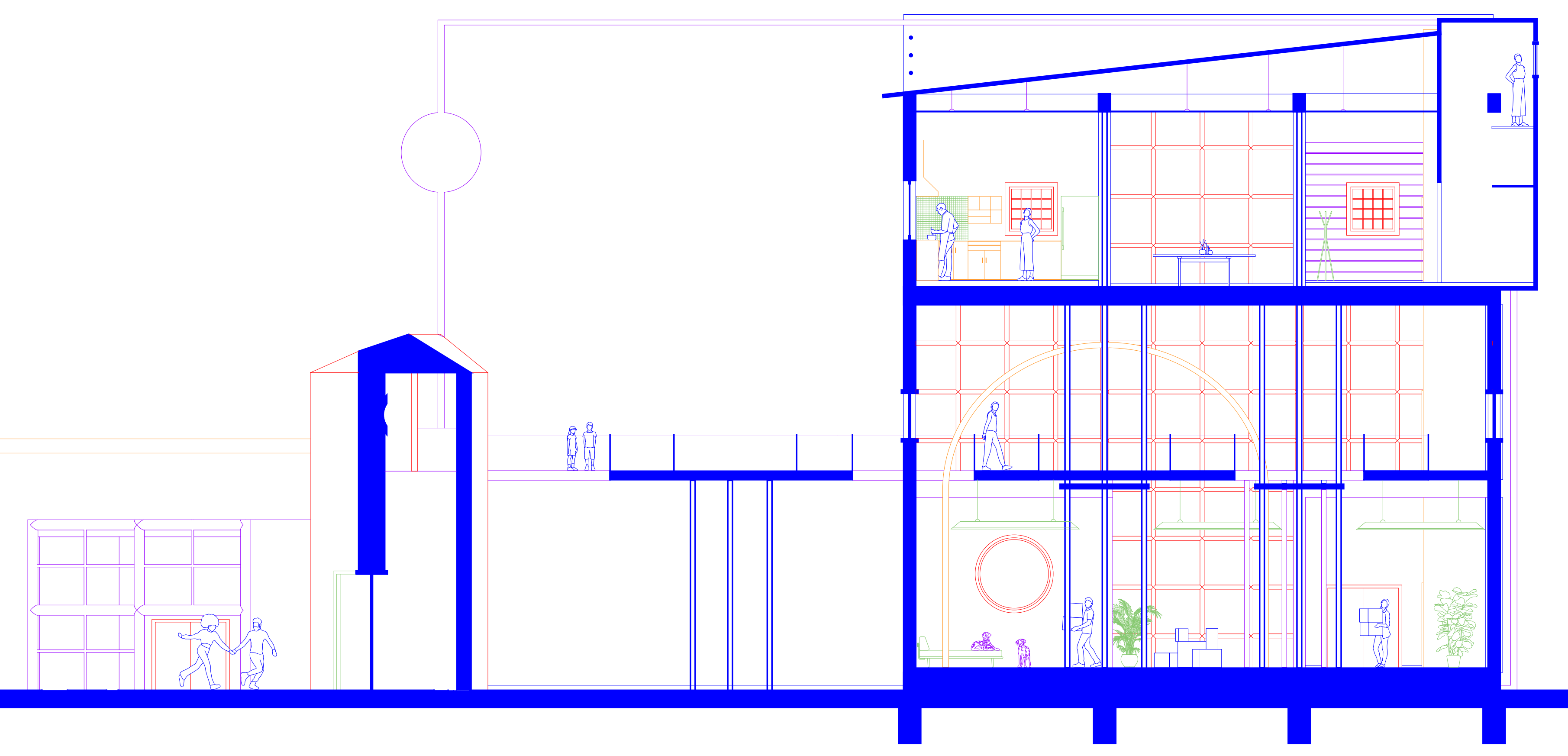




\section{reflection*}

This was my least successful design. Faced with the issue of trying to create an enclosed design, this one resulted in defaulting to a solid volume with stuff protruding out of it. I started with drawing/diagramming instead of modelling and it has developed a flat design. Flat in plan and section ending up flat on all sides, it is a box. The previous paper models have a more captivating form but are not enclosed. The hand-drawing of this site gave me a good understanding of context however led me down a rabbit hole of conformity. The diagramming almost pulled me out of it but I feel physical modelling would have been more successful.

The 1:20 window frame model was the most successful part of this design. It provides a playful yet sophisticated level of detailing. It indicates a timber structure with fun railings and large window frames. It is reserved as it flirts with sohistication and indicates play. This surfaced the need to develop an in between level of sophistication and playfulness. This design is too reserved and the previous design is too fictional so a balance between these would hit the spot.

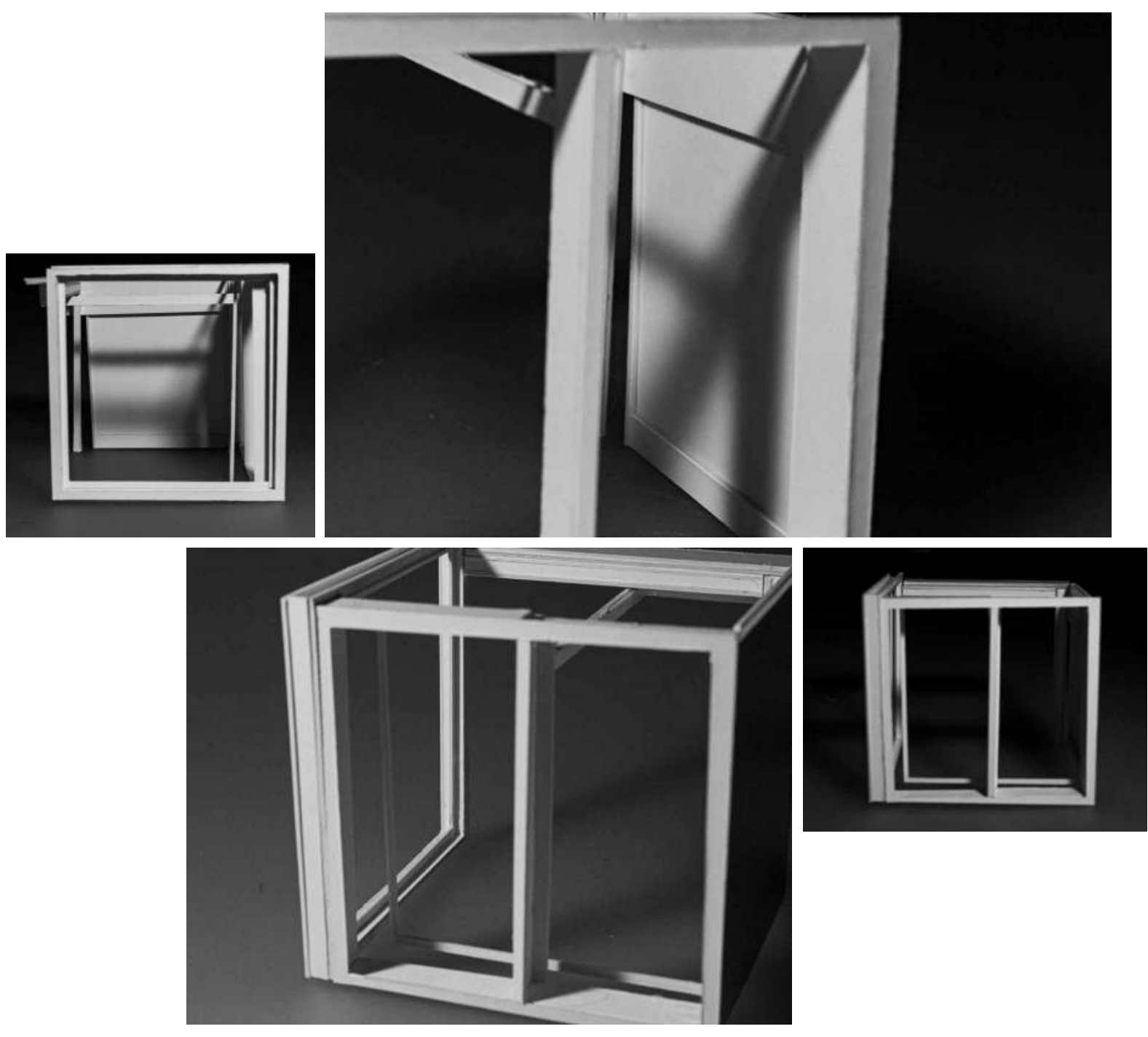

I had also fallen into the exact zoning, bordered, rule trap I was challenging. It was so easy to conform to context and sit safely on site I did not realize I was doing it. It shows how hard it can be to break through the conformity modern cities have created (Constant, 1998, p. 9). The last thing I want is for my creative factory to be a place where people are working machines for capitalist society (Constant, 1998, p. 9), conforming to zoning rules, lunch time rushes and peak hour traffic. 


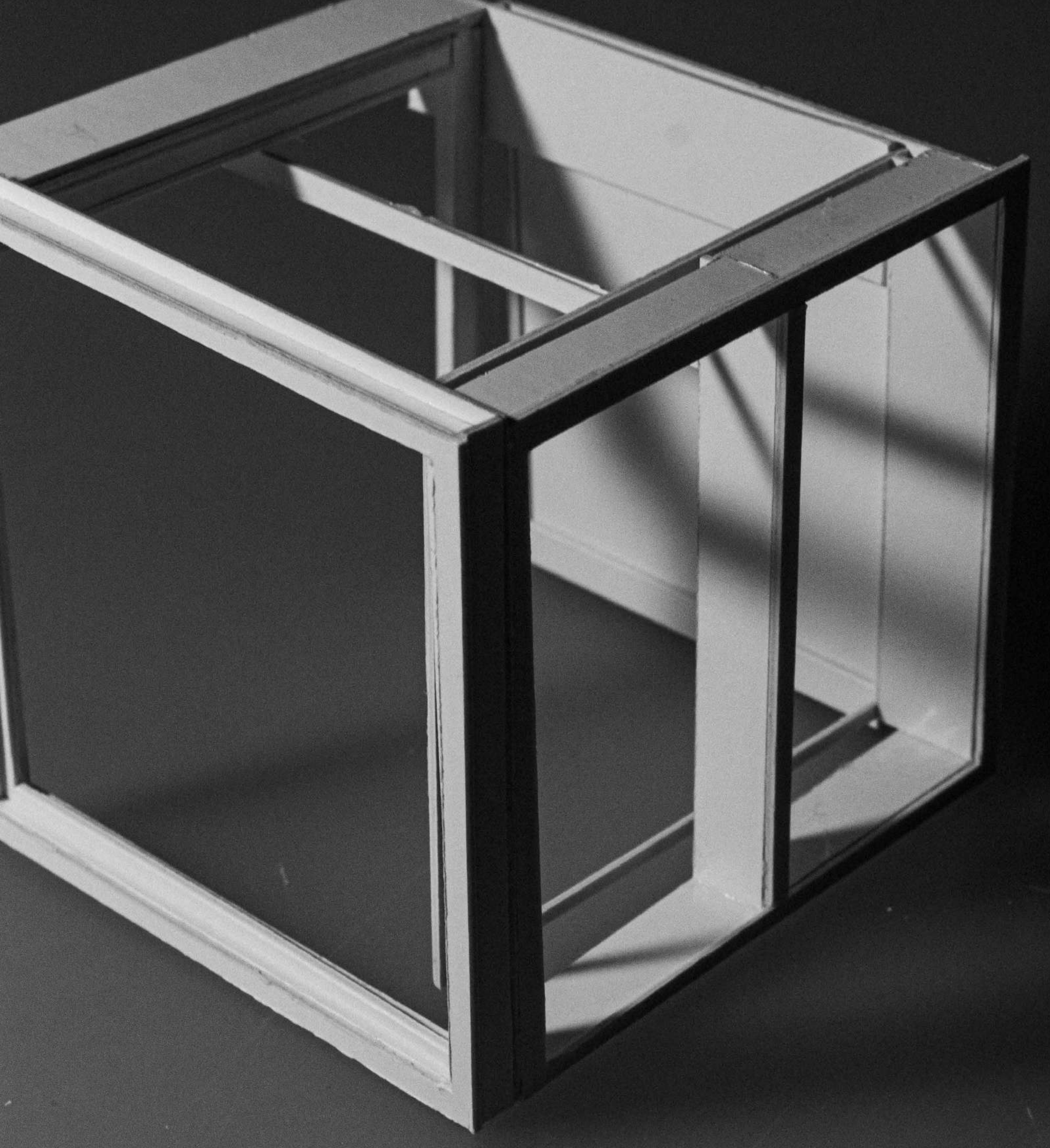




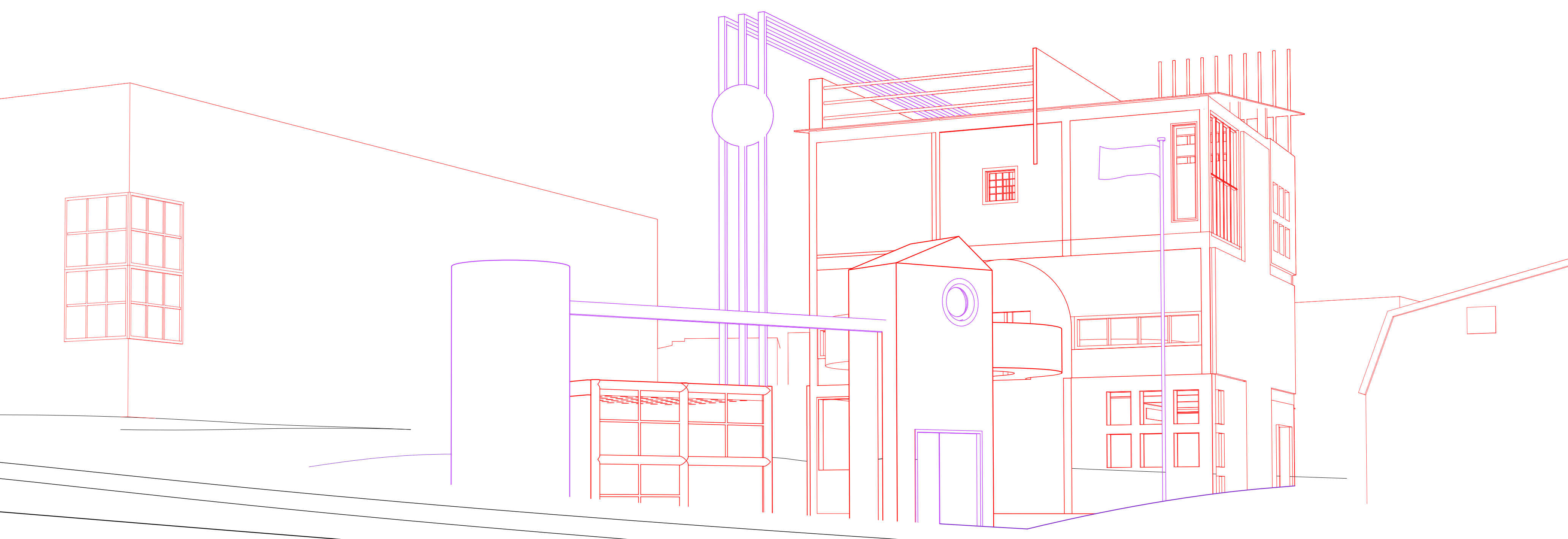




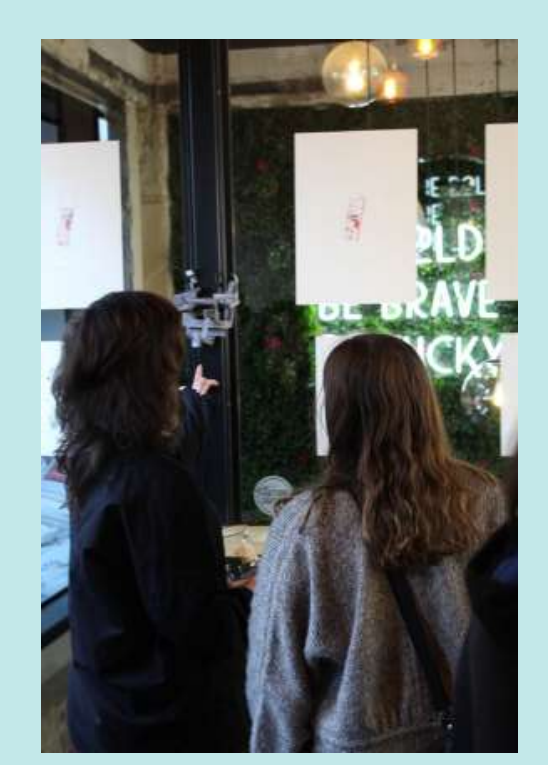


flash exhibition*

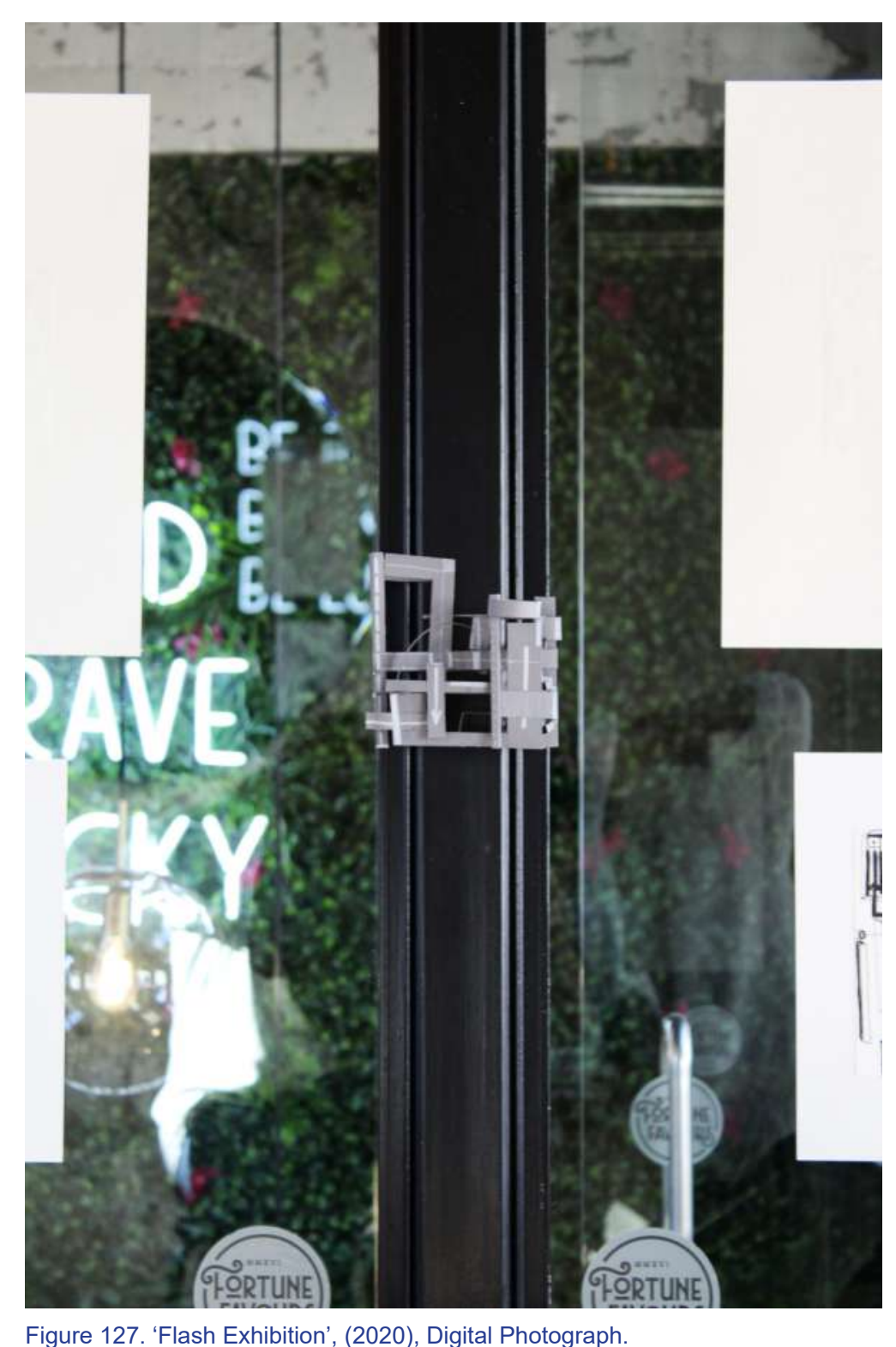




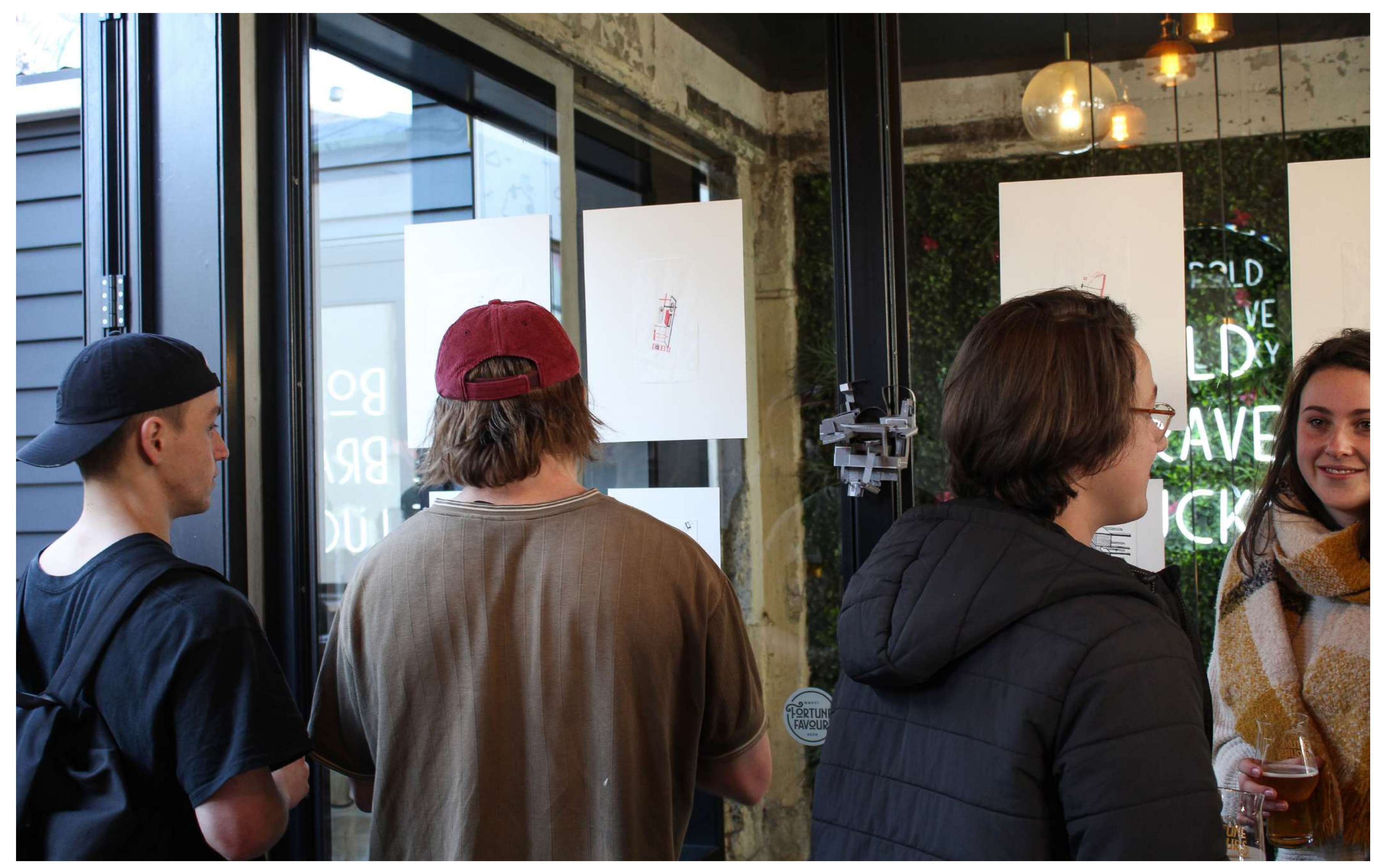




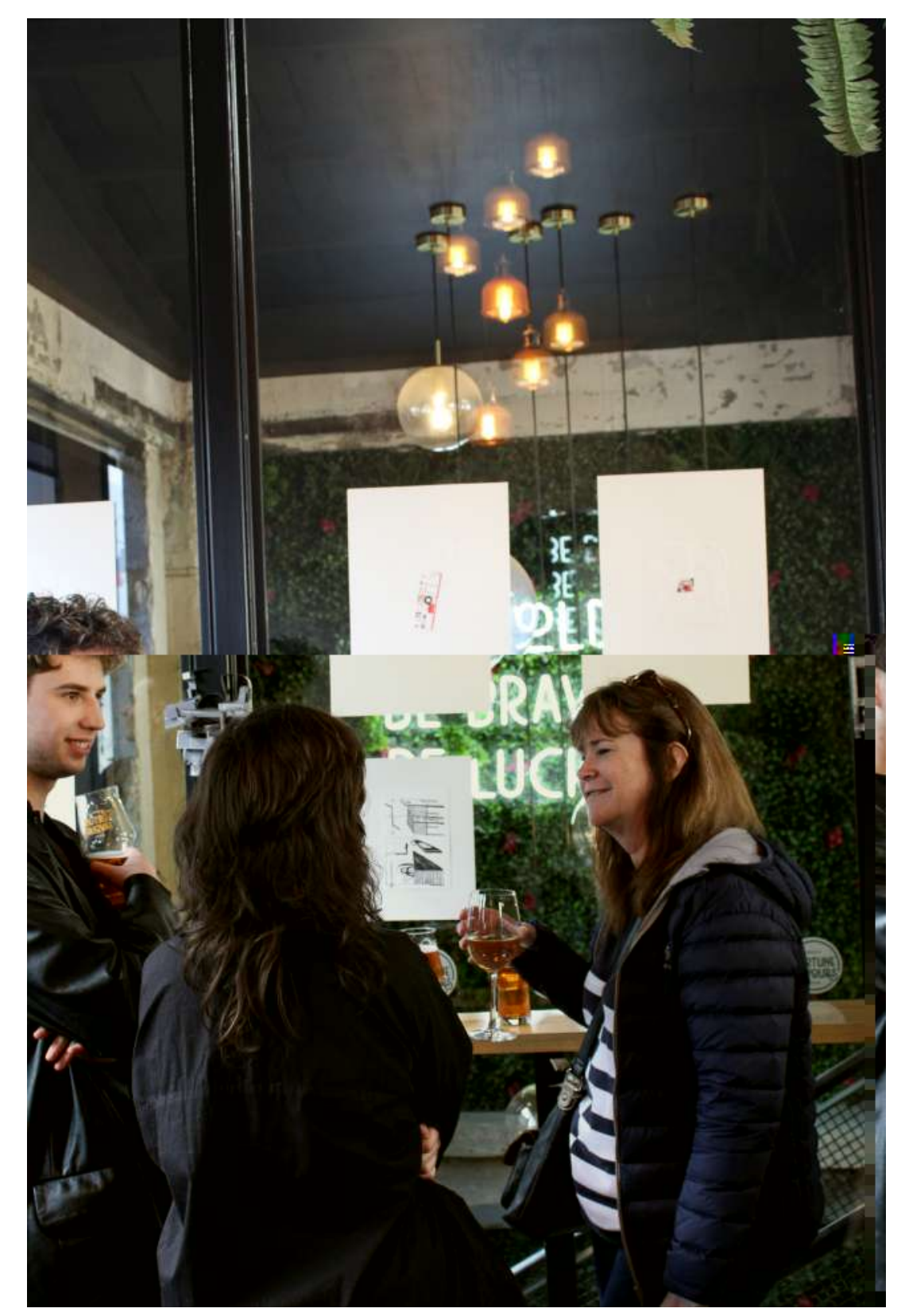

The task of curator was one I enjoyed. Placing physical models, drawings and diagrams in a brewery, outside of university allowed me to separate myself from my work. I saw work across multiple medians which speak a similar language, that language seemed to be just developing and I was excited to see more. 


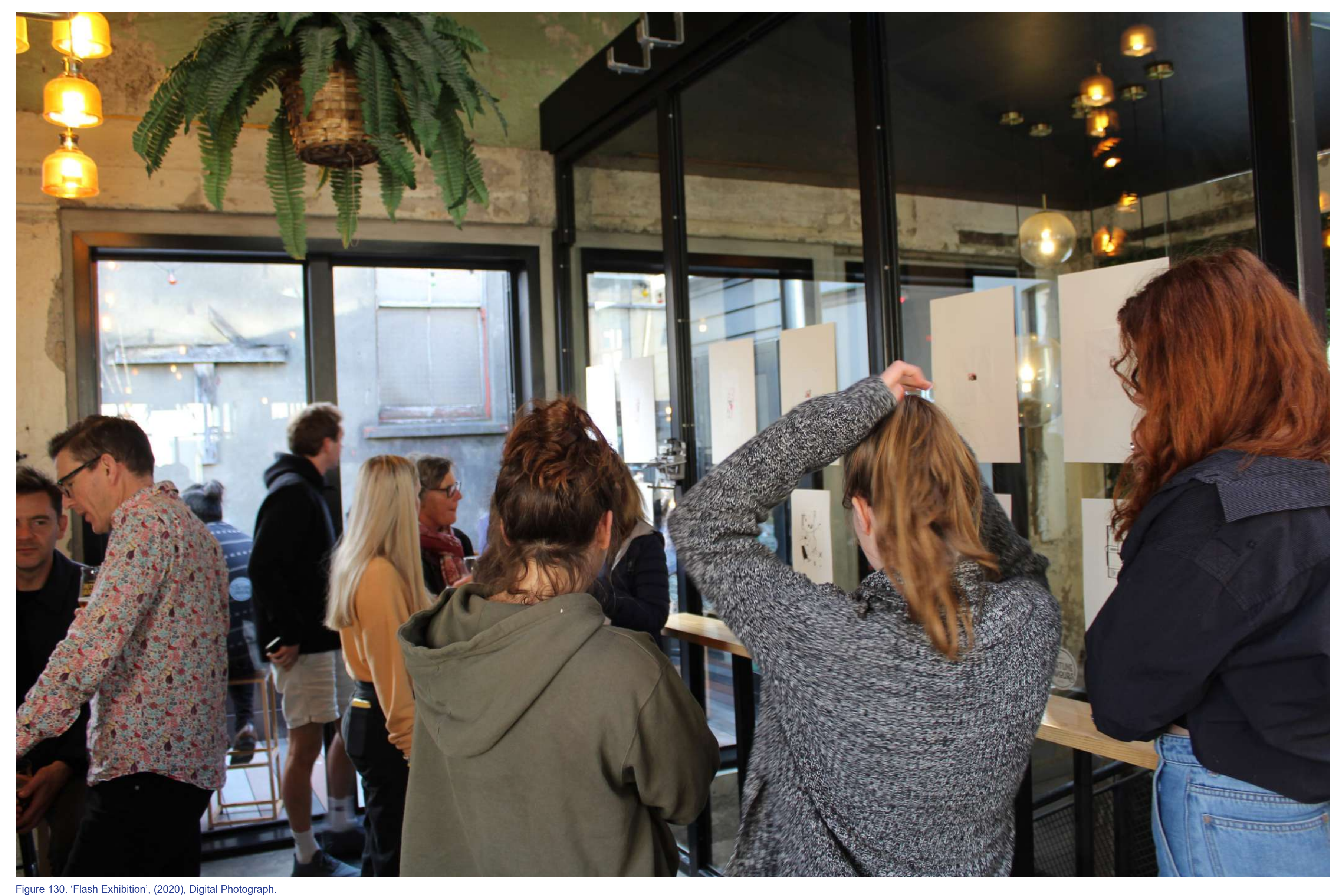




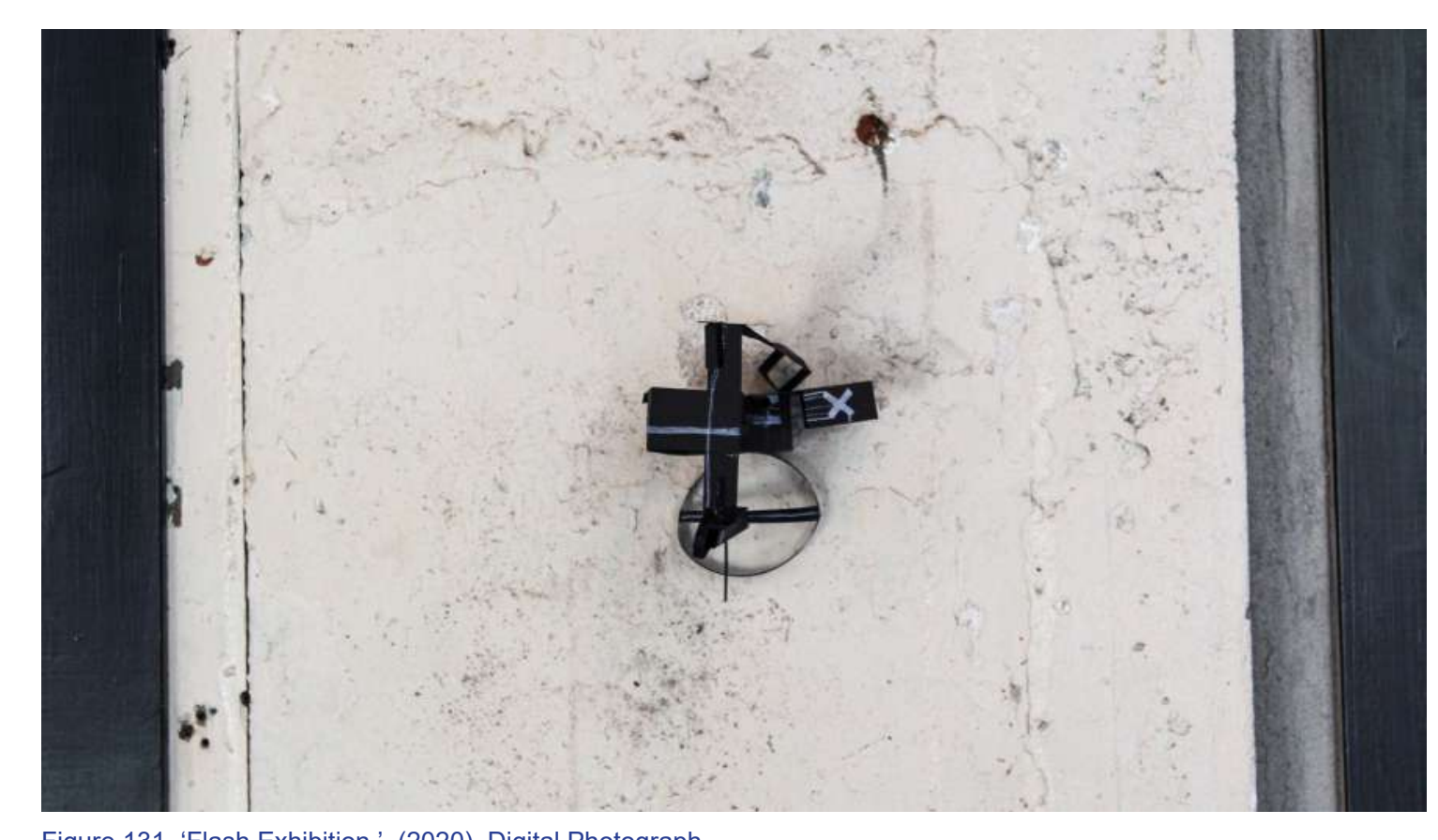

Figure 131. 'Flash Exhibition ', (2020), Digital Photograph. 


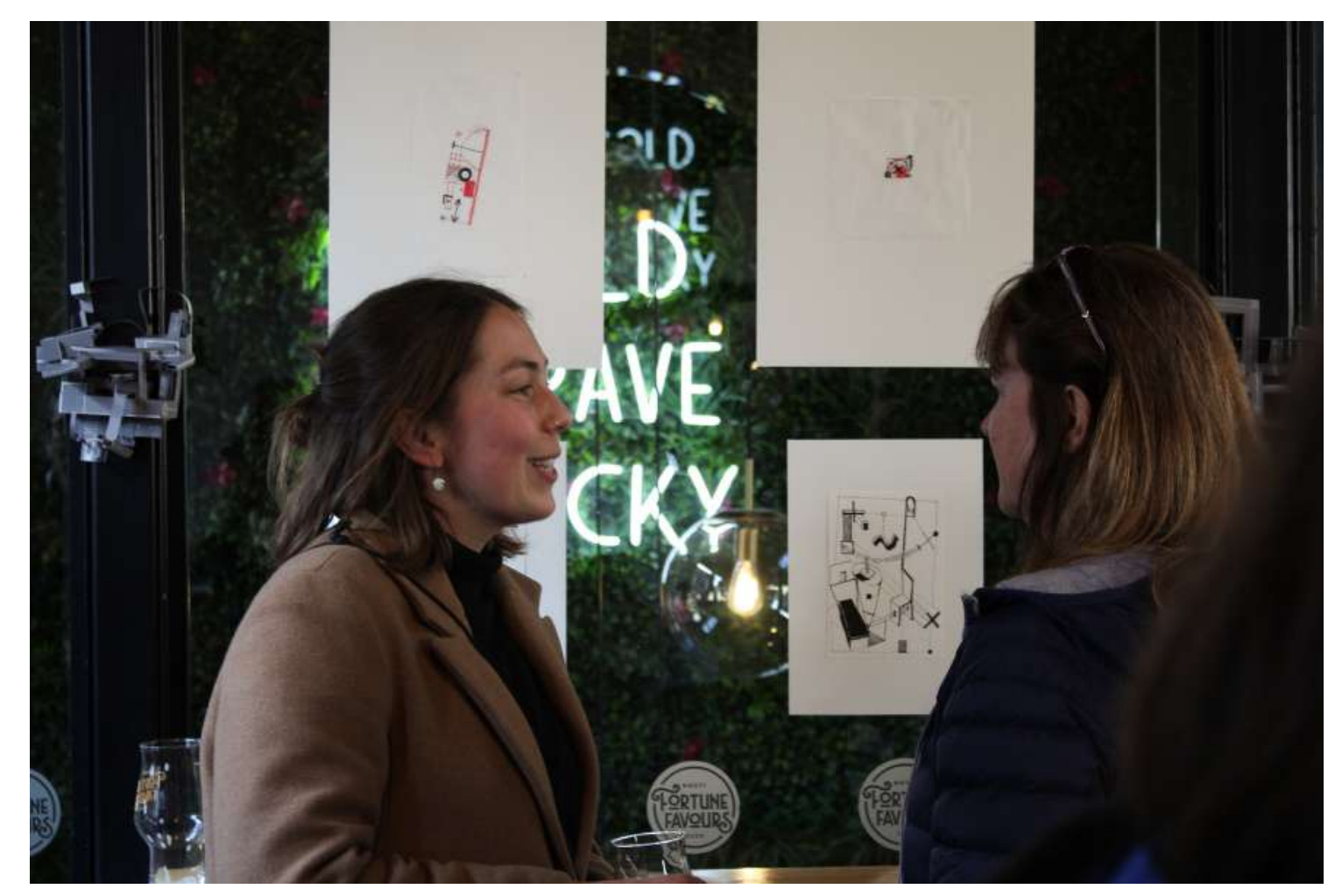

Figure 132. 'Flash Exhibition', (2020), Digital Photograph. 


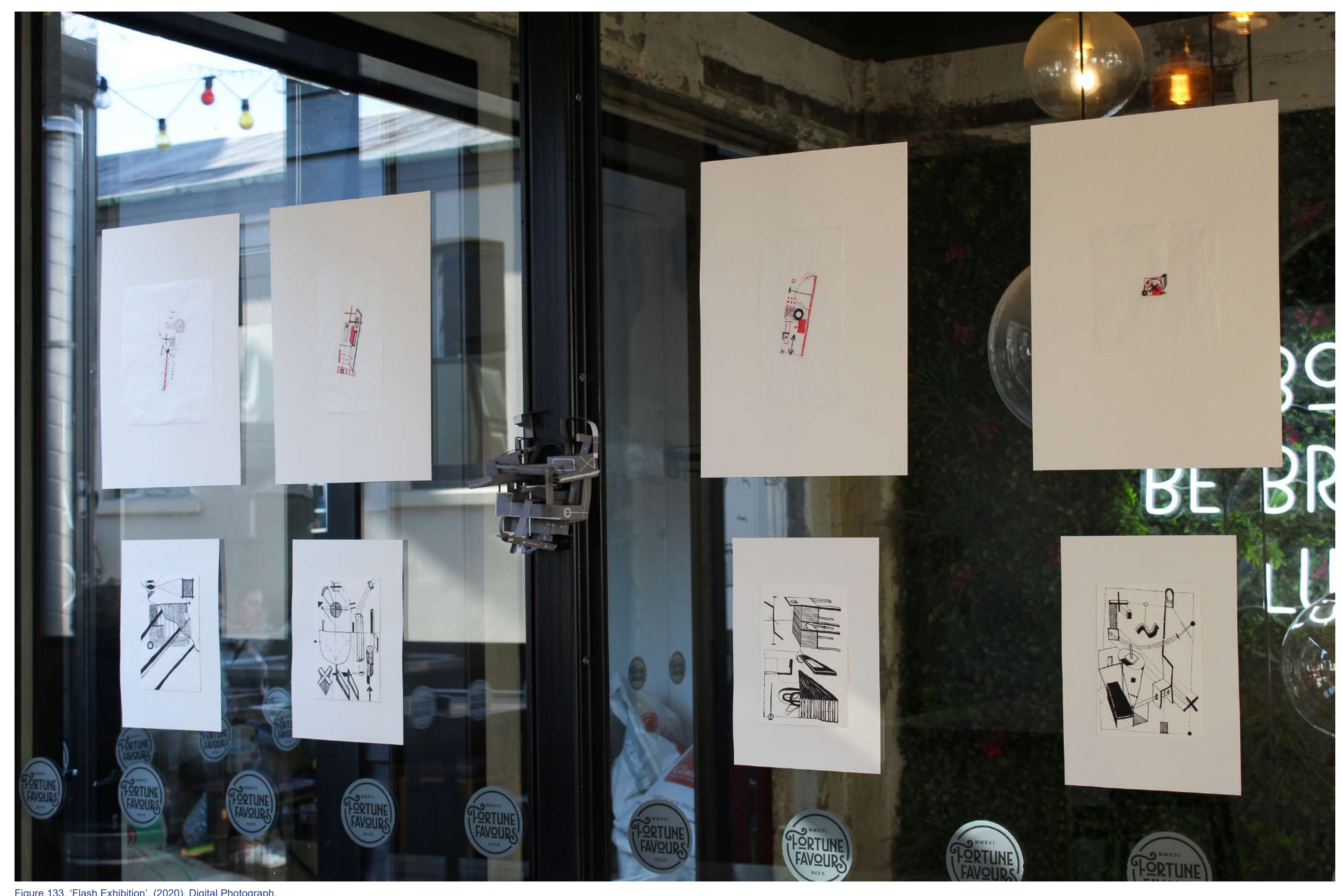




\section{review}

\section{realizations*}

The discussion before, during and after the August review presented new perspectives, potential issues, reassurance and a sense of direction. The physical act of pinning up my work and organising a presentation was challenging. Due to the nature of my sometimes frantic way of creating left me with piles of stuff I had to try and find a direct line through. This is the biggest challenge I faced many times throughout the thesis and I still haven't found an easy way through it. Discussing with friends, supervisors, and family about it has been the biggest help.
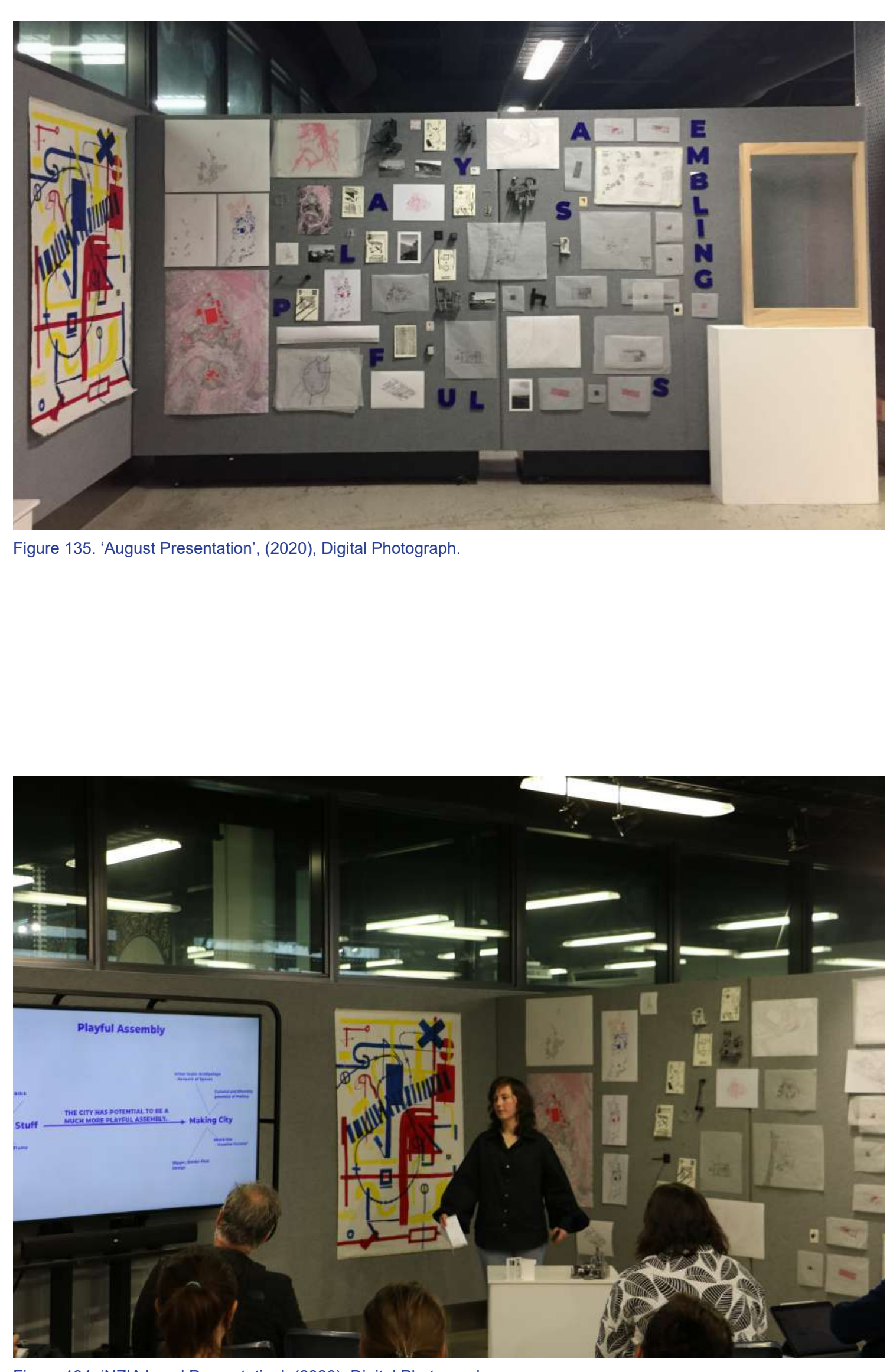

Figure 134. 'NZIA Local Presentation', (2020), Digital Photograph. 


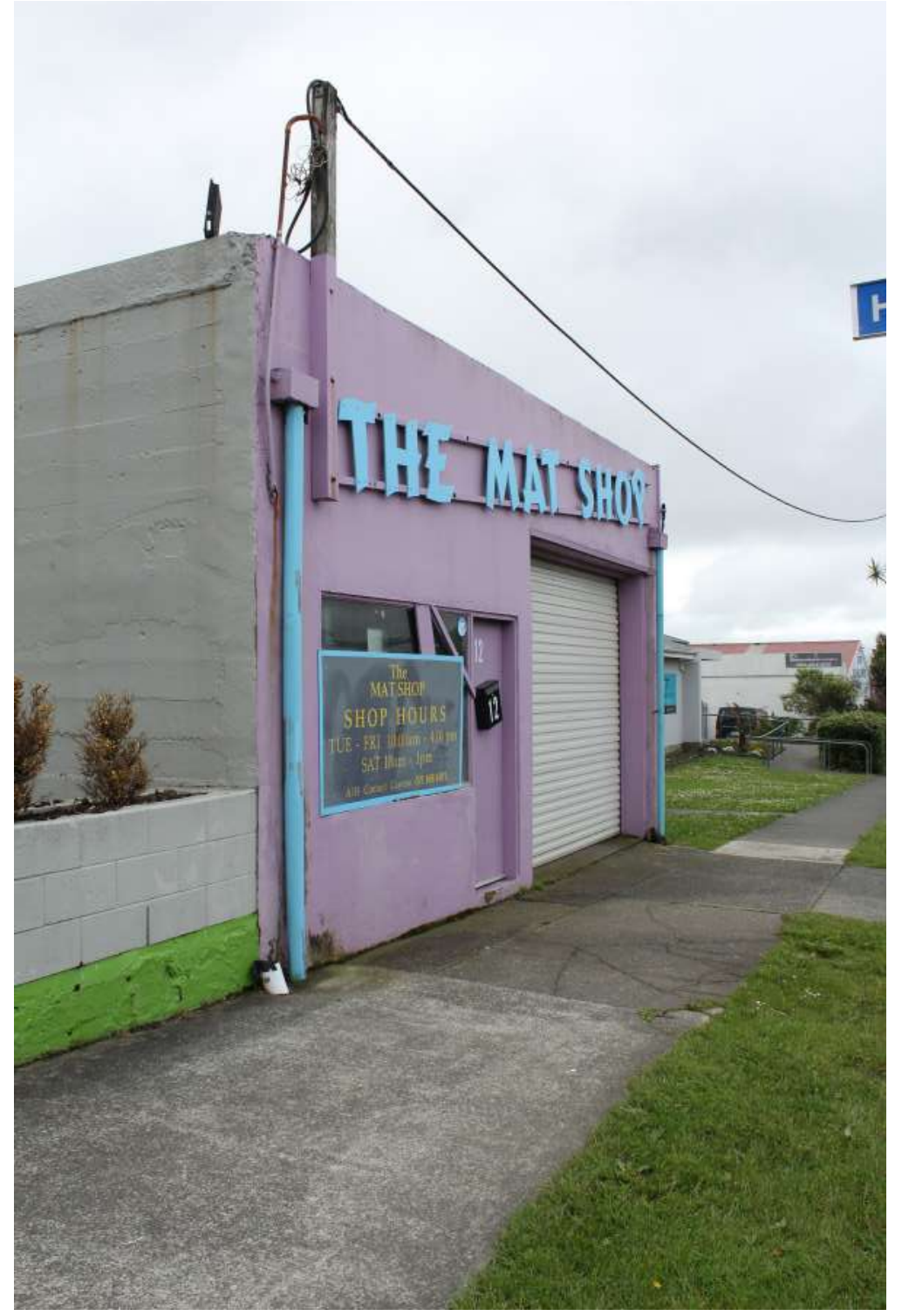

Figure 136. '12 Prosser St, Elsdon', (2020), Digital Photograph. 


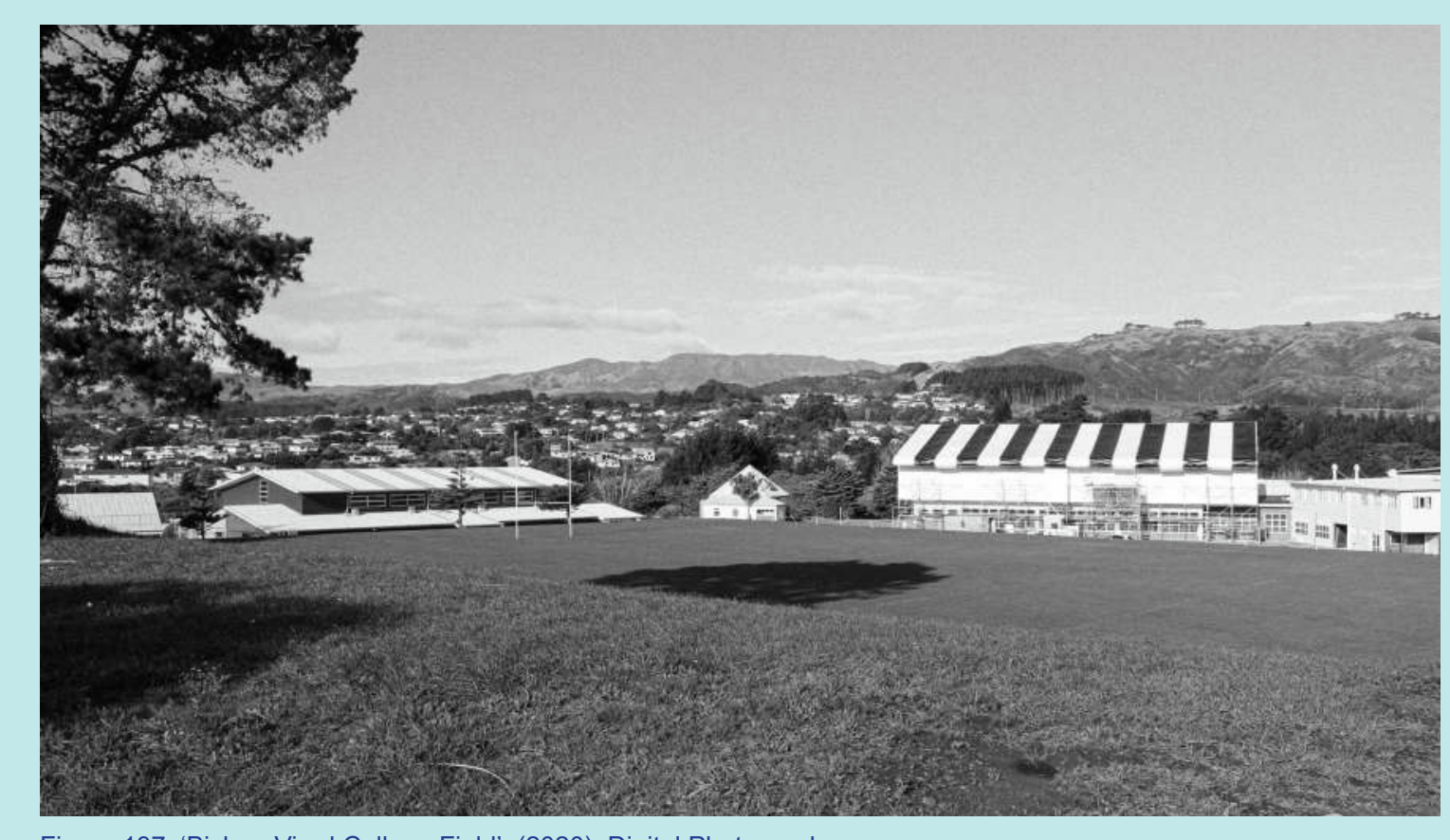

Figure 137. 'Bishop Viard College Field', (2020), Digital Photograph. 


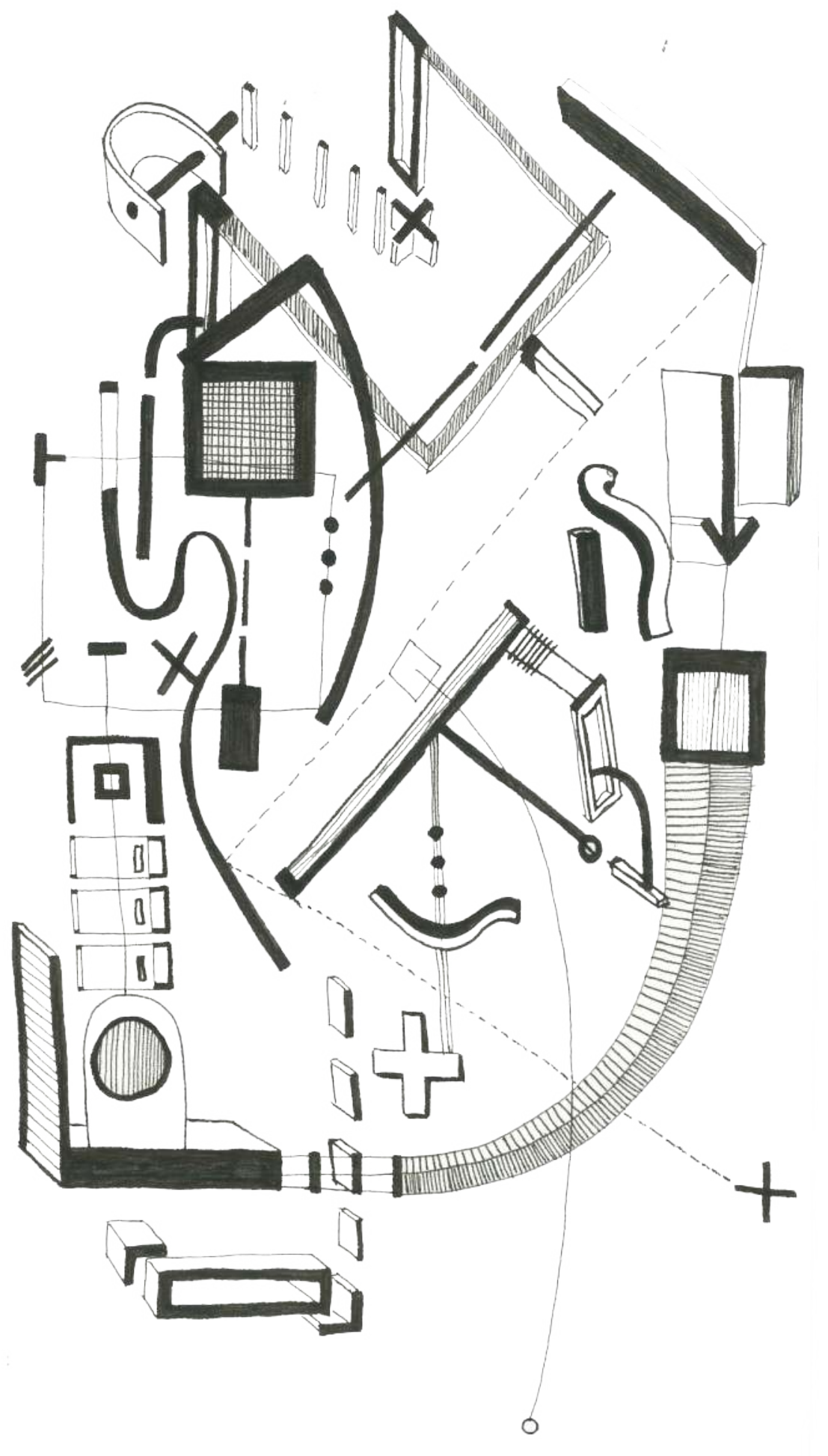

Figure 138. 'Elemental Sketch', (2020), Fountain Pen Drawing.

\section{composition criteria*}

The direct line through this project lies in the consistent development of an architectural language. This language has used composition frequently found in painting as a design tool to inform decisions. The compositional language requires development to find its balance between sophistication and play.

Composing opposite elements in a complementary respect for each other plays a crucial role in the composition of my architecture. The elemental approach allows elements to play rather than fight.

Elements are composed to surface their playful nature. Each element is autonomous yet must live together in order to create an architecture. This is similar to "...the painting, while all the while preserving the individuality of its elements, subordinated them to a life together in a composition of the ensemble" (Lucan, 2012, p. 409). The architectural composition stands true to painting. The main difference is architecture lives in the city while paintings live on the wall. The building creates playful assemblies at all scales forming a whole architecture of playful compositions.

Whether I am composing a city, painting, building or model they are all made from individual elements which are composed together. The playful assemblies need to be composed in order to respect each element individually and collectively. 


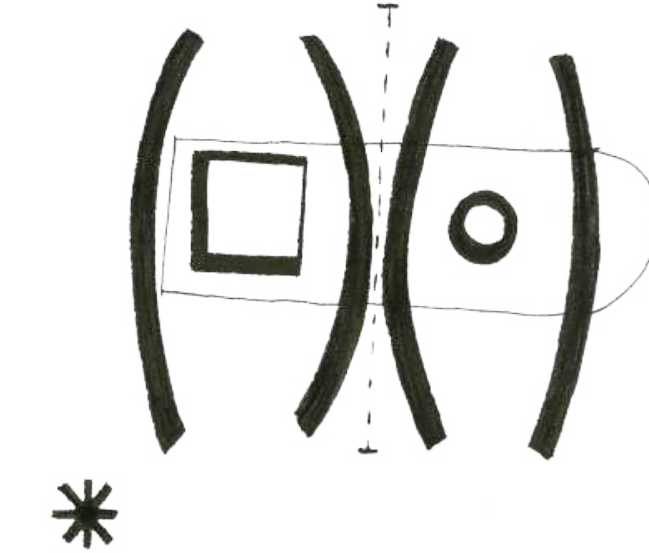

Figure 139. 'Composition Sketch', (2020), Fountain Pen Drawing.
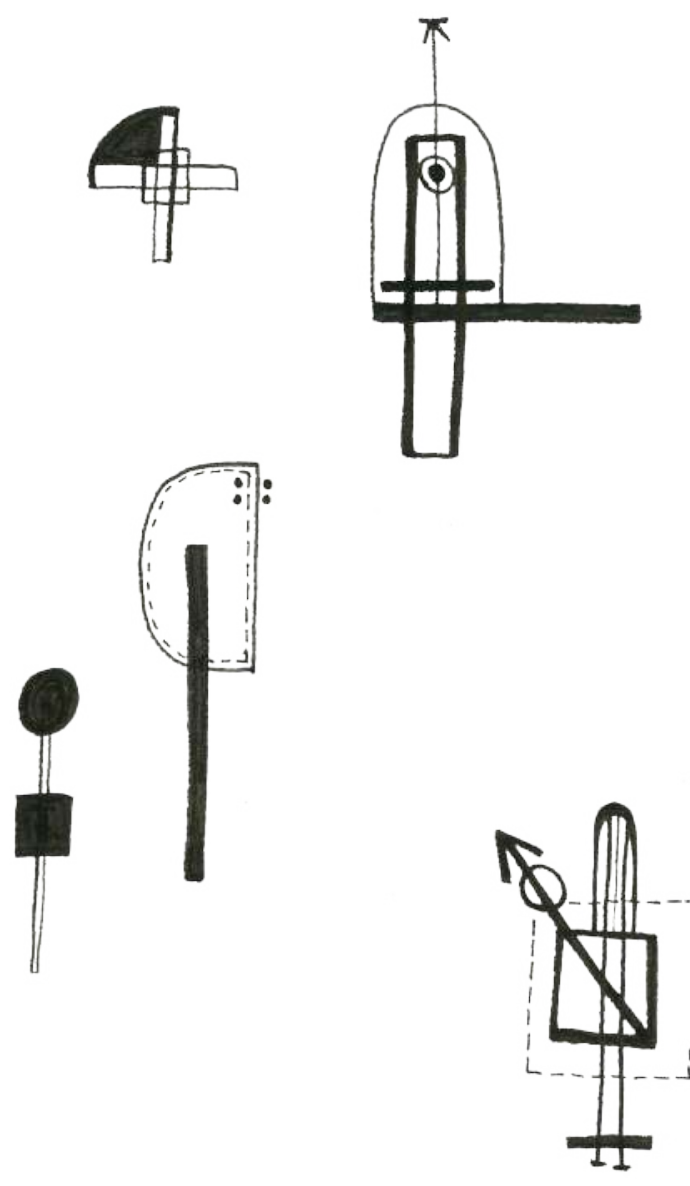

Figure 140. 'Composition Iterations', (2020), Fountain Pen Drawing. 



\section{form + colour compositions*}

1:100 Form + Colour Models: These models explore a playful assembly of colour and form. The 25 elements can be used as designs themselves or the individual elements can be re-assembled, pulled apart, combined to create a larger design.

They are a set of abc's for the current playful assembly language. I am most proud of this set of models, they architecturally compose both autonomous objects and a collective ensemble.

They add a layer of colour and develop the playful assembly form. The form refines the 'opposites attract' observation combining it with colour. These elements can be playfully assembled in a variety of ways lending themselves to the compositional criteria.

Now these elements are created they can be truly played with.

These architectural compositions provide a basis for the play of form and colour adding a layer of refinement to this architectural language. As Le Corbusier selects 'object types' I have selected 'elemental types'. Objects types are daily objects which already exist and elemental types are various forms or shapes that can be applied to an architectural element. Now these types are selected it "...dispensed one from having to concentrate immoderate focus on the object itself thereby becoming 'free to concentrate on the play of shapes and colours'" (Lucan, 2012, p. 406). This provokes the next design which compositionally refines form and colour architecturally.

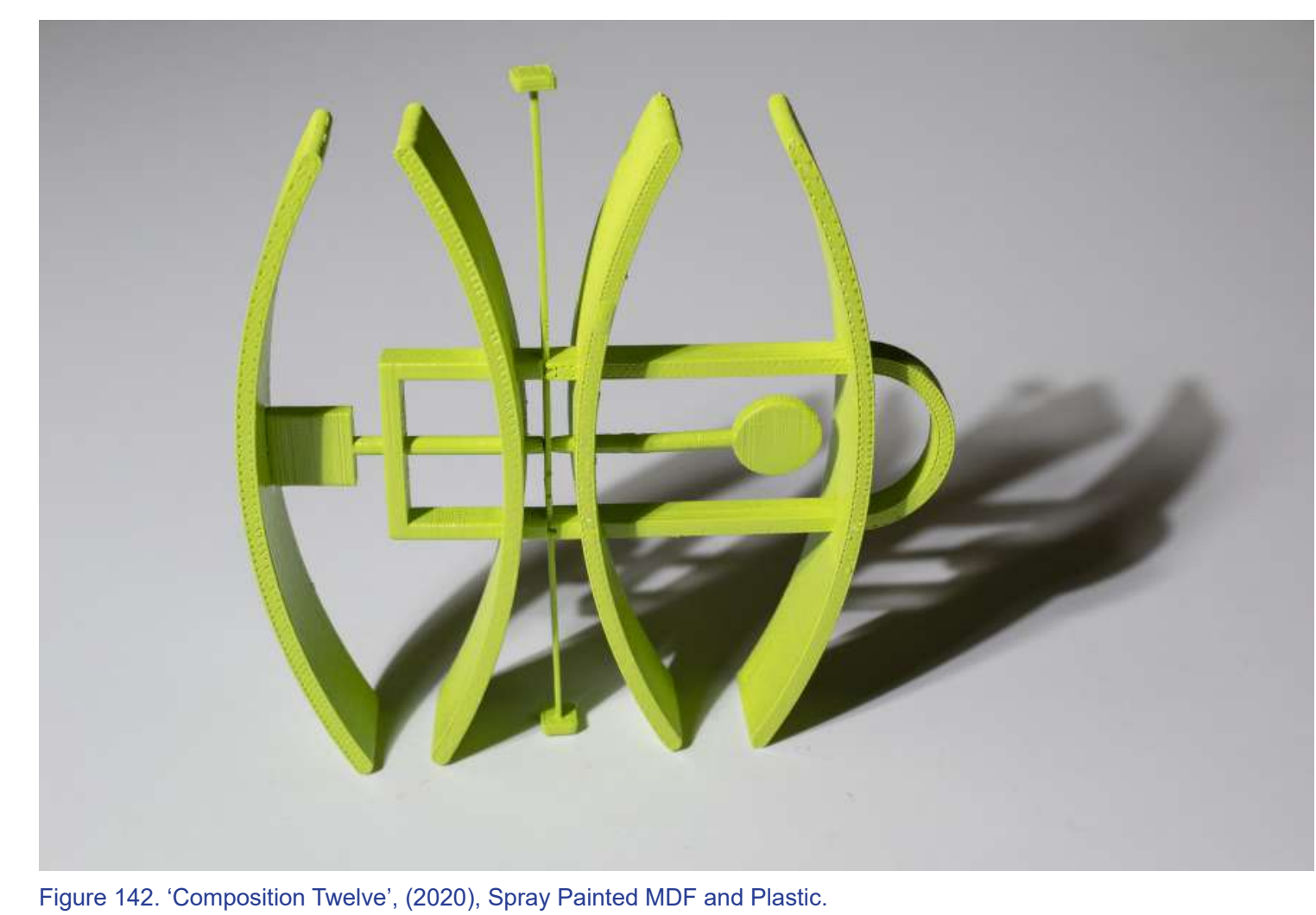

Figure 142. 'Composition Twelve', (2020), Spray Painted MDF and Plastic. 

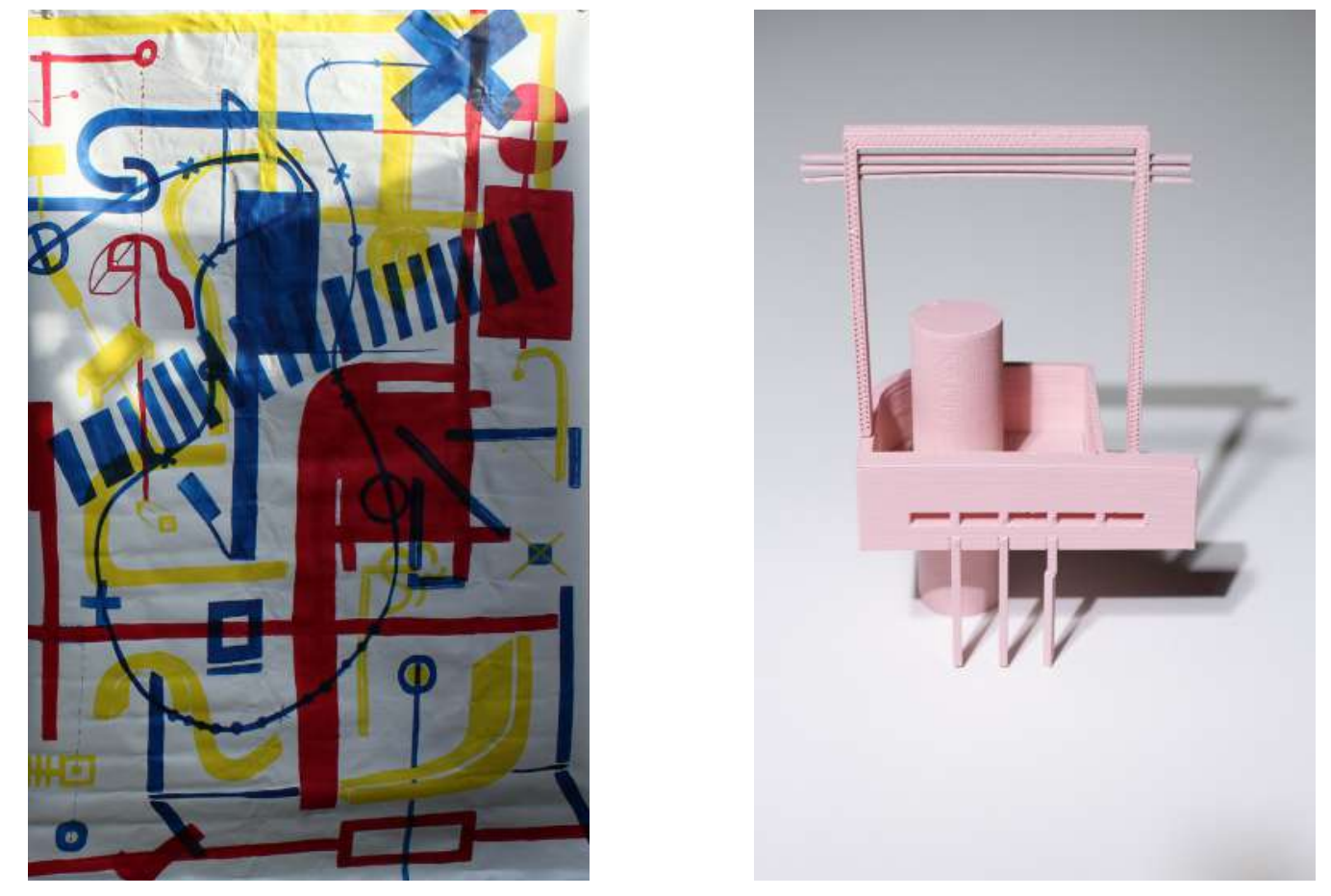

Figure 143. 'Corbusier Comparison', (2020), Acrylic Painting, Physical Model.

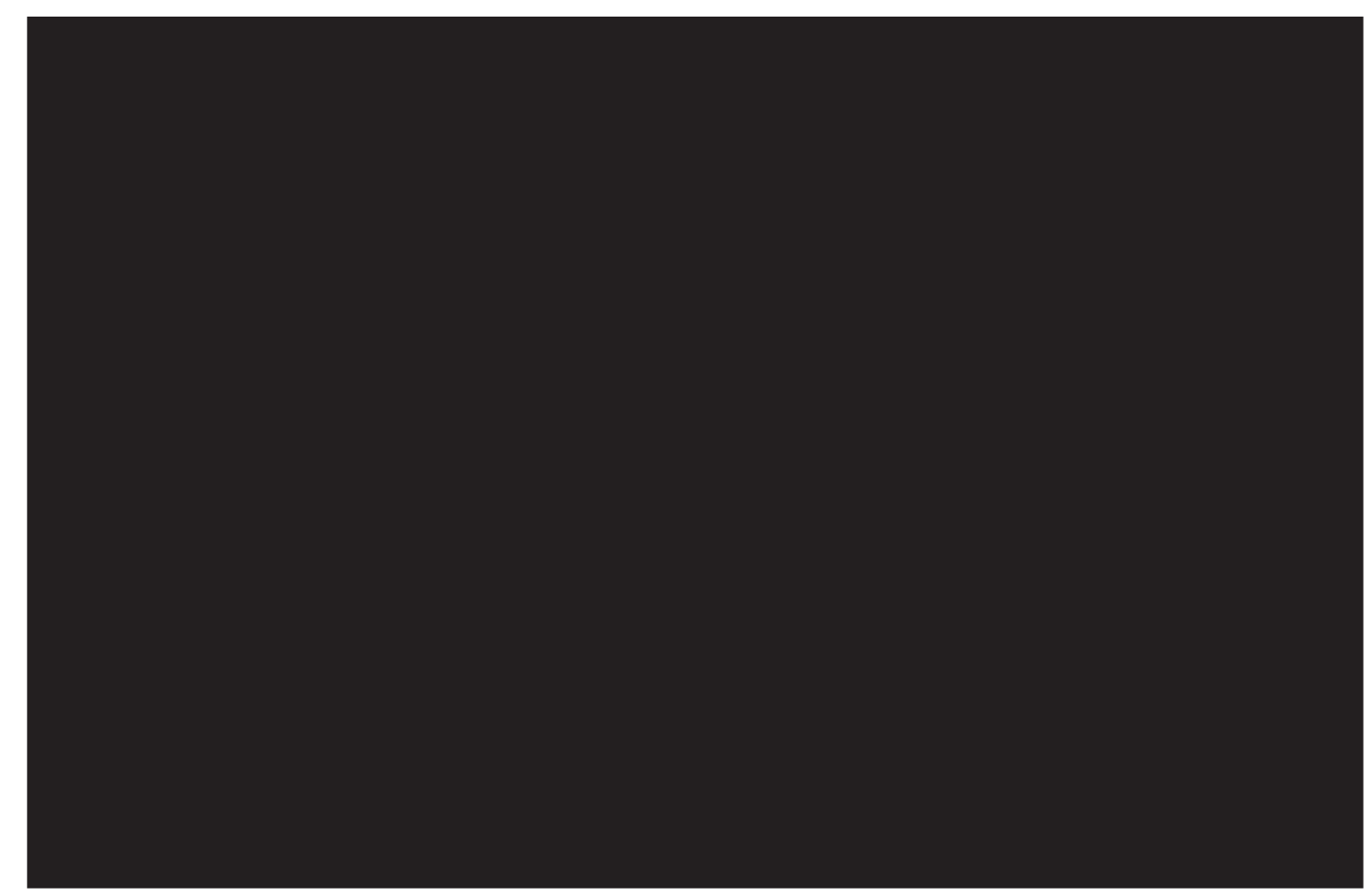

Figure 144. 'Corbusier Comparison', (2020), Acrylic Painting, Physical Model.

Thinking of architecture as a painting allowed me to compose its elements with the same playful nature I would a painting. Using the visual narrative of Le Corbusier's still life paintings and his Villa's (Sbriglio, 2008) gave me an understanding on how to translate the painting composition within architecture. 

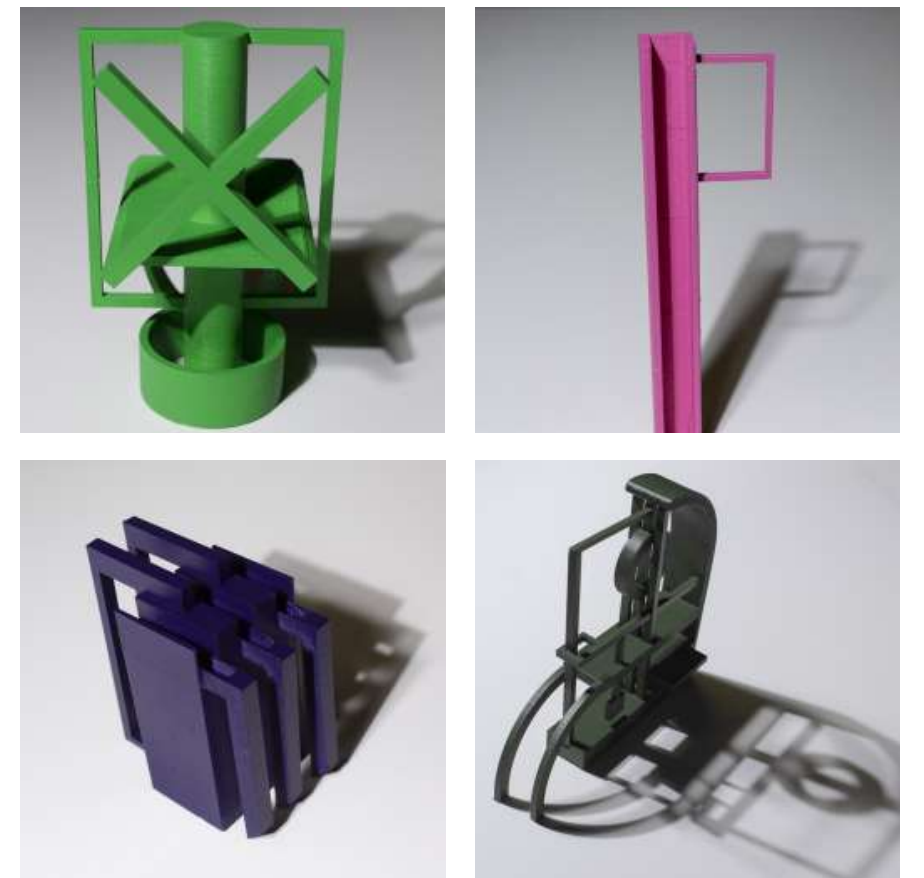

Figure 145. 'Least Successful Architectural Compositions', (2020), Spray Painted MDF and Plastic.
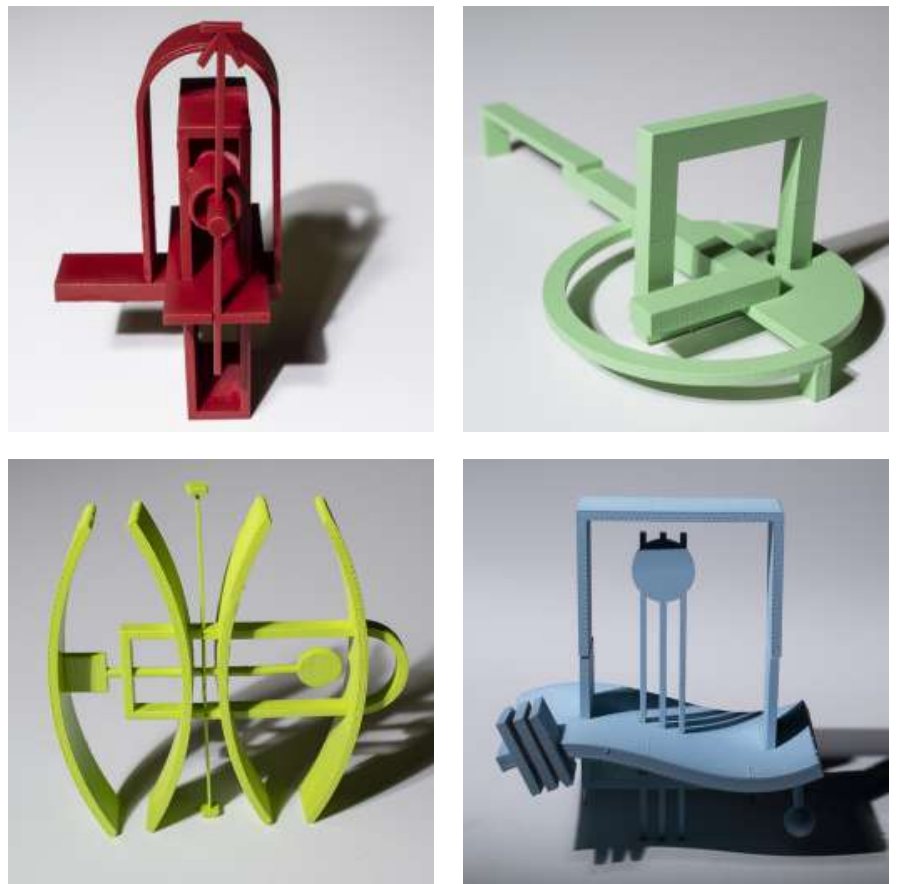

Figure 146. 'Most Successful Architectural Compositions', (2020), Spray Painted MDF and Plastic.
Solid volumes, flat single axis and geometrically limited forms are the least playful. I struggle to work with solid volumes, they are heavy individual objects which are difficult to compose. Large solid volumes lend themselves to themselves rather than the collective. Simple forms are kept interesting with a variety of geometries and intersecting elements on different axis, without that simple forms remain that, just simple.
The architectural compositions require a variety of geometries intersecting and enclosing each other along various axis. The nature of the compositions avoid solid volumes or any form which demands all the attention. 


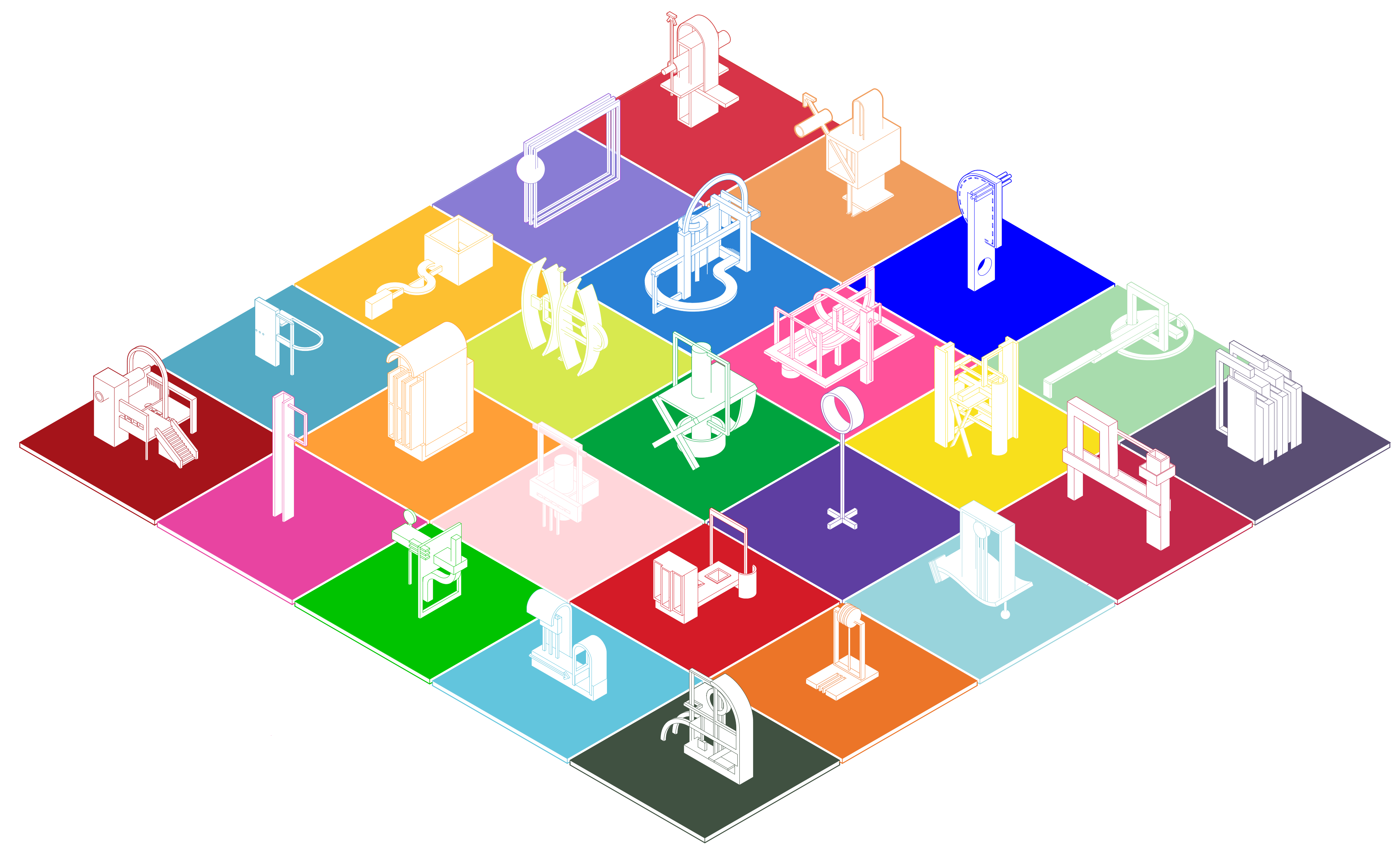



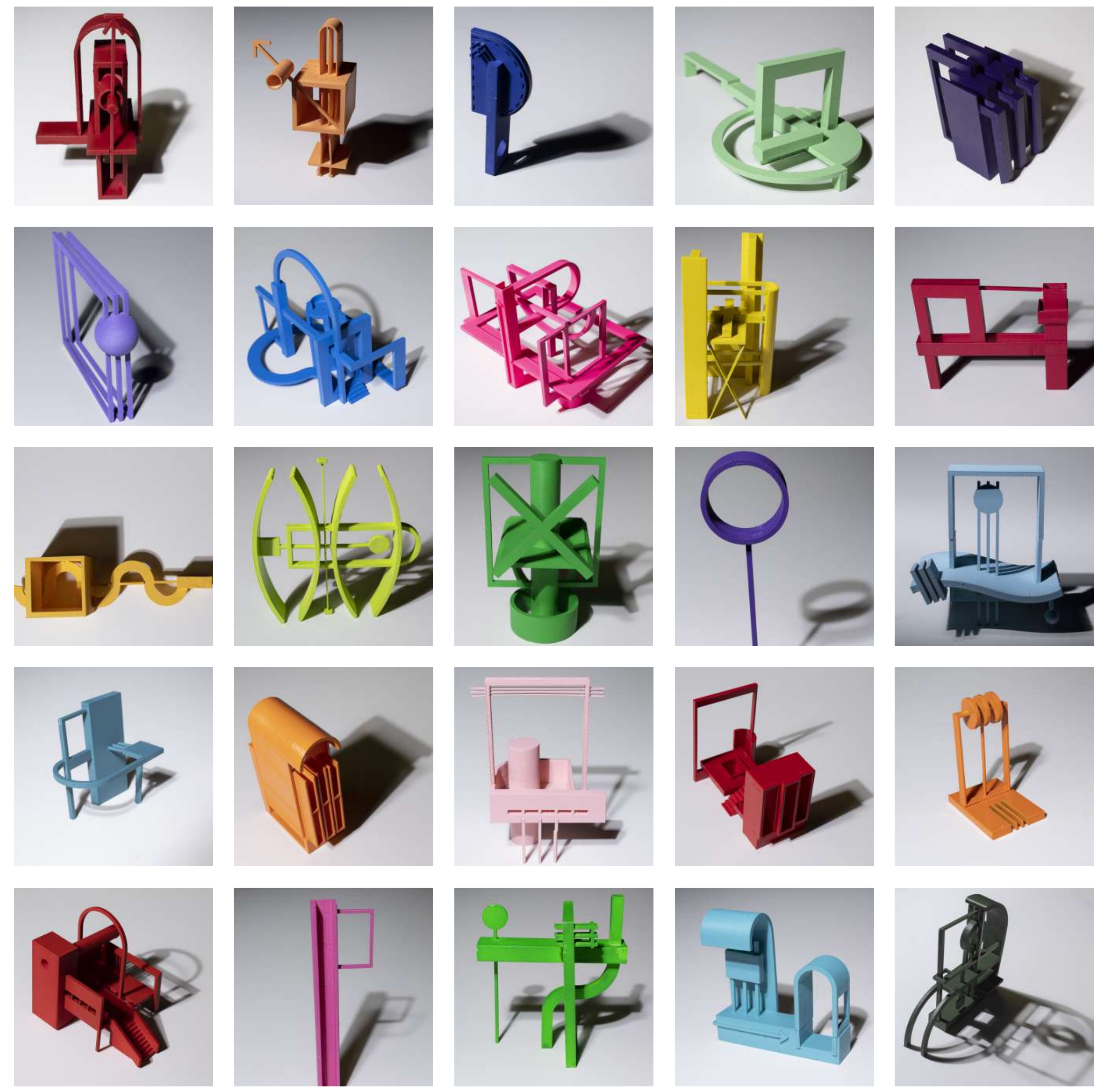

Figure 149. 'Architectural Compositions', (2020), Spray Painted MDF and Plastic. 


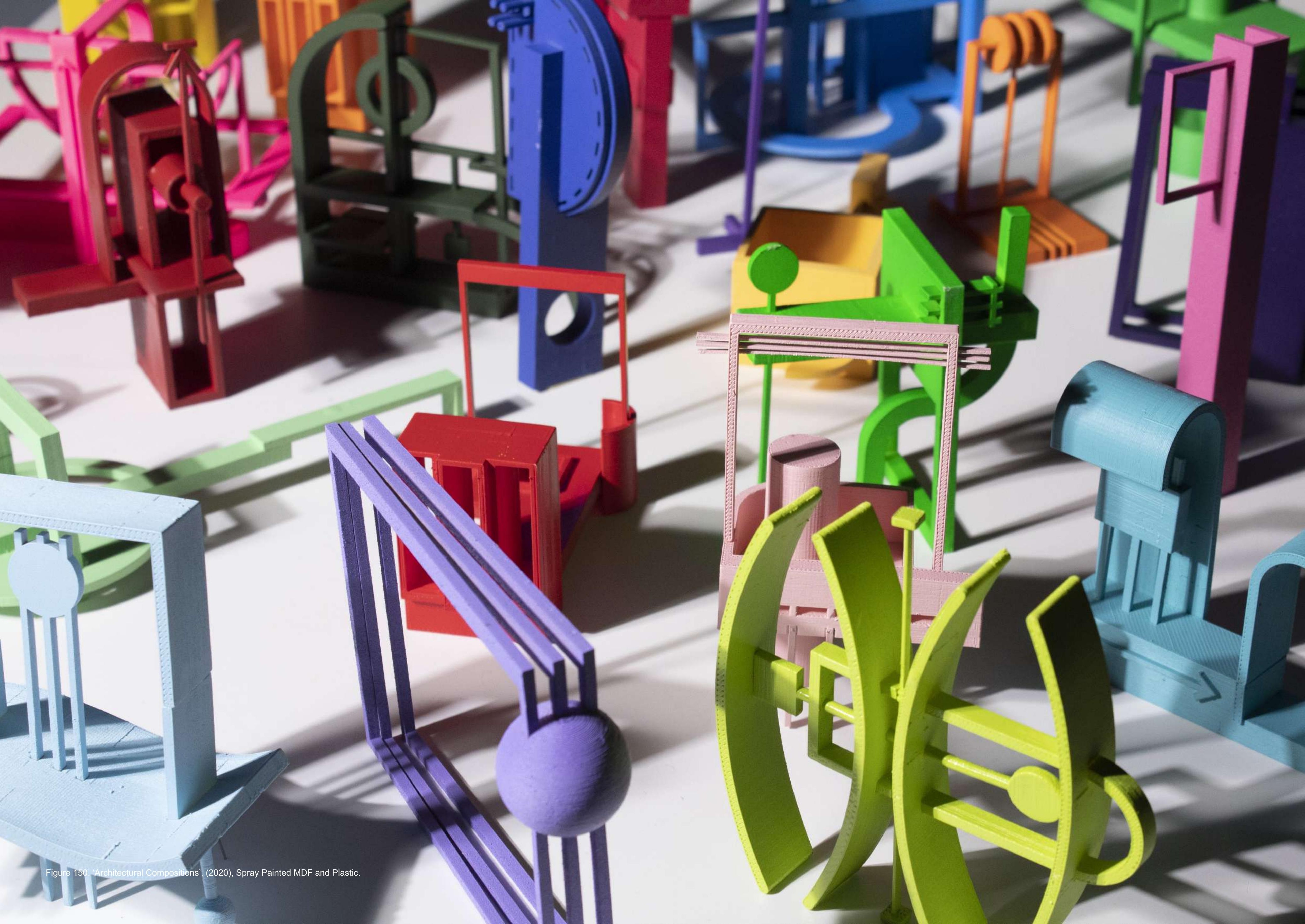




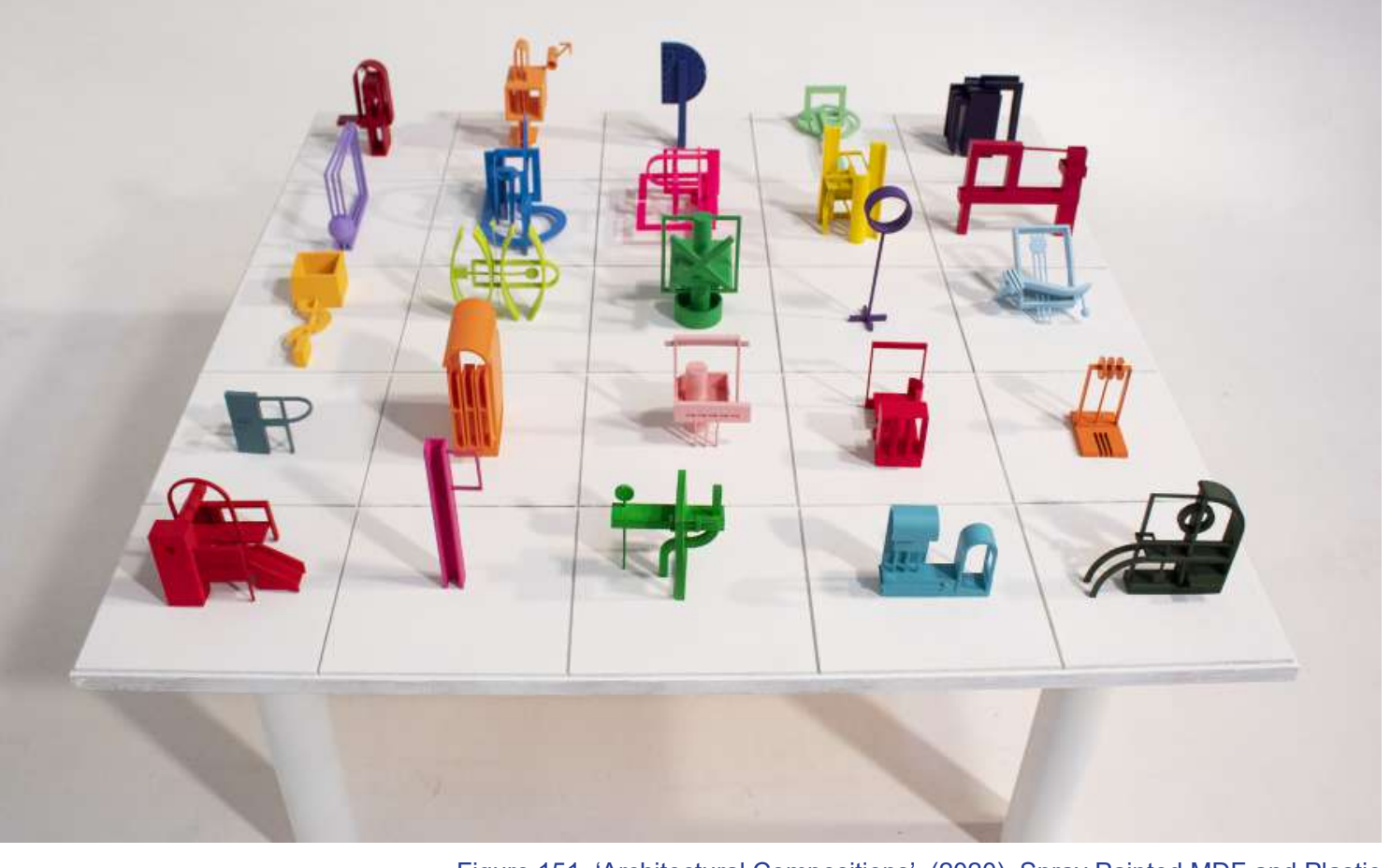

Figure 151. 'Architectural Compositions', (2020), Spray Painted MDF and Plastic

Spray Paint: Thirteen of the colours were borrowed from friends and left-overs in the workshop, two I already owned, and ten I purchased. By borrowing from friends it can be seen as a community sharing resources resulting in less consumption and more sustainable, locally supported production. 


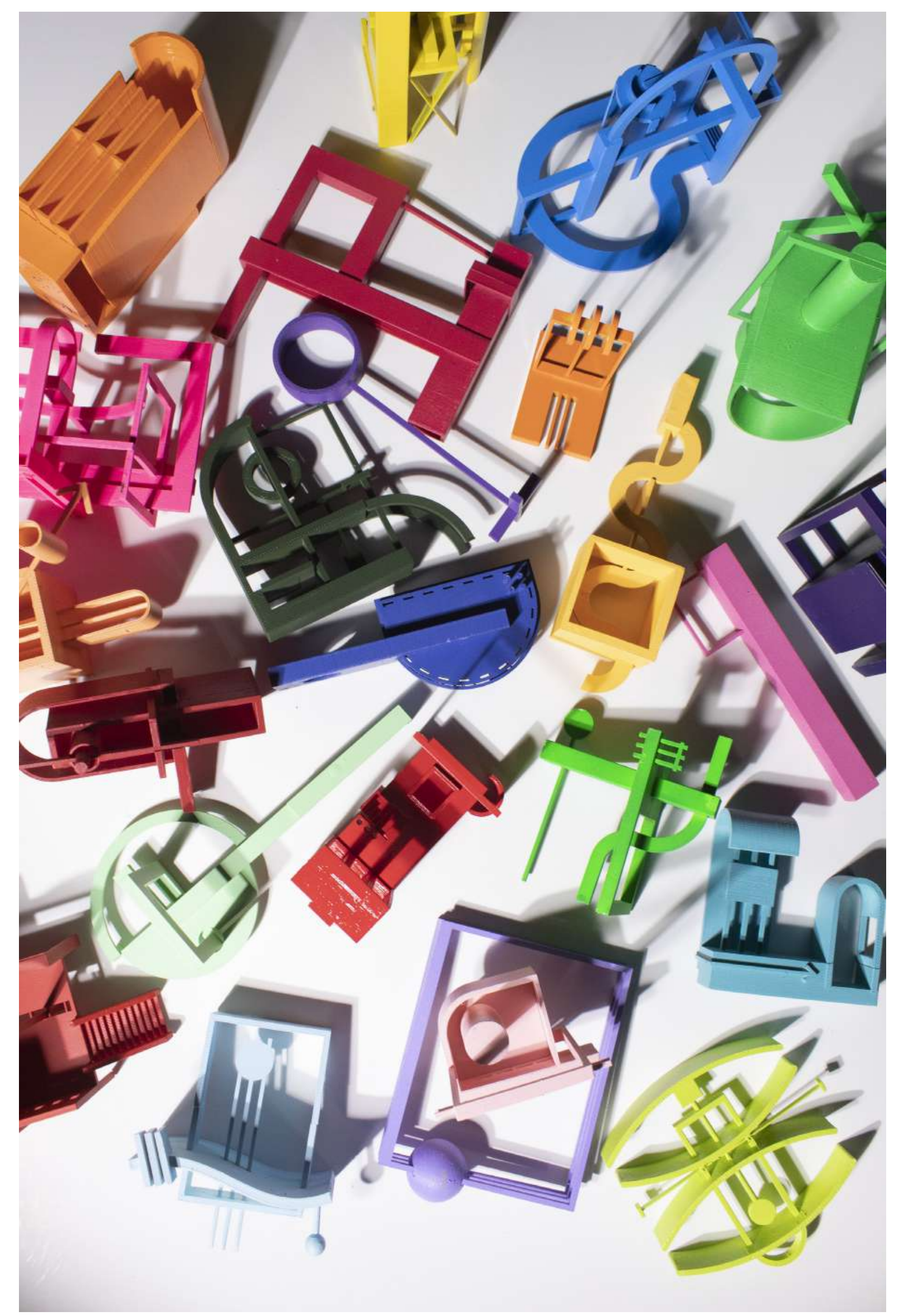

Figure 153. 'Architectural Compositions', (2020), Spray Painted MDF and Plastic 


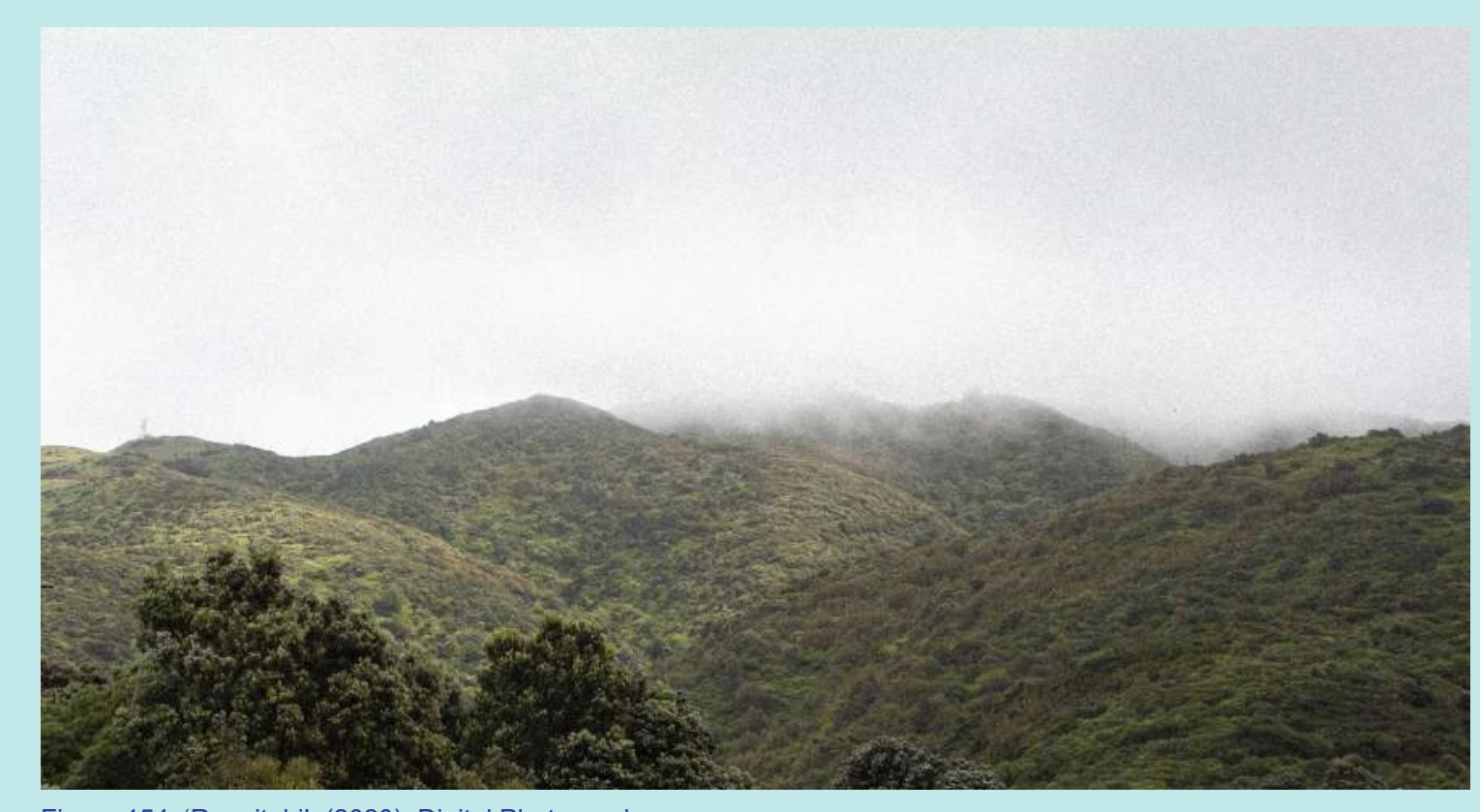

Figure 154. 'Rangituhi', (2020), Digital Photograph. 


\section{materiality*}

1:100 Tile models: When playing with colour and shapes I began to question materiality. It was important that colour and form was not just superficial paint or furniture but a concrete part of the building. Tiles allow an interior and exterior surface treatment and come in many shapes, sizes and colours. This saw a paper model develop combining both colour and shapes from previous models with an architectural material.

This developed the previous forms of the paper models with the composition models and refined both with colour/material. The model was also created in parts which contribute to the whole design, remaining consistent with the elemental composition of architecture.

The tile model enforced that tiling the whole building is not as silly of an idea as it first sounded. It is the only option I could think of which successfully applies colour to the whole building without being superficial. The colours have a de-saturation which remains calming and complementary to each other. If one colour was too bold then it would come across too harsh and demand more attention than others (fig. $155,156)$. They need to have almost a desaturated filter allowing the colours to read as one family.

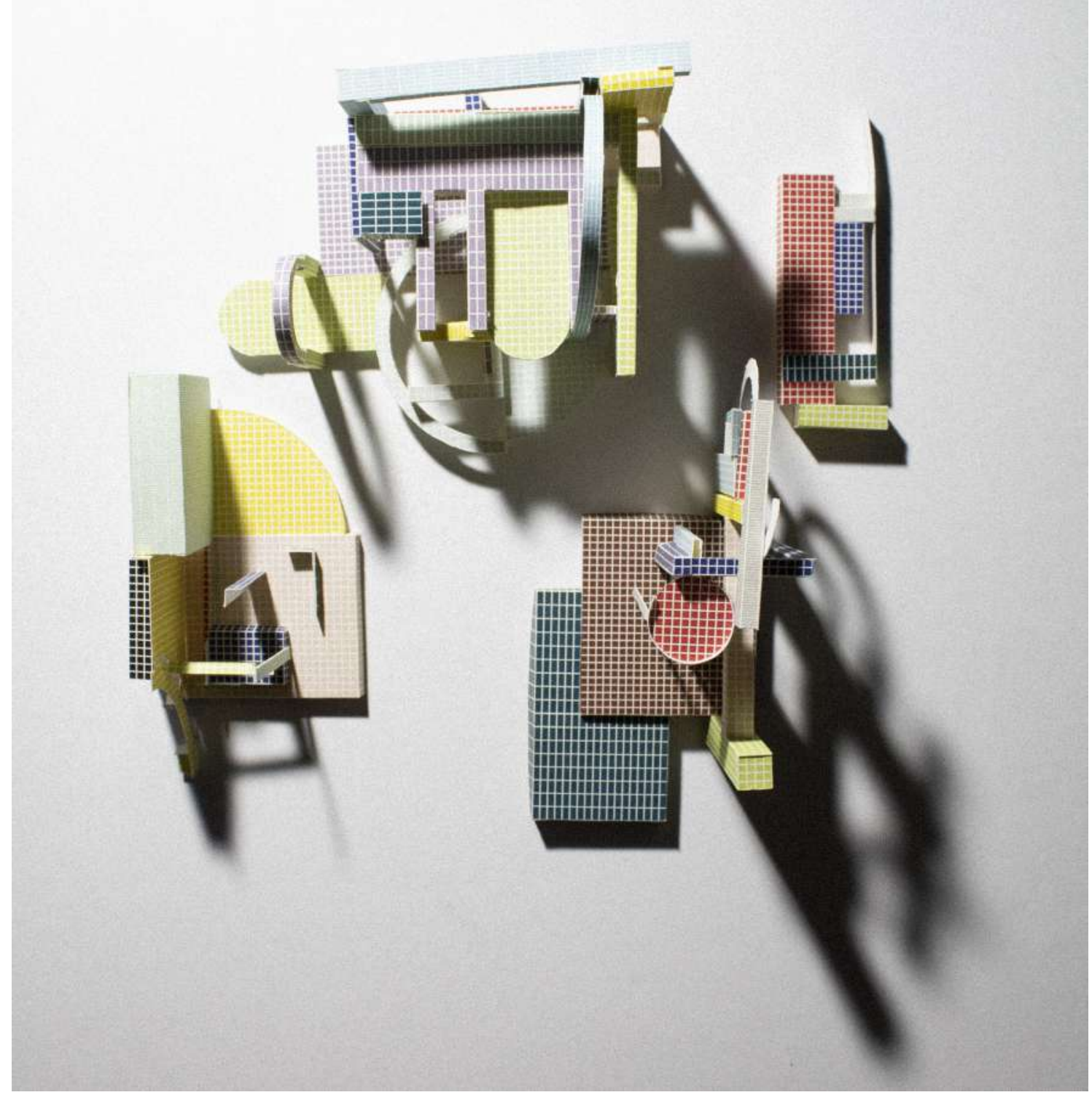

Figure 155. 'Tile Model', (2020), Tile Paper. 


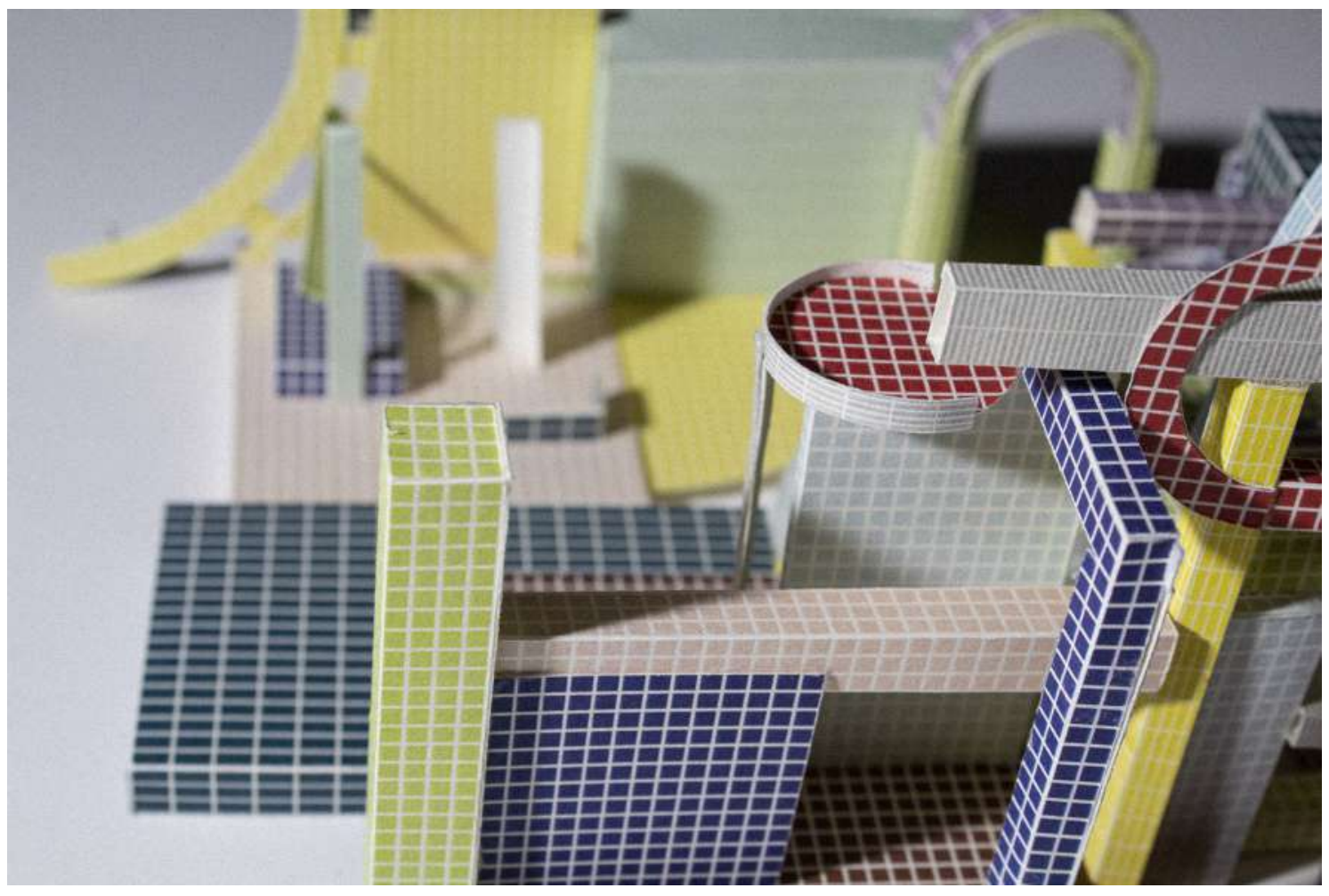

Figure 156. 'Tile Model', (2020), Tile Paper.

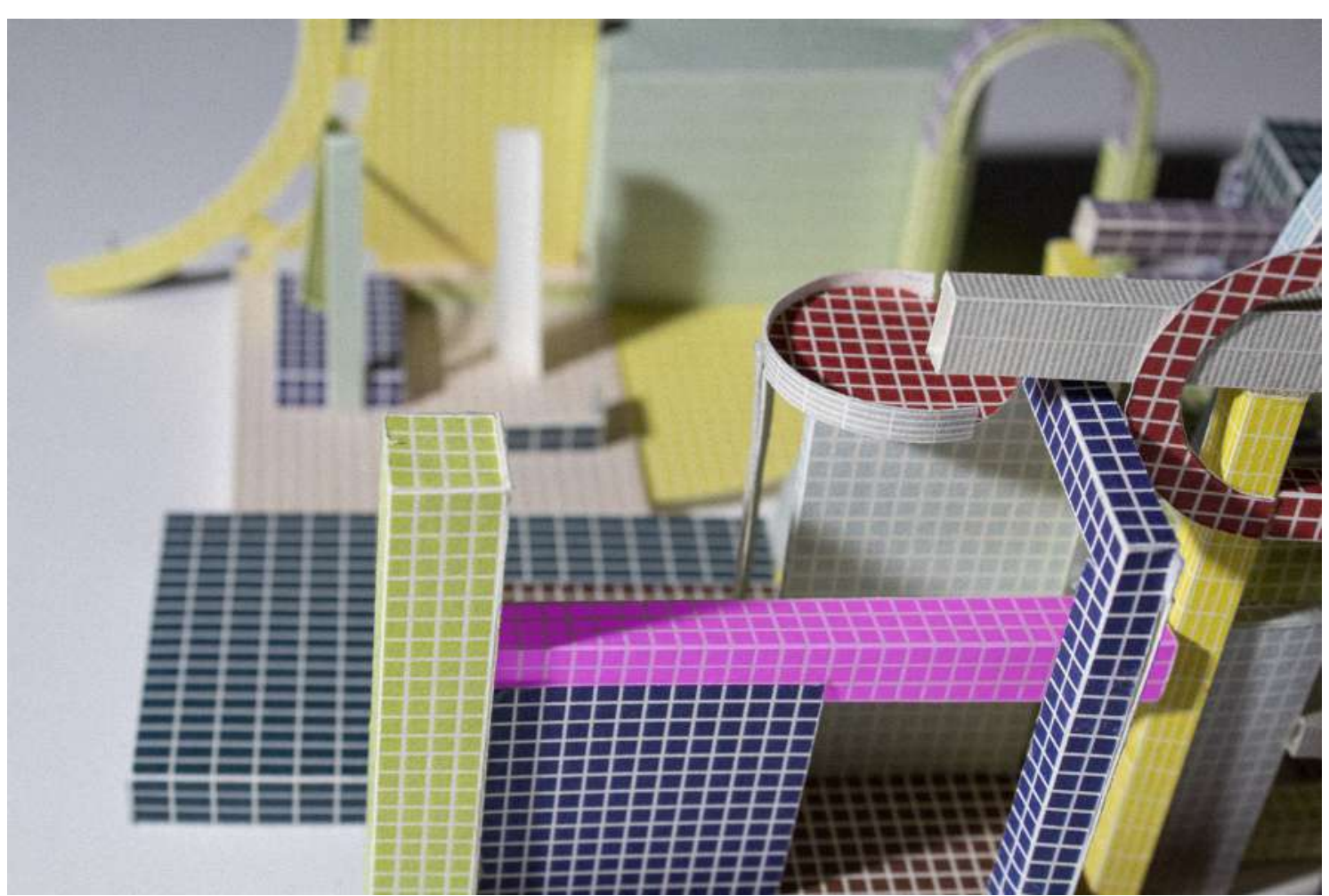

Figure 157. 'Tile Model', (2020), Tile Paper.
The tile colours have a balance of light, dark and middle ground hues. This variance in tone allows the darks to be expressive next to the lights and the middle tones to balance both. They are complementary, respectful and sensitive to one another. A layer of de-saturation allows the variety of colours to read as a collective.
The pink tiles here are too harsh and demand more attention than the other tile colours. This skews the architectural composition to focus more on the pink element than the others. The architecture reads less as a collective and more as individual elements with a pink dictator in sole control of the composition. 


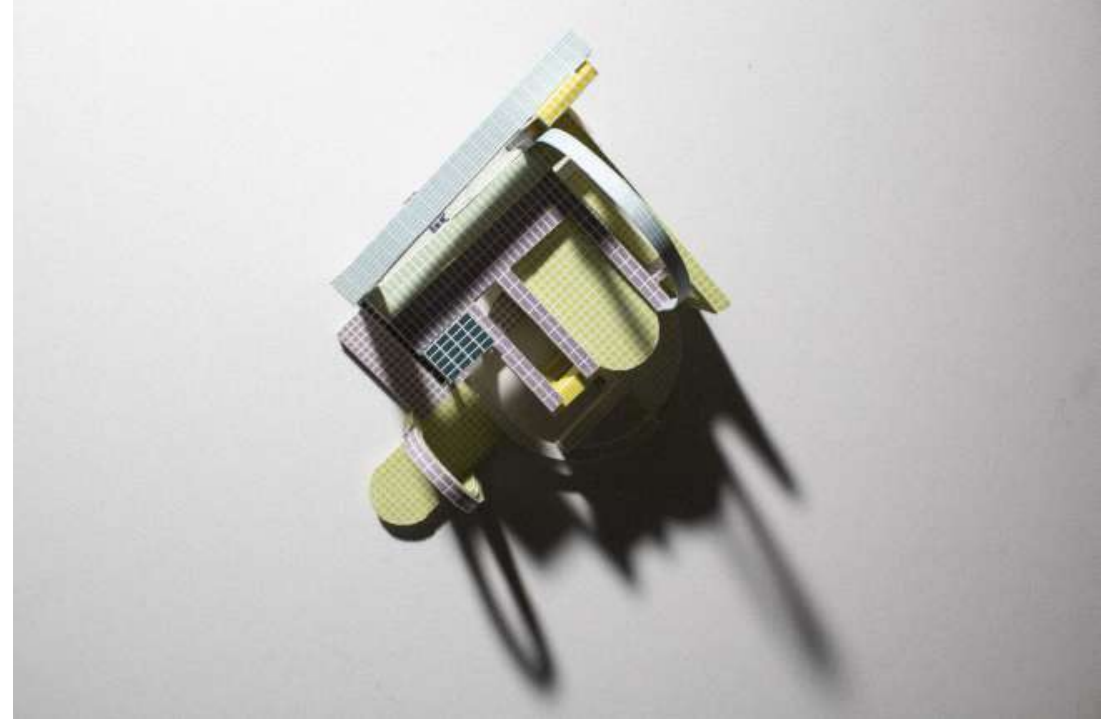

Figure 159. 'Tile Model 1', (2020), Tile Paper.

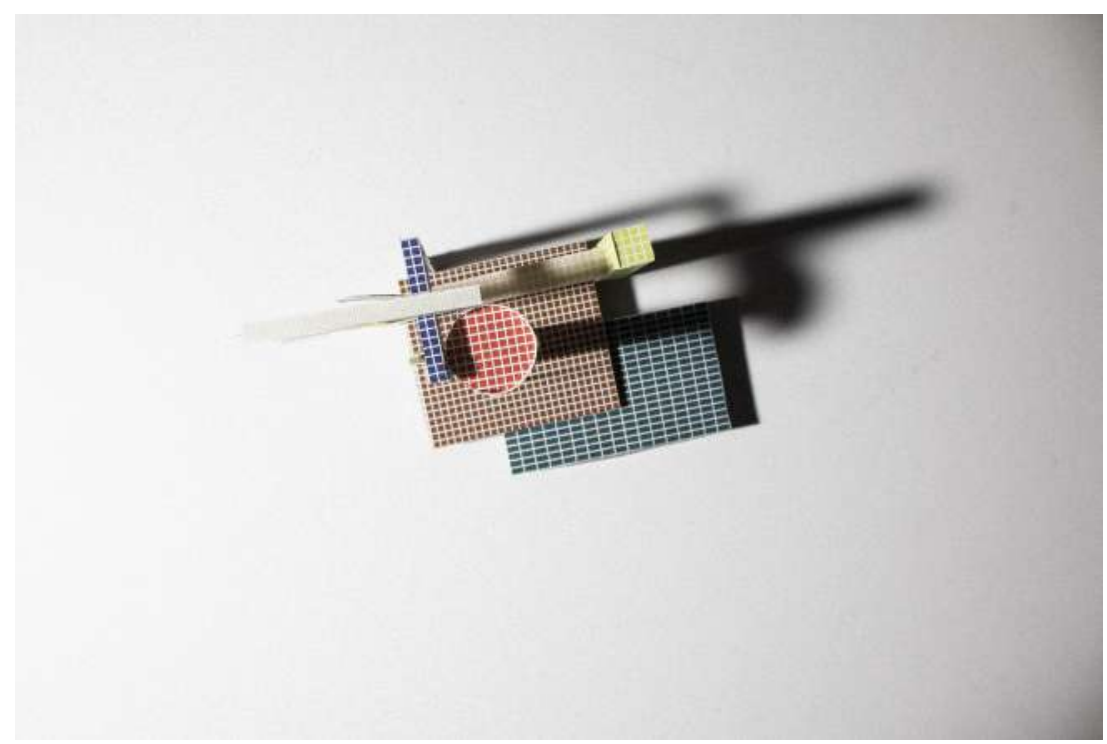

Figure 160. 'Tile Model 2', (2020), Tile Paper

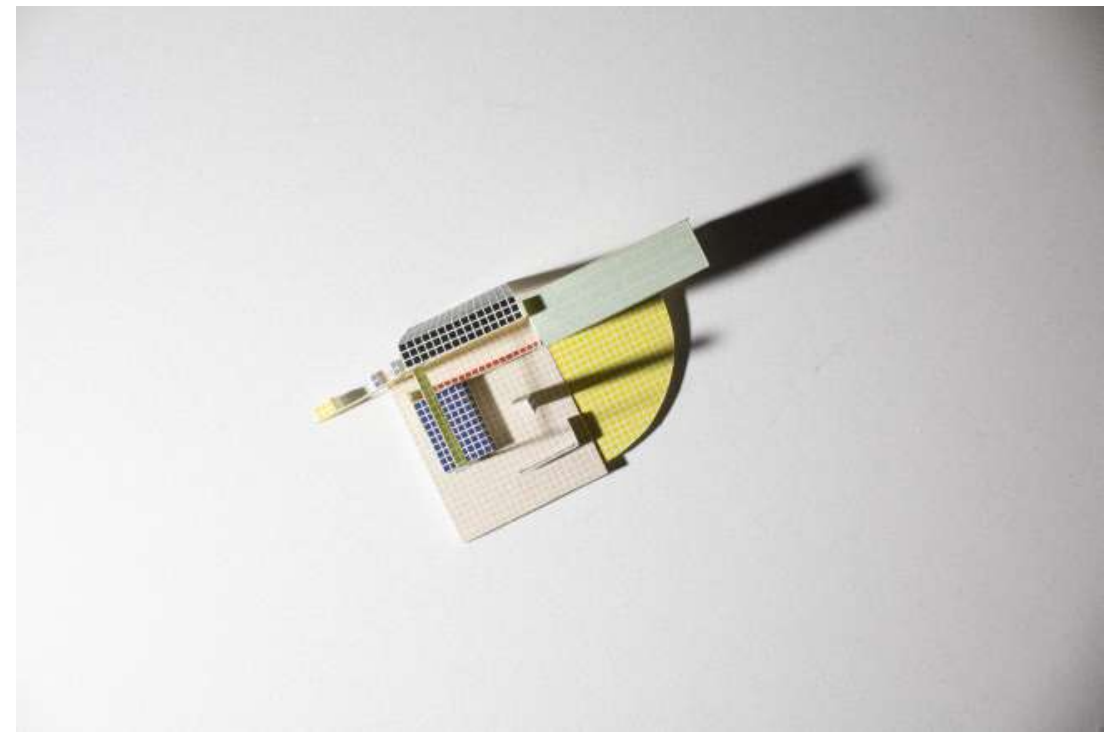

Figure 161. 'Tile Model 3', (2020), Tile Paper- 


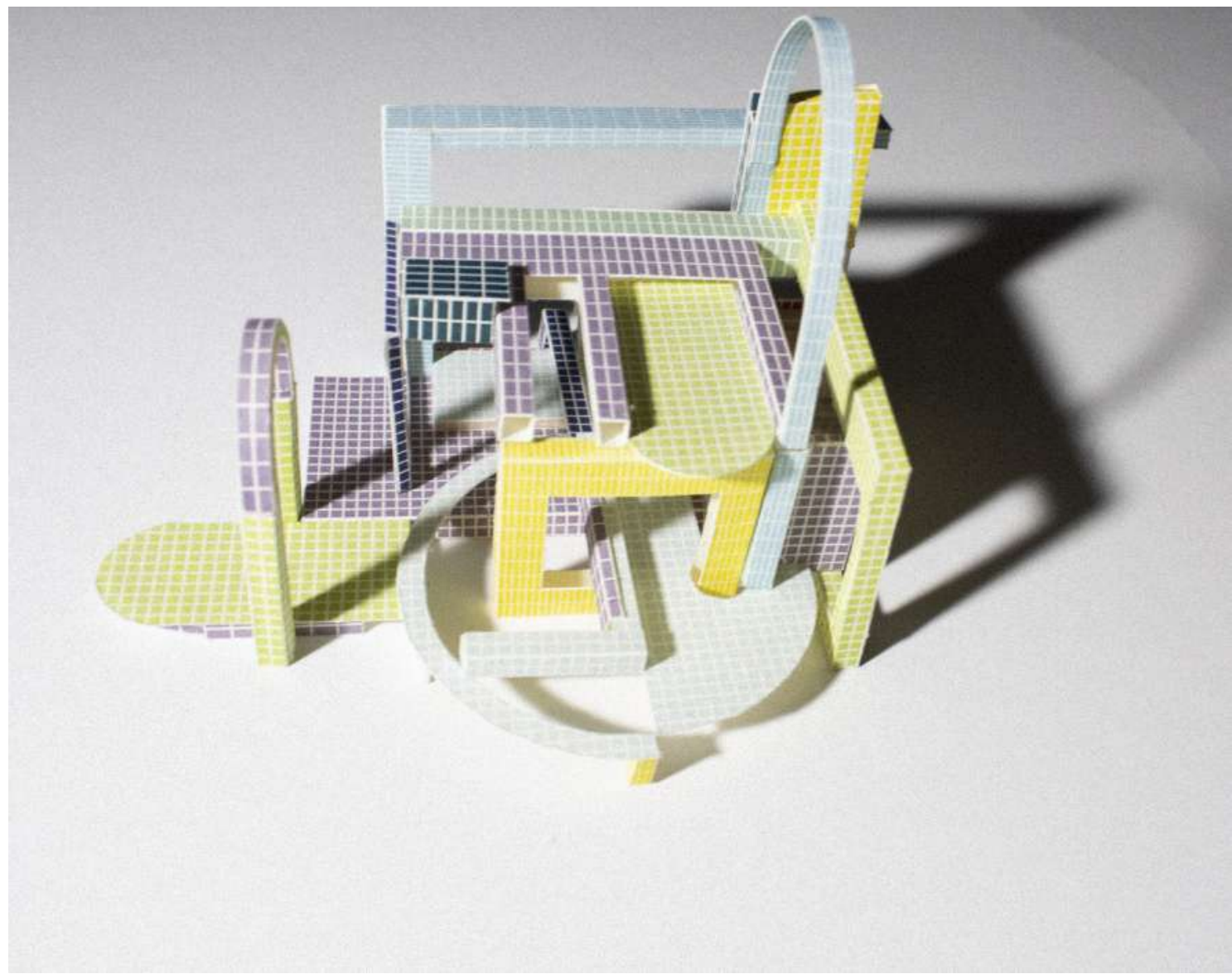

Figure 162. 'Tile Model 1', (2020), Tile Paper.

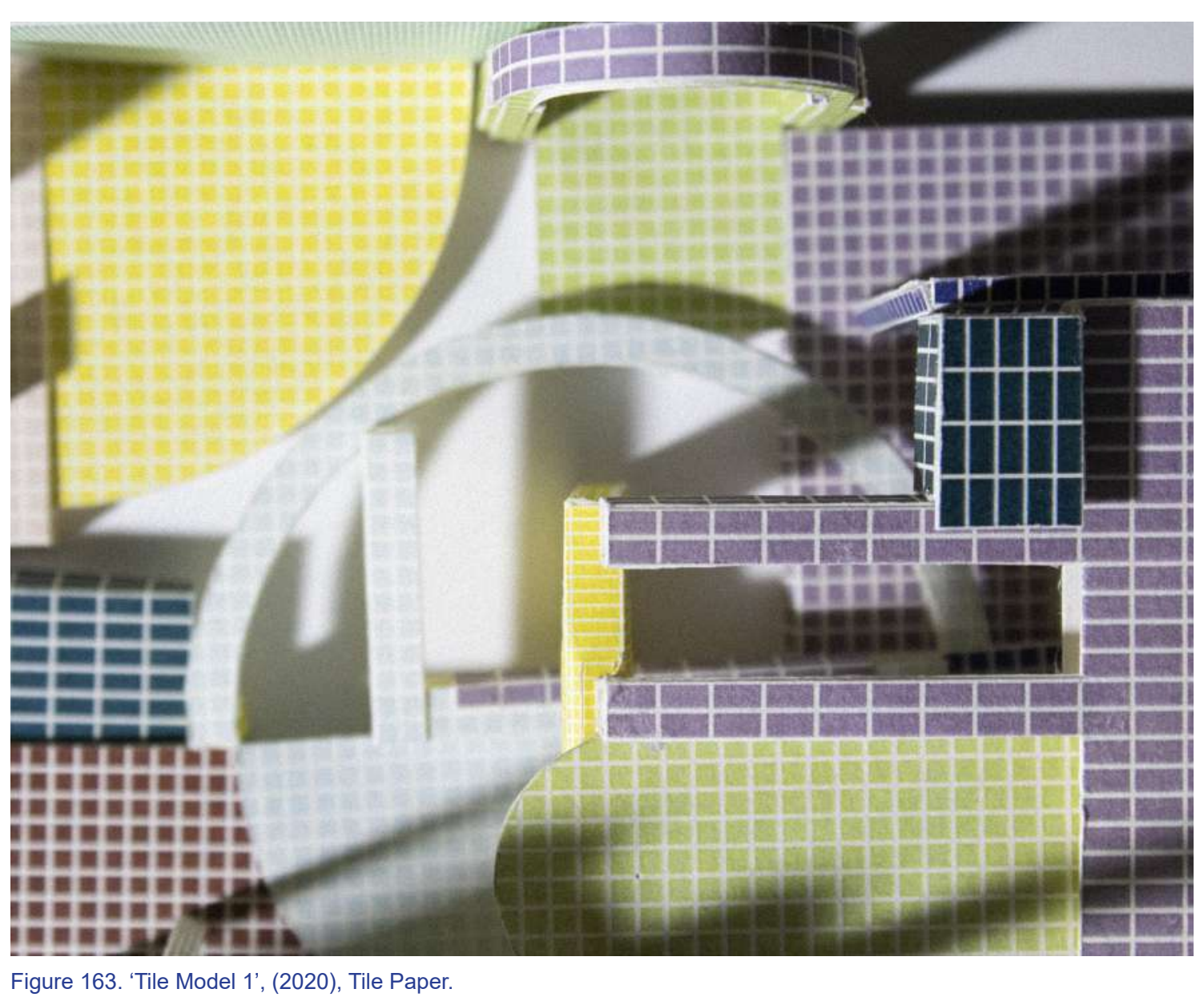

Figure 163. 'Tile Model 1', (2020), Tile Paper. 

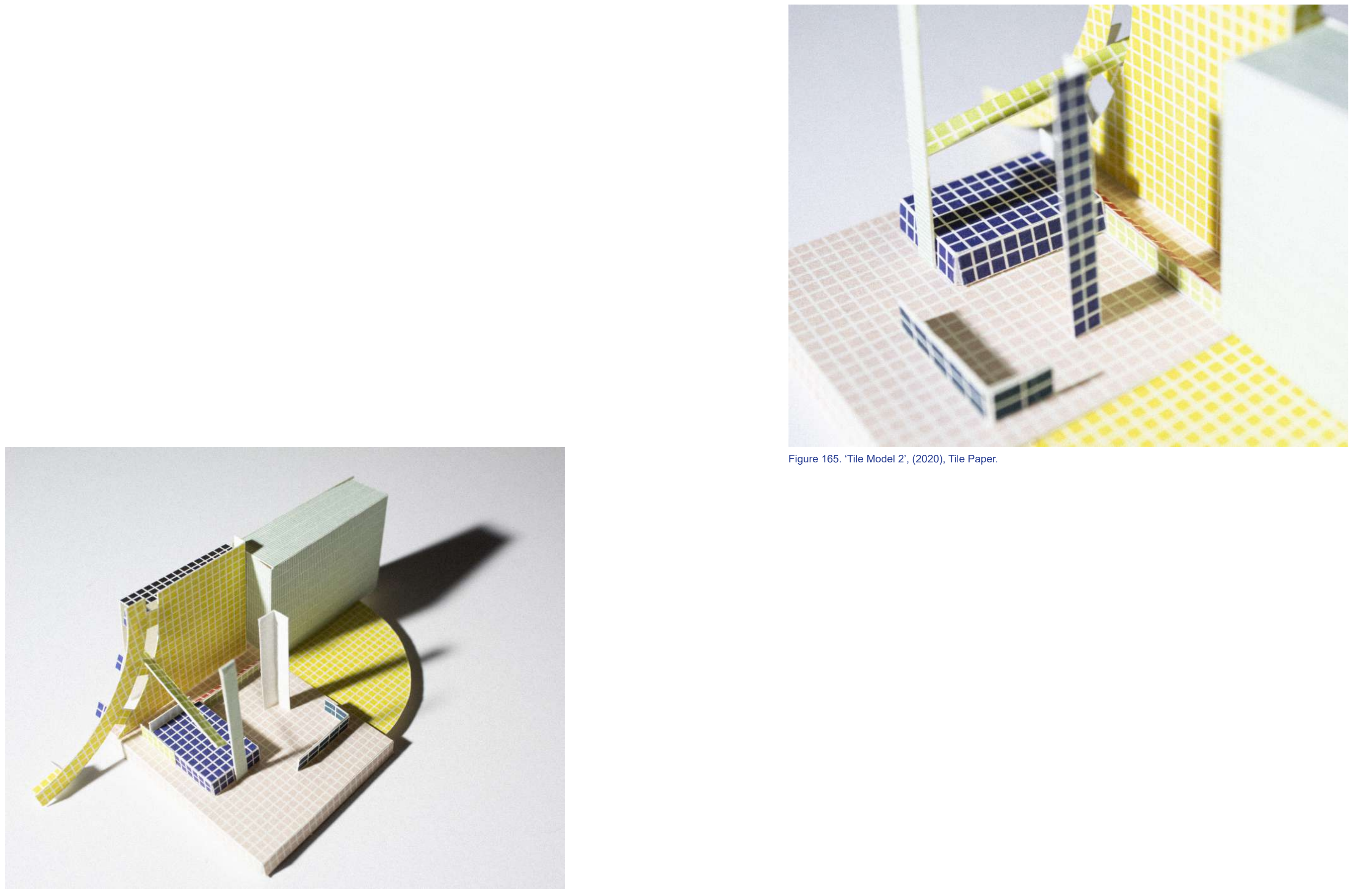

Figure 164. 'Tile Model 2', (2020), Tile Paper. 


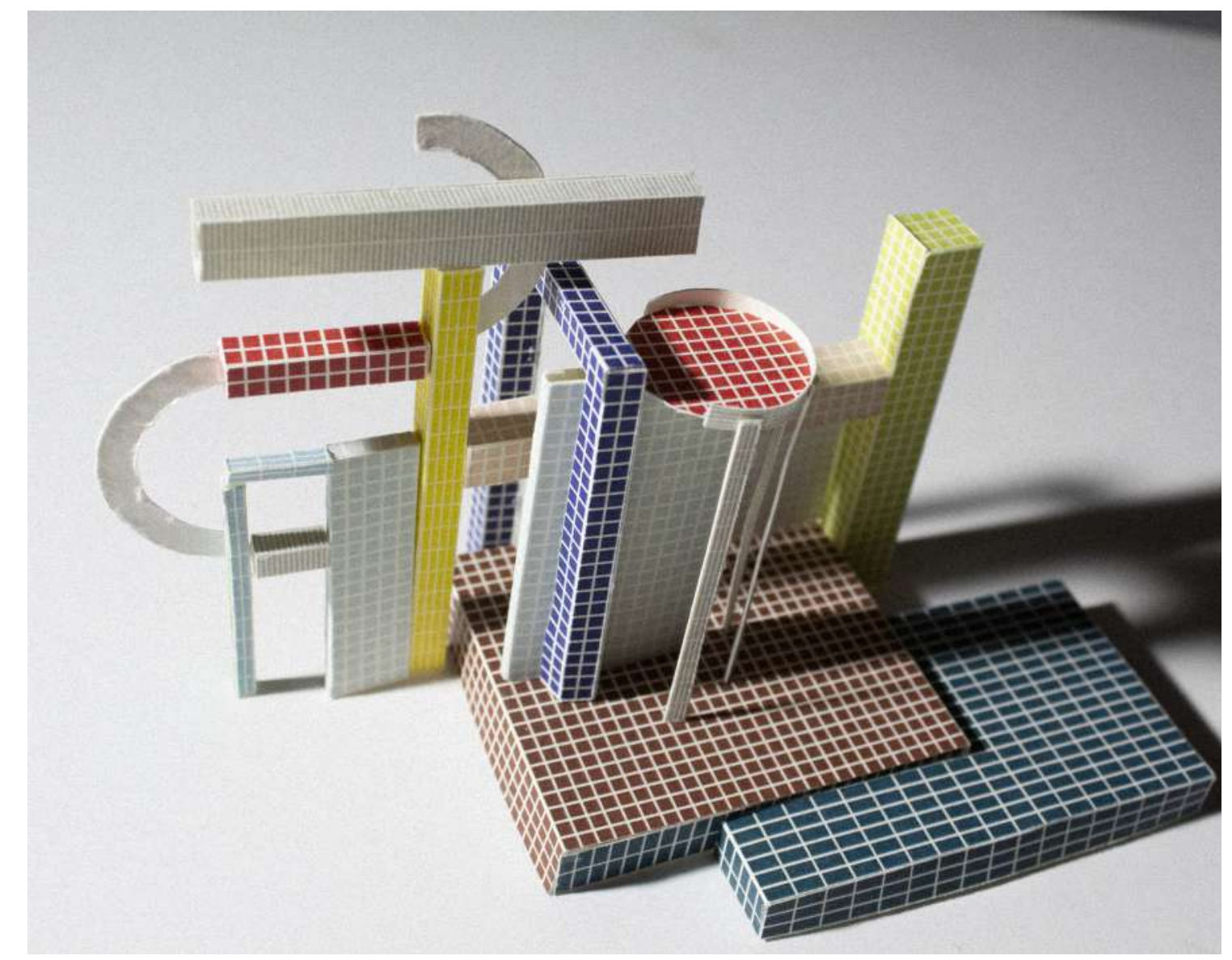

Figure 166، 'Tile Model 3', (2020), Tile Paper.

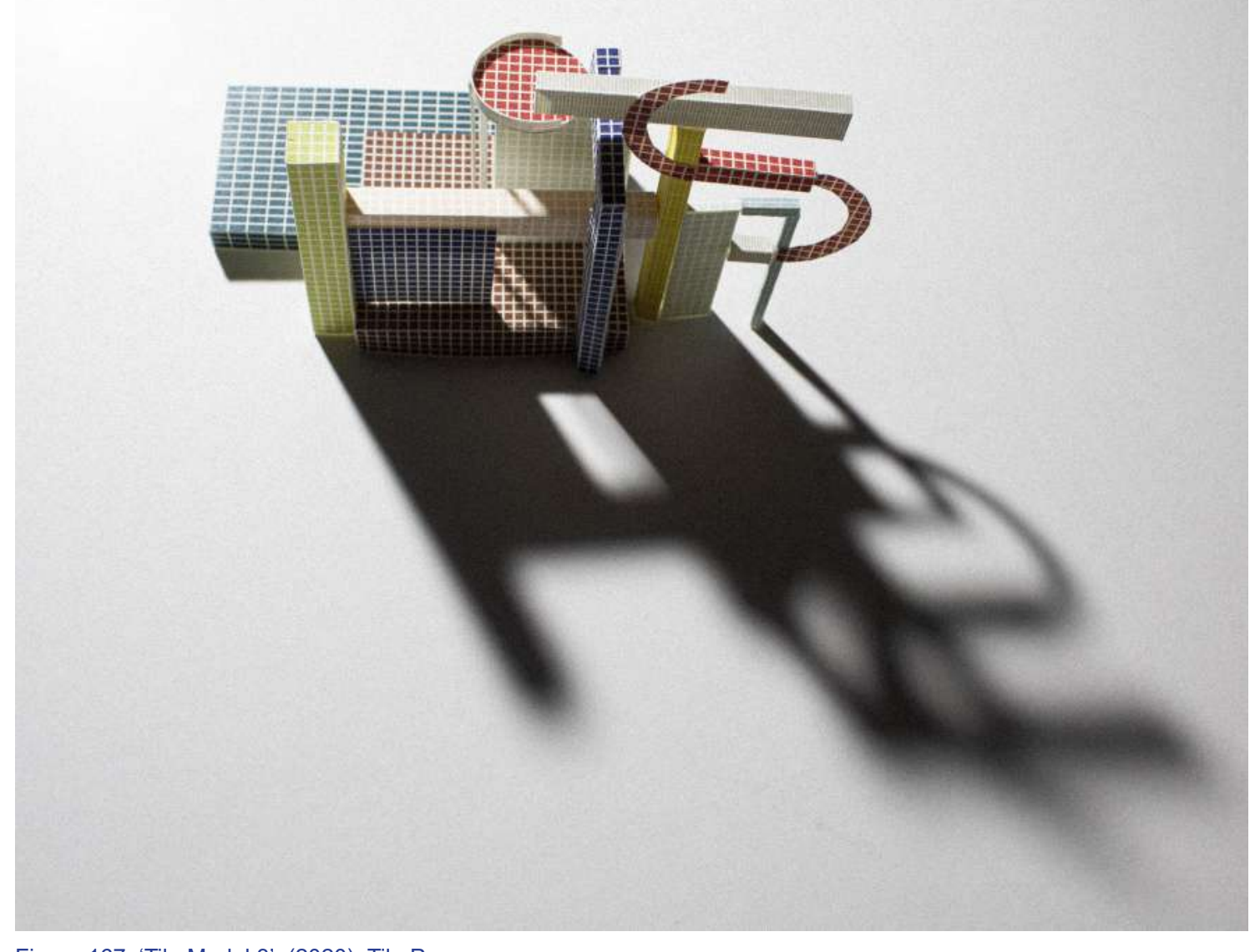

Figure 167. 'Tile Model 3', (2020), Tile Paper. 


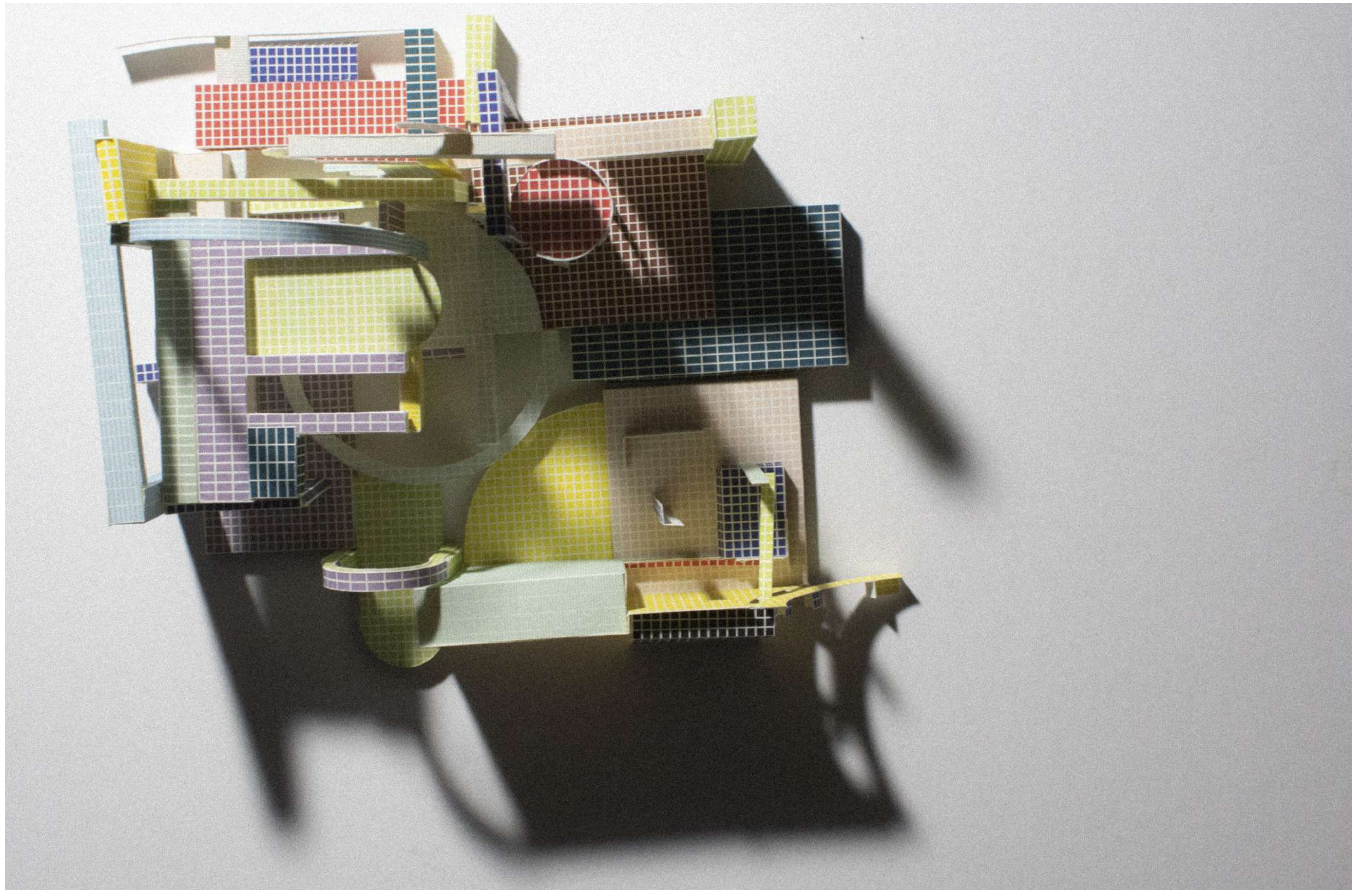




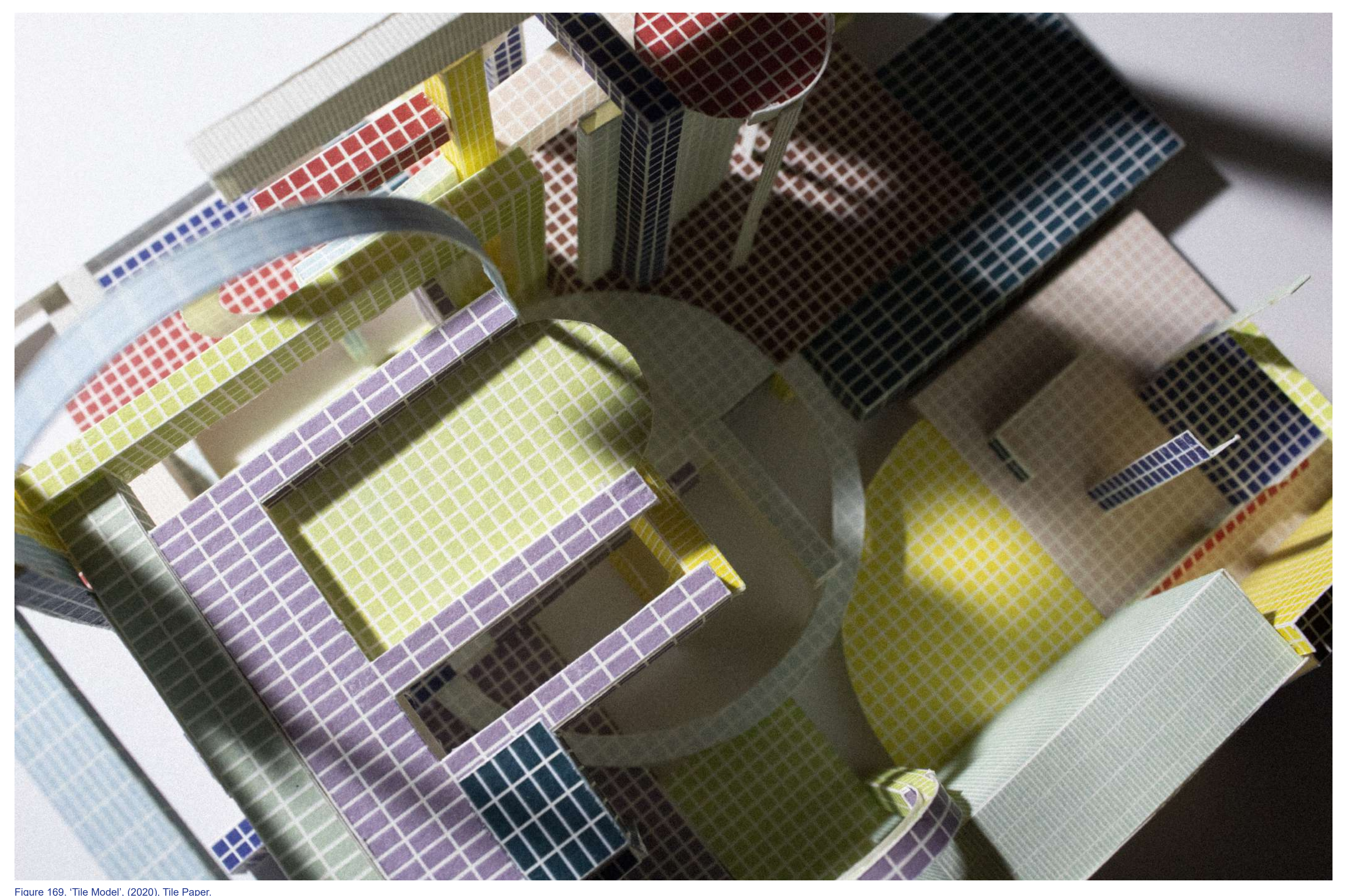




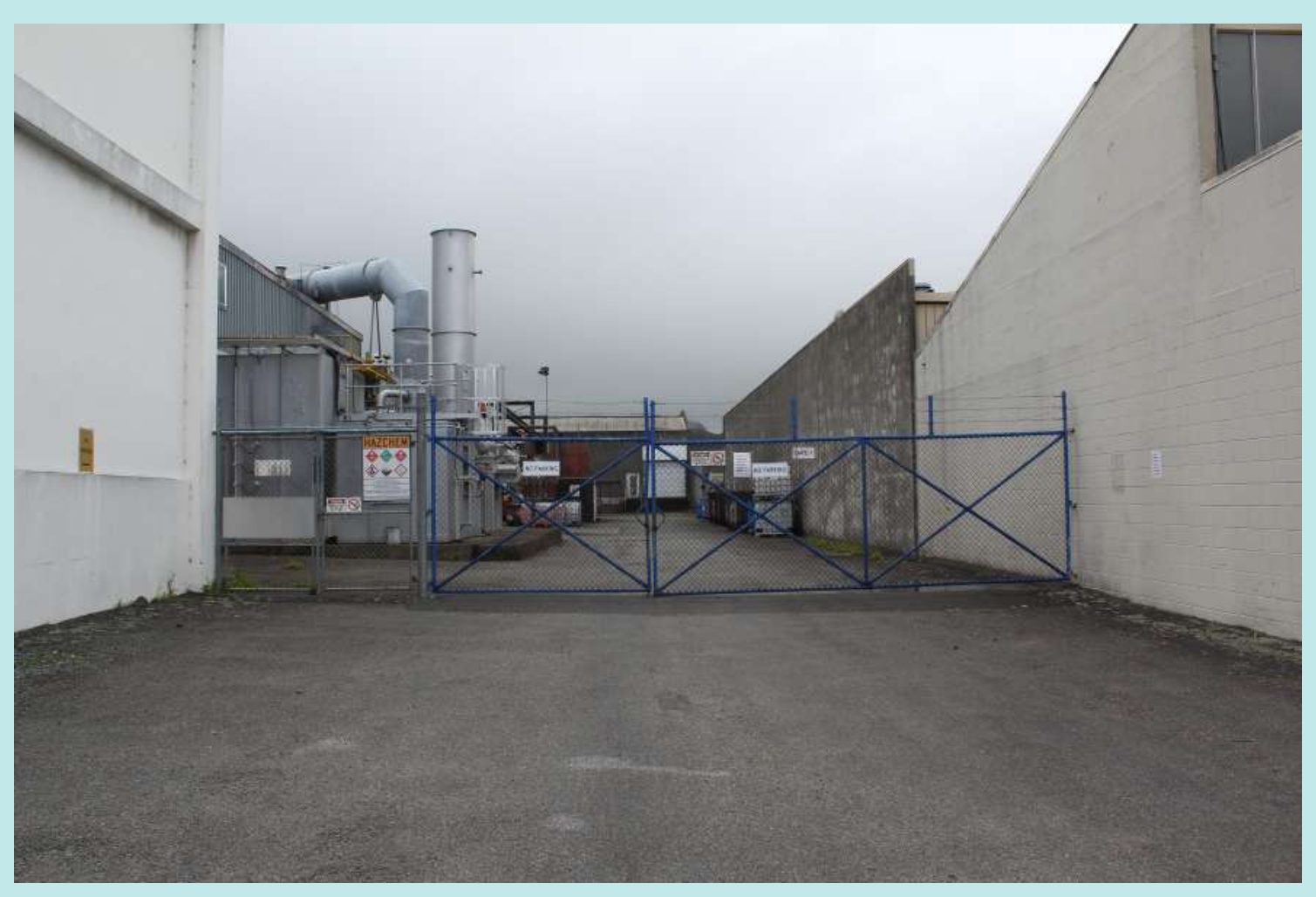

Figure 170. '25 Prosser St', (2020), Digital Photograph. 


\section{Prosser St*}

This design puts the compositional narrative to test. Like the previous site, it is located in the heart of Porirua's industrial area allowing the creative factory to thrive. This design refines both the form \& colour models and tile discovery with the creative factory motif.

The creative factory is designed as a personal creative outlet with the purpose to support individual creativity. It understands the intense uniqueness of the creative voice and strives to provide diversity of space, colour, form and purpose to suit a range of personal creative needs. It focuses on local unique production rather than mass production which is a more sustainable approach to creation.

With the ethical aim to develop local craft and creative freedom the factory will be home to workshops and studios of many kinds. It should promote learning opportunities for creators alike to learn new crafts allowing a mentor atmosphere to emerge. This program is similar to a craft market just indoors and includes workshops, housing, studios, gallery's, cafe's and anything else the local community would need for their personal crafts.

Instead of putting the economy at the heart of the city it puts creativity. Instead of giving value to money it gives value to craft. Instead of applying wealth to capital it applies wealth to culture. Then we have the Creative City. Full of creative factories instead of industrial factories.

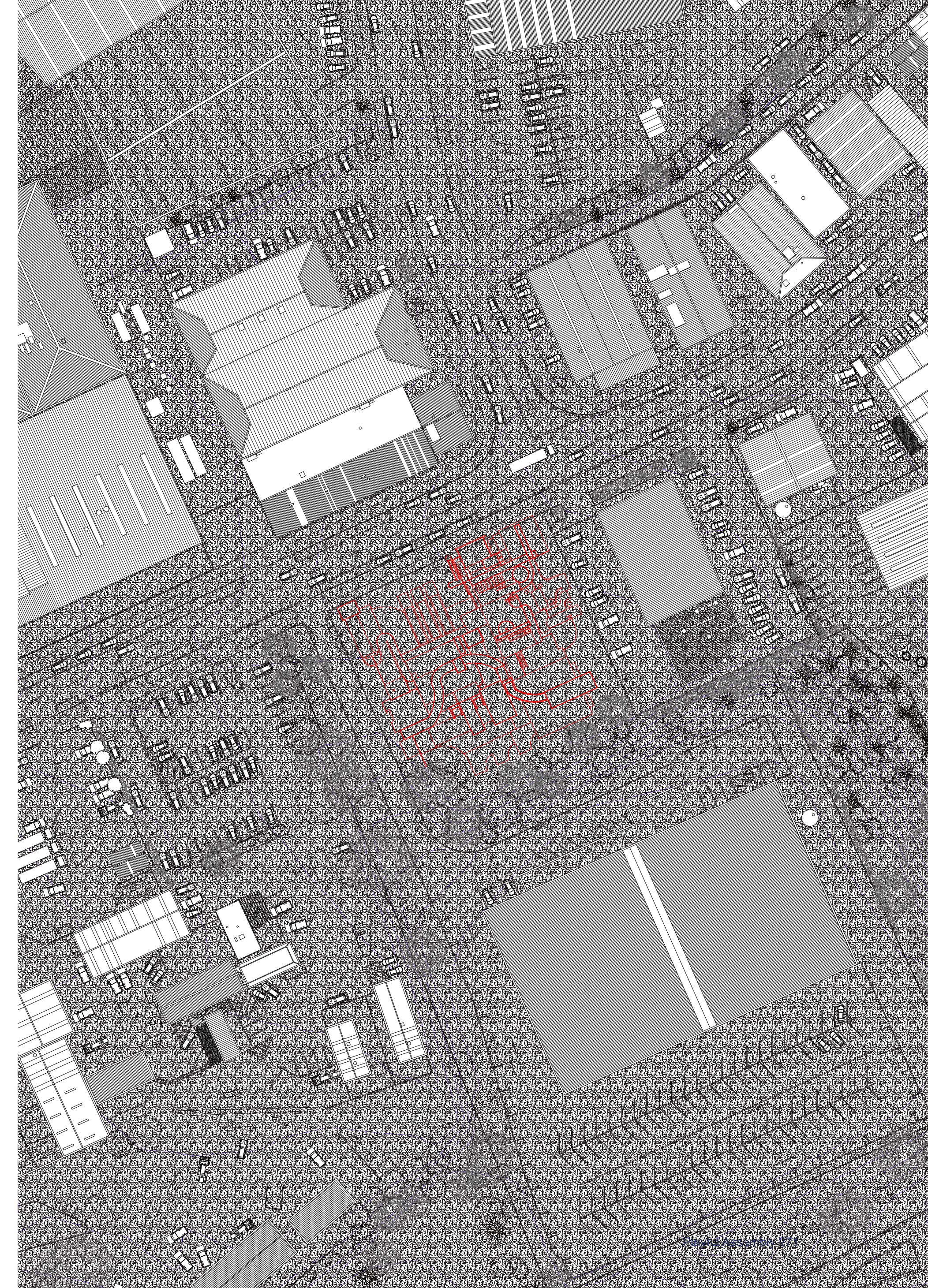


"Work gives way to an endless collective play in which all fantasies are ccted out"

(Constant, 1998, p. 9) 


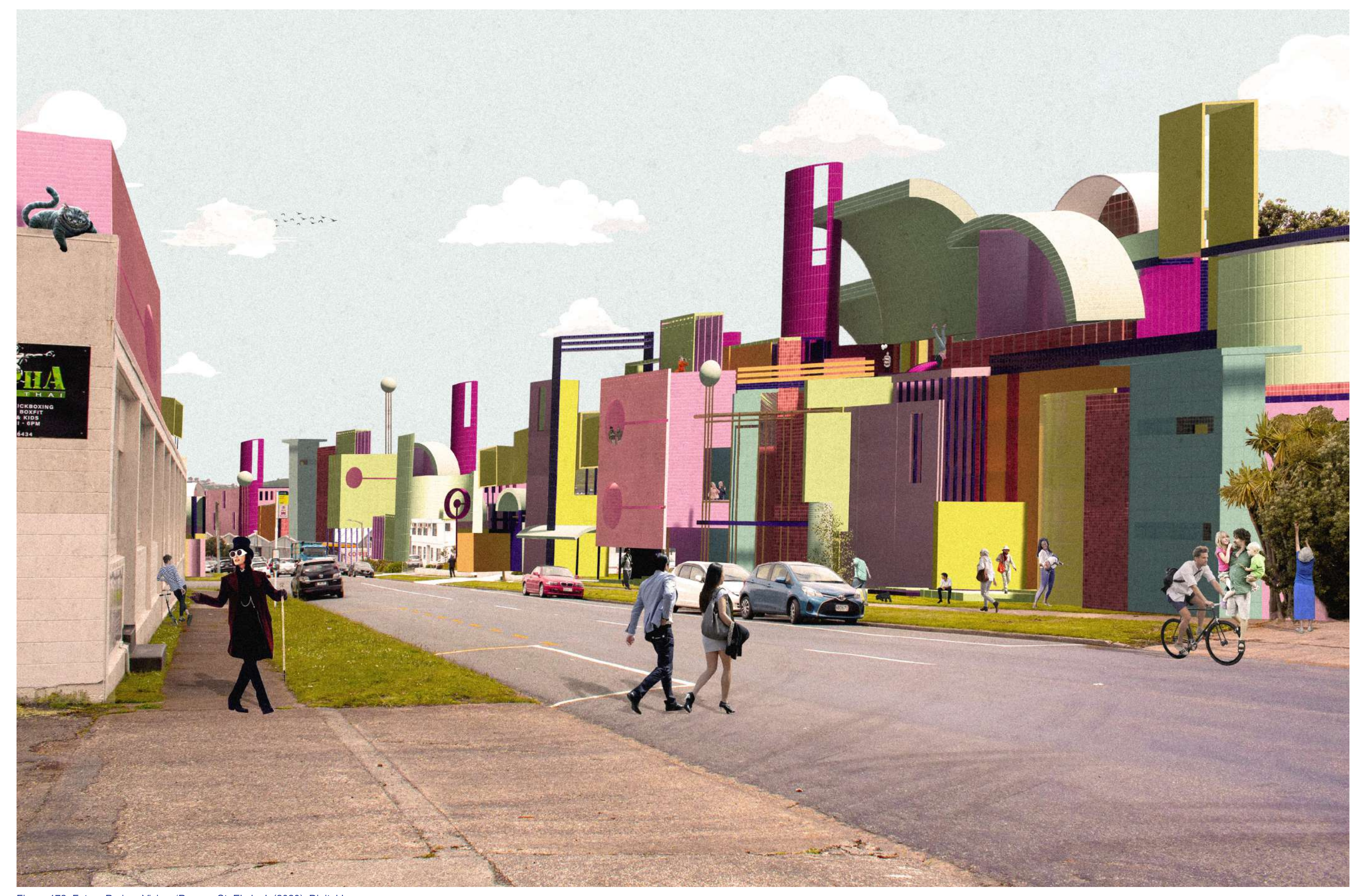




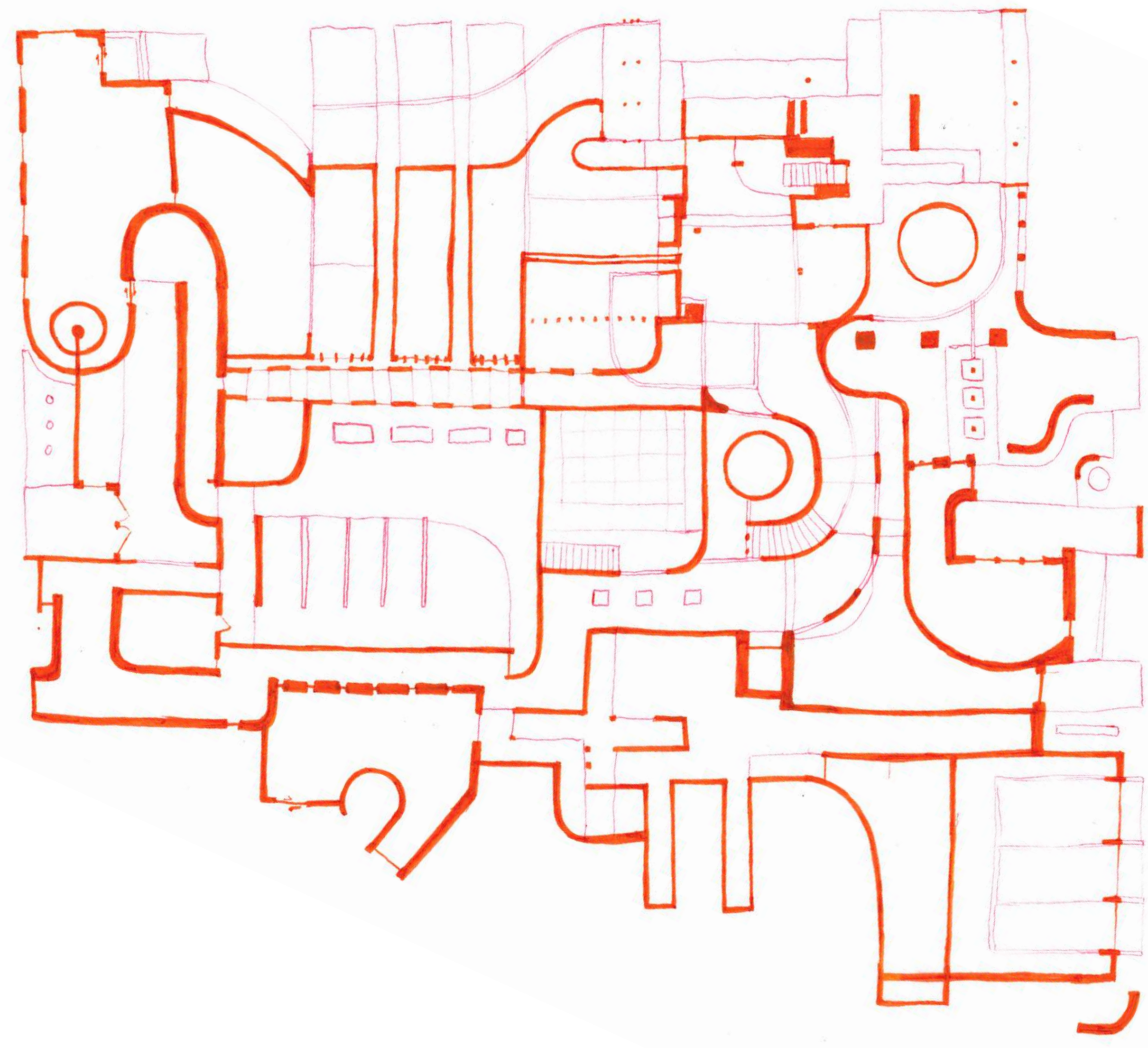

"Leisure time will be the only time"

(Constant, 1998, p. 9) 


\section{circulation*}

This maps the potential circulation of the building in a way which expresses movement. Caters for wandering, walking with purpose to almost breaking a jog, slow distracted walking and specific points people may walk to. This was done to develop the ground level plan as that is the most public and used level of the current design. I am looking for a dispersed type of movement, similar to a playground, where you can slide run jump and swing in a congested space.

It is interesting to see the design without the design but just the users. The users must exert the same, if not more, playful elements than the design. The design is there partly to promote this and encourage people to have more fun in their day-to-day by creating or observing creations. It is also a personal creation within itself, additionally promoting the final product of creation as well as the creative process it holds within.

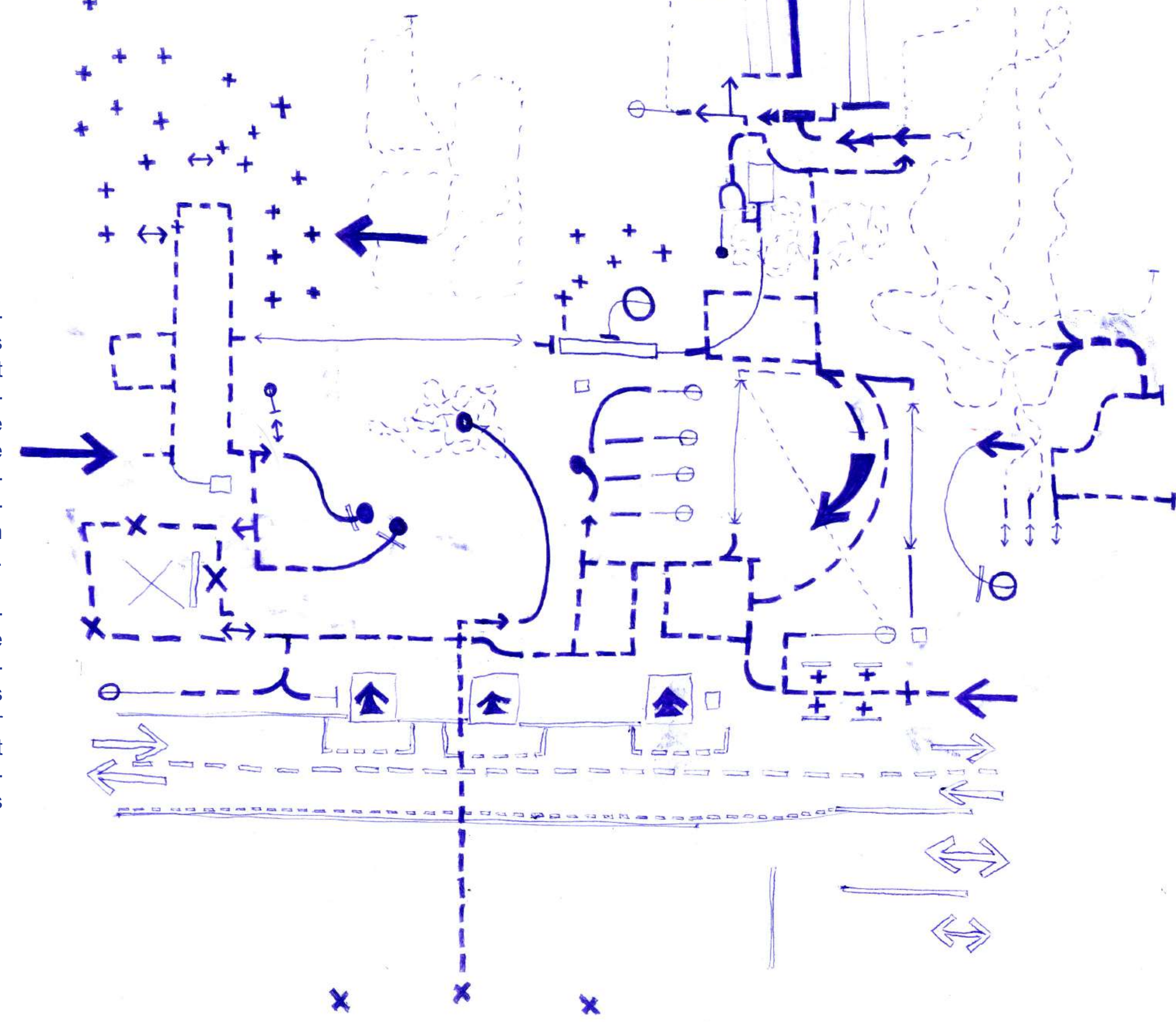


The real challenge isn't the dream, but working out if the dream is real?

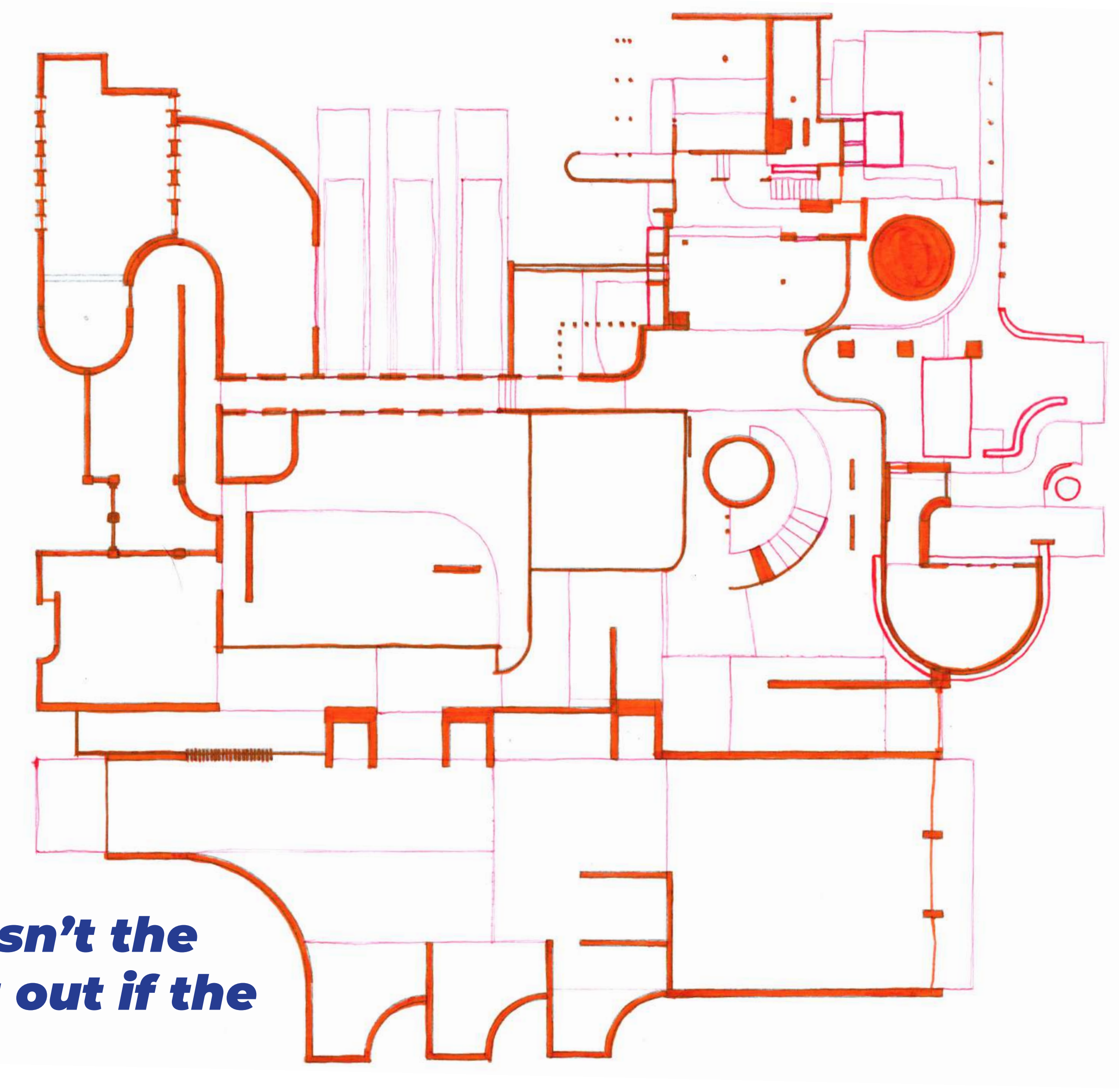



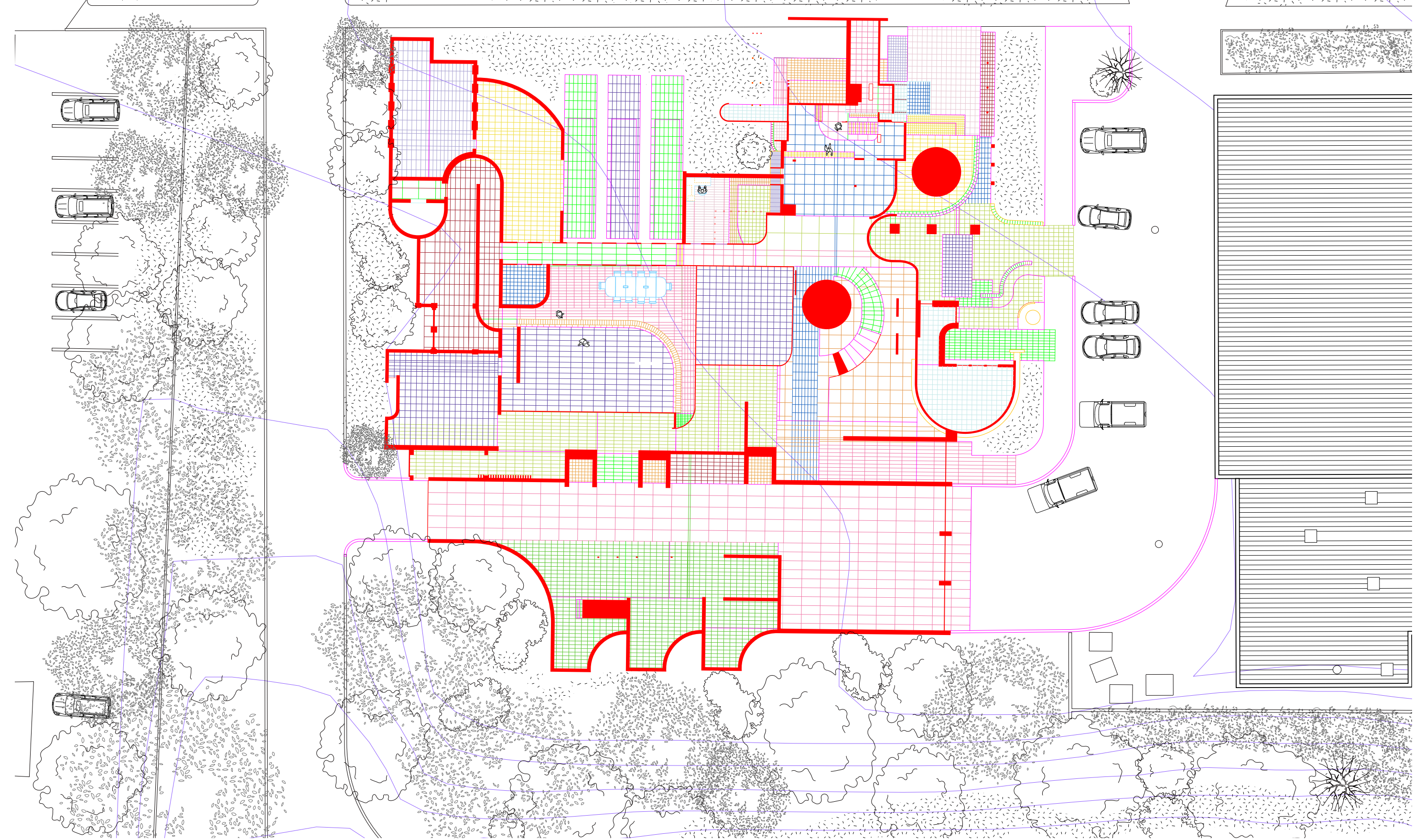

Figure 176. 1:200 Plan, '9 Prosser St, Elsdon', (2020), Digital Drawing. 


\section{sectional}

\section{composition*}

The section becomes crucial for showing the playful nature of subtle and dramatic changes in floor and ceiling heights. A hop, skip and a jump sort of level movement. The classic butter paper and pen allow quick iterations to develop from the digital model. The thick red pen makes it pop. It is important to make it pop, so it remains fun, exciting, surprising while developing into a sophisticated design.

I struggled to compose this design in section. The section provides a level of depth which I had not approached yet. The section also forces the architecture to be seen along one axis which I previously have found to be a negative component of the architectural compositions. The section therefore, puts emphasis on the level of depth to represent the formal complexity in the section composition.

The more successful compositions were the ones which balance verticality, depth and horizontality along with representing a range of intersecting geometries. There needs to be a mix of moments within the factory to give inhabitants options of the space they inhabit. Not all spaces can be seen in one section which, again, makes the sense of depth a crucial element in this composition.

The two refined sections (fig. 178, 179) provoke an unfinished architecture in a balanced composition. They question the static energy of composition and seek an architecture which is open to change. The architecture is presented as a base for its inhabitants to finish.
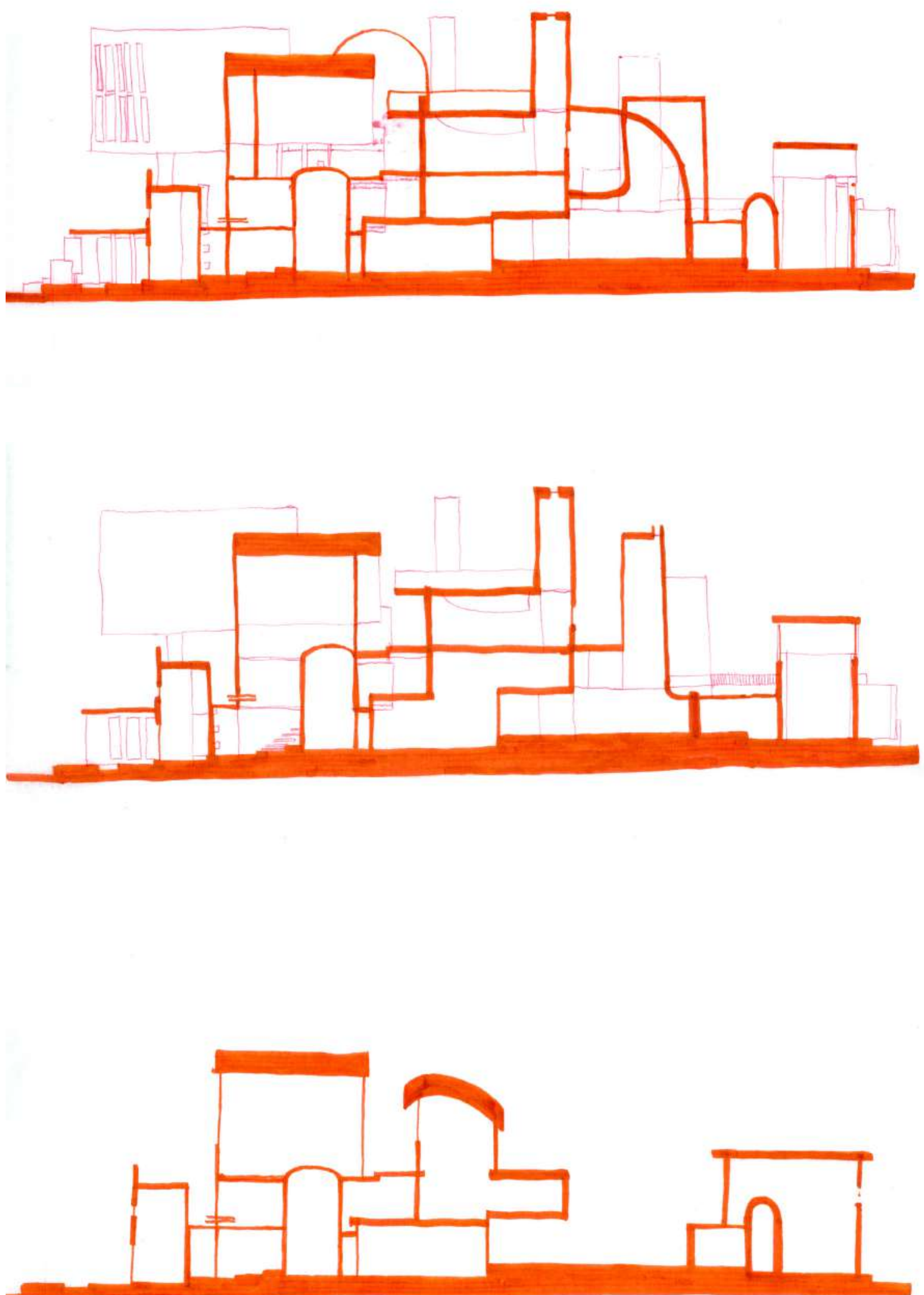


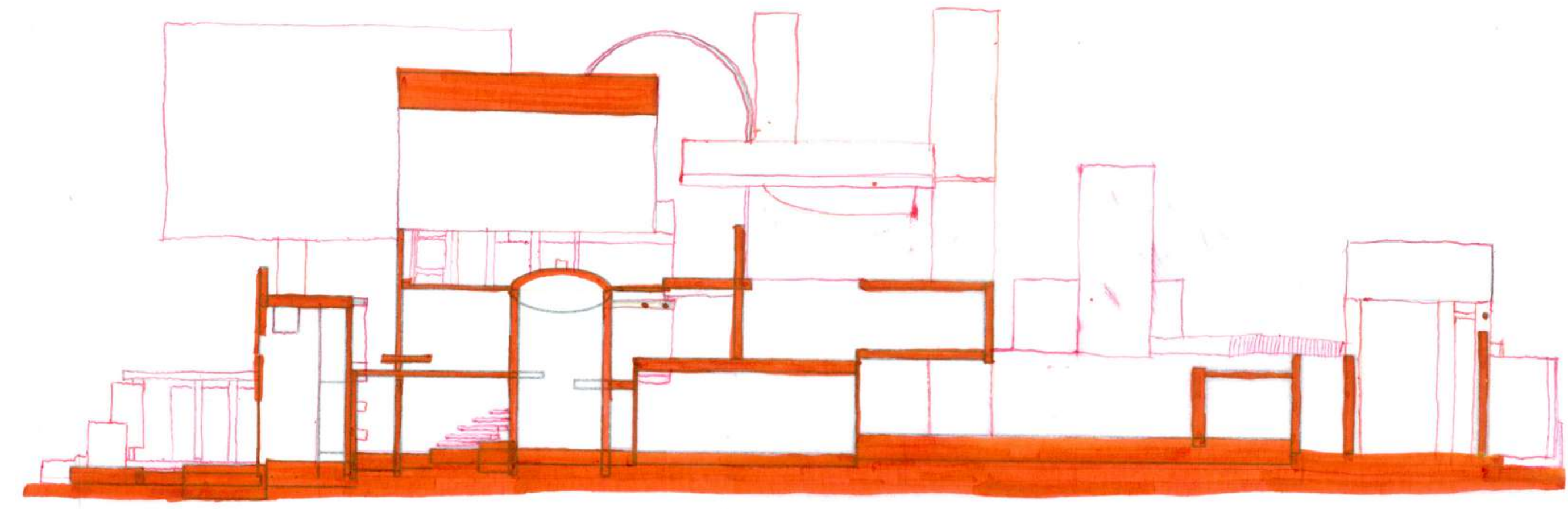

Figure 178. Long Section One, '9 Prosser St, Elsdon', (2020), Mixed Media. 


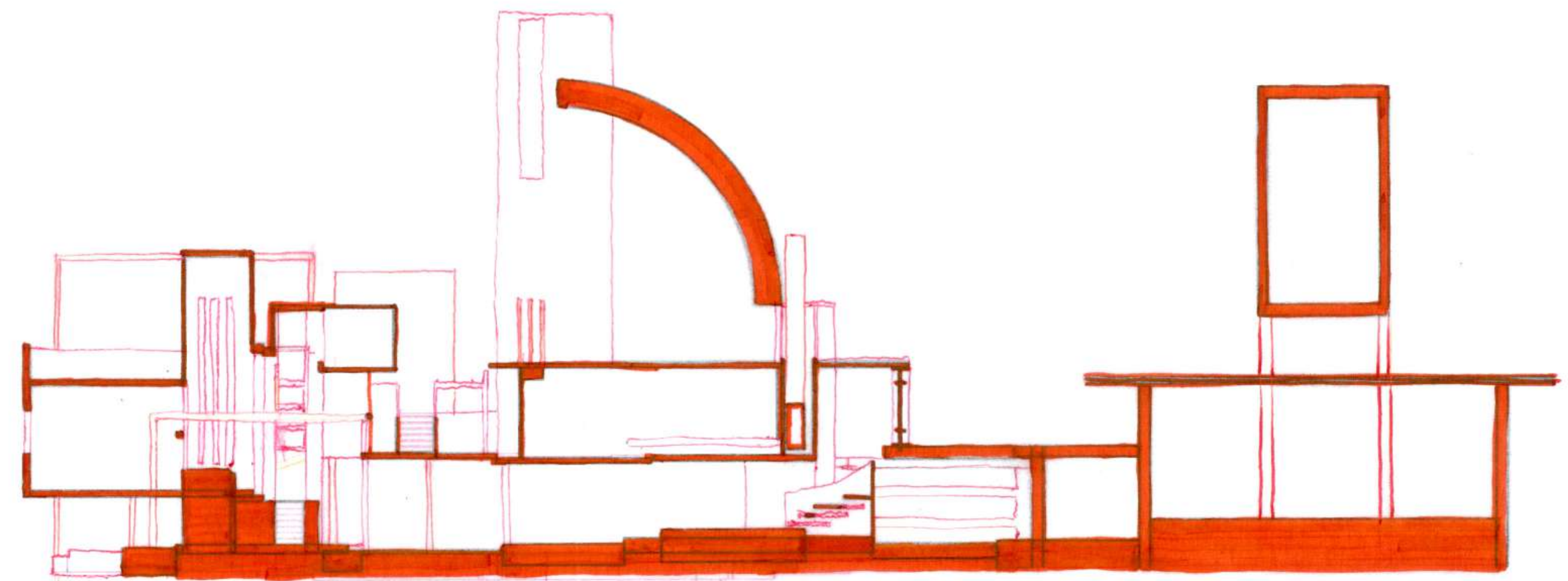

Figure 179. Long Section Two, '9 Prosser St, Elsdon', (2020), Mixed Media. 
1
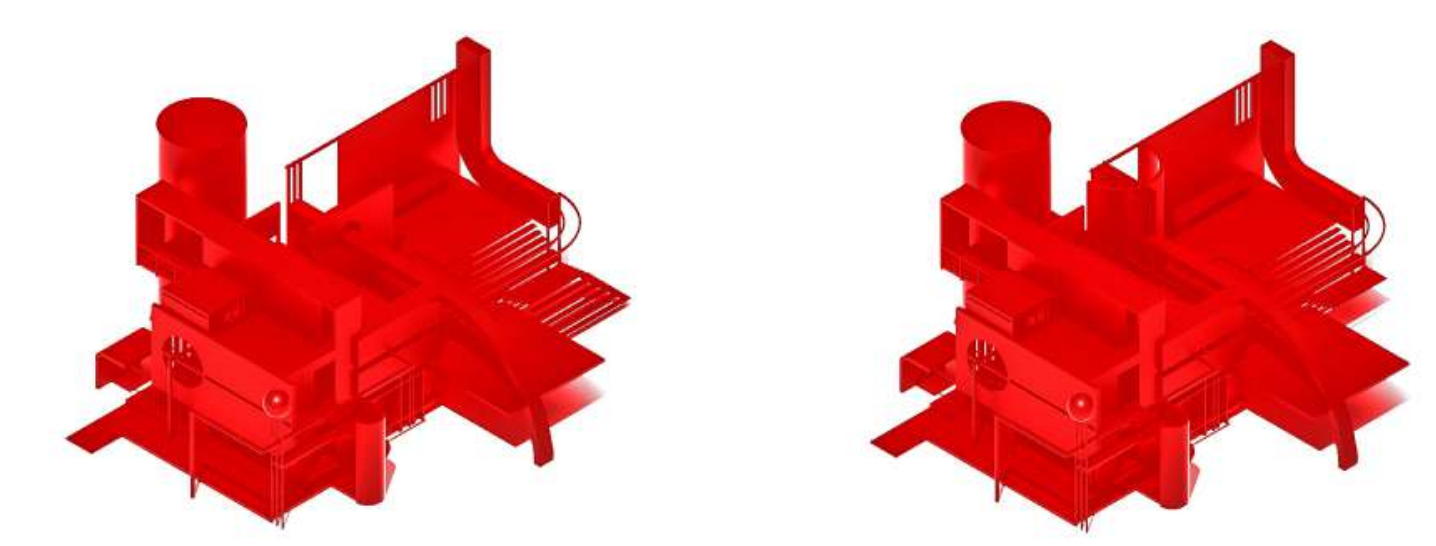
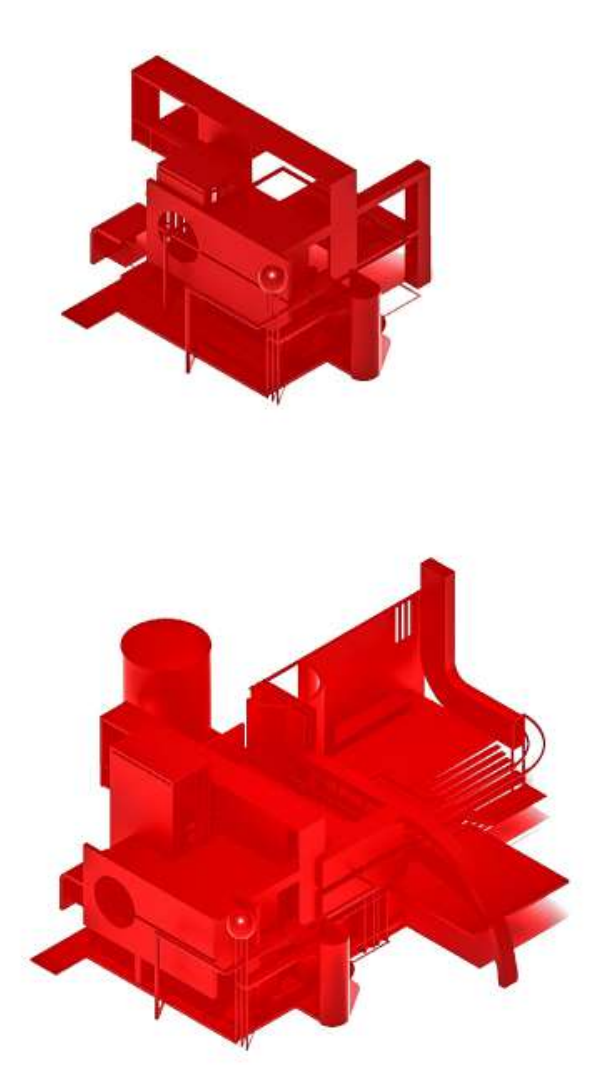
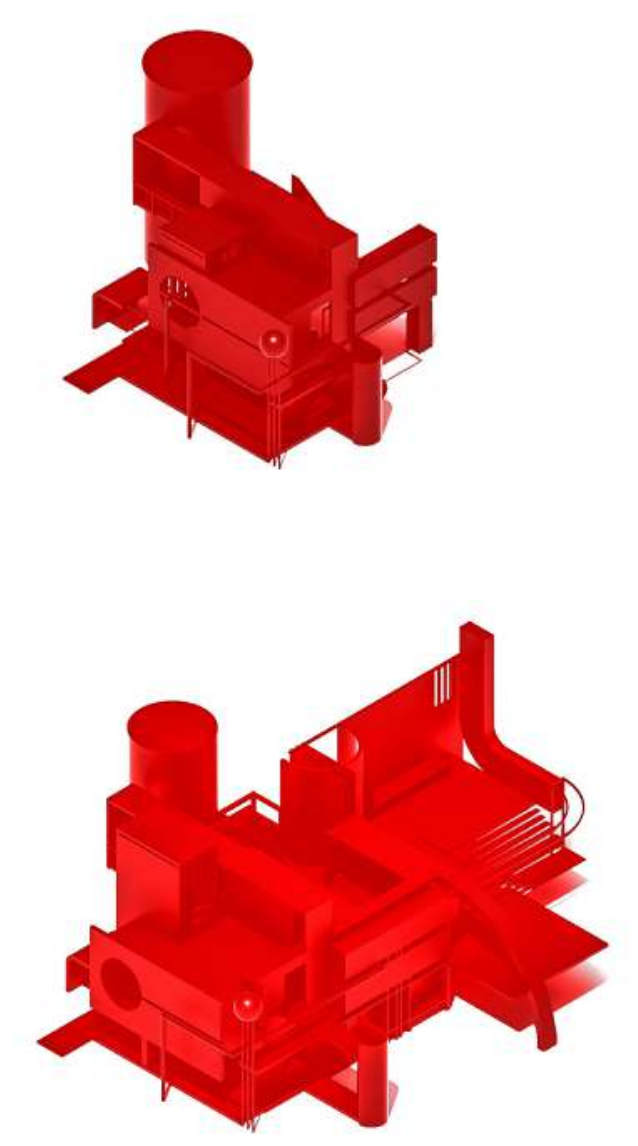
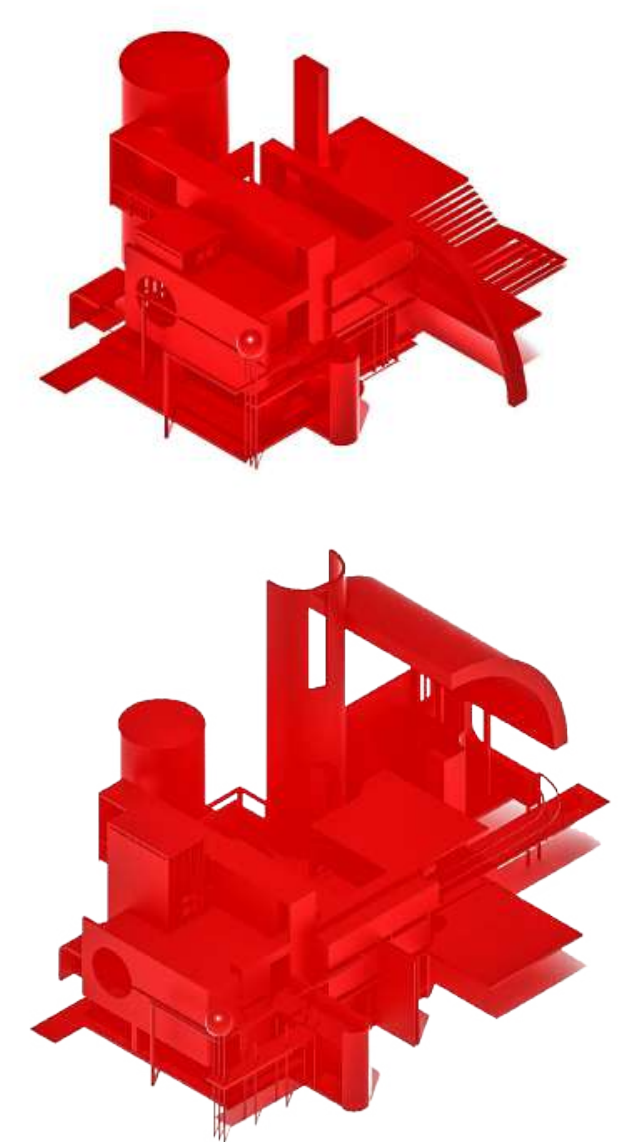


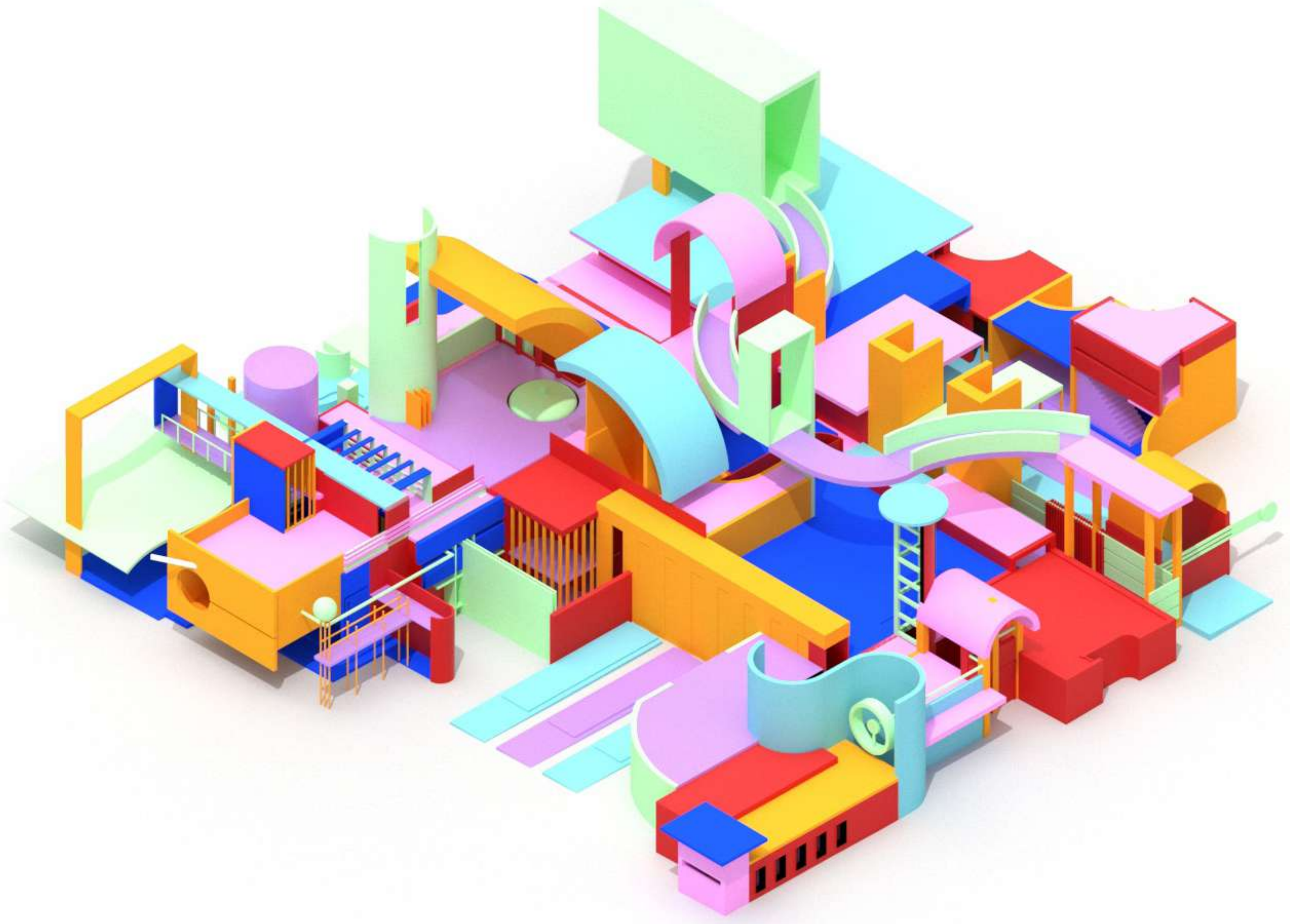




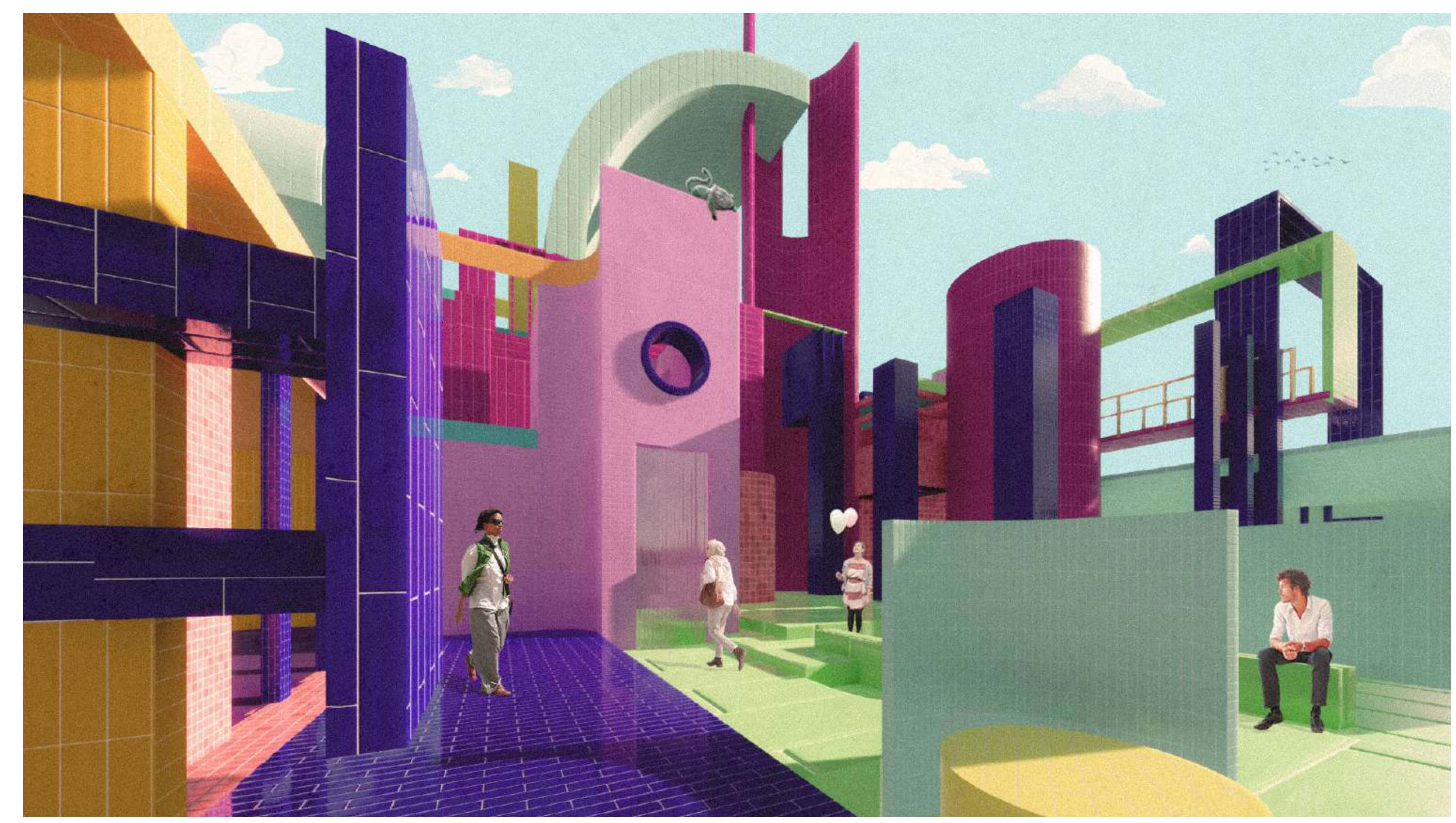

Figure 182. East Detail, '9 Prosser St, Elsdon', (2020), Digital Image. 


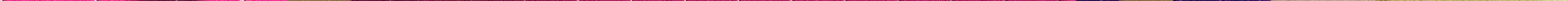




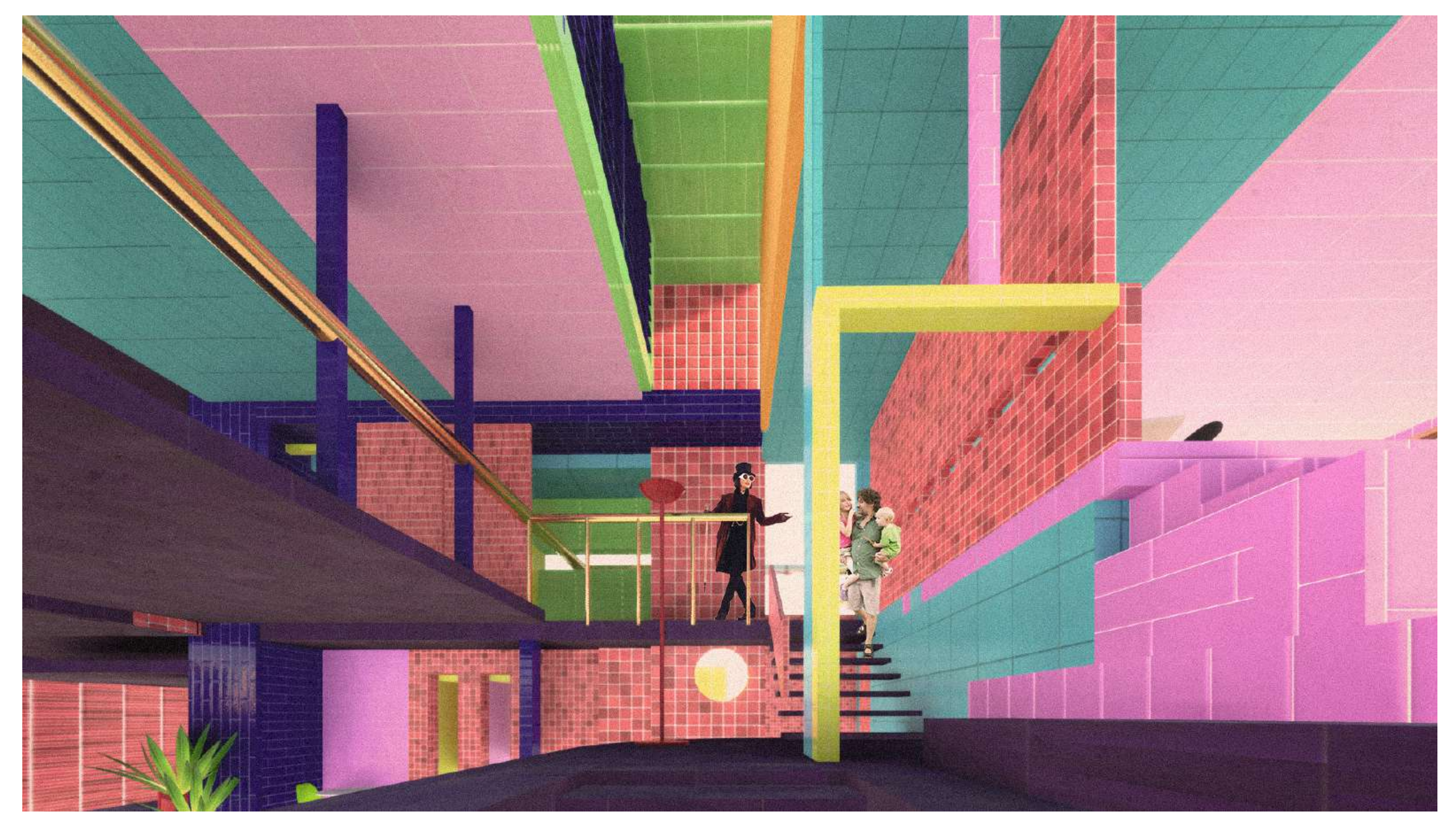

Figure 184. Towards Private Dwelling, '9 Prosser St, Elsdon', (2020), Digital Image. 


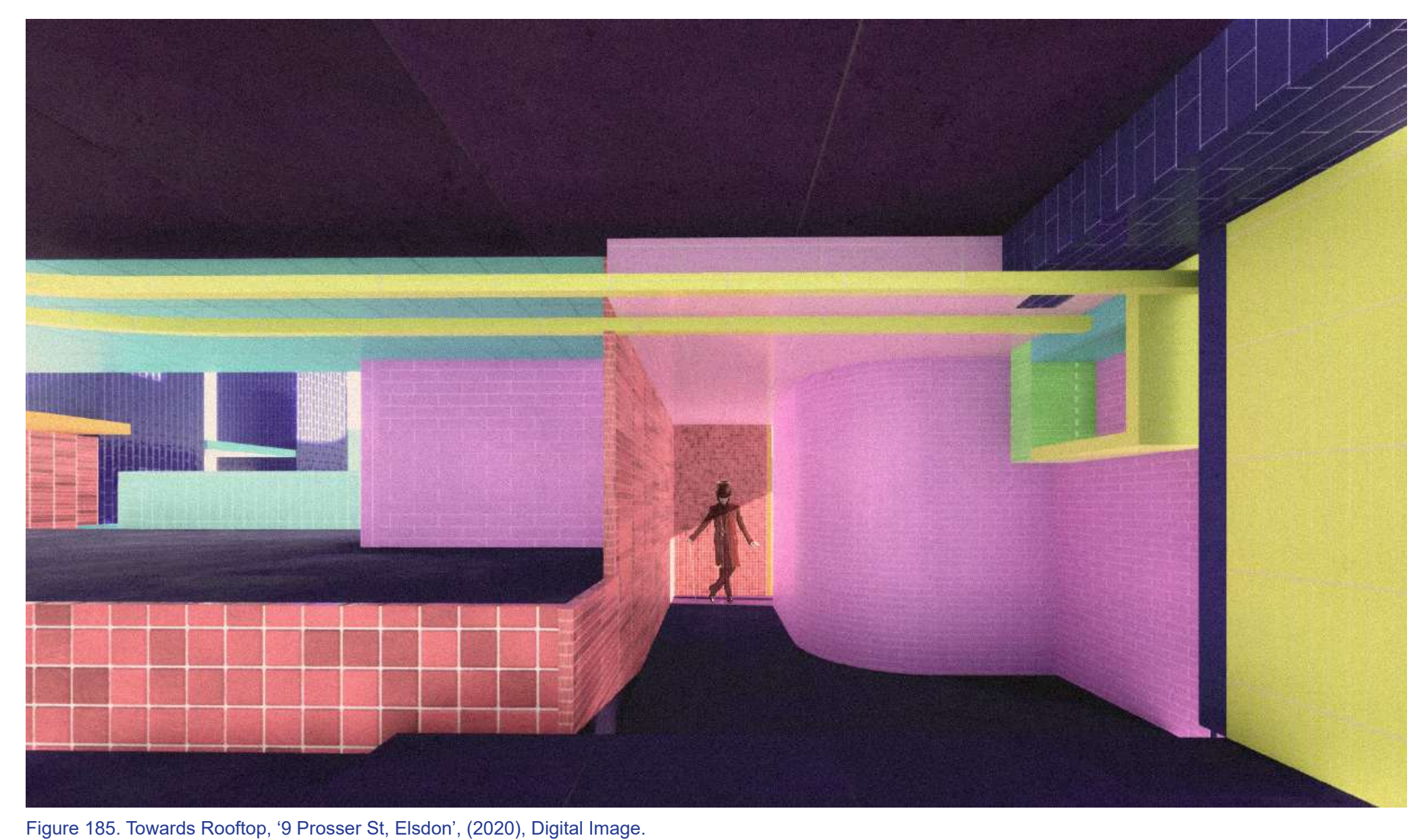




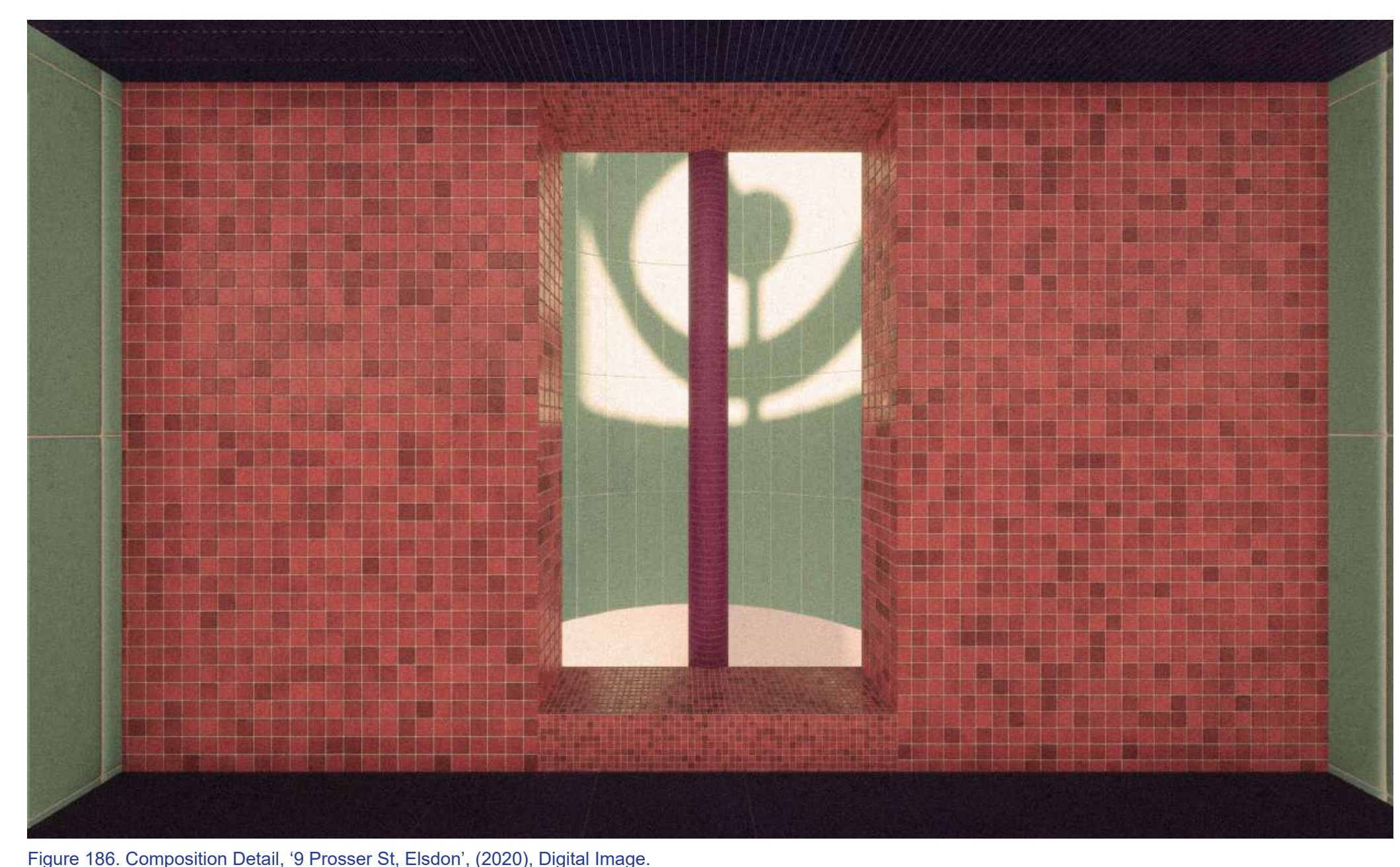

Figure 186. Composition Detail, '9 Prosser St, Elsdon', (2020), Digital Image. 

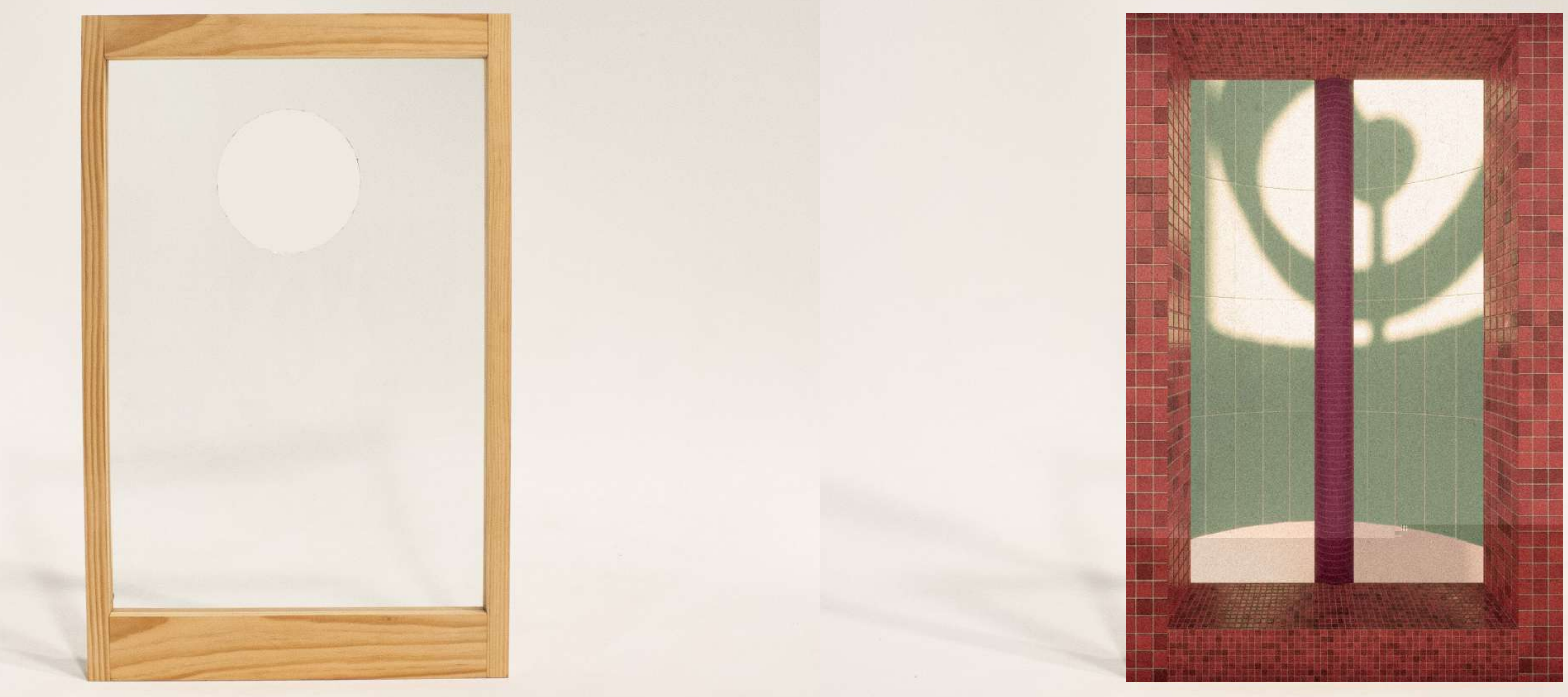


\section{tile}

\section{reflection*}

Tiles successfully apply texture and colour physically to the design. They are an invaluable architectural element in this respect; however they brutally collide and follow a rigorous order.

I found it difficult to decide how to intersect different sized tiles. They hold a complexity which I struggled to understand and made it difficult to play with. I started by letting them clash awfully and purposefully to express the difficulties of the strict alignment tiles require. This made me feel uncomfortable and brought out my frustration with the grid.

It was important to have a variety of tile sizes and arrangements, as well as colour, to allow each space a unique detail. I tried to align one of the directions with the adjacent tiles, allowing the tile order to flow through and create a new size; while the adjacent tiles provide a different direction. Still clashing un-poetically I thought to bring through one row of the tile into the next layout, allowing it to break through the strict gridded layout while being composed and not harshly butting heads.

This last option allowed the previous mark-making technique from the paper-models to be interpreted within the tile arrangement. The tiles can make arrows, dashes, lines, arches etc. to flow people through the building and become a playful assembly within themselves. It creates an opportunity for intense detailing and a sophisticated embedded playful mark on the design. The tiles allow the playful assembly to exist in the finer details of design.

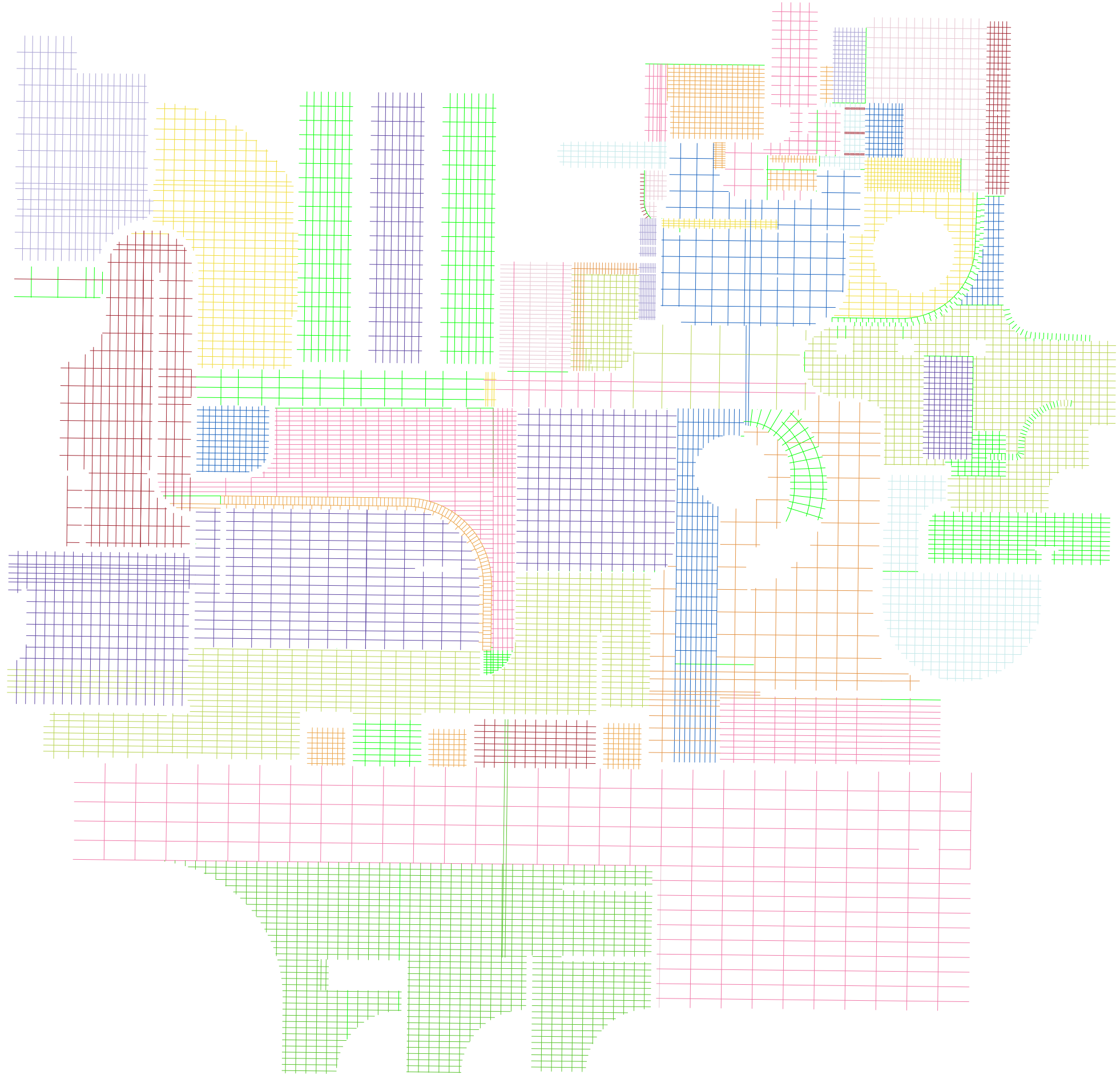

Figure 189. Tile Detail, ‘9 Prosser St, Elsdon', (2020), Digital Drawing. 


\section{last physical model*}

The tiles are a great way to architecturally express 'play' through materials. The last physical model of this project intended to be a refined multi-colour 3D print model of the creative factory design. This would allow the tiles to be printed at their respective colours and expressed cleanly. However, the small $40 \mathrm{~mm} \times 50 \mathrm{~mm}$ test print would have cost $\$ 40$. This is too expensive to build, just like the tiles are an expensive building material. This colourful 3D printer is too costly for a student, resulting in a similar situation to designing for clients on a budget.

If funds run out when building the process needs to adapt, and so did I. Faced with the economic reality of being a student and trying to create one last model left me stuck. I was confronted with the question: what is the real point I want to end on? Is it really some spectacular tiles which are too expensive to build?

The model that remained a test print.

I have found physical modelling more useful as a problem solving tool rather than a representative tool. All my models, until the attempt at this one, have been at the beginning of the design process rather than at the end. This is why I found this one such a struggle to understand, and a lot less enjoyable. Physical modelling is more playful and intuitive when you do not know the outcome, but use it to find out.

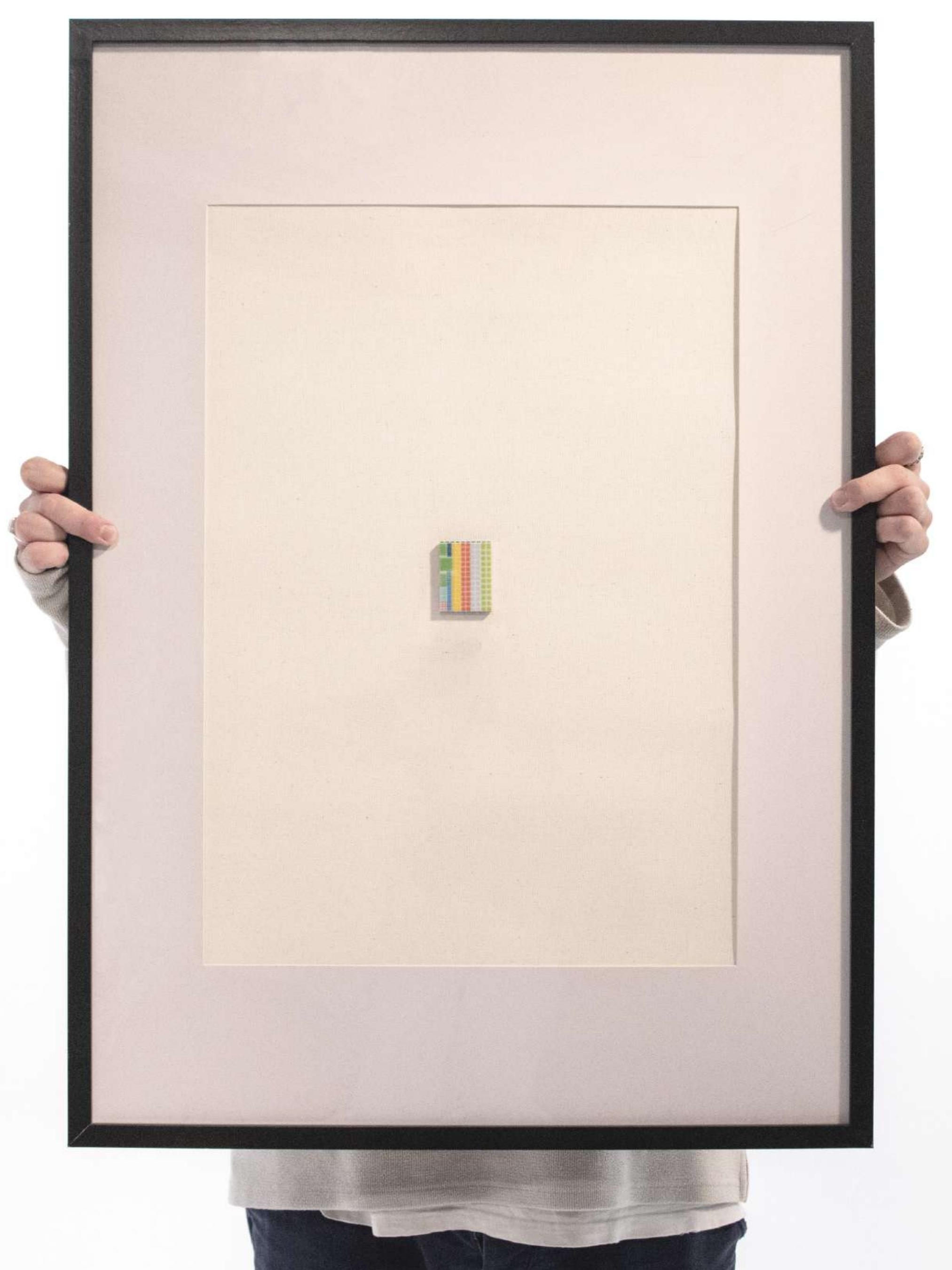




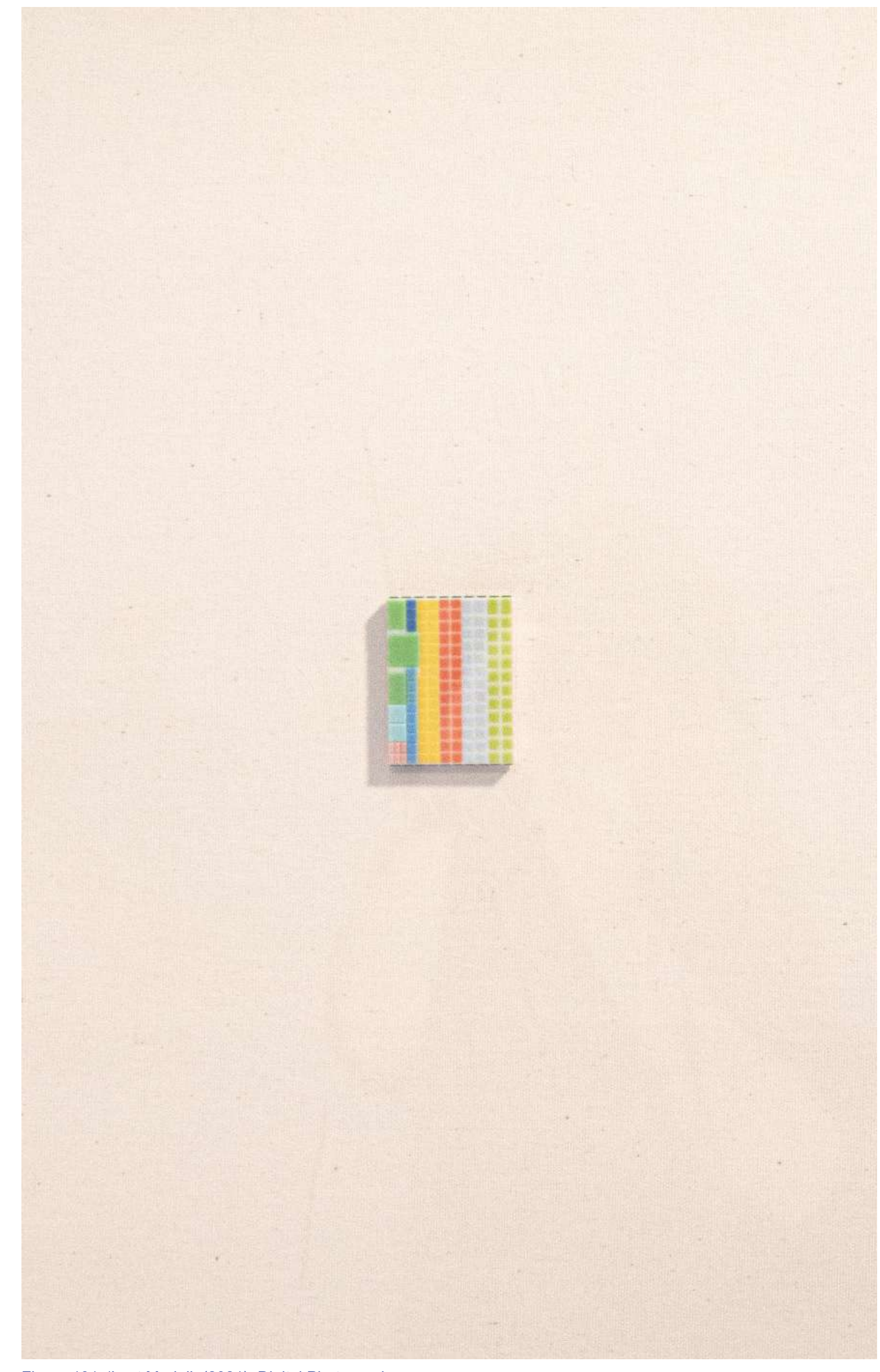

Figure 191. 'Last Model', (2021), Digital Photograph. 


\section{new}

\section{babylon*}

New Babylon presents a humanist approach to the city. It is interesting that cities have the potential to hold joyous diversity of life yet are often criticised for their failures. My experience in Mexico City gave me a positive turn-around on my view of cities. Literature such as Delirious New York has grown my perspective on congestion and density in cities to promote diversity and community.

The New Babylon is a structure created by the situationist Constant Nieuwenhuys. It is a Situationists architecture aimed to "...one day revolutionize everyday life and release the ordinary citizen into a world of experiment, anarchy, and play" (Sadler, 1999, p. 69). It gives autonomy back to the city's inhabitants and releases them from the mechanism of the city.

My creative factory follows this motif. The creative factory has a creative focus aiming to move away from mass production and promote self-expression. As the situationists would put it, individualism. The New Babylon is an important case study to understand how the individual building can exist in a larger network. How architecture can start to implement diversity, community and self-expressive motifs in the city. 
"The modern city is a thinly disguised mechanism for extracting productivity out of its inhabitants, a huge machine that destroys the very life it is meant to foster"

(Constant, 1998, p. 9) 


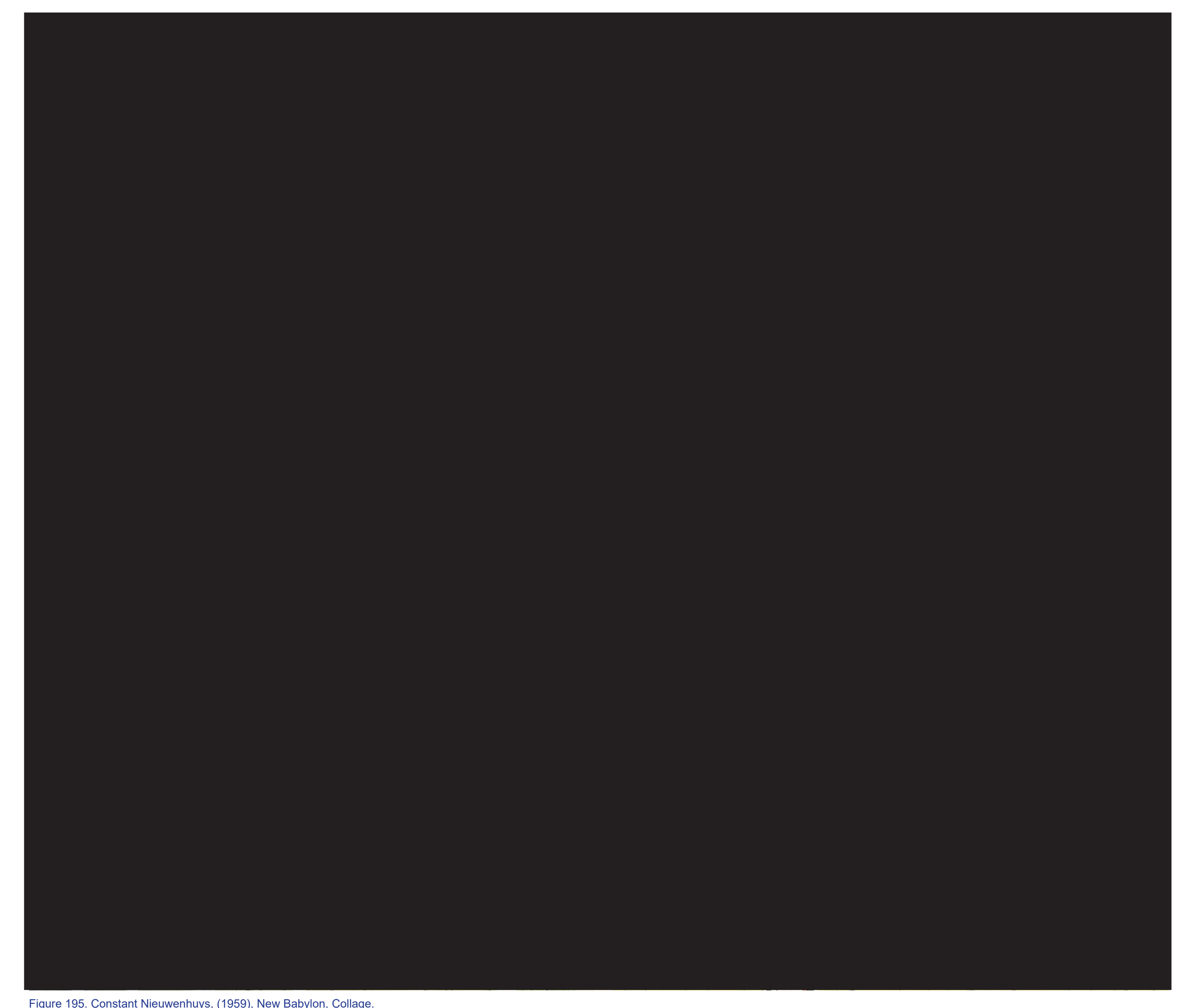




\section{creative}

\section{monumen-}

tality*

The tiles are a great way to architecturally express 'play' through materiality. Yet this project is less about materials and colourful tiles than it is about architectural language and the cultural network of sites. Each move of this playful assembly process has been bold whether small or large. This project's purpose to create a welcoming and enjoyable city for Porirua, has resulted in an architectural language which promotes the creative city.

The urban scale focuses on the cultural network of Porirua by understanding it as an archipelago. The archipelago provides a framework for compositional forms to exist within a collective. These forms, known as creative factories, encourage cultural interaction by providing locals places for creative production instead of mass production. This architecture shifts Porirua's cogs to nurture the lifestyles of its inhabitants rather than consume them. Self-expressionist city.

The creative factory is not a place of complete anarchy, more a place of creative religion. A church for creativity. This final point is not colourful tiles, it's where the playful assembly meets creative monumentality. The creative factory becomes monumental. It's monumental in purpose and boldness. This network of cultural urban artefacts (Rossi, 1982, p. 21) leads my architecture to be monumental, not by individual size, but by its contribution to the collective.

The last element of this project is by no means the end, but a continuation of the means. It is not to be a colourful 3D print extravaganza, but an exploration of creative monumentality. It presents itself in the form of a painting; as the beginning of the end. Finishing this project the same way I started it presents the circular back-and-forth nature of my playful assembly process. It provides a clear comparison to the first painting and sets a path for what future research would entail.

This painting simplifies the complexity of the architectural language to focus on its simple set of geometries. These shapes sit on a bed of red spray paint earth and an uneven black urban grid. The geometries represent the individual sites of creative production which together create the cultural layer of the city. The faint white pen is the people and their self-expressive creative productions. As a whole the shapes and their people create a sense of creative monumentality. The white frame symbolizes the collective as a creative monumentality of the whole playful assembly, that's why it's so bold.

It is important to emphasise that creative monumentality is a collective composition of the city's cultural network, not a title to be expressed by an individual building. The network finds monumentality in the collective, not the individual. 


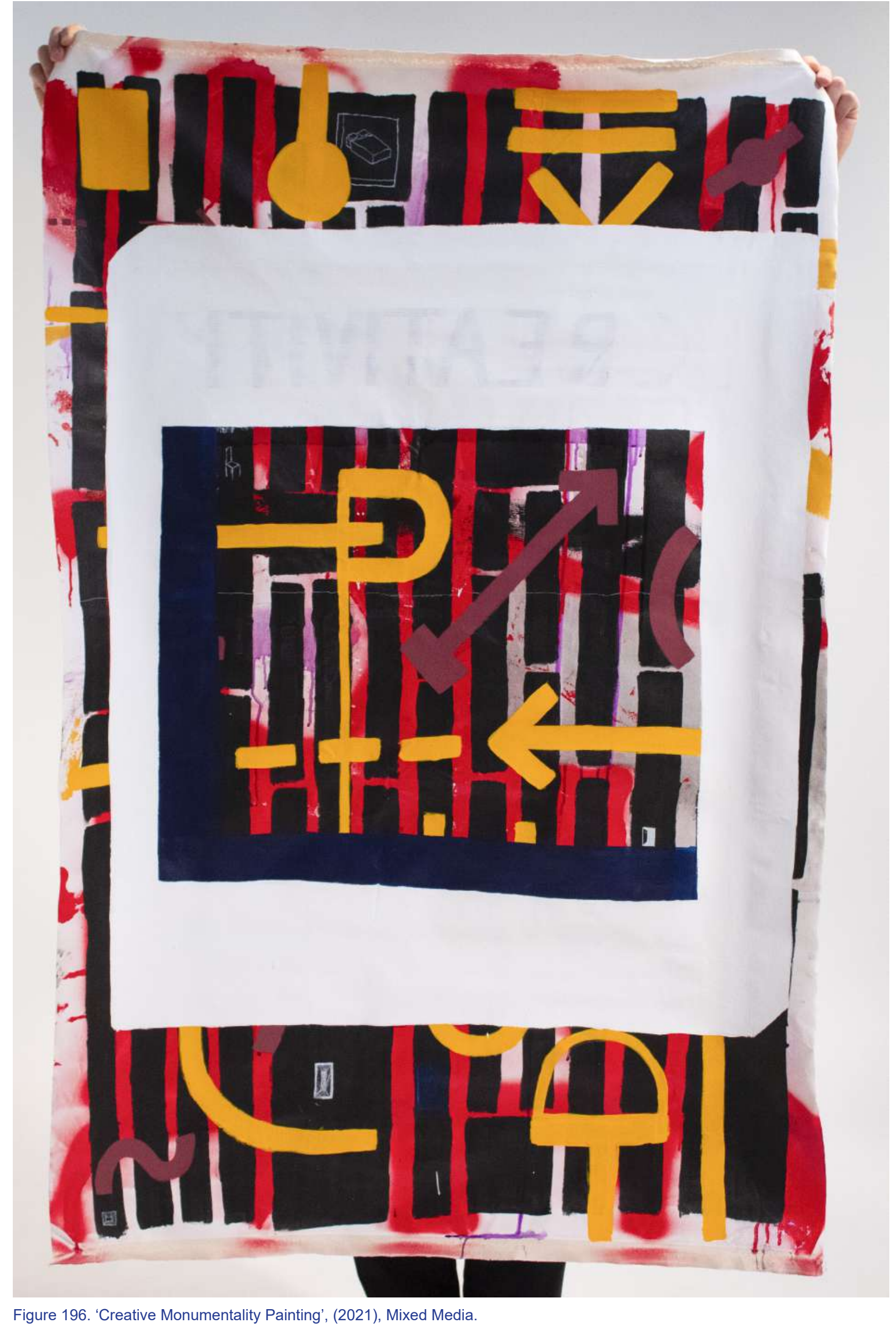




\section{concluding comments}




\section{playful assembly*}

This thesis started with a search for my creative voice and has resulted in a narrative of painting, the city and architecture. It pulls on my childhood and draws on my fascination with the city and creativity.

Through diving into my own creative practice I have discovered the importance of self-expression in the city. I have discovered the agency the city has to provide spaces which welcome creativity and promote local craft production. I have used research through design to define an architectural language which aims to promote the creative city through a network of sites. This architecture is a product of my self-expression, in order to encourage others in the city to be self-expressive in their craft.

Through many stages of reflection and discussion the creative factory was born.

Located in Porirua, this network of sites for creative production is a proposal promoting positive growth for the city, giving it a well needed dose of life, vibrance and community. The factory is an aspect of this project which uses the expected growth of Porirua (Porirua City Council, 2019, p. 11) as an opportunity for the city to begin development inwards rather than outwards. Porirua has had ample housing growth in the recent past and faces more, yet the city centre has stayed stagnant. Through developing the cultural layer of Porirua, its city centre becomes a place for excitement, colour, creation, community, diversity and wellbeing.

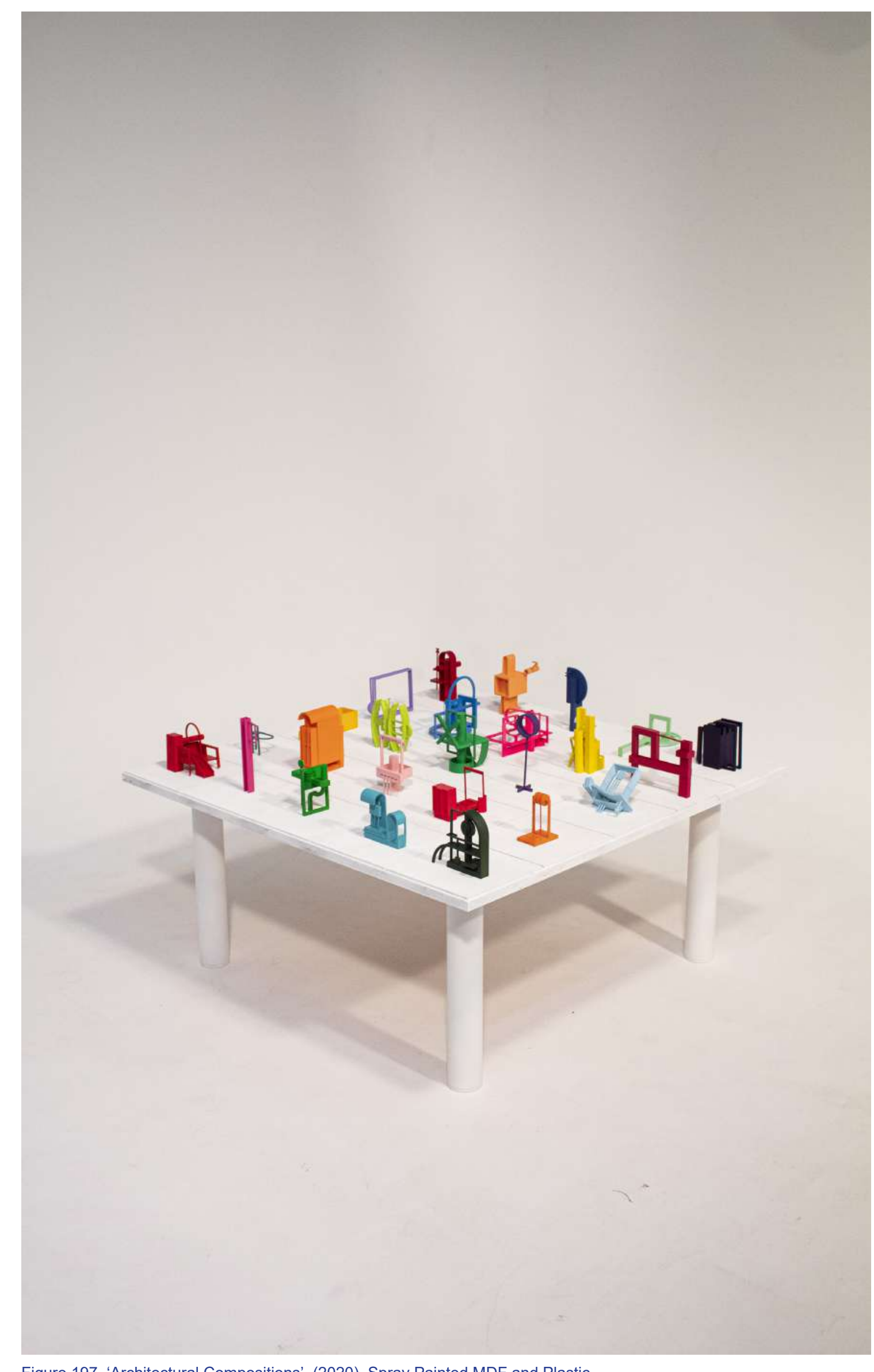


"The static constructions of architects and town

planners are thrown away."

(Constant, 1998, p. 9)

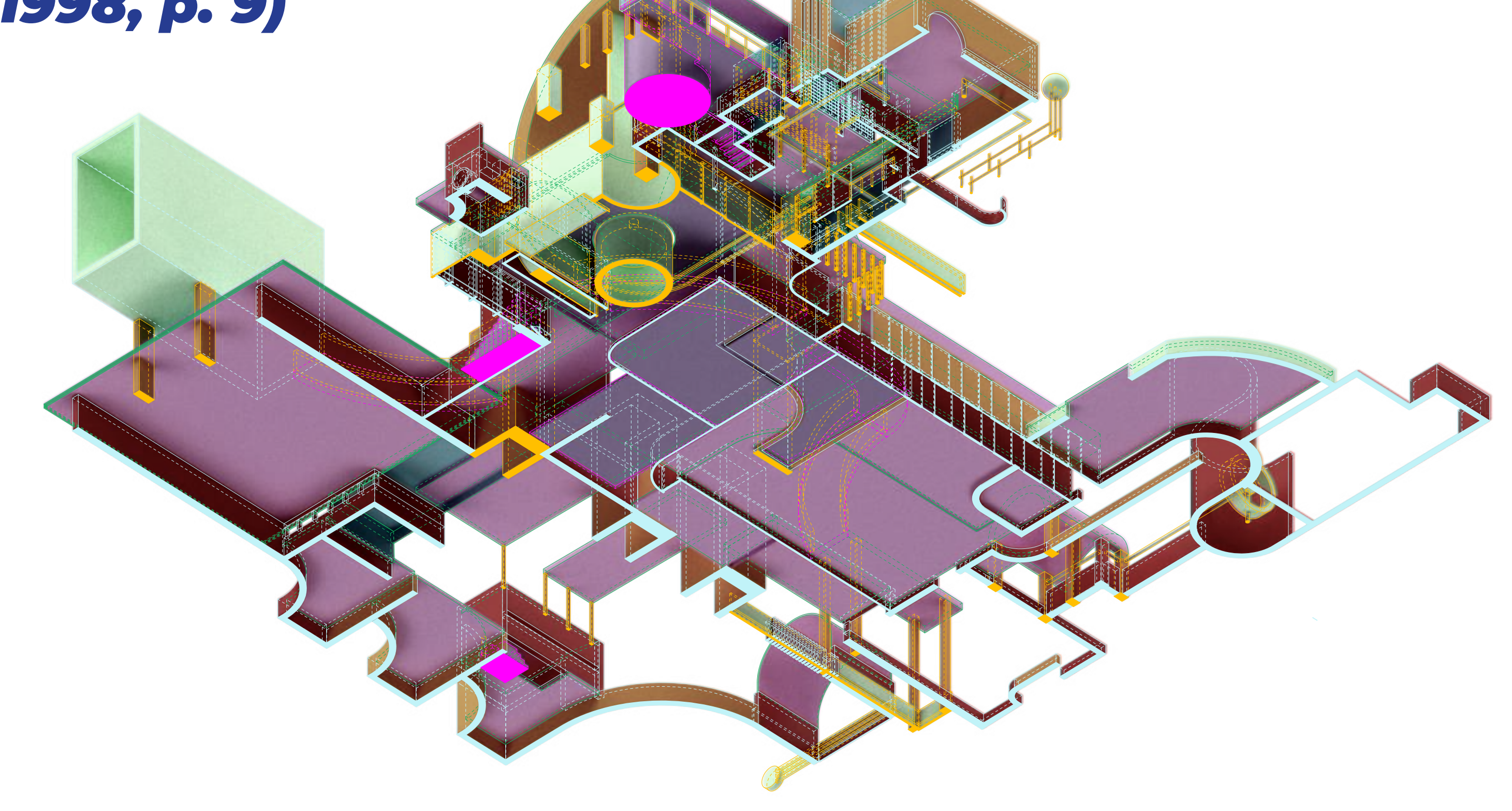




\section{everchanging architecture*}

Much like the city, the factory is proposed to remain under construction indefinitely. As the city is under a state of constant change architecture is often challenged to be adaptable in the future. An adaptable architecture can support the predicted increase in population and need for more housing and community infrastructure (Porirua City Council, 2019 , p. 11). Expected growth is seen in many cities resulting in the common site of construction and commercial cranes. Why do buildings always end up being 'finished' when everything around them is changing?

Due to the promotion of the creative city it is interesting to challenge the stationary compositional element of architecture to be more adaptable, more mobile, like the city. The factory is purposefully left 'unfinished' allowing room for it to grow with its inhabitants and its city. This provocative notion leaves some rooms as shells and an accessible roof. The roof will not be used much in the current weather conditions, (we do not live in Mexico after all) but it does provide a platform to be expanded on in the future. I like to think of it as an 'open architecture', open for improvement, open for continuation and local contribution.

For architecture in the city to maintain the 'equilibrium' which composition demands it must be constantly changing. Otherwise it will get left behind the times and stuck as an expression of the past not of the present.

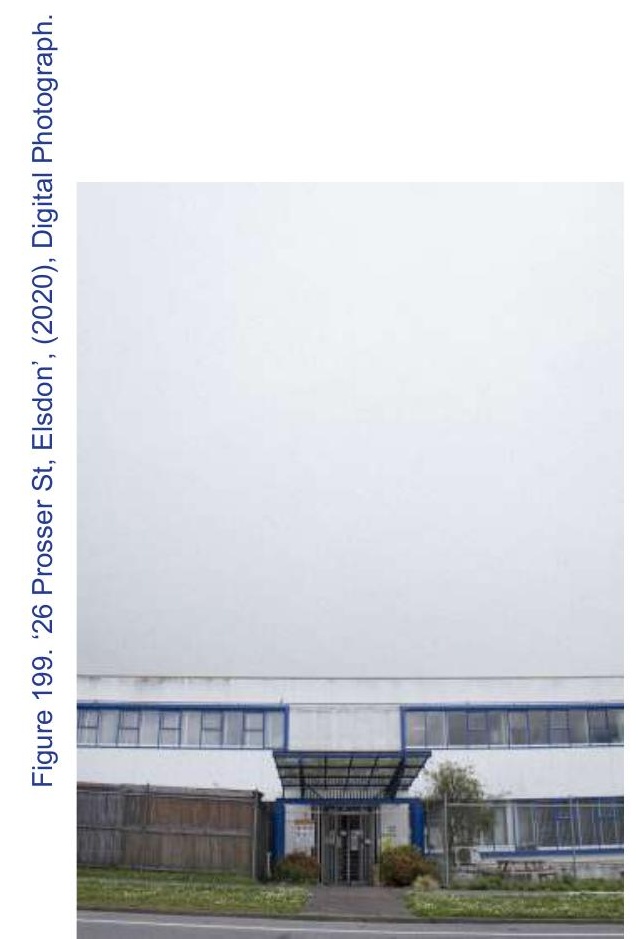




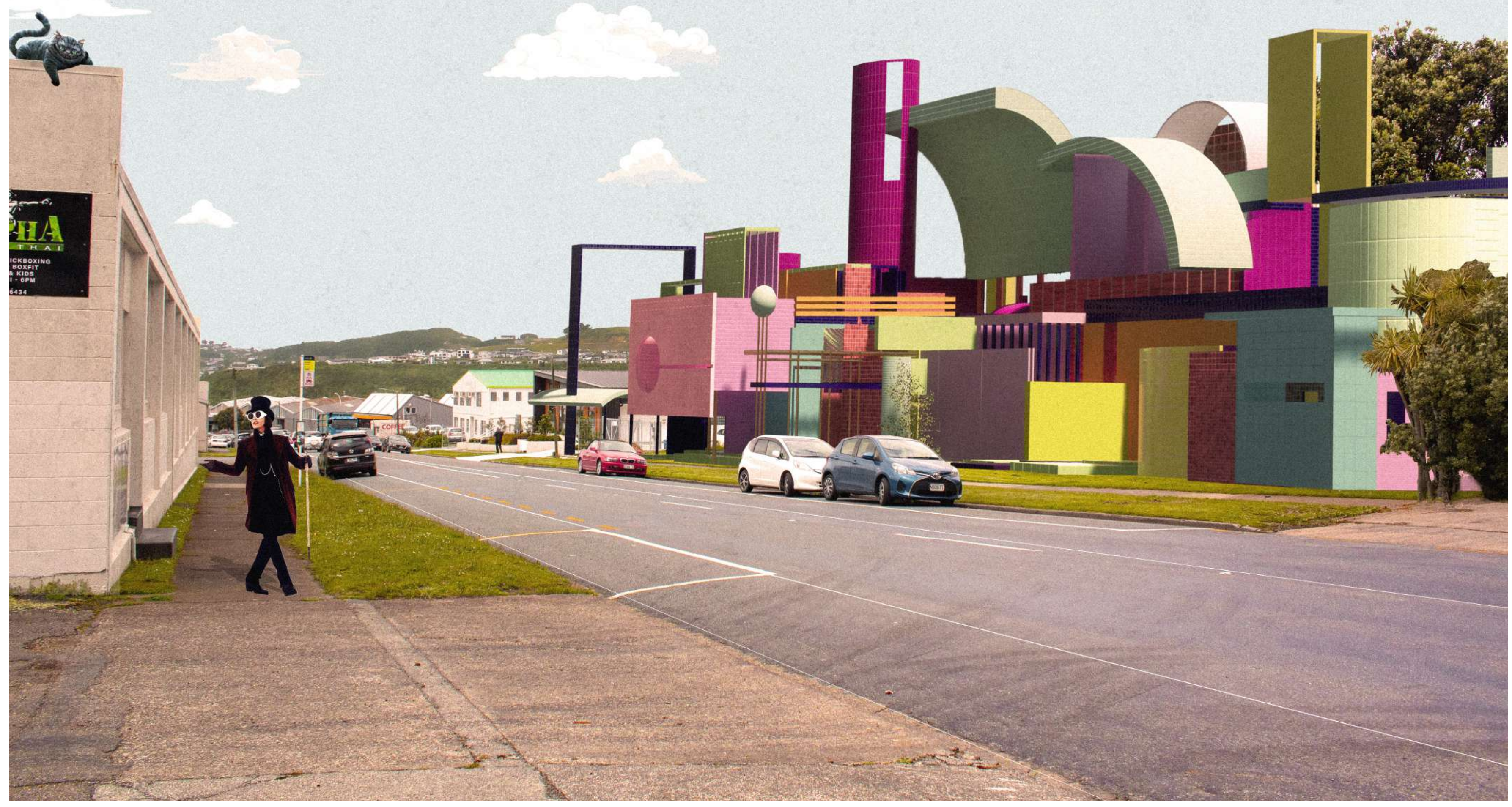




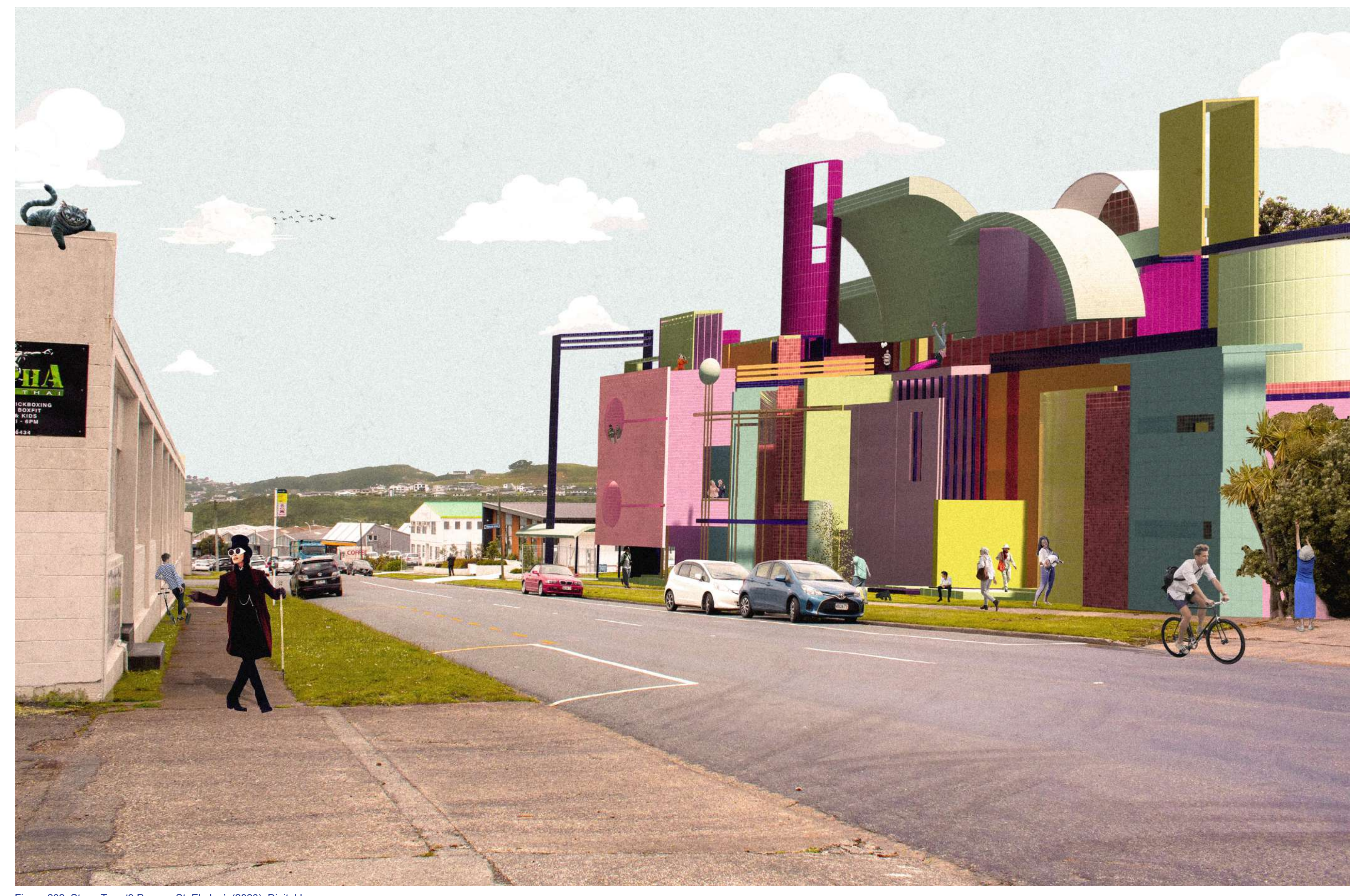




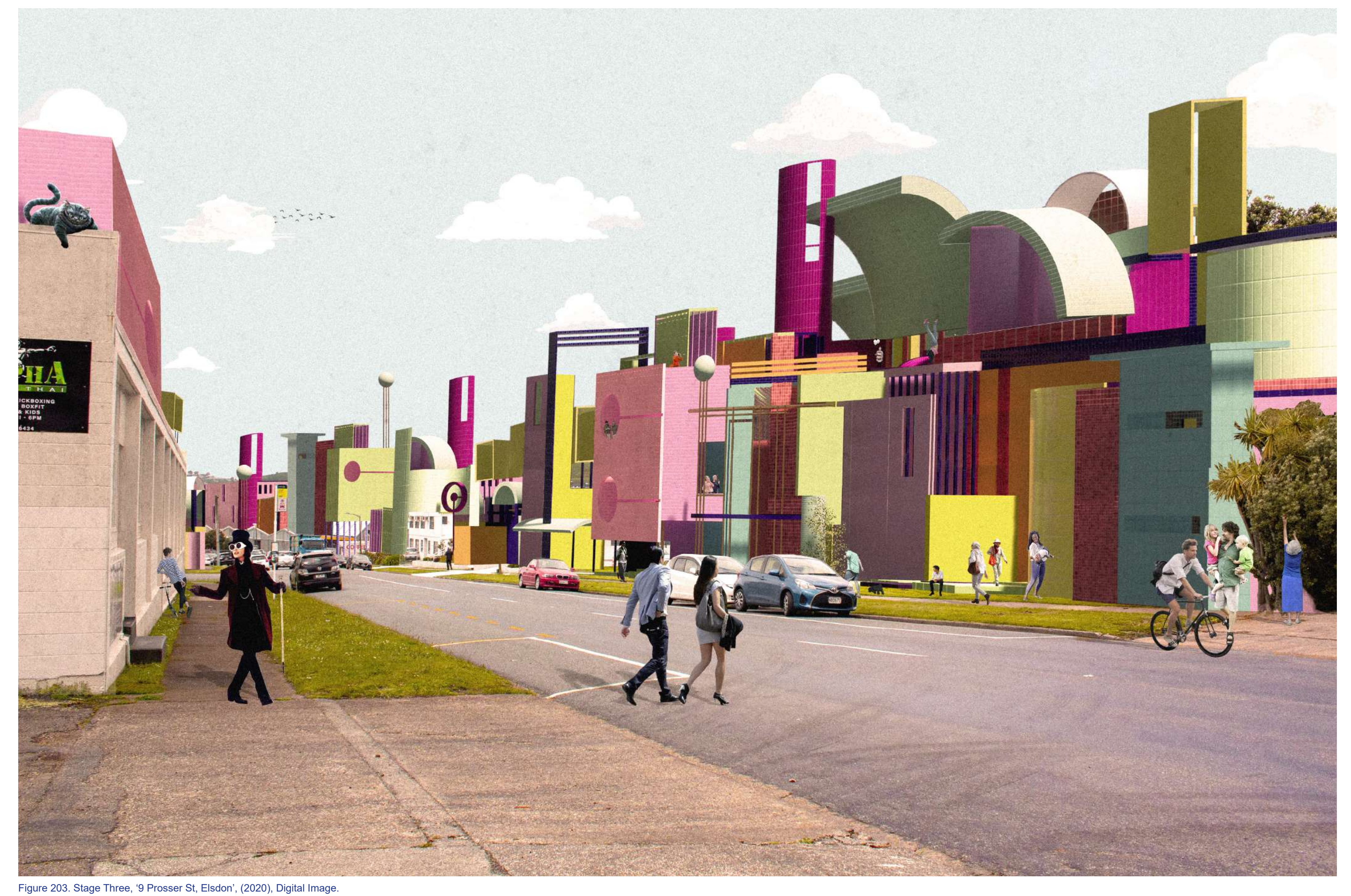




\section{archipelago porirua*}

Archipelago provides an alternative way to compose the cultural network of the city. It moves the city "... away from typecasting and standardization" (Ungers \& Koolhaas, 2013, p. 96) by condensing the city into unique 'islands'. This congests elements of the city creating rich relationships and diverse communities. In doing this, it densifies large parts of the city into smaller 'islands' providing a positive congestion of diversity, of the city.

In a contemporary sense it follows the Delirious New York mantra, "The culture of congestion is the culture of the 20th century" (Koolhaas, 1994, p. 125). It promotes a city's growth inwards rather than outwards, allowing more land for green space maintaining native lands and habitats. This moves away from urban sprawl and towards positive congestion, diversity and community. 


\section{still city life composition*}

Composition is used as a design tool throughout the development of this thesis. It gives autonomy to architecture while expressing its unity with the city. This elemental approach to composition relates to arguments around architecture and painting as, "The painting, while all the while preserving the individuality of its elements subordinated them to a life together in a composition of the ensemble" (Lucan, 2012, p. 407). Here the elements can be seen as the architecture and the ensemble as the city. This theory is also scalable allowing the elements to be parts of architecture, and the ensemble as the collective architecture.

It is often described that, "....composition has achieved unity once nothing could be added or taken away from it" (Lucan, 2012, p. 409), yet the city, the archipelago, is in constant flux, an ever-changing composition. The architecture of the city is constantly being altered as well as its surroundings. The still life in the city is both permanent and temporary. The city's ensemble is restless and requires change as frequently as society does. It must keep up with the humans and they develop fast. Architecture is permanent but it can be taken away from and added to. It must adapt to the constant evolving society.

Composition is both a criteria for my designs and challenged by my process. It's unity is argued by the city and its architecture pushes past the stationary equilibrium state of composition towards an evolving composition. The architectural compositional theory moves beyond still life painting towards the excitement of the city.

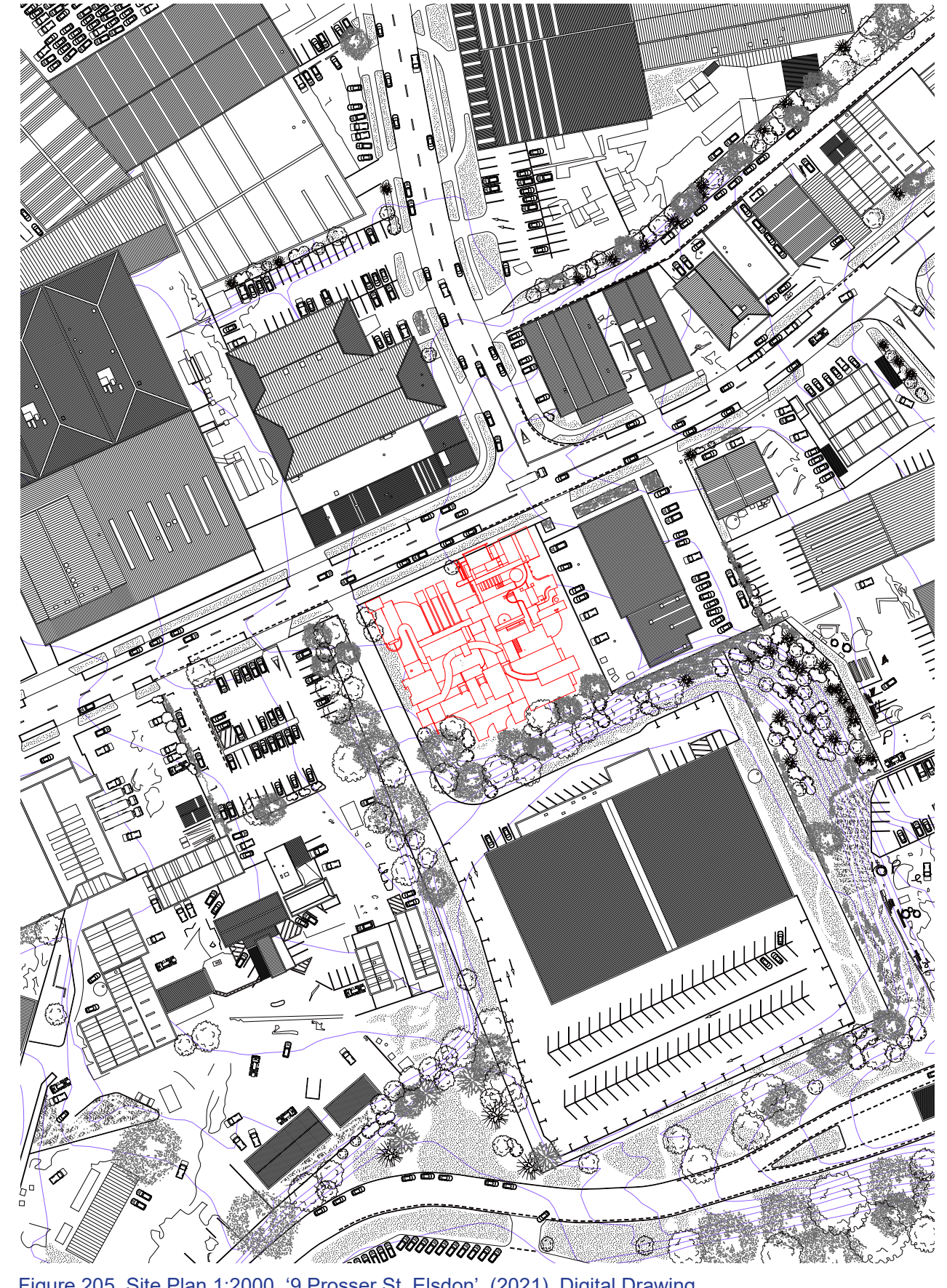

Figure 205. Site Plan 1:2000, '9 Prosser St, Elsdon', (2021), Digital Drawing. 


\section{future}

\section{research*}

I have generated an architectural language inspired by the city and for the city. Just like the city, it has "the ability to pursue a variety of agendas simultaneously..." (Hopkins, 2021). The architectural language for the network of sites emphasises the creative culture of cities along with representing the "ideological and environmental chaos of the contemporary world" (Hopkins, 2021). This architectural language development coincides with the discipline's development of Multiform.

Multiform situates this project in a current disciplinary discussion around the development of architectural languages within the city. If this project were to continue, I would research Multiform to understand how my playful assembly architectural language could evolve, and contribute to contemporary discussions of architecture and its implications on the city.

The network of sites would look towards creative monumentality as a starting point for progression. Both lines of research would overlap seeing a monumental network of Multiform-inspired playful assemblies of architecture.

It also is worth pointing out the irony of exploding my creative voice over Porirua City. This thesis discusses the importance of individual self-expression to contribute to the collective. I can not speak for the others who would contribute to such development of Porirua if it was developed in the way imagined by this thesis, but I do need to say that

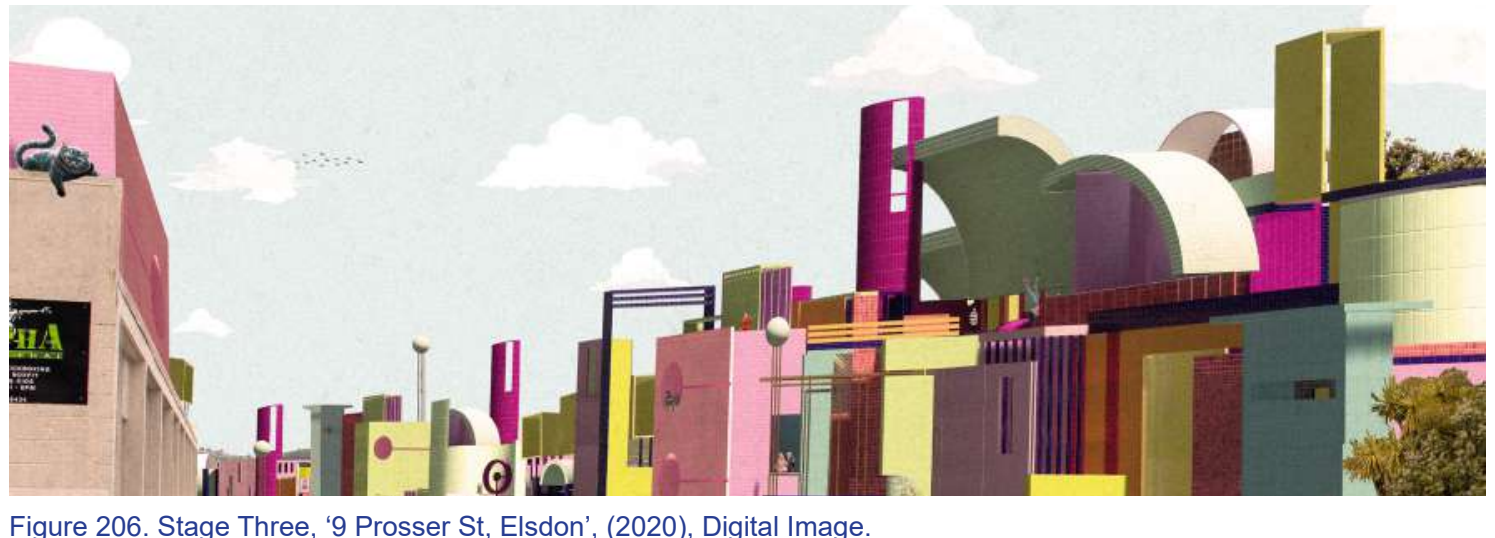

Figure 206. Stage Three, '9 Prosser St, Elsdon', (2020), Digital Image.

Porirua's CBD would not look as I have depicted. It would be more of an ensemble presenting minimalist, brutalist, classical, post-modernist expressions of architecture; in ways I cannot imagine. The CBD would welcome all creative voices the local character would bring, not just mine. This project, ideally, would be handed to a collective group of people who value culture and creativity as much as I do and want to explore their own creative voice to contribute to the Porirua City. I am only one voice creating my little piece of lego building for the creative city, the imagination of others could bring more than I could imagine. I can only show you my voice, so here it is; with all its ironic glory days. 


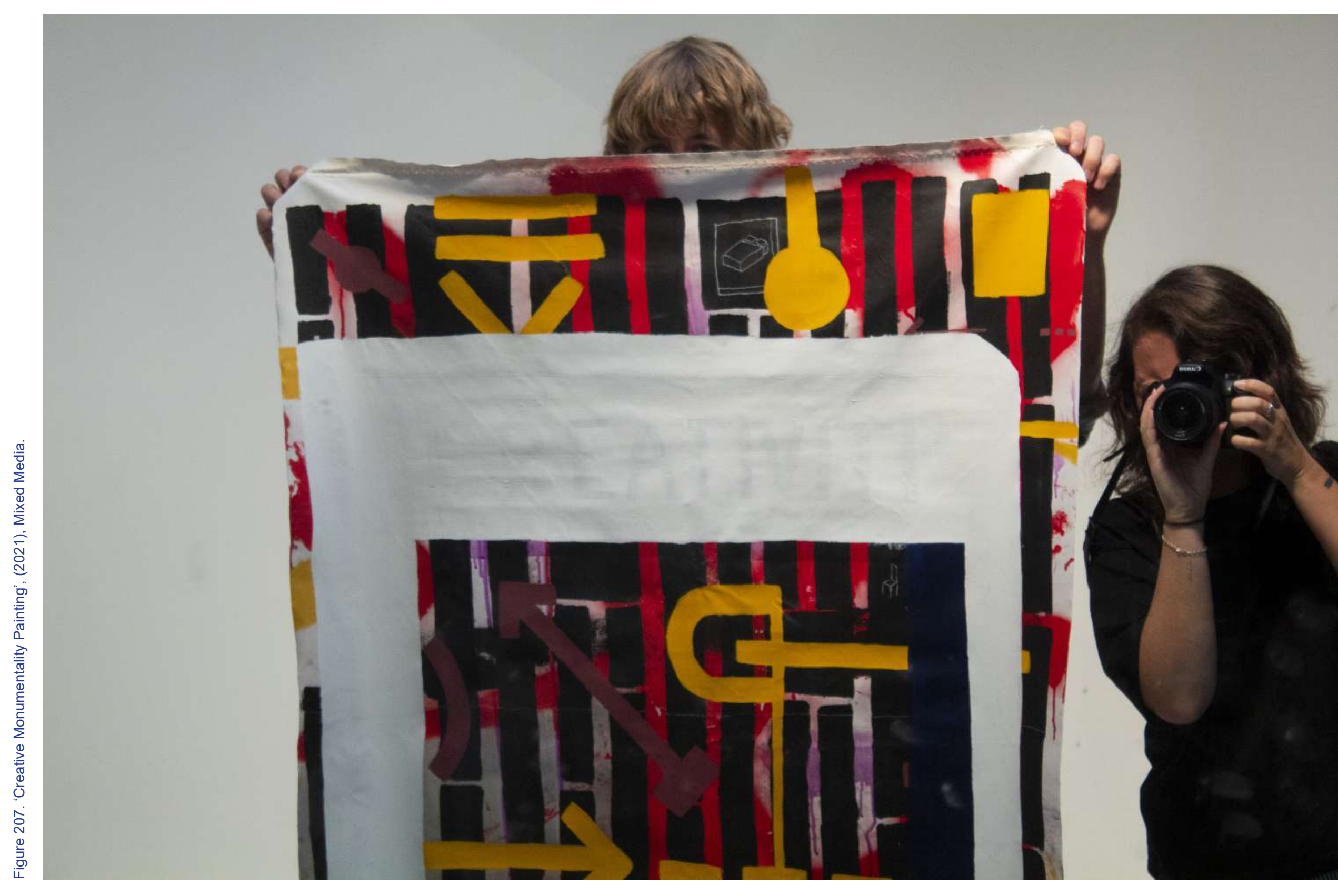




\section{the end*}

A series of creative, self-expressive, autonomous monuments inspired by the city and for the city. The creative factory as a monumental urban artefact (Rossi, 1986) for the city's cultural wealth network. A network which follows an archipelago dispersal framework. An architectural language which follows a compositional design still city life criteria. An inclusive new babylon structure for all creatives. 


\section{cited works*}

Aureli, P. V. (2011). The possibility of an absolute architecture. Cambridge, Mass. : MIT Press.

Burton, T. (2005). Charlie and the Chocolate Factory. Warner Bros.

Constant. (1998). Constant's New Babylon: The hyper-architecture of desire. Witte de With, Center for Contemporary Art.

Hopkins, O. (2021, February 25). Multiform is the architectural manifestation of our present moment. Dezeen. https://www.dezeen.com/2021/02/25/multiform-architecture-style-owen-hopkins-opinion/

Koolhaas, R. (1994). Delirious New York: A retroactive manifesto for Manhattan (New ed.). Monacelli Press.

Lissitzky, E. (1919). Untitled from Proun. The Museum of Modern Art. https:// www.moma.org/collection/works/86774

ucan, J. (2012). Composition, non-composition: Architecture and theory in the nineteenth and twentieth centuries (1st ed.). Lausanne, Switzerland : EPFL Press ; Abingdon, Oxford : Routledge.

Porirua City Council. (2019). Porirua Growth Strategy 2048. https://stor age.googleapis.com/pcc-wagtail-media/documents/Porirua_Growth_Strat egy 2048.pdf? Expires $=1613595376 \&$ GoogleAccess $I=5407370534$-com pute $\% 40$ developer.gserviceaccount.com\&Signature $=\mathrm{FkdVK} \% 2 \mathrm{FI} \%$

2FoEujLudco2MFOLqpKWzslqxFxrA9rnp9FrKKKJ9elLt1BtoIGr2L96sf bWr6GT9C2oErd9oO\%2BsmECWGaQgVQJDrXidbYC8\%2BoKX

4bRIIOu6hcAbu21JydQGT53o9p9bfzAh4GFISu2Ala8s6vmTIHaE3\%2F9F BLOBUEc2pHelu\%2B6ThyrGi85KrQIlpdMO1uE5MZ\%2BDr0e0U0Qa2rD
jnxPJZOM8HblpwtFdMBx3ETG2y2qQiqK45ejlVViNJURttZ\%2B30lo 9vH7IMZwG8574Ef58DsKbexDjfHk0GYDU95ab2DZNa0NWgGyi53px 1Cel4cx\%2BkAQizA0shvgBwikA\%3D\%3D

Rossi, A. (1982). The architecture of the city. MIT Press.

Sadler, S. (1999). The situationist city. Cambridge, Mass. ; London : MIT.

Sbriglio, J. (2008). Le Corbusier: The villa Savoye. Fondation Le Cor busier.

Ungers, O. M., \& Koolhaas, R. (2013). The City in The City: Berlin: A Green Archipelago. Zürich : Lars Müller Publishers. 


\section{list of figures*}

Figure 1.'Scrap yard, Elsdon', (2020), Digital Photograph. Figure 2. Stage Three, ' 9 Prosser St, Elsdon', (2020), Digital Image.

(Figure 3. 'Arlat view of Porirua', (2019), Digital Pholograph

Figure 4. 'Jigsaw', (2020), Digital Photograph.

Figure 6. 'Porirua Harbour', (2020) Digital Photograph

Figure 7. 'Kenepuru', (2020), Digital Photograph.

Figure 8. 'Transmission Gully Kenepuru Interchange', (2020), Digital Drawing.

Figure 9. 'Kenepuru Housing Development, (2020), Digital Photograph.

Figure 10. 'Compostion or The 11 . 'Bly, (2020,', Acrylic on Canvas.

Figure 12. 'Lockdown Desk' (2020) Digital Photograph.

Figure 13. 'Raumati Beach', (2020), Digital Photograph.

Figure 14. 'Brick Exploded Isometric', (2020), Photomontage.

Figure 15. ''Brick meets Paint', (2020), Digital Photograph.

Figure 17. 'Big Stick' (2020), Digital Phoghaph.

Figure 18. 'Small Stick' (2020) Digital Photoghraph

Figure 19, 'Brick Tights', (2020), Digital Photograph.

Figure 20. 'Brick Paint', (2020), Digital Photograph.

Figure 21. Wood', (2020), Digital Photograph.

Figure 22. '"Brick Tights', (2020), Digital Photograph.

Figure 24. 'BrickTights', (2020), Digital Photograph.

Figure 25. 'Composition of The City', (2020), Acrylic on Canvas

Figure 26. 'Composition of The City', (2020), Acrylic on Canvas.

Figure 27. 'Composition of The City', (2020), Acrylic on Canvas.

Figure 28. Process, 'Composition of The City', (2020), Acrylic on Canvas.

Figure 30 . 'Composition of The City', (2020). Acrylic on Canvas.

Figure 31. 'Composition of The City', (2020). Acrylic on Canvas.

Figure 32. 'Composition of The City', (2020). Acrylic on Canvas.

Figure 33. 'Composition of The City', (2020), Acrylic on Canvas.

Figure 34. 'Composition of The City', (2020), Acrylic on Canvas.

Figure 35.' 'Frame Dimensions', (2020), Digital Drawing

Figure 37. 'Frame Construction Process', (2020), Photomontage.

Figure 38. 'Frame Reuse Construction' (2020), Digital Image

Figure 39. 'Frame Sculpture', (2020), Plywood, Glass.

Figure 40. 'Frame Scuipture, (220), Plywood, Glass.

Figure 41. 'Frame Sculpture, (2020), Pyywood, Glass.

Clpture', (2020), Plywood, Glass.
Figure 43. 'Frame Sculpture', (2020), Plywood, Glass.

Figure 45. 'Playful Assembly of Complementary Elements', (2020), Fountain Pen on Watercolour Paper

Figure 46. 'Objects to Form' (2020), Fountain Pen on Waterolour Paper.

Figure 47. 'Objects to Trajectories', (2020). Fountain Pen on Watercolour Paper.

Figure 48. Imperfect Urban Grid', (2020), Fountain Pen on Watercolour Paper.

Figure 49. 'Circle and Square', (2020), Fountain Pen on Watercolour Paper.

Figure 50. 'Singularity of Place, (2020), Fountain Pen on Watercolour Pap

Figure 52. 'Play Assembly of Complementary Elements' (2020). Fountain Pen on Watercolour Paper.

Figure 53 'A5 Ink Arawing', (2020) Fountin Pen on Watercolour Paner.

Figure 54. 'Exploration', (2020), Mixed Media.

Figure 55. Isometric, 'Painting to Form', (2020), Digital Draw

Figure 56. Plan, 'Painting to Form', (2020), Digital Drawing.
Figure 57. 'Composition of The City', (2020). Acrylic on Canvas.

Figure 57. 'Composition of The City', (2020), Acrylic on Canyas
Figure 58. 'Porirua Figure Ground', (2020), Digital Drawing

Figure 59. Population Density, 'Porirua Networks', (2020), Group Work, Digital Drawing.

(Figure 60. Parks and Reserves 'Porirua Networks', (2020), Group Work, Digital Draw

Figure 61. Schools and Public Services, 'Porirua Networks', (2020), Group Work, Digital Drawing.

Figure 62. Public Transport, 'Porirua Networks', (2020), Group Work, Digital Drawing.
Figure 63. Harbour Patterns, 'Porirua Networks', (2020), Group Work, Digital Drawing.

Figure 65. 'Porina

Figure 66 'Porivu Sites', (2020), Digits Drawing.

Figure 67. 'Porirua Urban Interventions', (2020), Digital Drawing

Figure 68. 'Porirua Urban Interventions', (2020), Digital Drawing

Figue 60. 'Ar shipelago Porina', (202), Digla Drawing.

Figure 70. Oswald Ungers, 'Berlin Archipelago Proposal', (1977), Drawing.

Figure 72. 'Existing Porirua Urban Plan', (2020), Digital Drawing.
Figure 73. 'Proposed Porirua Urban Plan', (2020), Digital Drawing.

Figure 74. 'Existing Commercial Network', (2020), Digital Drawing

Figure 75. 'Proposed Commercial Network', (2020), Digital Drawing.

Figure 76. 'Existing Health/Educalion Nework, (2020), Digital Drawing

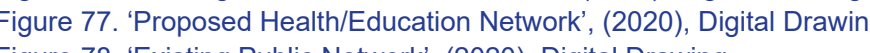

Figure 79. 'Proposed Public Network', (2020) Digita Drawing

Figure 80. 'Existing Housing Network', (2020), Digital Drawing.

Figure 81. 'Proposed Housing Network', (2020), Digital Drawing.

Figure 82. 'Porirua Urban Analysis', (2020), Mixed Media.

Figure 83. Rem Koolhaus, 'Delirious New York', (1994), Drawing. 
Figure 85. '1:100 Sketch Model', (2020), Digital Photograph. Figure 86. '1.100 Sketch Models', (2020), Digital Photograph

Figure 88 ' '11100 Skech Modes', (2020), Dight Photograph.

Figure 89. '1:100 Sketch Models', (2020), Photomontage.

Figure 90. '1:100 Sketch Model', (2020), Digital Photograp .

Figure 91. '1:100 Sketch Model', (2020), Digital Photograph.

Figure 92. '1:100 Sketch Models 3', (2020), Digital Photograph

Figure 94. 1.500 Site Plan '5 Heriot Drive', (2020), Digital Drawing

Figure 99. 'Theatre Design 1:200', (2020), Digital lllustration.

Figure 10. Section Sketch, '5 Heriot Drive', (2020), Drawing

Figure 102 . Isometric, '5 Heriot Drive', (2020), Digital Illustration.

Figure 103. Plan Diagram, '2b Raiha St', (2020), Red Pen on Butter Paper.

Figure 104. Isometric, '2b Raiha St', (2020), Digital Drawing.

Figure 105. Site Plan, '2b Raiha St',(2020), Fountain Pen on Butter Paper.

(2020) Fountain Pen and Red Pen on Butter Paper

Figure 108. Plan Diagram, '2b Raiha St', (2020), Fountain Pen and Red Pen on Butter Paper
Figure 109. Plan Diagram, '2b Raiha St', (2020). Fountain Pen and Red Pen on Butter Paper.

Figure 110. Street Elevation, '2b Raiha St', (2020), Mixed Media.

Figure 111. Elevation Diagram, $2 b$ Raiha St, (2020), Fountain Pen and Red Pen on Butter Paper

Figure 112. Elevation Diagram, ' $2 \mathrm{~b}$ Raiha St', (2020), Fountain Pen and Red Pen on Butter Paper
Figure 113. Elevation Diagram, '2b Raiha St', (2020), Fountain Pen and Red Pen on Butter Paper.

Figure 114. Plan Diagram, '2b Raiha St', (2020), Mixed Media.
Figure 115. Plan Diagram, '2b Raiha St', (2020), Mixed Media.

Figure 116. Elevation Diagram, '2b Raiha St', (2020), Fountain Pen on Butter Paper

Figure 117. Elevation Diagram, '2b Raiha St', (2020), Mixed Media.

Figure 118. 'Willy Wonka', (2020), Digital Image.

Figure 19. Long Section 1.200, 26 Raiha St', (2020), Digital Drawing

Figure 121 Window Frame Model '22 Raina St', (2020), White Card

Figure 122. Window Frame Model, '2b Raiha St', (2020), White Card

Figure 123. Window Frame Model, '2b Raiha St', (2020), White Card.

Findow Frame Model, 2b Rainh St', (2020), White Card.

Figure 125. Perspective, '2b Raiha St', (2020), Digital Drawing
Figure 127. 'Flash Exhibition', (2020), Digital Photograph.

Figure 129. 'Fash Exhibition', (2020), Digital Photograph.

Figure 130 ' 'Flash Exhibition', (2020). Digital Photograph.

Figure 131 'Flash Exhibition', (2020). Digital Photograph.

Fure 132. Flash Exhibition,', (2020), Digital Photograph.

.

Figure 134. 'NZIA Local Presentation'' (2020) Digitograph.

Figure 136. '12 Prosser St Elsdon', (2020), Digitial Photograph

Figure 137. 'Bishop Viard College Field', (2020), Digital Photograp

Figure 138. 'Elemental Sketch', (2020), Fountain Pen Drawing.

Figure 139. 'Composition Sketch', (2020), Fountain Pen Drawing.

(

Figure 141. Worms-eye Iteration, '9 Prosser St, Elsdon', (2020), Digital Drawing.

Figure 142. 'Composition Twelve', (2020), Spray Painted MDF and Plastic.

Figure 144. 'Corbusier Comparison', (2020), Acrylic Painting, Physical Model.

Eigure 145. 'Least Successful Architectural Compositions', (2020), Spray Painted MDF and Plas

146. 'Most Successful Architectural Compositions', (2020), Spray Painted MDF and Plas Ict.

Figure 147. Isometric, 'Architectural Compositions', (2020), Digital Drawing.

Figure 148. 'Architectural Compositions', (2020), Spray Painted MDF and Plastic.

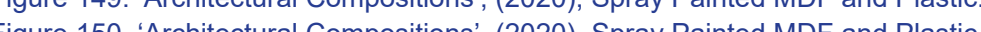

Figure 151. 'Architectural Compositions' (2020). Spray Painted MDF and Plastic.

Figure 152. 'Composition Twenty-One', (2020), Spray Painted MDF and Plastic.

Figure 153. 'Architectural Compostions', (2020), Spray Painted MDF and Plastic.

Figure 154. 'Rangituhi', (2020), Digital Photograph.

Figure 156. 'Tile Mode', (2020), Tile Paper.

Figure 157. 'Tile Model', (2020), Tile Paper.

Figure 158. 'Tile Model', (2020), Tile Paper.

Figure 159. 'Tile Model 1', (2020), Tile Paper.

Figure 160. 'Tile Model 2', (2020), Tile Paper.

Figure 161. 'Tie Model 3,' (2020), The Paper.

Figure 163. 'Tilo Model 12', (2020). Tile Paper.

Figure 164. 'Tile Model 2', (2020) Tile Paper

Figure 165. 'Tile Model 2', (2020), Tile Paper.

Figure 166. 'Tile Model 3', (2020), Tile Pape

Figure 167. 'Tile Model 3', (2020), Tile Pape 
Figure 177. Section Iterations, ' 9 Prosser St,' Elsdon', (2020), Red Felt, Butter Paper.

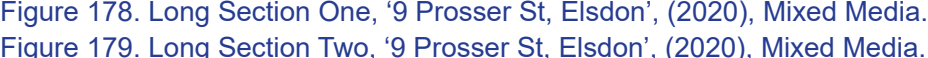

Figure 180. Form Iterations, ' 9 Prosser St, Elsdon', (2020). Digital Image.

Figure 181. Form Development, '9 Prosser St, Elsdon', (2020), Digital Image.

Figure 182. East Detail, '9 Prosser St, Elsdon', (2020), Digital Image.

Figure 183. Street Lookout, ' 9 Prosser St, Elsdon', (2020), Digital Image.
Figure 184. Towards Private Dwelling, ' 9 Prosser St, Elsdon', (2020), Digital Image
Figure 185. Towards Rooftop, ' 9 Prosser St, Elsdon', (2020), Digital Image.

Figure 185. Towards Rooftop, ' '9 Prosser St, Elsdon', (2020), Digital Image.
Figure 186. Composition Detail, '9 Prosser St, Elsdon', (2020), Digital Image.

Figure 187. 'Frame Sculpture', (2020), Plywood, Glass.

Figure 188. Composition Detail, '9 Prosser St, Elsdon', (2021), Photomontage.

Figure 189. Tile Detail, '9 Prosser St, Elsdon', (2020), Digital Drawing.

Figure 191. 'Last Model', (2021), Digital Photograph.

Figure 191. Last Model, (2021), Digital Photograph.
Figure 192. Constant Nieuwenhuys, (1955), New Babylon, Photograph.
Figure 193. Constant Nieuwenhuys, (1959), New Babylon, Physical Model

Figure 194. Constant Nieuwenhuys, (1959), New Babylon, Physical Model.

Figure 195. Constant Nieuwenhuys, (1959), New Babylon, Collage.

Figure 196. 'Creative Monumentality Painting', (2021), Mixed Media.

Figure 197. 'Architectural Composititions', (2020), Spray Painted MDF and Plas

Figure 198. Worms Eye, ' 9 Prosser St, Elsdon', (2020), Digital Montage.

Figure 200. 'Creative Monumentality Painting', (2021). Mixed Med

Figure 201. Stage One, '9 Prosser St, Elsdon', (2020), Digital Image.

Figure 202. Stage Two, '9 Prosser St, Elsdon', (2020), Digital Image.

Figure 203. Stage Three, ' 9 Prosser St, Elsdon', (2020), Digital Image.

Figure 204. 'Potial Itlands', (2020), Digital Drawing,

Figure 206. Stage Three 'g Prosser St, Elsdon', (2020)', (2021), Digital Drawing

Figure 207. 'Creative Monumentality Painting', (2021), Mixed Media.

Figure 208. 'Architectural Compositions', (2020), Spray Painted MDF and Plastic. 
